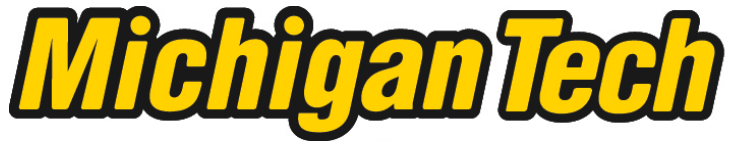 \\ Michigan Technological University Create the Future Digital Commons @ Michigan Tech
}

2014

ELECTROCATALYTIC PROCESSING OF RENEWABLE BIOMASSDERIVED COMPOUNDS FOR PRODUCTION OF CHEMICALS, FUELS AND ELECTRICITY

Le Xin

Michigan Technological University

Follow this and additional works at: https://digitalcommons.mtu.edu/etds

Part of the Chemical Engineering Commons, and the Oil, Gas, and Energy Commons Copyright 2014 Le Xin

Recommended Citation

Xin, Le, "ELECTROCATALYTIC PROCESSING OF RENEWABLE BIOMASS-DERIVED COMPOUNDS FOR PRODUCTION OF CHEMICALS, FUELS AND ELECTRICITY", Dissertation, Michigan Technological University, 2014.

https://doi.org/10.37099/mtu.dc.etds/784

Follow this and additional works at: https://digitalcommons.mtu.edu/etds

Part of the Chemical Engineering Commons, and the Oil, Gas, and Energy Commons 


\title{
ELECTROCATALYTIC PROCESSING OF RENEWABLE BIOMASS-DERIVED COMPOUNDS FOR PRODUCTION OF CHEMICALS, FUELS AND ELECTRICITY
}

\author{
By
}

Le Xin

\begin{abstract}
A DISSERTATION
Submitted in partial fulfillment of the requirements for the degree of DOCTOR OF PHILOSOPHY

In Chemical Engineering
\end{abstract}

MICHIGAN TECHNOLOGICAL UNIVERSITY

2014

(C) 2014 Le Xin 
This dissertation has been approved in partial fulfillment of the requirements for the Degree of DOCTOR OF PHILOSOPHY in Chemical Engineering

\section{Department of Chemical Engineering}

Dissertation Advisor: $\quad$ Dr. Wenzhen Li

Committee Member: $\quad$ Dr. David R. Shonnard

Committee Member: Dr. Adrienne Minerick

Committee Member: Dr. Patricia A. Heiden

Committee Member: Dr. Kazuya Tajiri

Department Chair: $\quad$ Dr. S. Komar Kawatra 
To my Mom and Dad 


\section{Table of Contents}

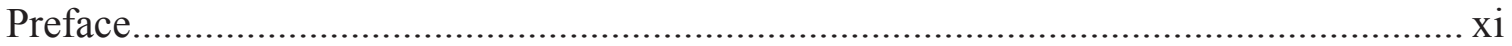

Publications List at Michigan Technological University................................................. xiii

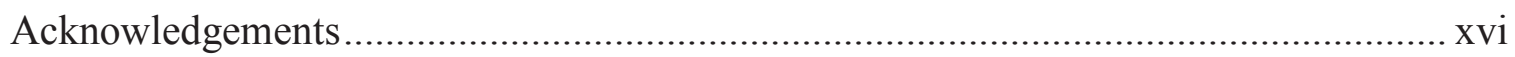

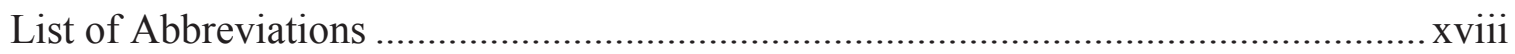

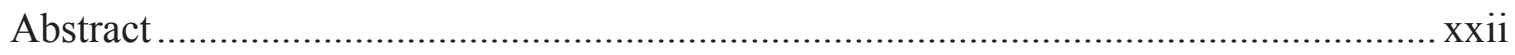

Chapter 1 Introduction and Significance of the Research ................................................ 1

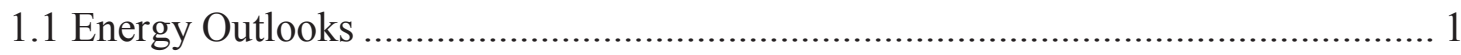

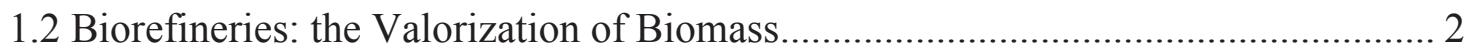

1.3 Electro-biorefinery: Electrocatalytic Processing of Biomass-derived Oxygenated Compounds to Chemicals, Liquid fuels and Electricity ................................................ 6

1.4 Research Goals and Significance............................................................................. 11

Chapter 2 Experimental Details and Materials ............................................................... 13

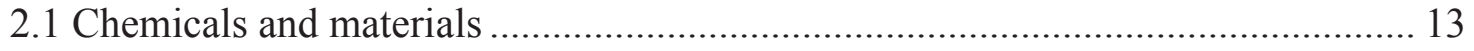

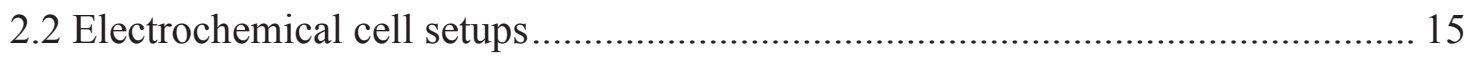

2.2.1 Batch-type three-electrode cell reactor ...................................................... 15

2.2.2 Continuous flow-type AEM or PEM-based electrolysis cell reactor................ 18

2.2.3 Continuous flow-type AEM based fuel cell reactor ........................................ 20

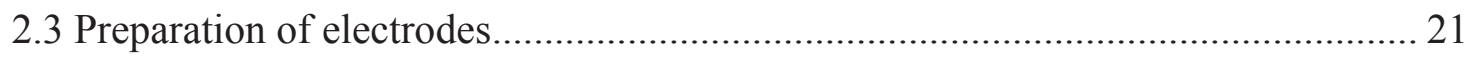


2.3.1 Glassy carbon electrode

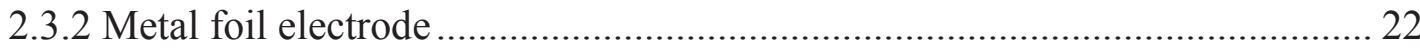

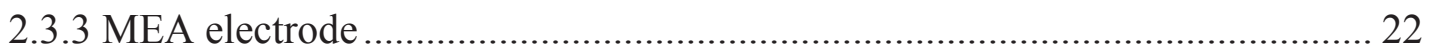

2.4 Preparation of supported electrocatalysts ................................................... 22

2.4.1 Pretreatment and preparation of carbon supporting materials ....................... 23

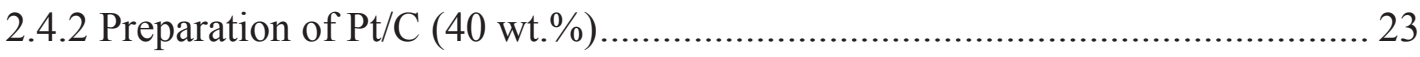

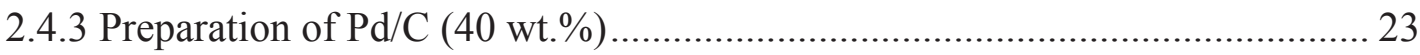

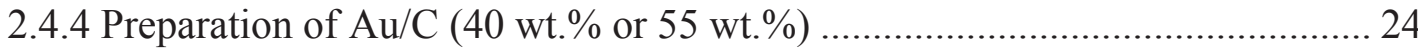

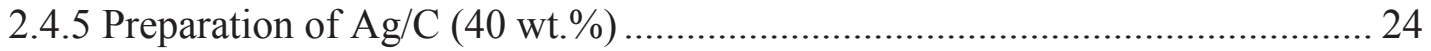

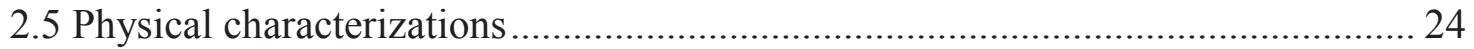

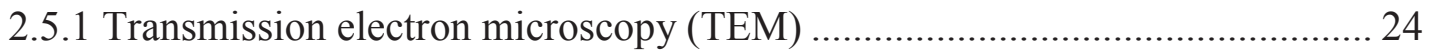

2.5.2 Scanning electron microscopy (SEM) ................................................. 25

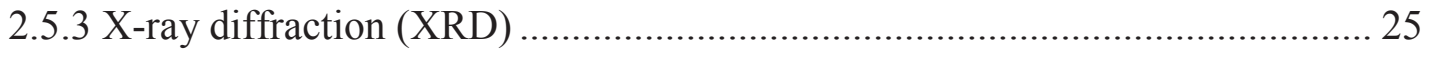

2.5.4 Inductively coupled plasma optical emission spectroscopy (ICP-OES)......... 26

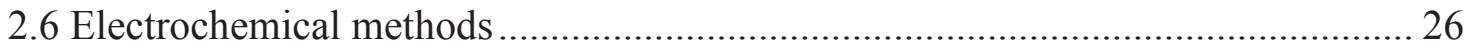

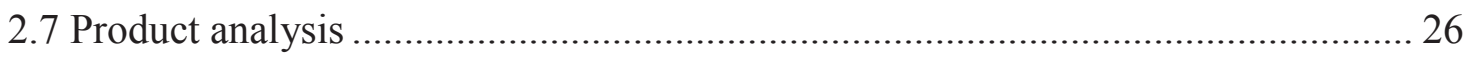

Chapter 3 Supported Pt, Pd and Au Anode Catalysts for Anion-Exchange MembraneDirect Glycerol/Crude Glycerol Fuel Cells (AEM-DGFCs/DCGFCs) ${ }^{*}$.......................... 28

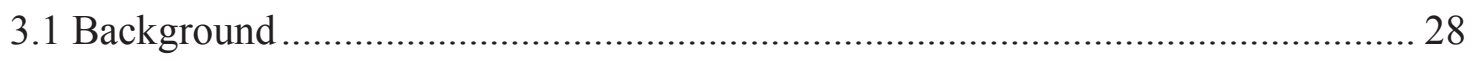

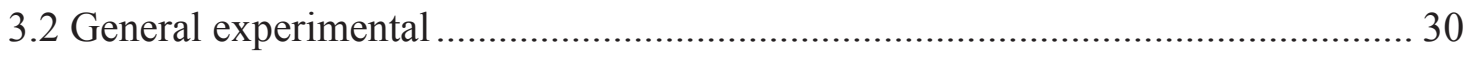

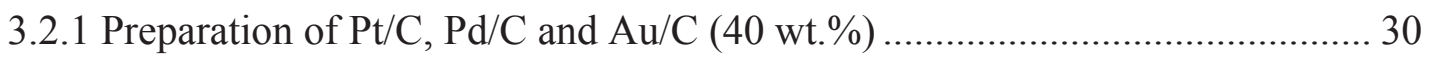


3.2.2 Physical characterizations 30

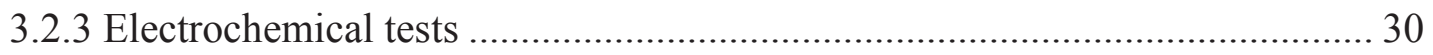

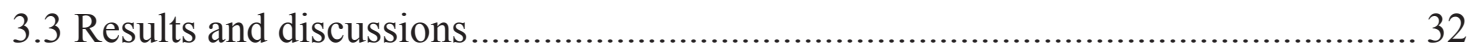

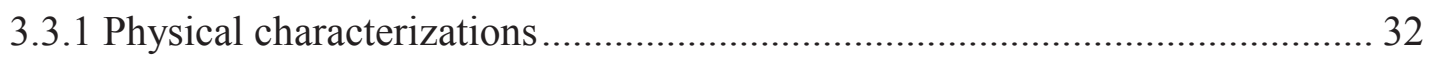

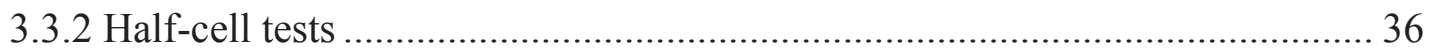

3.3.3 Pt/C, $\mathrm{Pd} / \mathrm{C}$, and $\mathrm{Au} / \mathrm{C}$ anode AEMFCs with high purity glycerol (99.8\%) .... 45

3.3.4 Pt/C, $\mathrm{Pd} / \mathrm{C}$, and $\mathrm{Au} / \mathrm{C}$ anode AEMFCs with crude glycerol (88\%) ................ 47

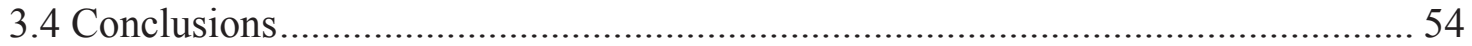

Chapter 4 Simultaneous Generation of Mesoxalate or Tartronate and Electricity from Glycerol in Continuous Flow-type AEM-based Fuel Cell Reactors " ........................... 56

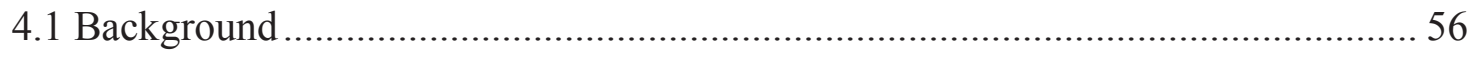

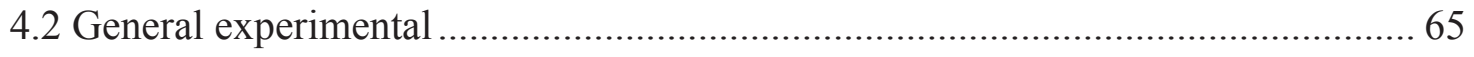

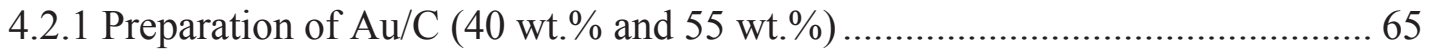

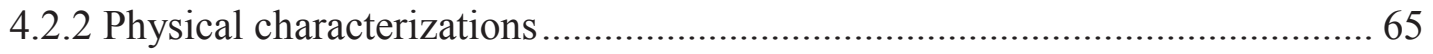

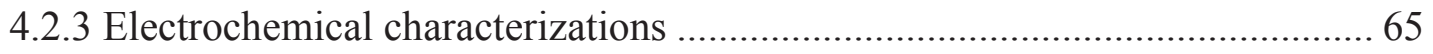

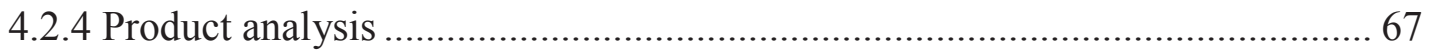

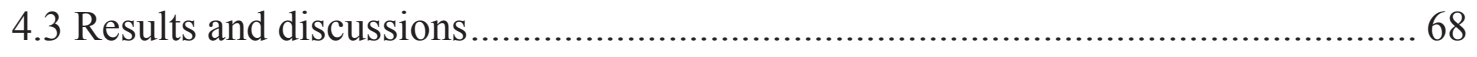

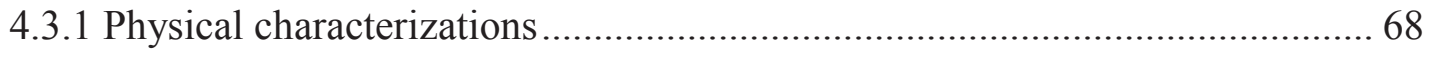

4.3.2 The effects of MEA structures and reaction conditions on the selectivity of tartronate and mesoxalate in AEM-DGFCs and electro-oxidation activity evaluation of main glycerol partial oxidation $\mathrm{C}_{3}$ products in half cells ................................ 70 
4.3.3 Cogeneration of electricity and tartonate with high yield in the continuous flow-type AEM-DGFCs reactor

4.3.4 Cogeneration of electricity and mesoxalate with high selectivity in the continuous flow-type AEM-DGFCs reactor .......................................................... 81

4.4 Conclusions 88

Chapter 5 Electrocatalytic Selective Oxidation of Ethylene Glycol (EG): Reaction Pathway Investigation via On-line Sample Collection System Collected to Three-

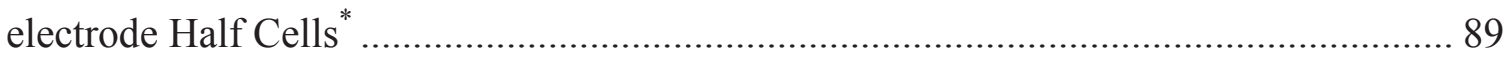

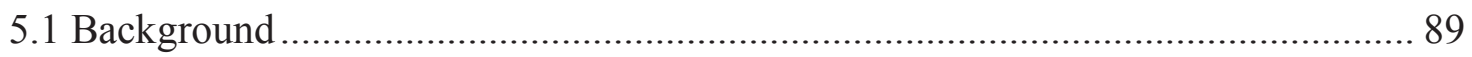

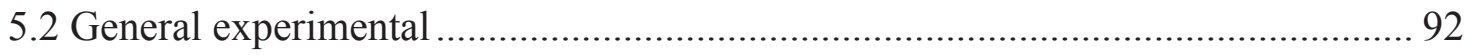

5.2.1 Preparation of Au/C (40 wt.\%) and Pt/C (40 wt.\%) .................................... 92

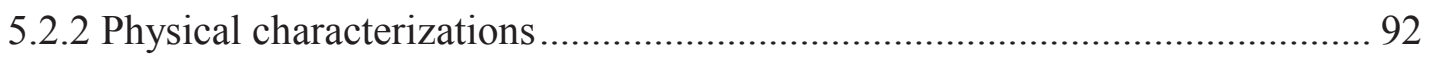

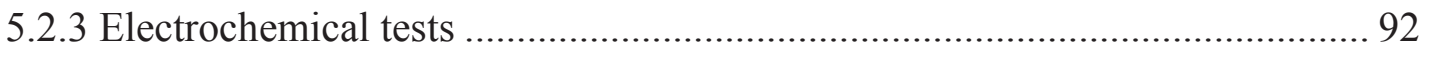

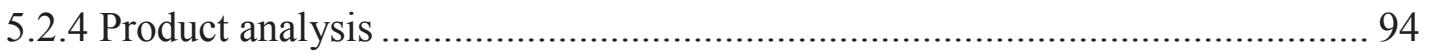

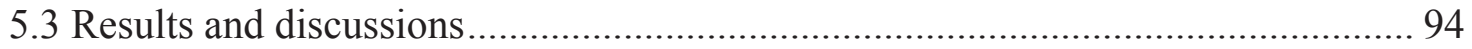

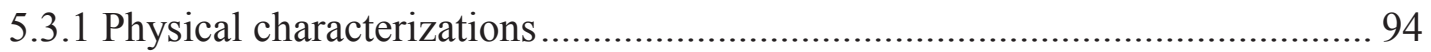

5.3.2 Electrocatalytic selective oxidation of $\mathrm{EG}$ on $\mathrm{Pt} / \mathrm{C}$ and $\mathrm{Au} / \mathrm{C}$ catalysts in threeelectrode cells with an on-line sample collection system ........................................ 95

5.3.3 Proposed pathways for electro-oxidation of $\mathrm{EG}$ on $\mathrm{Pt} / \mathrm{C}$ and $\mathrm{Au} / \mathrm{C}$ in alkaline

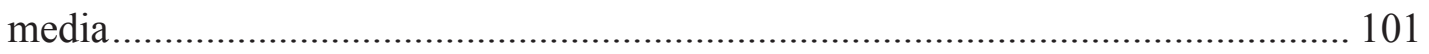

5.3.4 Electrocatalytic selective oxidation of EG in continuous flow-type AEMDEGFC reactors with $\mathrm{Pt} / \mathrm{C}$ and $\mathrm{Au} / \mathrm{C}$ anode catalysts........................................... 104

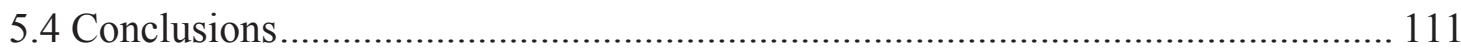


Chapter 6 Electrocatalytic Selective Oxidation of 1,2-Propanediol in the Continuous Flow AEM-based Electrolysis Cell Reactor: Potential Controlled Electro-oxidation Mechanism Determination via Combined Experimental and Theoretical DFT Studies 113

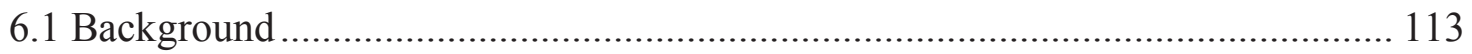

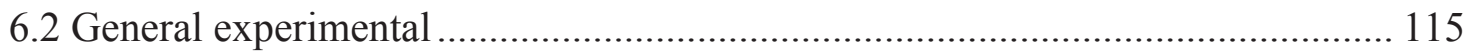

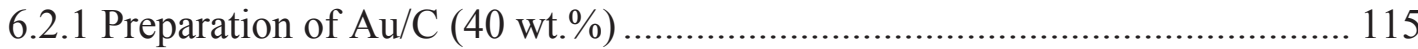

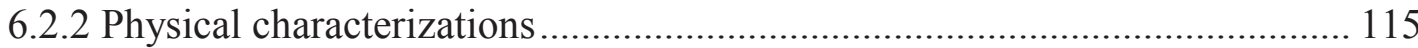

6.2.3 Electrocatalytic selective oxidation of 1,2-propanediol in AEM based electrolysis cell reactor .................................................................................... 115

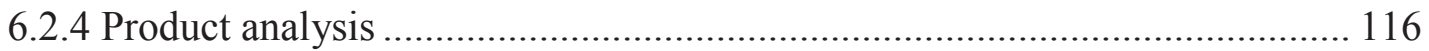

6.2.5 DFT simulations of 1,2-propanediol electrocatalytic oxidation on $\mathrm{Au}$ (111)

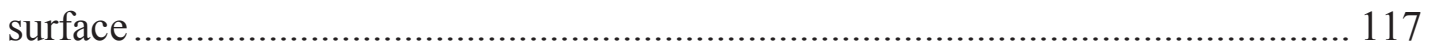

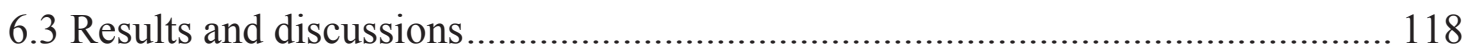

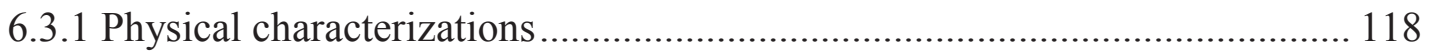

6.3.2 Electrocatalytic selective oxidation of 1,2-propanediol Au/C (40 wt.\%) in the continuous flow AEM based electrolysis cell reactor............................................... 118

6.3.3 Electrocatalytic oxidation mechanism determination for lactic acid and pyruvic acid from 1,2-propanediol using density functional theory (DFT) ……………...... 119

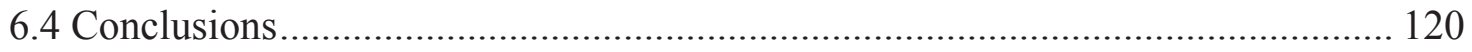

Chapter 7 Electrocatalytic reduction of Levulinic Acid (to Valeric Acid or $\gamma$ -

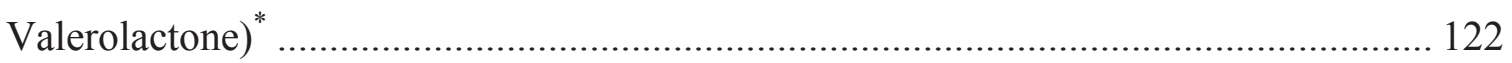

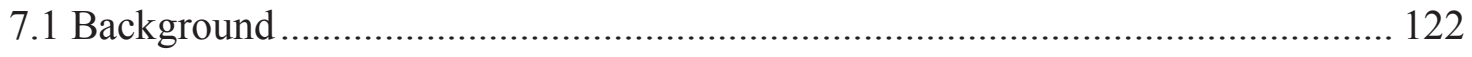

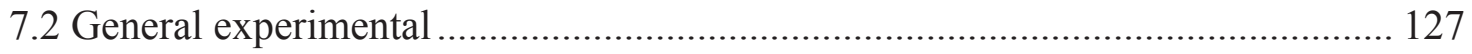


7.2.1 Preparation of electrode materials

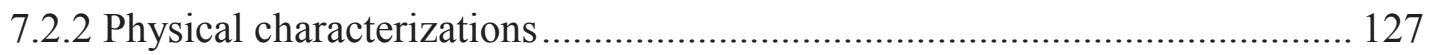

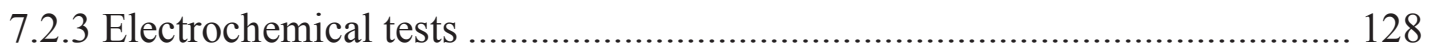

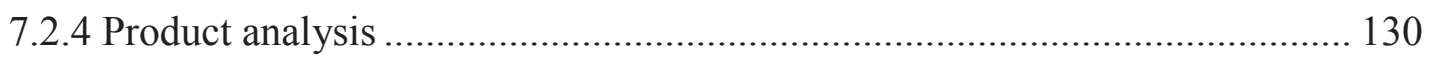

7.3 Results and Discussion ............................................................................. 130

7.3.1 Thermodynamics and kinetics of the ECH reaction ............................... 130

7.3.2 Potential-/pH- regulated selective ECH of levulinic acid to valeric acid and GVL on a Pb electrode in batch-type half-cell reactors.................................... 133

7.3.3 Selective $\mathrm{ECH}$ of levulinic acid on a $\mathrm{Pb}$ electrode in the continuous flow-type AEM or PEM based electrolysis cell reactors

7.3.4 Reaction pathway and molecular structure effects on $\mathrm{ECH}$ of oxygenates containing ketone or aldehyde groups ........................................................ 150

7.3.5 ECH of levulinic acid + formic acid in the continuous flow-type PEM-based

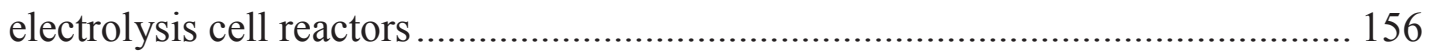

7.3.6 Electrocatalytic oxidation of formic acid + valeric acid ......................... 161

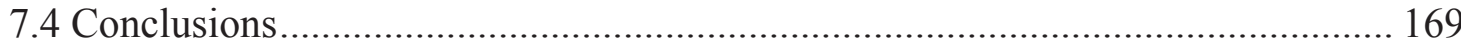

Chapter 8 Supported Non-Platinum Group Metal Ag Catalyst for Oxygen Reduction

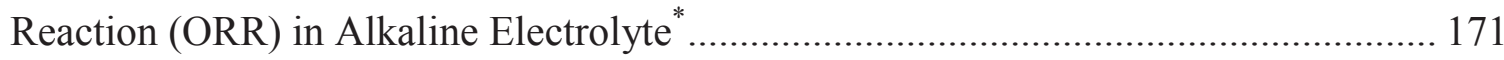

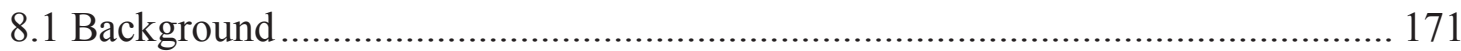

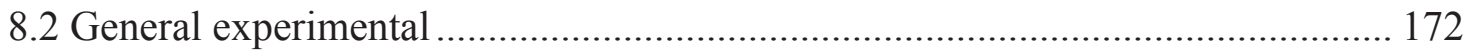

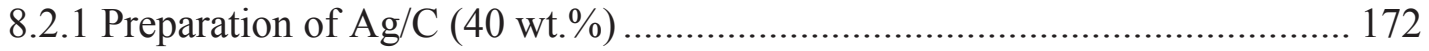

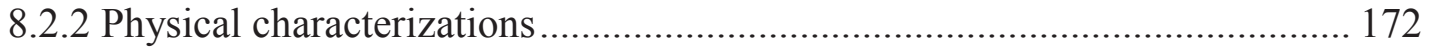


8.2.3 Electrochemical tests in half cells.....

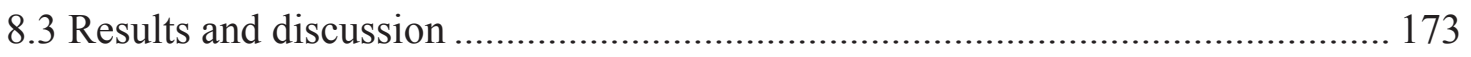

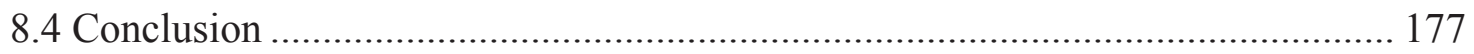

Chapter 9 Concluding Remarks and Recommendations ....................................... 178

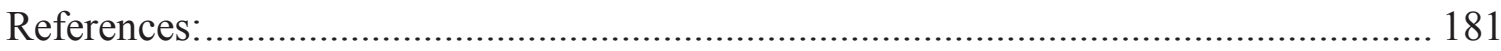

Appendix A Copyright permission of Fig. 1.1 (a) and Fig. 1.4 ................................. 205

Appendix B Copyright permission of Fig. 1.1 (b) .................................................. 206

Appendix C Copyright permission of Chapter 3 ................................................... 207

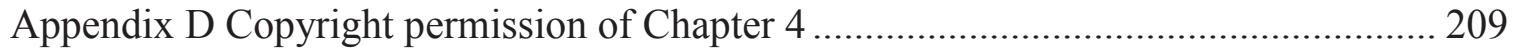

Appendix E Copyright permission of Chapter 5................................................. 215

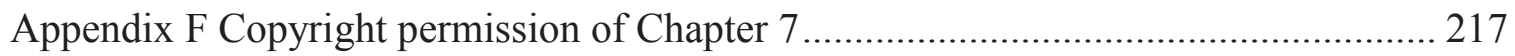

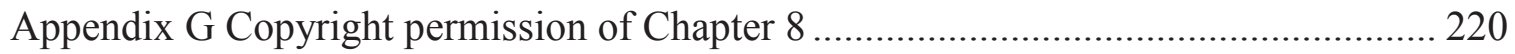




\section{Preface}

Chapter $\mathbf{3}$ is an article I co-first authored with Zhiyong Zhang and published in Applied Catalysis B: Environmental, Volume 136-137, Pages 29-39, 2013. I and Zhiyong Zhang synthesized the catalysts and performed the physical characterizations; Zhiyong Zhang did the half-cell tests; I did the fuel cell tests; I and Zhiyong Zhang analyzed the data and wrote the manuscript. Ji Qi and David J. Chadderdon provided helpful discussions.

Chapter 4 combines three articles. Part of Section 4.1 is based on the publication in Applied Catalysis B: Environmental, Volume 147, Pages 871-878, 2014, where I assisted Zhiyong Zhang with the electrochemical tests. The rest parts of Section 4.1 and Section 4.3.1-4.3.3 are from the publication in Applied Catalysis B: Environmental, Volume 154155, Pages 360-368, 2014 where I co-first authored with Ji Qi: I did all the experiments and wrote the manuscript included in the Chapter 4 with the assistance of Ji Qi. David J. Chadderdon, Yang Qiu, Yibo Jiang, Neeva Benipal, and Prof. Dr. Changhai Liang proofread the manuscript and provided helpful comments as well as revisions. Section 4.4.4 is an article I published in ChemCatChem, Volume 4, Pages 1105-1114, 2012 where I did all the experiments and data analysis and wrote the manuscript with the assistance of Zhiyong Zhang and Zhichao Wang.

Chapter 5 is an article I published in Applied Catalysis B: Environmental, Volume 125, Pages 85-94, 2013. I did all the experiments, analyzed the data, and wrote the manuscript with Zhiyong Zhang's assistance. Ji Qi and David J. Chadderdon provided helpful discussions and proofread the manuscript.

Chapter 6 includes unpublished data. I, in collaboration with David J. Chadderdon did all the experiments. Brain Brady and Prof. Dr. Michael Janik from The Pennsylvania State University performed DFT modeling.

Chapter 7 combines two articles. Section 7.3.1-7.3.4 is from an article I published in ChemSusChem, Volume 6, Pages 674-686, 2013, where I did all the experiments and data analysis as well as wrote the manuscript with the assistance of Zhiyong Zhang and 
Yang Qiu. Ji Qi, David J. Chadderdon and Kayla M. Warsko provided helpful discussions and proofread the manuscript. Section 7.3.5 and 7.3.6 is from an article I cofirst authored with Yang Qiu and published in Green Chemistry, Volume 16, Pages 13051315, 2014, where I and Yang Qiu did all the experiments and analyzed the data; I and Yang Qiu co-wrote the manuscript. David J. Chadderdon, Ji Qi, and Prof. Dr. Changhai Liang provided helpful comments and proofread the manuscript.

Chapter $\mathbf{8}$ is from an article I published in Frontiers in Chemistry, Volume 1, Article 16, 2013. I did all the experiments, with Zhiyong Zhang's assistance. Zhichao Wang and Ji Qi provide helpful discussions and also proofread the manuscript.

All my Ph.D research was advised by Prof. Dr. Wenzhen Li and the results were discussed with all the co-authors before publication. 


\section{Publications List at Michigan Technological University}

1. Pd-Ni Electrocatalysts for Efficient Ethanol Oxidation Reaction in Alkaline Electrolyte

Zhiyong Zhang, Le Xin, Kai Sun, Wenzhen Li,

INTERNATIONAL JOURNAL OF HYDROGEN ENERGY, 2011, 36, 1268612697.

2. Supported Gold Nanoparticles as Anode Catalyst for Anion Exchange MembraneDirect Glycerol Fuel Cell (AEM-DGFC)

Zhiyong Zhang, Le Xin, Wenzhen Li

INTERNATIONAL JOURNAL OF HYDROGEN ENERGY, 2012, 37, 93939401.

3. Electrocatalytic Oxidation of Glycerol on $\mathrm{Pt} / \mathrm{C}$ in Anion-exchange Membrane Fuel Cell: Cogeneration of Electricity and Valuable Chemicals

Zhiyong Zhang, Le Xin, Wenzhen Li

APPLIED CATALYSIS B: ENVIRONMENTAL, 2012, 119, 40-48.

4. Selective Electro-conversion of Glycerol to Glycolate on Carbon Nanotube Supported Gold Catalyst

Zhiyong Zhang, Le Xin, Ji Qi, Zhichao Wang, Wenzhen Li

GREEN CHEMISTRY, 2012, 14, 2150-2152.

5. Simultaneous Generation of Mesoxalic acid and Electricity from Glycerol on $\mathrm{Au}$ Anode Catalyst in Anion Exchange Membrane Fuel Cells

Le Xin*, Zhiyong Zhang*, Zhichao Wang, Wenzhen Li

(* equal contribution)

CHEMCATCHEM, 2012, 4, 1105-1114.

6. Electrocatalytic Oxidation of Ethylene Glycol (EG) on Supported Pt and Au Catalysts in Alkaline Media: Reaction Pathway Investigation in Three-electro Cell and Fuel Cell Reactors

Le Xin, Zhiyong Zhang, Ji Qi, Wenzhen Li

APPLIED CATALYSIS B: ENVIRONMENTAL, 2012, 125, 85-94.

7. Supported Pt, Pd, and Au Nanoparticle Anode Catalysts for High Performance Anion-Exchange Membrane Fuel Cells with Glycerol and Crude Glycerol Fuels Zhiyong Zhang*, Le Xin*, Ji Qi, David J. Chadderdon, Wenzhen Li

(* equal contribution)

APPLIED CATALYSIS B: ENVIRONMENTAL, 2013, 136-137, 29-39.

8. Electricity Storage in Biofuels: Selective Electro-catalytic Reduction of Levulinic Acid to Valeric Acid or $\gamma$-Valerolactone 
Le Xin, Zhiyong Zhang, Ji Qi, David J. Chadderdon, Kayla M. Warsko, Wenzhen $\mathrm{Li}$

CHEMSUSCHEM, 2013, 6, 674-686.

9. Surface Dealloyed Pt Nanoparticles Supported on Carbon Nanotubes: Facile Synthesis and Promising Applications for Direct Crude Glycerol Anion-exchange Membrane Fuel Cell

Ji Qi, Le Xin, Zhiyong Zhang, Kai Sun, Haiyoing He, Fang Wang, David Chadderdon, Yang Qiu, Changhai Liang, Wenzhen Li

GREEN CHEMISTRY, 2013, 15, 1133-1137.

10. Carbon Supported Ag Nanoparticles with Different Particle Size as Cathode Catalysts for Anion Exchange Membrane Direct Glycerol Fuel Cells

Zhichao Wang, Le Xin, Xusheng Zhao, Yang Qiu, Zhiyong Zhang, Olga Baturina, Wenzhen $\mathrm{Li}$

RENEWABLE ENERGY, 2014, 62, 556-562.

11. Carbon Supported Ag Nanoparticles as High Performance Cathode Catalyst for $\mathrm{H}_{2} / \mathrm{O}_{2}$ Anion Exchange Membrane Fuel Cell

Le Xin, Zhiyong Zhang, Zhichao Wang, Ji Qi, Wenzhen Li FRONTIERS IN GREEN AND ENVIROMENTAL CHEMISTRY, 1:16.

12. Selective Electro-Oxidation of Glycerol to Tartronate or Mesoxalate on $\mathrm{Au}$ Nanoparticle Catalyst via Electrode Potential Tuning in Anion-Exchange Membrane Electro-Catalytic Flow Reactor

Zhiyong Zhang, Le Xin, Ji Qi, David J. Chadderdon, Kai Sun, Kayla M. Warsko, Wenzhen Li

APPLIED CATALYSIS B: ENVIRONMENTAL, 2014, 147, 871-878.

13. Integrated Electrocatalytic Processing of Levulinic Acid and Formic Acid to Biofuel Intermediate Valeric Acid

Yang Qiu*, Le Xin*, David J. Chadderdona, Ji Qi, Changhai Liang, Wenzhen Li (" equal contribution)

GREEN CHEMISTRY, 2014, 16, 1305-1315.

14. Electrocatalytic Selective Oxidation of Glycerol to Tartronate on $\mathrm{Au} / \mathrm{C}$ Anode Catalysts in Anion Exchange Membrane Fuel Cells with Electricity Cogeneration Ji Qi*, Le Xin*, David J. Chadderdon, Yang Qiu, Yibo Jiang, Neeva Benipal, Changhai Liang, Wenzhen Li

(* equal contribution)

APPLIED CATALYSIS B: ENVIRONMENTAL, 2014, 154-155, 360-368.

15. Electrocatalytic Oxidation of 5-Hydroxymethyl-2-Furfural to 2,5Furandicarboxylic Acid on Supported Au and Pd Alloyed Nanoparticles

David J. Chadderdon, Le Xin, Ji Qi, Yang Qiu, Phani Krishna, Karren L. More, Wenzhen $\mathrm{Li}$ 
GREEN CHEMISTRY, 2014, DOI: 10.1039/C4GC00401A

16. An Effective Supported Ni-Fe Electrocatalyst for Water Oxidation Yang Qiu*, Le Xin*, Wenzhen Li

(* equal contribution)

LANGMUIR, 2014 (submitted)

17. $\mathrm{CO}_{2}$ Electroreduction to Hydrocarbons on Carbon-supported $\mathrm{Cu}$ Nanoparticles Olga A. Baturina, Qin Lu, Monica A. Padilla, Le Xin, Wenzhen Li, Alexey Serov, Albert Epshteyn, Greg Collins, Todd Britlinger, Mike Schouette ACS CATALYSIS, 2014 (submitted)

18. Numerical Analysis of Glycerol Anion Exchange Membrane Fuel Cell under Steady State and Dynamic Operation

Xiaotong Han, David J. Chadderdon, Ji Qi, Le Xin, Wen Zhou, Wenzhen Li INTERNATIONAL JOURNAL OF HYDROGEN ENERGY, 2014 (submitted)

19. Electrocatalytic Selective Oxidation of 1,2-Propanediol to Lactate or Pyruvate over Supported $\mathrm{Au}$ and Pt Catalysts: Potential Controlled Electro-oxidation Mechanism Determination Combining Experimental and Theoretical DFT Study David J. Chadderdon*, Le Xin*, Brian Brady, Michael Janik, Wenzhen Li (* equal contribution) (in preparation) 


\section{Acknowledgements}

Doing Ph.D. is a tough while amazing journey that pushes beyond my intellectual and physical limits every single day. It makes me become stronger, and more importantly, entitles me be called "doctor". However, I would never have been able to finish it without the help from many people.

I would like to express my deepest and sincere gratitude to my advisor, Prof. Dr. Wenzhen $\mathrm{Li}$, for his constant encouraging, patience, and expert guidance that have shaped my course of Ph.D. study. He always encouraged me to explore new electrocatalytic routes for important energy-related applications. His enthusiastic in natural science and hardworking attitude are contagious and will radiate through my entire academic career. I would also like to thank the Michigan Tech Doctoral Finishing Fellowship and Dr.Wenzhen Li's research funds from NSF CBET 1032547, 1159448, 1235982 and ACS-PRF-DNI that supported my Ph.D. research.

I am also grateful to Profs. Drs. David R. Shonnard, Adrienne Minerick, Patricia A. Heiden and Kazuya Tajiri for serving on my Ph.D. defense committee, and providing helpful feedbacks and suggestions on this dissertation.

I am very thankful to our collaborators: Profs. Drs. Yushan Yan and Shuang Gu from University of Delaware for their help in AEMFC research; Prof. Dr. Michael Janik and Brian Brady from Penn State University for their DFT modeling work and insight discussions; Dr. Olga A. Baturina from Naval Research Laboratory for her collaborations in $\mathrm{CO}_{2}$ electrocatalytic conversion project; Prof. Dr. Kai Sun and Dr. Karren L. More from University of Michigan and Oak Ridge National Lab, respectively, for their assistance on material characterizations; Profs. Drs. David R. Shonnard and Susan T. Bagley for their discussion on HPLC analysis; Mr. David L. Perram for his instruction on GC operations; and Mr. Jerry A. Nokol and Mr. Timothy P. Gasperich for helping me set up laboratory instruments. I would also like to extend my warm thanks to all other faculty and staff in department of chemical engineering at Michigan Tech. 
I also own a debt of gratitude to my colleagues in Dr. Li's group: Dr. Zhiyong Zhang, Ji Qi, Zhichao Wang, David J. Chadderdon, Yang Qiu, Neeva Benipal, Phani Krishna, Brandon S. Spigarelli and Kayla M. Warsko. Without them, it would have been a lonely lab.

Finally, I would express my special thanks to my wonderful parents and many other family members. They are always there cheering me up and supporting me with their endless and unconditional love. 


\section{List of Abbreviations}

AEM

AEM-DAFCs

AEM-DEGFCs

AEM-DGFCs

AEMFCs

BOE

CA

CAES

CCG(L)

$\mathrm{CCM}$

CV

DAFCs

DEGFCs

DEMS

DFT

DMF

DOE

EC
Anion exchange membrane

Anion-exchange membrane-direct alcohol fuel cells

Anion-exchange membrane-direct ethylene glycol fuel cells

Anion-exchange membrane-direct glycerol fuel cells

Anion-exchange membrane fuel cells

Barrels of oil energy equivalent

Chronoamperometry

Compressed-air energy storage

Catalyst coated gas/liquid diffusion layer

Catalyst coated membrane

Cyclic voltammogram

Direct alcohol fuel cells

Direct ethylene glycol fuel cells

Differential electrochemical mass spectrometry

Density functional theory

N,N-Dimethylformamide

Department of Energy

Electricity consumption

xviii 


\begin{tabular}{|c|c|}
\hline ECH & Electrocatalytic hydrogenation \\
\hline ECSA & Electrochemical surface area \\
\hline EDX & Energy-dispersive X-ray spectroscopy \\
\hline EG & Ethylene glycol \\
\hline EIA & Energy information administration \\
\hline ESE & Energy storage efficiency \\
\hline FCC & Face-centered cubic \\
\hline FTIR & Fourier transform infrared spectroscopy \\
\hline GDL & Gas diffusion layer \\
\hline GVL & $\gamma$-valerolactone \\
\hline GO & Graphite oxide \\
\hline HER & Hydrogen evolution reaction \\
\hline HMF & 5-(hydroxymethyl)furfural \\
\hline HPLC & High performance liquid chromatography \\
\hline ICP-OES & $\begin{array}{l}\text { Inductively coupled plasma optical emission } \\
\text { spectroscopy }\end{array}$ \\
\hline IEA & International energy agency \\
\hline LDE & Liquid diffusion electrode \\
\hline LSV & Linear sweep voltammetry \\
\hline MEA & Membrane electrode assembly \\
\hline MONG & Matter organic non glycerol \\
\hline
\end{tabular}




\begin{tabular}{|c|c|}
\hline MTHF & Methyl tetrahydrofuran \\
\hline MWCNTs & Multi-wall carbon nanotubes \\
\hline $\mathrm{OCV}$ & Open circuit voltage \\
\hline OER & Oxygen evolution reaction \\
\hline ORR & Oxygen reduction reaction \\
\hline PEM-DFAFC & $\begin{array}{l}\text { Proton exchange membrane-direct formic acid fuel } \\
\text { cell }\end{array}$ \\
\hline PEM-DGFCs & $\begin{array}{l}\text { Proton-exchange membrane-direct glycerol fuel } \\
\text { cells }\end{array}$ \\
\hline PEMFCs & Proton exchange membrane fuel cells \\
\hline PGMs & Platinum group metals \\
\hline PSH & Pumped-storage hydropower \\
\hline PV & Photovoltaic \\
\hline $\mathrm{RDE}$ & Rotation disk electrode \\
\hline $\mathrm{rGO}$ & Reduced graphene oxide \\
\hline RHE & Reversible hydrogen electrode \\
\hline RRDE & Rotating ring-disk electrode \\
\hline SEM & Scanning electron microscopy \\
\hline SHE & Standard hydrogen electrode \\
\hline TEM & Transmission electron microscopy \\
\hline THF & Tetrahydrofuran \\
\hline
\end{tabular}


TOE

TOF

XRD
Tones oil equivalents

Turnover frequency

X-ray diffraction 


\section{Abstract}

The dual problems of sustaining the fast growth of human society and preserving the environment for future generations urge us to shift our focus from exploiting fossil oils to researching and developing more affordable, reliable and clean energy sources. Human beings had a long history that depended on meeting our energy demands with plant biomass, and the modern biorefinery technologies realize the effective conversion of biomass to production of transportation fuels, bulk and fine chemicals so to alleviate our reliance on fossil fuel resources of declining supply. With the aim of replacing as much non-renewable carbon from fossil oils with renewable carbon from biomass as possible, innovative $\mathrm{R} \& \mathrm{D}$ activities must strive to enhance the current biorefinery process and secure our energy future.

Much of my Ph.D. research effort is centered on the study of electrocatalytic conversion of biomass-derived compounds to produce value-added chemicals, biofuels and electrical energy on model electrocatalysts in AEM/PEM-based continuous flow electrolysis cell and fuel cell reactors. High electricity generation performance was obtained when glycerol or crude glycerol was employed as fuels in AEMFCs. The study on selective electrocatalytic oxidation of glycerol shows an electrode potential-regulated product distribution where tartronate and mesoxalate can be selectively produced with electrode potential switch. This finding then led to the development of AEMFCs with selective production of valuable tartronate or mesoxalate with high selectivity and yield and cogeneration of electricity. Reaction mechanisms of electrocatalytic oxidation of ethylene glycol and 1,2-propanediol were further elucidated by means of an on-line sample collection technique and DFT modeling. Besides electro-oxidation of biorenewable alcohols to chemicals and electricity, electrocatalytic reduction of keto acids (e.g. levulinic acid) was also studied for upgrading biomass-based feedstock to biofuels while achieving renewable electricity storage. Meanwhile, ORR that is often coupled in AEMFCs on the cathode was investigated on non-PGM electrocatalyst with comparable activity to commercial $\mathrm{Pt} / \mathrm{C}$. The electro-biorefinery process could be coupled with 
traditional biorefinery operation and will play a significant role in our energy and chemical landscape. 


\section{Chapter 1 Introduction and Significance of the Research}

\subsection{Energy Outlooks}

The rapid growth of global population and rising standards of living will place additional demand on energy supply, ${ }^{1-3}$ The U.S. Energy Information Administration (EIA) has projected that the overall energy consumption in the U.S. will increase by $12 \%$ from 95 quadrillion Btu in 2012 to 106 quadrillion Btu in $2040,{ }^{4}$ while the global energy demand grows by $50 \%$ from 12 billion toe (tones oil equivalents) in 2009 to 18 billion toe by 2035 as projected by International Energy Agency (IEA). ${ }^{2,5}$ Non-renewable fossil fuels (coal, petroleum and natural gas) have been serving to boost the fast growth of human society for decades and are expected to remain the dominant energy source, accounting for $80 \%$ of total consumption in U.S. as of 2040 projected by the U.S. EIA (Fig. 1.1 (a) $)^{4}$ and for $75 \%$ of global energy demand as of 2035 projected by the IEA (Fig. 1.1 (b) $)^{5}$. However, with continuing improvement of the people's living standards, our heavy addiction to fossil fuels has aroused great concerns, mainly due to the dwindling supply of the fossil fuel resulting in the rising and volatility of prices of the transportation fuels and electricity in the long term, ${ }^{2,6}$ and more importantly, to the air quality deterioration and global climate change because of the global greenhouse gas, $\mathrm{CO}_{2}$, emission that is expected to be $27 \%$ higher in 2030 than today. ${ }^{3}$ Therefore, the dual problems of meeting future energy demand and preserving the environment for future generations urge us to shift our focus from exploiting fossil fuels to researching and developing more affordable, reliable and clean energy sources. This trend has been reflected in the energy outlooks by different agencies and companies, among which the U.S. EIA projects that the consumption of marketed renewable fuels will grows by $1.4 \%$ per year in their 2014 Annual Energy Outlooks ${ }^{4}$ and BP forecasts that renewables will account for $18 \%$ of the global energy growth in $2030 .^{3}$ 
(a)

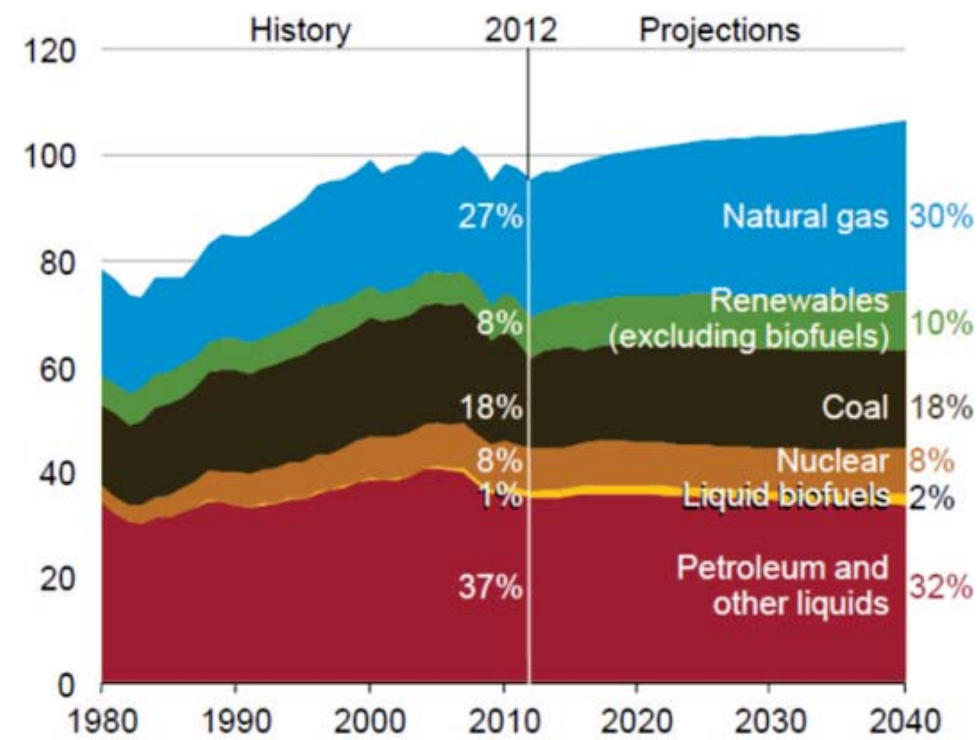

(b)

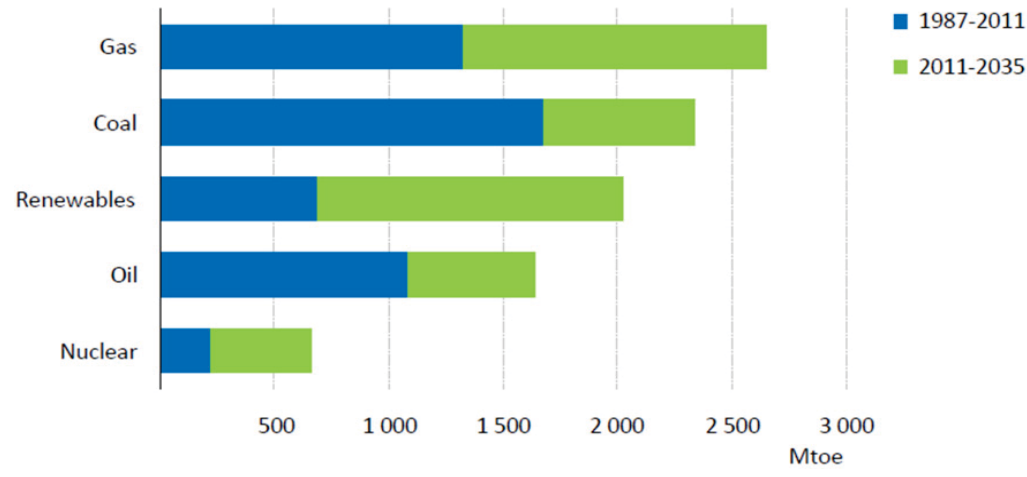

Fig. 1.1 (a) U.S. primary energy consumption by fuels, 1980-2040 (quadrillion Btu). (Source: U.S. Energy Information Administration (December 16, 2013)) ${ }^{4}$ (b) World growth in total primary energy demand, 1987-2035. (Source: World Energy Outlook 2013 Launch - a presentation by Maria van der Hoeven in London (C) OECD/IEA, 2013) ${ }^{5}$.

\subsection{Biorefineries: the Valorization of Biomass}

In the short term, biomass is the only renewable carbon resource that can replace petroleum derived transportation fuels, commodity and fine chemicals. ${ }^{7}$ It is estimated that the annual production of biomass in nature by photosynthesis is 170 billion metric tons $(\mathrm{t})$, only $3.5 \%$ of which are used by human worldwide for food purpose. ${ }^{8,9}$ The current cost of lignocellulosic biomass in the U.S. ranges from $\$ 5$ to 15 boe (barrels of oil energy equivalent), ${ }^{10}$ which is significantly lower than crude oil of $\$ 97 /$ bbl (per barrel) averaged in $2013,{ }^{11}$ and the price gap between the delivered biomass and crude oil will be 
enlarged as the demand growing in the future. ${ }^{4}$ On the other hand, it has been predicted that in 2050, the world wide raw biomass will have an energy content between $25 \times 10^{9}$ to $79 \times 10^{9}$ boe, ${ }^{10,12}$ and by $2030,20 \%$ of transportation fuels and $25 \%$ of chemicals in the U.S. will ultimately derived from biomass. ${ }^{10}$

The effective exploitation of biomass resources largely relies on the development of modern biorefinery processes that employ biological, chemical and thermal approaches to convert biomass to biofuels, bio-chemicals and direct energy (heat and electricity). ${ }^{6,9,10}$ The U.S. Department of Energy (DOE) has identified the top ten platform molecules that can be readily obtained from the established biorefinery processes, including ethanol, furans, glycerol and derivatives, biohydrocarbons, lactic acid, succinic acid, hydroxypropionic acid/aldehyde, levulinic acid, sorbitol and xylitol. ${ }^{13-15}$ These chemicals will be of particular importance as promising starting materials for further conversion to a viable range of derivatives as building blocks for commodity chemicals, fuels and polymers. The focus of my Ph.D research was however only laid on the electrocatalytic conversion of glycerol, levulinic acid and their derivatives (1,2-propanediol, ethylene glycol), while the developed innovative electrocatalytic processes and acquired knowledge will possibly be extended to the rest of platform chemicals for the synthesis of bio-based products.

According to the source provided by the U.S. EIA, the production of biodiesel (B100, $100 \%$ biodiesel) in the U.S. was 1339 million gallons with a capacity of 2236 million gallons. ${ }^{16}$ The most common inputs of biodiesel production are vegetable oils and animal fats that contain non-edible triglycerides. They are upgraded by trans-esterification with alcohols (e.g. methanol, ethanol or 2-propanol) in the presence of acid or base catalyst (Fig. 1.2 (a)). ${ }^{10,17}$

Roughly speaking, every 100 pounds of biodiesel will produce 10 pounds of glycerin as a co-product. ${ }^{18}$ The expanding production of biodiesel (Fig. 1.3) will result in the surplus production of glycerol as byproduct; therefore the drop of market price of glycerol is

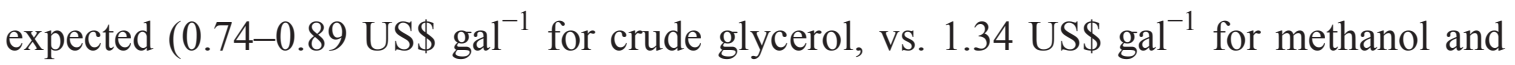


3.15 US\$ $\mathrm{gal}^{-1}$ for ethanol, the latter two beings are obtained mainly from the microorganism fermentation process of biomass). Although the traditional uses of glycerol have already been found in the production of food additives, cosmetics, pharmaceuticals, antifreeze, detergents, etc., ${ }^{9,19}$ the utilization of glycerol as platform molecule for producing larger-volumes of fine chemicals and fuel additives will better meet industrial interest. ${ }^{10,19}$ Various technologies, including fermentation, oxidation, reduction, dehydration, polymerization, esterification, pyrolysis, etc., for the valorization of glycerol are current under investigation and some of them have already been commercialized. ${ }^{9,14}$

(a)

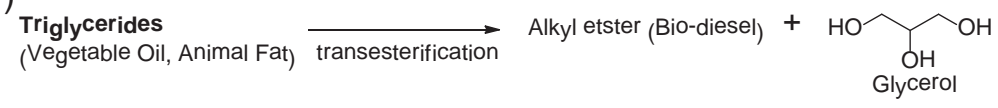

(b)

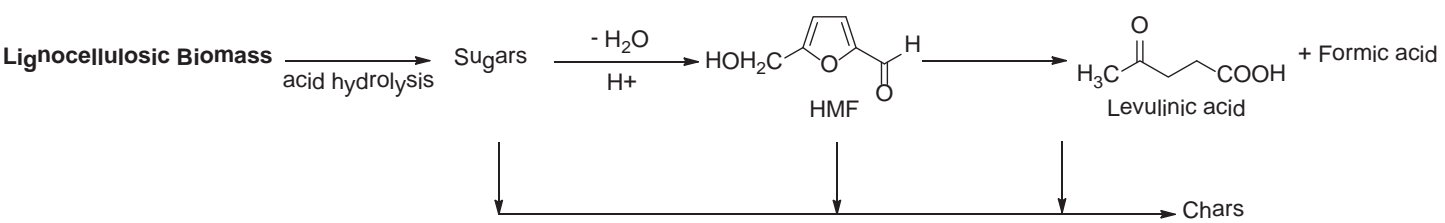

Fig. 1.2 Production of (a) glycerol and (b) levulinic acid by biorefinery process.

\section{U.S. Biodiesel Production, Exports, and Consumption}

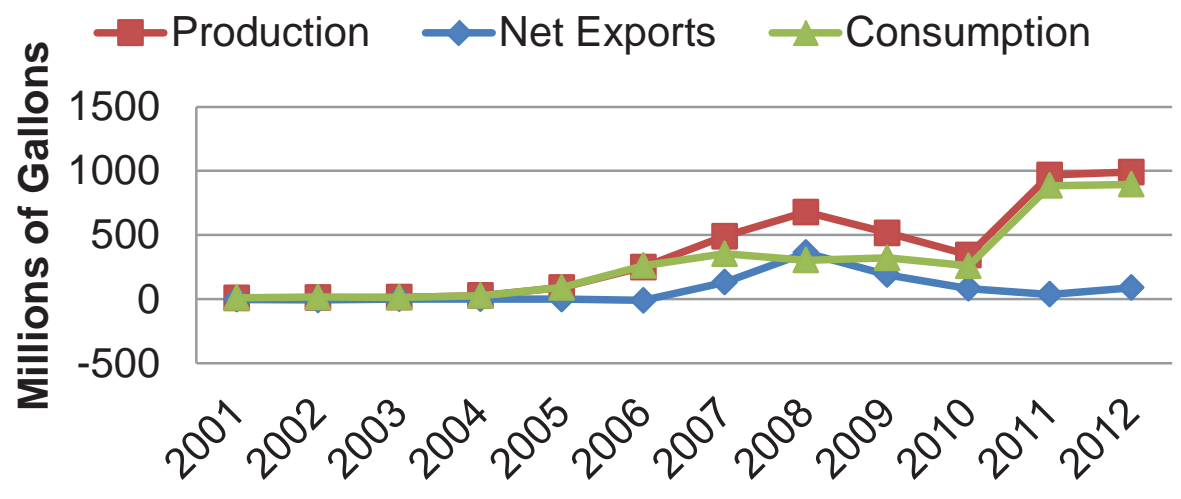

Fig. 1.3 U.S Biodiesel production, exports and consumption (Data adapted from ${ }^{16,20}$ ).

Levulinic acid is also suggested as the primary building block for our future production of chemicals and fuels. It can be efficiently manufactured via acid-hydrolysis of 
lignocellulosic biomass containing cellulose and hemicellulose (> 75\%) (Fig. 1.2 (b)). ${ }^{10,21-24}$ Both experimental results and the kinetic models have demonstrated that the yield of levulinic acid is influenced by reaction conditions, such as the composition of reaction mixtures, operation temperatures, acid concentrations and initial amount of cellulose. Highest yield of 76 mol.\% levulinic acid was predicted by kinetic study when using the optimum process conditions with insoluble humins/tars as the main byproduct that could be easily separated for the sub-sequential upgrading process. ${ }^{25}$ The analysis of liquid mixture revealed that the water soluble reaction intermediates and byproducts of glucose, 5-(hydroxymethyl)furfural (HMF) and furfural $(<0.1 \mathrm{wt} . \%)$ were negligible compared to the yields of levulinic acid and formic acid that were in an equal molar ratio. The Biorefine process developed by BioMetics Inc. has realized a large-scale production of levulinic acid in pilot plant at a yield of $50-70 \%$ and a cost of only $\$ 0.09-0.11 \mathrm{~kg}^{-1}$ was estimated, ${ }^{26-29}$ which is significantly cheaper than $\$ 5 \mathrm{~kg}^{-1}$ for pure levulinic acid in the global market. ${ }^{30}$

The transformation of levulinic acid has been actively explored. Numerous useful compounds can be derived from levulinic acid through dehydration/hydrogenation, esterification, oxidation, condensation and reductive amination reactions. ${ }^{9,10,14,26}$ Methyl tetrahydrofuran (MTHF) produced from dehydration/hydrogenation of levulinic acid has been reported to have a high octane number of 87. The U.S. DOE has approved the blend of MTHF in regular gasoline (up to 70\%) as a component of P Series fuel. ${ }^{10}$ Valeric ester, another levulinic acid derivative developed by Shell, has been proved by road run trial to be an excellent cellulosic biofuel that can be directly used as a blending component of high ratio in both gasoline and diesel. ${ }^{21}$

Many advances in science and technologies have been made recently toward extracting energy content of renewable biomass to produce chemicals and fuels. Nevertheless, with an aim of replacing as much non-renewable carbon from fossil fuels with renewable carbon from biomass, innovative R\&D activities are still needed to increase the efficiency and sustainability of present biorefinery process so as to diversify and secure our energy future. 


\subsection{Electro-biorefinery: Electrocatalytic Processing of Biomass-derived Oxygenated Compounds to Chemicals, Liquid fuels and Electricity}

Driven by the government policies and requirements in short terms and cost competitiveness with nonrenewable technologies in long terms, renewable electrical energy is expected to account for $28 \%$ of the overall electricity generation in the U.S. from 2012 to 2040 (Fig. 1.4). ${ }^{4}$ This motivates us to not only improve the efficiency of the current renewable electricity generation processes, but also develop new technologies for generation electricity from biorenewable feedstock and renewable electricity storage, in order to make significant contributions to this trend. Therefore, electrocatalytic processing of biomass-derived oxygenated compounds to chemicals, liquid fuels and electricity in electrochemical cells (including fuel cells and electrolysis cells) may play a significant role in our energy and chemical landscape.

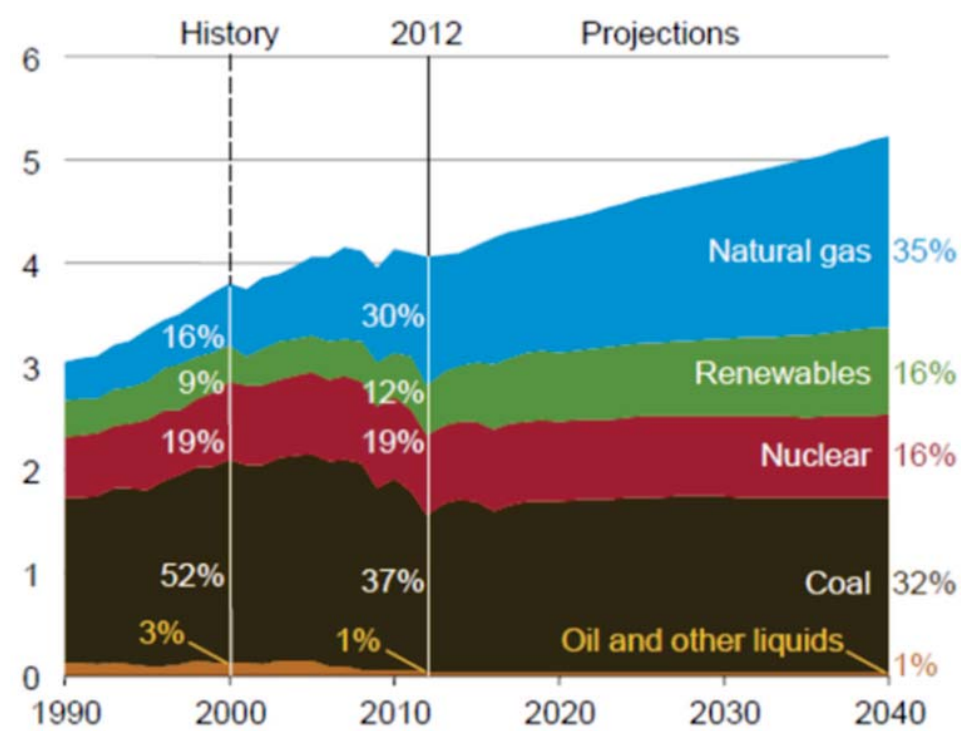

Fig. 1.4 Electricity generation by fuel type, 1990-2040 (trillion kWh) (Source: U.S. Energy Information Administration (December 16, 2013)) ${ }^{4}$.

Fuel cells have attracted considerable research interest as potentially alternative options for portable, transport and stationary power supply sources, as they can alleviate major problems associated with the production and consumption of fossil fuel based energy, including greenhouse gas emission and environment pollution. ${ }^{31,32}$ Fuel cells are the 
energy conversion device in which the efficient transformation of chemical energy stored in small organic molecules directly to electrical energy has been a long-time research challenge and appreciable key successes have been achieved. ${ }^{33}$ Several $\mathrm{H}_{2}$-PEMFCs (proton exchange membrane fuel cells) powered cars have been unveiled, including Chevrolet Equinox Fuel Cells vehicle, Honda FCX Clarity, Hyundai ix35 Fuel Cell electrical vehicle, Mercedes-Benz F-Cell vehicle and Toyota FCV. However, the cost involved in the high loading of platinum-group catalysts, the development of $\mathrm{H}_{2}$ gas storage materials and the $\mathrm{H}_{2}$ gas transport infrastructure make $\mathrm{H}_{2}$ fuel cell vehicle less competitive in the automobile market. ${ }^{2,34}$ While intensive researches are undergoing to resolve these concerns, direct alcohol fuel cells (DAFCs) have recently been recognized as another promising alternative electrical power general device to meet the humanity's energy demand. ${ }^{32,35}$ The interest in DAFCs is mainly aroused by higher volumetric energy density and thermodynamic efficiency of alcohol fuels when compared with liquid $\mathrm{H}_{2}$ fuel (Table 1.1). Also, liquid alcohol fuels are easy to store and transport, and can be derived from annually renewable biomass feedstock. In addition, the introduction of anion exchange membrane (AEM) serving as solid alkaline electrolyte can further improve the cell performance as both the anode and cathode reactions are significantly enhanced by the better mass transfer and lower adsorption of spectator charged species. ${ }^{36,37}$ High $\mathrm{pH}$ environment also allows the participation of low cost non-platinum catalysts thereby significantly reducing the cost of fuel cells. ${ }^{35,36}$ On the other hand, the products, including carbonate $\left(\mathrm{CO}_{3}{ }^{2-}\right)$ of anion exchange membrane-direct alcohol fuel cells (AEM-DAFCs) remain in the aqueous solution, with zero environmental impact. Therefore, numerous studies have been carried out in AEM-DAFCs, including

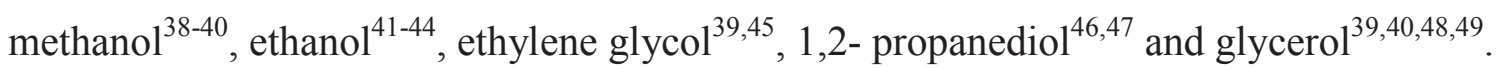


Table 1.1 The standard thermodynamic voltage $\left(E^{9}\right)$, energy density $\left(W_{e}\right)$, and maximum reversible efficiency $\left(\eta_{\text {rev }}\right)$ of hydrogen and selected pure polyols under standard conditions. ${ }^{37,50}$

\begin{tabular}{|c|c|c|c|}
\hline Fuel & $E / \mathrm{V}$ & $W_{e} / \mathrm{kWh} \mathrm{Kg}^{-1}\left[\mathrm{kWh} \mathrm{L}^{-1}\right]$ & $\eta_{\text {rev }}$ \\
\hline Hydrogen $\left(\mathrm{H}_{2}\right)$ & 1.23 & $39.0\left[2.6\right.$ (liquid $\left.\left.\mathrm{H}_{2}\right)\right]$ & 0.83 \\
\hline Ethylene glycol $\left(\mathrm{HOCH} \mathrm{CH}_{2} \mathrm{OH}\right)$ & 1.22 & $5.3[5.9]$ & 0.99 \\
\hline 1,2-Propanediol $\left(\mathrm{CH}_{3} \mathrm{CHOHCH}_{2} \mathrm{OH}\right)$ & 1.16 & $6.7[6.9]$ & 0.98 \\
\hline Glycerol $\left(\mathrm{HOCH}_{2} \mathrm{CHOHCH}_{2} \mathrm{OH}\right)$ & 1.23 & $5.1[6.4]$ & 0.98 \\
\hline
\end{tabular}

On the other hand, aqueous phase selective oxidation of biorenewable alcohols to valuable chemicals over metal catalysts with molecular oxygen or $\mathrm{H}_{2} \mathrm{O}_{2}$ oxidant also represents a very attractive green process in heterogeneous catalysis due to its low environmental impact, especially when compared to current stoichiometric oxidation reaction. $^{51,52}$ Interestingly, there are many similarities between electrocatalysis and heterogeneous catalysis as in both areas, the oxidation of alcohols are often carried out on supported metal catalysts that are responsible for the adsorption of reactants, activation and stabilization of intermediates and desorption of the products. ${ }^{53}$ Density functional theory (DFT) calculations have revealed that the presence of $\mathrm{OH}^{-}$ions in high $\mathrm{pH}$ solution would greatly reduce the activation energy of the first dehydrogenation step, thereby facilitating the alcohol oxidation. They also inferred that $\mathrm{O}_{2}$ in heterogeneous catalysis merely facilitates the $\mathrm{OH}^{-}$regeneration loop via oxygen reduction reaction (ORR) without direct interaction with alcohol, whose function is similar to the reaction at the cathode of a fuel cell. ${ }^{54}$

In spite of these similarities, electrocatalysis holds significant advantages against the heterogeneous catalysis system. The energy barriers of a multistep reaction can be manipulated by controlling electrode potentials so that the product selectivity can be easily tuned. ${ }^{55}$ On the other hand, the current that is indicative of the extent of the electrochemical reactions (Equation 1-1) often relates exponentially to the variation of electrode potentials (Equation 1-2). ${ }^{56}$ Therefore, high temperature and pressure often required in heterogeneous catalysis are not needed in electrocatalysis:

$$
\text { Rate }\left(\frac{m o l}{s}\right)=\frac{d N}{d t}=\frac{i}{n F}
$$


where $N(\mathrm{~mol})$ is the moles of the reactant electrolyzed; $i$ (A) is the current; $n$ is the number of electrons transferred in the electrode reaction; $F$ is the Faraday constant.

$$
i=i_{0}\left[\frac{C_{O}(0, t)}{C_{O}^{*}} e^{-\alpha f \eta}-\frac{C_{R}(0, t)}{C_{R}^{*}} e^{(1-\alpha) f \eta}\right]
$$

where $i_{0}$ is the exchange current; $C_{O}^{*}$ and $C_{R}^{*}$ are the bulk concentrations of oxidized and reduced species, respectively; $C_{O}(0, t)$ and $C_{R}(0, t)$ are the electrode surface concentrations of oxidized and reduced species as the function of time, respectively; $\alpha$ the transfer coefficient; $f=F / R T ; \eta=E-E_{e q}$ is called overpotential of the reaction.

In this context, an AEM-DAFC can be envisioned not only as an electrical energy generator for the current delivery but also as a chemical reactor for the useful chemicals production, as illustrated in Fig. 1.5 (a). The cogeneration process is thought to be highly desirable and with great commercial potentials from energy conservation, economics and sustainability viewpoints.

(a)

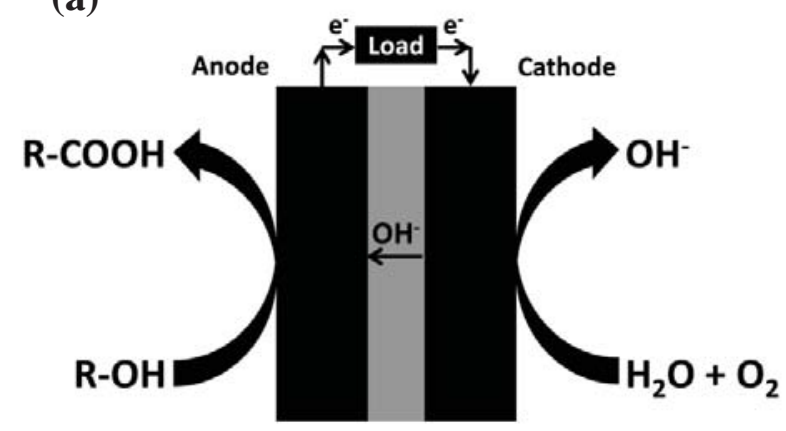

(b)

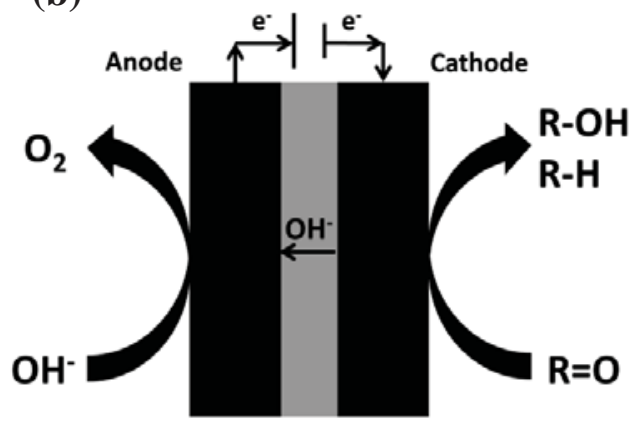

Fig. 1.5 Schematics of (a) AEM fuel cell reactor for cogeneration of electrical energy and valuable chemicals from biorenewable alcohols and (b) AEM electrolysis cell reactor for electrochemical hydrogenation of biomass derived oxygenates into liquid fuels.

Electrolysis cell is another operative derivative of fuel cell setups, where electric energy is consumed to produce chemical compounds of interest as shown in Fig. 1.5 (b). Production of $\mathrm{H}_{2}$ fuel through electrolysis of water by renewable energy sources (solar, wind, geothermal, tidal powers, etc.) has been reported as a sustainable energy option for the widespread applications of for $\mathrm{H}_{2}$-PEMFC in automobile industry. ${ }^{34,57}$ However, in the foreseeable future, the most desirable energy carriers for transportation purposes 
(autos, ships, airplanes, etc.) are still long-chain hydrocarbon fuels, such as gasoline, diesel, and kerosene, due to their unparalleled high energy density as well as the already established infrastructures for their storage and transportation. ${ }^{58}$ However, the finite nature of fossil fuels calls for the devotion of active research and development to renewable biomass resources. Though the advances in plant science have led to improvement of carbon capture efficiency of biomass from atmosphere, the harvest efficiency of solar energy in the most energetic plants is less than $2 \%$, making further increasing of biomass energy content very limited. ${ }^{6}$ As a comparison, great progress has been made in photovoltaic (PV) cells that are already commercially available for capturing solar energy in the form of electric energy with a harvest efficiency of more than $15 \%{ }^{59}$ In these respects, electrochemical hydrogenation in electrolysis cells takes advantages of using highly efficient man-made renewable electricity generation techniques (e.g. PV cell) for raising the energy content of biomass related compounds and upgrading these oxygenates to biofuels. Meanwhile, the electrical energy produced from PV cells that is absent during the off-peak hours, could be stored in the liquid fuels of high chemical energy densities.

The operation modes of both electrochemical cells are coupled with the oxygen electrode (Fig. 1.5). During cogeneration process in AEM-DAFC mode, ORR reduces $\mathrm{O}_{2}$ to $\mathrm{OH}^{-}$that is a ubiquitous cathode reaction in AEM-based fuel cell reactor. On the other hand, in electrolysis cell mode during electrochemical hydrogenation process, oxygen evolution reaction (OER) that oxidizes $\mathrm{OH}^{-}$back to $\mathrm{O}_{2}$ takes place on the anode side of AEM electrolysis cell reactor. The interconversion of $\mathrm{O}_{2}+2 \mathrm{H}_{2} \mathrm{O}+4 e^{-} \leftrightharpoons \mathrm{OH}^{-}$ involving multiple electron transfer is a sluggish reaction that requires the employment of platinum-group metals (PGMs), such as $\mathrm{IrO}_{2}$ or $\mathrm{RuO}_{2}$ for OER and Pt or Pd for ORR. However, the scarcity of these metals and expensive cost are a serious challenge to the broad deployment of these novel energy conversion and storage technologies. Therefore, extensive efforts have been taken to understand these reactions, and explore efficient and durable catalysts based on earth-abundant metals, which becomes the focal point of the current research. ${ }^{60-72}$ 


\subsection{Research Goals and Significance}

My Ph.D. research goals are to efficiently electro-catalytically convert biomass-derived polyols (glycerol, ethylene glycol and 1,2-propanediol) and keto-acid (levulinic acid) to produce value-added chemicals, hydrocarbon fuels or electricity, on supported nanoparticle electro-catalysts and acquire new understanding of these electrocatalytic reactions. In Chapter 3, kinetics and electricity performance of glycerol and crude glycerol electro-oxidation were studied on three model precious metal catalysts, $\mathrm{Pt} / \mathrm{C}$, $\mathrm{Pd} / \mathrm{C}$ and $\mathrm{Au} / \mathrm{C}$ in both half cells and AEMFCs. After better understanding of electrode potential-regulated electrocatalytic selective oxidation of glycerol (featuring two primary and one secondary - $\mathrm{OH}$ groups) through developing novel continuous flow AEM-based electrolysis cells, cogeneration of chemicals (tartronate or mesoxalate) and electricity was realized in AEM-DGFCs under different reaction conditions (see Chapter 4). To study the electrode potential-dependent electro-oxidation reaction pathway in-depth, selective electrocatalytic oxidation of ethylene glycol, the simplest polyol that contains only two primary alcohol groups, was performed by means of on-line sample collection system in conjunction with electrochemical tests (i.e. LSV) (see Chapter 5). The electrocatalytic oxidation mechanism associated with the charge transfer at the electrode-electrolyte interface was further elucidated via combining the preliminary computational quantum mechanical modeling (i.e. DFT) and the experimental results from electrocatalytic oxidation of 1,2-propanediol, a $\mathrm{C}_{3}$ polyol including one primary and one secondary hydroxyl groups, in AEM-based electrolysis cells (see Chapter 6). In addition to electrooxidation and conversion of biorenewable alcohols to chemicals and electrical energy, my Ph.D. research was also devoted to electro-reduce and upgrade biomass derived compounds to biofuels with simultaneous storage of renewable electricity (see Chapter 7). In Chapter 8, efficient non-PGMs ORR catalysts were also evaluated, so as to facilitate the development of AEM-DAFCs. My Ph.D. research has gained new insights into electrocatalytic processing of biomass-derived feedstocks on model catalysts and may open up a new sustainable electrochemical biorefinery route that could be coupled 
with traditional biorefinery facilities for the production of chemicals, biofuels and electricity, at the same time enabling the storage of other renewable electrical energy. 


\section{Chapter 2 Experimental Details and Materials}

\subsection{Chemicals and materials}

The chemicals and materials used for my Ph.D. research are purchased from different sources as follows.

\section{Chemicals from Sigma Aldrich:}

Oleylamine (70\%), Oleic acid (90\%), Super-Hydride solution (1.0 M lithium triethylborohydride $\left(\mathrm{LiBEt}_{3} \mathrm{H}\right)$ in THF), 1-Propanol $(99.5+\%)$, Potassium hydroxide $(\mathrm{KOH}, 85+\%)$, Potassium hydroxide (99.99\%, trace metal basis), Polytetrafluoroethylene preparation (60 wt.\% dispersion in $\mathrm{H}_{2} \mathrm{O}$ ), Glycerol (99\%, GC Grade), D-(+)Glyceraldehyde (98+\%, HPLC), 1,3-Dihydroxyacetone dimer (97\%), Mesoxalic acid monohydrate disodium salt (98+\%, Fluka Analytical), $\beta$-Hydroxypyruvic acid $(95+\%)$, Glycolic acid (99\%), Glycolaldehyde dimer, Oxalic acid dihydrate (99+\%, GC), Glyoxal (40 $\mathrm{wt} \%$ solution in water), 1,2-Propanediol (99.5+\%), Levulinic acid (97+\%), Valeric acid (99+\%), Nitric acid (70\%), Potassium hexacyanoferrate(III) $\left(\mathrm{K}_{3}\left[\mathrm{Fe}(\mathrm{CN})_{6}\right], 99.99+\%\right.$, trace metal basis), Propionic acid (99.5+\%), Butyric acid (99+\%)

\section{Chemicals from Acros Organics:}

Platinum(II) acetylacetonate $\left(\mathrm{Pt}(\mathrm{acac})_{2}, 98 \%\right)$, Palladium(II) acetylacetonate $\left(\mathrm{Pd}(\mathrm{acac})_{2}\right.$, $35 \% \mathrm{Pd})$, Gold(III) chloride (64.4+\% Au), 1-Octadecene (90\%), Glyoxylic acid (98\%), DL-Lactic acid (85\%), Pyruvic acid (98\%), $\gamma$-valerolactone (98\%)

\section{Chemicals from Alfa Aesar:}

Dibenzyl ether (98+\%), Tartronic acid (98\%), Hydroxyacetone (95\%)

\section{Chemicals from Fisher Scientific:}

Glycerol (99.8\%), Hydrogen peroxide $\left(\mathrm{H}_{2} \mathrm{O}_{2}\right.$, aqueous solution, 31.6\%), N,NDimethylformamide (DMF, 99.9\%) 


\section{Chemicals from BDH Chemicals:}

Isopropanol (99\%), Ethylene glycol (99+), Acetic acid (99.7+\%), Ammonium hydroxide $(28-30 \%)$

\section{Chemicals from PHARMCO-AAPER:}

Ethanol (200 proof, anhydrous)

\section{Chemicals from TCI AMERICA:}

DL-Glyceric Acid (20\% in water, ca. $\left.2 \mathrm{~mol} \mathrm{~L}^{-1}\right)$

\section{Chemicals from EMD Chemicals Inc.:}

Potassium phosphate dibasic $\left(\mathrm{K}_{2} \mathrm{HPO}_{4}\right.$, Powder, 98+\%), Hydrochloride acid (36.5$38.0 \%)$, Sulfuric acid (17.8 M, 95.0-98.0\%)

\section{Chemicals from Mallinckrodt Chemicals:}

Potassium phosphate monobasic $\left(\mathrm{KH}_{2} \mathrm{PO}_{4}\right.$, Crystal, $\left.99+\%\right)$, Formic acid (88+\%)

\section{Materials:}

Crude glycerol (88\%, a byproduct from soy bean biodiesel manufacturing, Kingdom Bio Solution Inc.), Carbon black Vulcan XC-72R (Fuel Cell Store), 4020 series cathode catalyst (Fe-Cu-N $/$ C, HYPERMEC ${ }^{\mathrm{TM}}$, Acta), XGnp-M-5 graphite nanoplatelets (XG Sciences), Multi-wall carbon nanotubes-COOH (5-15 nm OD, 10-50 $\mu \mathrm{m}$ length, Cheaptubes Inc.), 25CC carbon paper (Teflon Treated, SGL Group), Carbon cloth (Teflon Untreated or Treated, $381 \mu \mathrm{m}$, Fuel Cell Store), AS-4 anion exchange ionomer (5.0 wt.\%, $\mathrm{OH}^{-}$conductivity of $13 \mathrm{mS} \mathrm{cm}^{-1}$ Tokuyama Corp.), Nafion117 proton exchange membrane (Ion Power, Inc.), Nafion proton exchange ionomer (LIQUION $^{\mathrm{TM}}$ Solution LQ-1105, 1100 EW, 5 wt.\%, Ion Power Inc.) A-201 anion exchange membrane (28 $\mu \mathrm{m}, \mathrm{OH}^{-}$conductivity of $38 \mathrm{mS} \mathrm{cm}{ }^{-1}$, Tokuyama Corp.), A-901 anion exchange membrane $\left(10 \mu \mathrm{m}, \mathrm{OH}^{-}\right.$conductivity of $42 \mathrm{mS} \mathrm{cm}^{-1}$, Tokuyama Corp.), FAA anion exchange membrane $\left(110 \mu \mathrm{m}, \mathrm{OH}^{-}\right.$conductivity of $17 \mathrm{mS} \mathrm{cm}{ }^{-1}$, Fuma-Tech, $\left.\mathrm{GmbH}\right)$, 
Silicon gaskets $(508 \mu \mathrm{m})$ Lead $(\mathrm{Pb})$ plate (Rotometals Inc., United States, 99.9\%), Copper $(\mathrm{Cu})$ plate (Small Parts Inc., United States, 99.9\%), Pt foil (0.5 mm thickness, Sigma-Aldrich, 99.99\%, trace metal basis), Pt/Vulcan Carbon (20 wt.\%, Fuel Cell Store), Pt/Vulcan Carbon (40 wt.\%, Fuel Cell Store)

\subsection{Electrochemical cell setups}

\subsubsection{Batch-type three-electrode cell reactor}

A conventional three-electrode cell is shown in Fig. 2.1. The setup includes a working electrode, a reference electrode (e.g. $\mathrm{Hg} / \mathrm{HgO} / 1.0 \mathrm{M} \mathrm{KOH}$ ), and a coiled platinum counter electrode that was placed in a glass tube with glass frits to prevent the diffusion of the products generated on the working electrode. The water jacket of the cell enables the system to be thermostated at various temperatures during the tests. The potential applied on the working electrode is controlled through a potentiostat hardware (VersaSTAT MC, Princeton Applied Research) with respect to a reference electrode that has a stable and known redox potential. To reduce the solution resistance, the distance between the reference electrode and working electrode was kept small $(<0.5 \mathrm{~cm})$. The counter electrode balances all the charge transfer of the working electrode from and to the electrolyte. All the electrochemical data in this dissertation was collected either versus a mercury/mercury oxide reference electrode $(\mathrm{Hg} / \mathrm{HgO})$ or a silver chloride reference electrode $(\mathrm{Ag} / \mathrm{AgCl})$ and had been converted to values versus reversible hydrogen electrode (RHE) as reported unless otherwise mentioned. Based on the manufacturer's specification (Pine Instrument Co.), the standard electrode potential of $\mathrm{Hg} / \mathrm{HgO}$ is 0.098 $\mathrm{V}$ vs. standard hydrogen electrode ( $\mathrm{SHE}$ ) and $\mathrm{Ag} / \mathrm{AgCl}$ (in saturated $\mathrm{KCl}$ solution) is $0.197 \mathrm{~V}$ vs. SHE, at $25^{\circ} \mathrm{C}$ Therefore, potentials versus RHE were calculated as:

$$
\begin{aligned}
& \text { V (vs. RHE })=\mathrm{V}(\text { vs. } \mathrm{Hg} / \mathrm{HgO})+0.098+0.059 \times \mathrm{pH}_{\text {supporting electrode }} \\
& \mathrm{V}(\text { vs. RHE })=\mathrm{V}(\text { vs. Ag/AgCl })+0.197+0.059 \times \mathrm{pH}_{\text {supporting electrode }}
\end{aligned}
$$

for example, the potential differences of the $\mathrm{Hg} / \mathrm{HgO}$ in $1.0 \mathrm{M} \mathrm{KOH}$ and $\mathrm{Ag} / \mathrm{AgCl}$ in $\mathrm{KH}_{2} \mathrm{PO}_{4} / \mathrm{K}_{2} \mathrm{HPO}_{4}$ buffer solution vs. RHE are $0.098+0.059 \times 14=0.924 \mathrm{~V}$ and $0.197+$ 
$0.059 \times 7.5=0.64 \mathrm{~V}$, respectively. Both reference electrodes were also calibrated against RHE (HydroFlex ${ }^{\circledR}$ ) in a fresh prepared $1.0 \mathrm{M} \mathrm{KOH}$ or $\mathrm{KH}_{2} \mathrm{PO}_{4} / \mathrm{K}_{2} \mathrm{HPO}_{4}$ buffer solution $(\mathrm{pH}=7.5)$ at the end of each electrochemical test, and the potential differences were maintained $0.924 \pm 0.007 \mathrm{~V}$ for $\mathrm{Hg} / \mathrm{HgO}$ electrode and $0.64 \pm 0.01 \mathrm{~V}$ for $\mathrm{Ag} / \mathrm{AgCl}$ electrode throughout all of the experiments.

Fig. 2.1 (a) shows the three electrode cell equipped with a glassy carbon rotation disk electrode (RDE) of $5 \mathrm{~mm}$ outer diameter. The employment of RDE allows the study of electrochemical reactions on an electrocatalyst that is deposited on the glassy carbon electrode under either stationary or rotation mode. For the purpose of acquiring more knowledge about the reactions occurring on the disk electrode, a second working electrode is added in the form of a ring surrounding the first disk working electrode. As shown in Fig. 2.1 (b), the platinum ring in the rotating ring-disk electrode (RRDE) is independent of the center disk electrode. ${ }^{56}$ Any products generated from electrochemical reactions on the disk electrode under a rotation are continuous swept pass the ring electrode held at a constant potential where those intermediate species can be collected and electrochemically reduced or oxidized. 

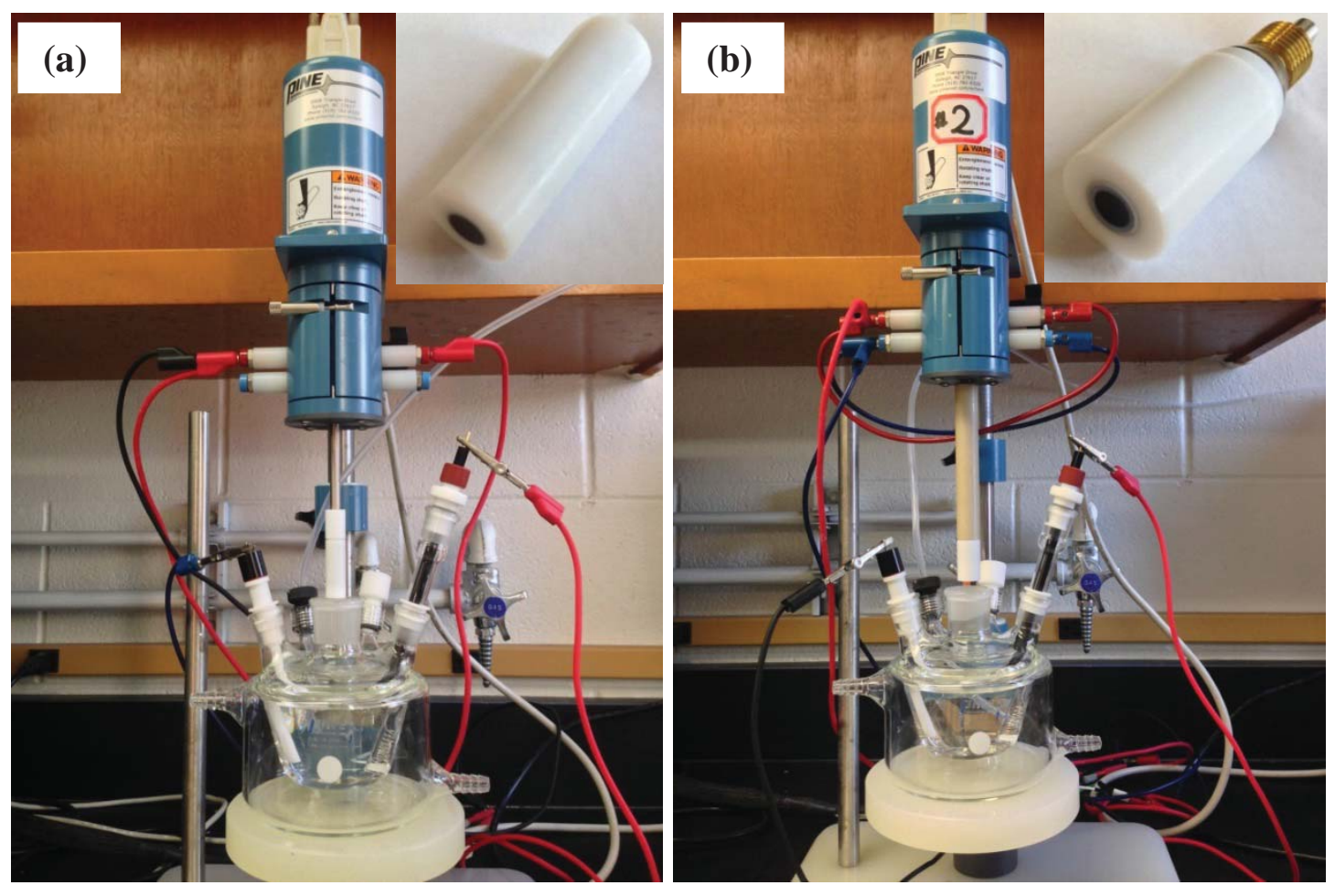

Fig. 2.1 Setups of three electrode cells with (a) RDE and (b) RRDE.

The collection efficiency, $N$, is the important factor in RRDE testing which measures the percentage of products on disk electrode that can be probed by the ring electrode. $N$ is only dependent on the geometry of RRDE, $r_{1}$ (disk radius), $r_{2}$ (ring inner radius), and $r_{3}$ (ring outer radius): ${ }^{56}$

$$
N=1-F(\alpha / \beta)+\beta^{2 / 3}[1-F(\alpha)]-(1+\alpha+\beta)^{2 / 3}\{1-F[(\alpha / \beta)(1+\alpha+\beta)]\}
$$

where,

$$
\begin{gathered}
\alpha=\left(\frac{r_{2}}{r_{1}}\right)^{3}-1 \\
\beta=\frac{r_{3}^{3}}{r_{1}^{3}}-\frac{r_{2}^{3}}{r_{1}^{3}} \\
F(\theta)=\left(\frac{\sqrt{3}}{4}\right) \ln \left\{\frac{\left(1+\theta^{1 / 3}\right)^{3}}{1+\theta}\right\}+\frac{3}{2 \pi} \arctan \left(\frac{2 \theta^{1 / 3}-1}{3^{1 / 2}}\right)+\frac{1}{4}
\end{gathered}
$$


For the RRDE (E6, Pine Instrument Co.) with $\mathrm{r}_{1}=2.5 \mathrm{~mm}, \mathrm{r}_{2}=3.25 \mathrm{~mm}$ and $\mathrm{r}_{3}=3.65$, $N=25 \%$. $N$ can be also determined experimentally by performing linear scan voltammetry with thin-film $\mathrm{Pt} / \mathrm{C}$ coated disk electrode in the $\mathrm{N}_{2}$ deaerated $0.1 \mathrm{M} \mathrm{KOH}+$ $10 \mathrm{mM} \mathrm{K}_{3} \mathrm{Fe}(\mathrm{CN})_{6}$ electrolyte, meanwhile a constant potential of $1.55 \mathrm{~V}$ vs. RHE will be held at the ring electrode, where the oxidation of $\mathrm{K}_{4} \mathrm{Fe}(\mathrm{CN})_{6}$ that produced by the reduction reaction at the disk electrode process purely under diffusion control. (Fig. 2.2) $N$ is then determined to be $23 \%$ according to:

$$
N=-\frac{I_{R}}{I_{D}}
$$

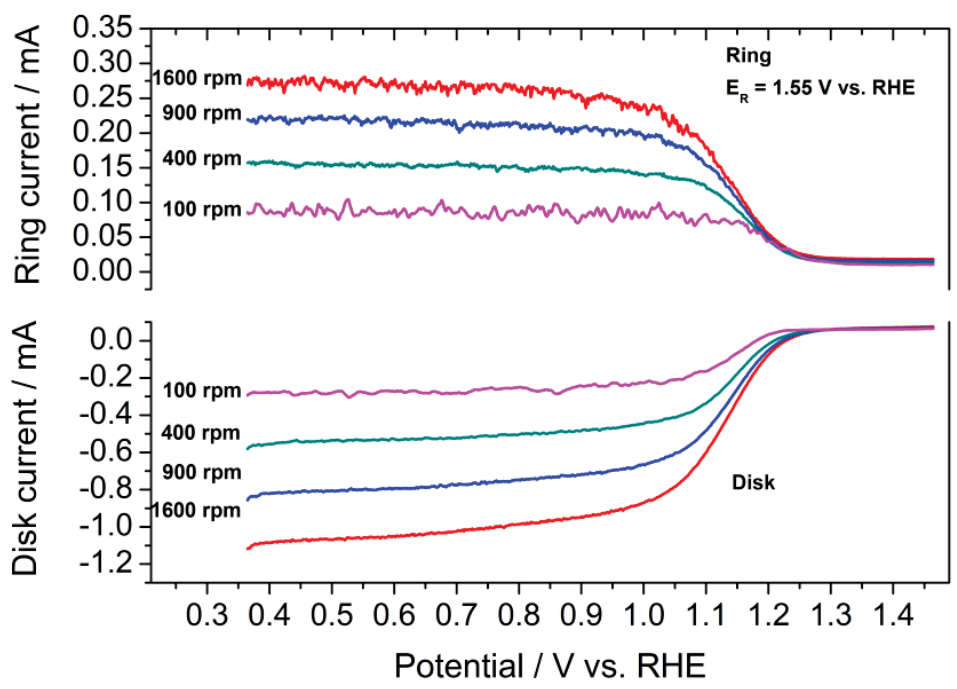

Fig. 2.2 Current of ring $\left(I_{R}, \mathbf{F e}(\mathbf{C N})_{6}^{4-} \rightarrow \mathbf{F e}(\mathbf{C N})_{6}^{3-}+\mathbf{e}^{-}\right)$and $\operatorname{disk}\left(I_{D}, \mathbf{F e}(\mathbf{C N})_{6}^{3-}+\right.$ $\left.\mathbf{e}^{-} \rightarrow \mathbf{F e}(\mathbf{C N})_{6}^{4-}\right)$ for the determination of the collection efficiency of the RRDE, $N$. Linear scan voltammetry performed on $\mathrm{Pt} / \mathrm{C}$ thin-film electrode in $\mathrm{N}_{2}$-saturated $0.1 \mathrm{M}$ $\mathrm{KOH}+10 \mathrm{mM} \mathrm{K}{ }_{3} \mathrm{Fe}(\mathrm{CN})_{6}$ electrolyte under rotation scan rates. Scan rate: $20 \mathrm{mV} \mathrm{s}$, $25^{\circ} \mathrm{C}$. $\mathrm{E}_{\text {ring }}=1.55 \mathrm{~V}$ vs. RHE.

\subsubsection{Continuous flow-type AEM or PEM-based electrolysis cell reactor}

Fig. 2.3 shows continuous flow AEM based electrolysis cell reactor that was custom made for selective electrocatalytic oxidation of polyols (Chapter 4 and 6). The electrode of a $5.0 \mathrm{~cm}^{2}$ active cross-sectional area was constructed by mechanically sandwiching the AEM (A201, Tokuyama Corp.), electrocatalysts sprayed anode and cathode carbon clothes as a membrane electrode assembly (MEA). The anode end plate was made of 
stainless steel (316L) so as to tolerate the alkaline environment. A home-made graphite block with a serpentine pattern was used in anodic half-cell where polyol alkaline solution was introduced at a flow rate regulated by a peristaltic pump (Gilson Miniplus 3), while an alkaline electrolyte of the same $\mathrm{pH}$ as the anode reactant solution was cycled through the cathode chamber that was made of high-density polyethylene. The cell was sealed with the assistance of unreactive silicon gasket and a torque of $20 \mathrm{~N} \mathrm{~m}$. The reaction temperature was controlled by a thermocouple and the potential applied on the anode side by potentiostats could be well controlled with respect to a $\mathrm{Hg} / \mathrm{HgO} / 1.0 \mathrm{M}$ $\mathrm{KOH}$ reference electrode that was inserted to the anode compartment.
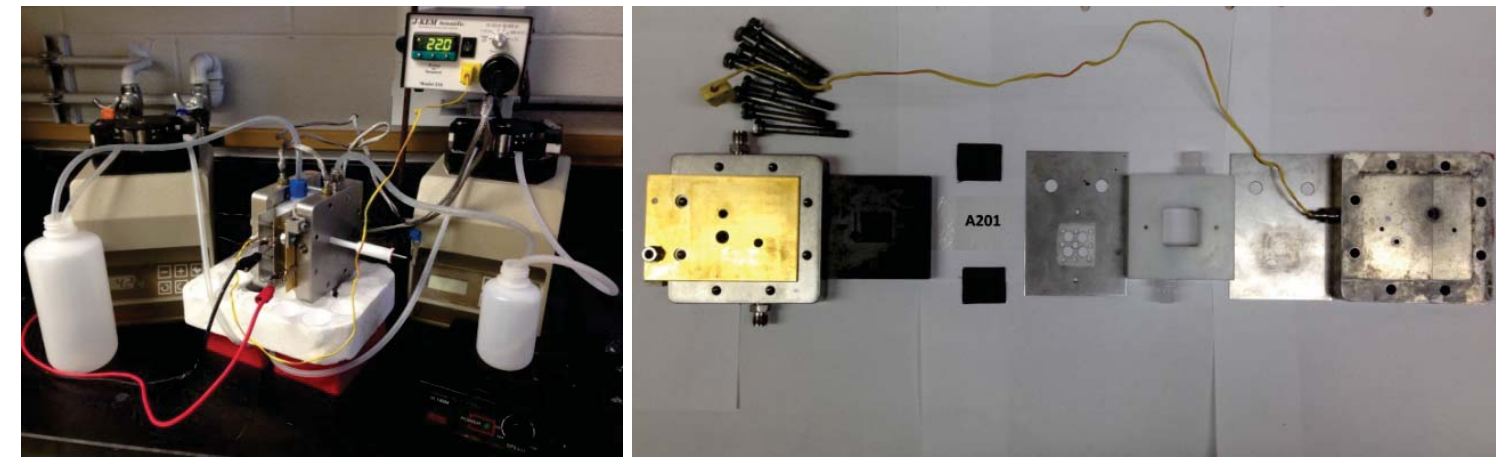

Fig. 2.3 Setups of continuous flow AEM based electrolysis cell reactor constructed with a MEA-type electrode for selective electrocatalytic oxidation of polyols.

Another type of continuous flow reactor was assembled, as shown in Fig. 2.4, for selective electrochemical reduction of keto acids (e.g. levulinic acid) and electrical energy storage (Chapter 7). Instead of using carbon cloth supported porous electrodes, the planar $\mathrm{Pb}$ or $\mathrm{Cu}$ plate with a projected area of $6.5 \mathrm{~cm}^{2}$ served as the working electrode, which was placed in the cathode chamber, while Pt foil employed as the counter electrode was placed in the anode chamber. Solid-polymer electrolyte membranes, including AEM (FAA, Fuma-Tech, GmbH) for reduction in a neutral environment or proton exchange membrane (PEM, Nafion 117, Ion Power, Inc.) for reduction in an acid environment, was used to separate the anode and cathode chambers in order to minimize the cross-over of the products or reactants from the cathode to the anode. The larger electrode area $\left(6.5 \mathrm{~cm}^{2}\right)$ and small cathode chamber volume $(12 \mathrm{ml})$, along with a fast flow rate of $30 \mathrm{ml} \mathrm{min}^{-1}$ were optimized to ensure a sufficient reactant fuel supply to the 
$\mathrm{Pb}$ electrode surface, while avoiding the mass transport issue resulting from hydrogen bubbles $\left(\mathrm{H}^{+}+\mathrm{e}^{-} \rightarrow 1 / 2 \mathrm{H}_{2}\right.$ in acid, $\mathrm{H}_{2} \mathrm{O}+\mathrm{e}^{-} \rightarrow \mathrm{OH}^{-}+1 / 2 \mathrm{H}_{2}$ in neutral) striking the $\mathrm{Pb}$ electrode. Keto acids in neutral or acid electrolyte were introduced into sealed fournecked glassware that was placed in an ice-bath and pumped into the cathode compartment through a closed loop by a peristaltic pump (Gilson Miniplus 3) at a controlled flow rate. At the same time, acid or buffer solution with the same $\mathrm{pH}$ as the cathode reactant solution was cycled through the anode chamber. A thermocouple was used to control the temperature of the reactant solution in order to minimize the evaporation of the low-boiling point products. Electrochemical reduction reactions were then initiated by the potential applied through a potentiostat at the cathode versus $\mathrm{Ag} / \mathrm{AgCl}$ reference electrode, and the products at the end of the reaction were collected.
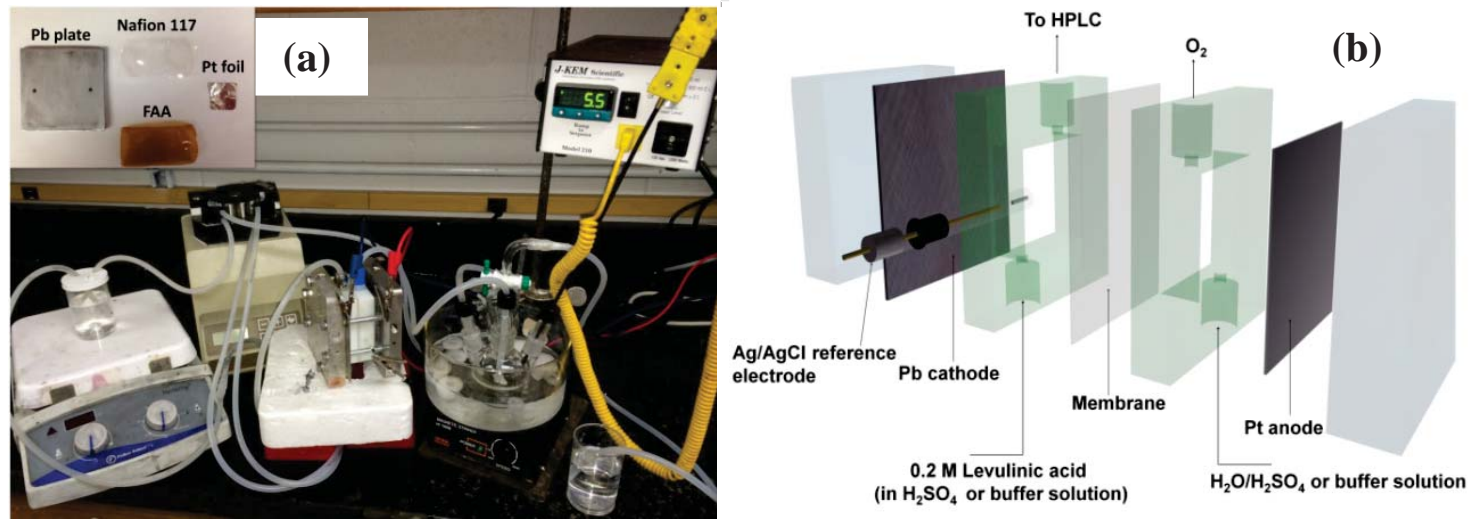

Fig. 2.4 (a) Setups and (b) schematic view of continuous flow solid-polymer electrolyte membranes (AEM or PEM) based electrolysis cell reactor constructed with metal foil electrodes for selective electrochemical reduction of keto acids and electrical energy storage.

\subsubsection{Continuous flow-type AEM based fuel cell reactor}

The performance of electricity generation and cogeneration of chemicals and electrical energy from polyols (Chpater $\mathbf{4}$ and 5) were tested on a Scribner fuel-cell test system (850e) (Fig. 2.5). The fuel-cell fixture was purchased from Fuel Cell Technology Inc. with an active area of $5 \mathrm{~cm}^{2}$ and modified with the stainless steel $(316 \mathrm{~L})$ end plates to tolerate the alkaline working environment. A port for the $\mathrm{Hg} / \mathrm{HgO} / 1.0 \mathrm{M} \mathrm{KOH}$ reference electrode was introduced so that the anode operation potential could be monitored by 
using an electrode load (BK Precision, 8540). A MEA based electrode involving anode catalysts sprayed carbon cloth and cathode catalysts coated membrane is responsible for polyols oxidation and $\mathrm{O}_{2}$ reduction, respectively. The performance of electricity generation from AEM-DAFCs was evaluated by a polarization scan at various cell temperatures, with a solution of polyols in alkaline fed into the anode compartment and the high-purity humidified $\mathrm{O}_{2}(99.999 \%)$ fed in into the cathode compartment under a back pressure of 30 psi. On the other hand, the cogeneration study was carried out by a constant voltage discharging for certain duration of time with a cycling of the polyols alkaline solution from a plastic vessel into the anode channels
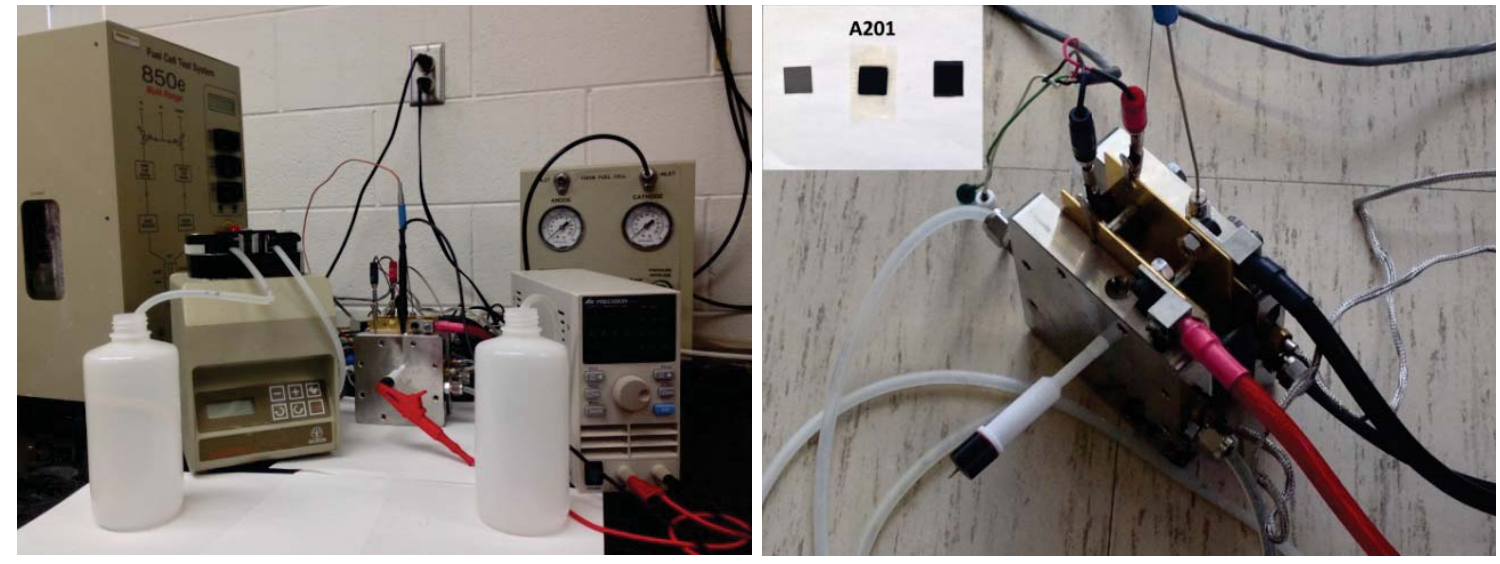

Fig. 2.5 Continuous flow-type AEM based fuel cell reactor for electricity generation and cogeneration of electrical power plus useful chemicals.

\subsection{Preparation of electrodes}

\subsubsection{Glassy carbon electrode}

Prior to catalyst deposition, glassy carbon electrode was polished using $1.0 \mu \mathrm{m}$ and then $0.05 \mu \mathrm{m}$ alumina suspensions (BUEHLER) to achieve a mirror like surface. 1.0-2.0 mg supported catalyst was then dispersed in $1.0 \mathrm{ml}$ isopropanol by ultra-sonication in an ice bath for at least $30 \mathrm{~min}$ to form uniform ink. And 20-40 $\mu 1$ of the catalyst ink was dropcasted using a syringe on the polished glassy carbon electrode, followed by 10-20 $\mu 1$ of $0.05 \mathrm{wt} \%$ AS-4 anion conductive ionomer solution (Tokuyoma Corp.) added on the top to bind the catalyst particles. 


\subsubsection{Metal foil electrode}

The $\mathrm{Pb}$ and $\mathrm{Cu}$ plates were served as working electrodes in electrochemical reduction reactions (Chapter 7). Prior to experiments, the metal electrodes were polished to a mirror finish using sandpaper (320 grit and subsequently 1200 grit) purchased from Leco Corporation. Then, they were further cleaned using acetone, ethanol under ultrasonication for 30 min each. DI water was used to rinse the electrode after each cleaning step.

\subsubsection{MEA electrode}

MEA electrode was fabricated via catalyst coated membrane (CCM) or catalyst coated gas/liquid diffusion layer (CCG(L))method. The anode catalyst ink, which was made by mixing a $10 \mathrm{wt} . \%$ dispersion of PTFE and supported catalyst powder in isopropanol, was sprayed onto a Teflon untreated carbon cloth that was used as a liquid diffusion electrode (LDE). On the cathode side in AEM-based electrolysis cell reactor (Fig. 2.3), a commercial Pt/Vulcan Carbon (40 wt.\%, Fuel Cell Store) dispersed in isopropanol with a 10 wt.\% PTFE suspension was airbrushed on a Teflon untreated carbon cloth, while in AEM-based fuel cell reactor (Fig. 2.5), the cathode catalyst ink, which was made form a commercial non-platinum-group-metal 4020 series catalyst $\left(\mathrm{Fe}-\mathrm{Cu}-\mathrm{N}_{4} / \mathrm{C}\right.$, HYPERMEC $^{\mathrm{TM}}$, Acta) that was blended with an AS-4 anion conductive ionomer (Tokuyama Corp.) in 1-propanol, was sprayed directly onto the AEM, followed by a Teflon treated carbon paper covered on the top as the gas diffusion layer (GDL). The MEA was then assembled by mechanically sandwiching anode and cathode electrode on separate side of AEM.

\subsection{Preparation of supported electrocatalysts}

Selective electrooxidation of polyols was studied on supported $\mathrm{Pt}, \mathrm{Pd}$ and $\mathrm{Au}$ monometallic catalysts (Chapter 3-6), and the electrocatalytic behaviors gained on these model catalysts will guide the future design and engineering of efficient and durable multi-metallic electrocatalysts. On the other hand, the carbon supported Ag catalysts for 
ORR (Chapter 8) was also studied in order to couple with the electro-biorefinery processes. For these purposes, an effective synthesis method is needed to produce metal nanoparticles with controlled structure and dispersion on the supporting materials. An organic solution phase-based nanocapsule synthesis method, first developed by IBM researchers for the preparation of monodispersed magnetite nanoparticles, ${ }^{73}$ was modified and used exclusively during my research. The $\mathrm{Pt}, \mathrm{Pd}, \mathrm{Au}$, and $\mathrm{Ag}$ nanoparticles synthesized via this method can be well controlled in a range of 2-5 nm, and the synthesis details are described below:

\subsubsection{Pretreatment and preparation of carbon supporting materials}

Vulcan XC-72R carbon black purchased from Fuel Cell Store was refluxed in a $2 \mathrm{M}$ $\mathrm{H}_{2} \mathrm{SO}_{4}+4 \mathrm{M} \mathrm{HNO}_{3}$ acidic solution for 6 hours in order to oxidize the surface before use.

\subsubsection{Preparation of Pt/C (40 wt.\%)}

$\mathrm{Pt}(\mathrm{acac})_{2}$ (Platinum (II) acetylacetonate, $\left.0.5 \mathrm{mmol}\right)$, oleylamine $(200 \mu \mathrm{l})$, and oleic acid $(200 \mu \mathrm{l})$ were dissolved in a mixture of Vulcan XC-72R carbon black $(146.3 \mathrm{mg})$ and benzyl ether $(40 \mathrm{ml})$ at $60^{\circ} \mathrm{C}$ under a $\mathrm{N}_{2}$ blanket. $\operatorname{LiBEt}_{3} \mathrm{H}(1.0 \mathrm{ml}, 1 \mathrm{M}$ in THF) was quickly injected by syringe into the system as the temperature was raised to $120^{\circ} \mathrm{C}$. After being maintained at $120^{\circ} \mathrm{C}$ for $30 \mathrm{~min}$, the temperature was slowly increased to $180^{\circ} \mathrm{C}$ and maintained at that temperature for an additional $30 \mathrm{~min}$. The $\mathrm{Pt} / \mathrm{C}$ catalyst was collected by filtration, washed with copious amounts of ethanol, and dried in a vacuum oven overnight at $50^{\circ} \mathrm{C}$.

\subsubsection{Preparation of Pd/C (40 wt.\%)}

$\operatorname{Pd}(\mathrm{acac})_{2}$ (Palladium (II) acetylacetonate, $0.5 \mathrm{mmol}$ ) and $79.8 \mathrm{mg}$ of carbon black were mixed in $40 \mathrm{ml}$ benzyl ether solvent, and was rapidly heated to $100^{\circ} \mathrm{C}$ in a $\mathrm{N}_{2}$ atmosphere. As the temperature reached $100^{\circ} \mathrm{C}, 200 \mu \mathrm{l}$ of oleylamine and $200 \mu \mathrm{l}$ of oleic acid were added into the system, followed by quick injection of $1.0 \mathrm{ml} \mathrm{LiBEt}{ }_{3} \mathrm{H}$ by syringe. The temperature was held for $20 \mathrm{~min}$, and then slowly raised to $180^{\circ} \mathrm{C}$ and held for an 
additional $30 \mathrm{~min}$. The $\mathrm{Pd} / \mathrm{C}$ catalyst was collected by filtration, washed with copious amounts of ethanol, and dried in a vacuum oven overnight at $50^{\circ} \mathrm{C}$.

\subsubsection{Preparation of $\mathrm{Au} / \mathrm{C}$ (40 wt.\% or 55 wt.\%)}

$\mathrm{AuCl}_{3}(0.5 \mathrm{mmol})$ was mixed with 1-Octadecene $(16 \mathrm{ml})$ and oleylamine $(4 \mathrm{ml})$ under a $\mathrm{N}_{2}$ blanket. The system was then rapidly heated to $80^{\circ} \mathrm{C}$, followed by a quick injection of $\mathrm{LiBEt}_{3} \mathrm{H}(1.5 \mathrm{ml}, 1 \mathrm{M}$ in THF) by syringe. After being maintained at the same temperature for $10 \mathrm{~min}$, the solution was cooled to room temperature and separated by centrifugation. The as-prepared $\mathrm{Au}$ were re-dispersed into $50 \mathrm{ml}$ hexane and slowly deposited in an ethanol dispersion of Vulcan XC-72R carbon black to afford an $\mathrm{Au} / \mathrm{C}$ catalyst with a loading of $40 \mathrm{wt} . \%$ or $55 \mathrm{wt} . \%$.

\subsubsection{Preparation of Ag/C (40 wt.\%)}

$\mathrm{Ag}(\mathrm{acac})(0.25 \mathrm{mmol})$ and $40.5 \mathrm{mg}$ VulcanXC-72R carbon black were mixed in $10 \mathrm{ml}$ oleylamine and $20 \mathrm{ml}$ benzyl ether by vigorous stirring under a $\mathrm{N}_{2}$ blanket. The temperature was kept at $30^{\circ} \mathrm{C}$, while $0.25 \mathrm{ml} \mathrm{LiBEt} 3 \mathrm{H}$ (1.0M THF solution) was injected into the solution by syringe. After held at that temperature for an additional $30 \mathrm{~min}$, the final product $\mathrm{Ag} / \mathrm{C}$ was collected after filtration, washed with $800 \mathrm{ml}$ ethanol, and drying overnight in a vacuum oven.

\subsection{Physical characterizations}

\subsubsection{Transmission electron microscopy (TEM)}

JEOL JEM-2010F TEM was employed to characterize the structure, morphology and composition of catalysts with an operation voltage of $200 \mathrm{kV}$. Before tests, a uniform and dilute solution of the as-prepared catalyst in ethanol or isopropanol was prepared by ultra-sonication, and then one or two drop was deposited on amorphous carbon film coated copper grids (Ted Pella, Inc.) and dried. The average size (length or diameter) and dispersion of metal catalysts on supporting materials were revealed from the TEM images. Histograms of particle size were obtained with imageJ software by randomly measuring 
over 100 nanostructures from representative regions on TEM images. The structure of the metal particles and supporting materials was characterized using selected area electron diffraction (SAED) on the TEM. In addition, the catalyst composition was analyzed by the Energy-dispersive X-ray spectroscopy (EDX) connected to the TEM by taking the average of at least five different regions from TEM images.

\subsubsection{Scanning electron microscopy (SEM)}

SEM (JOEL JSM-6400) equipped with EDX was used to characterize the surface of Cu and $\mathrm{Pb}$ electrode for keto acids electrochemical reduction (Chapter 7). Metal electrode was attached onto the sample holder by double sided scotch tape. The roughness of electrode surface was qualitatively revealed in SEM images.

\subsubsection{X-ray diffraction (XRD)}

XRD patterns of metal particles and supporting materials were collected by a Scintag XDS-2000 $\theta / \theta$ diffractometer using $\mathrm{Cu} \mathrm{K}_{\alpha}$ radiation $(\lambda=1.5406 \AA)$, with a tube current of $35 \mathrm{~mA}$ and a tube voltage of $45 \mathrm{kV}$. A silicon substrate of zero background was used to hold the deposition of catalysts whose structure information was obtained by using the Scintag DMSNT software. The average particle size in crystalline domain was calculated by Debye-Scherrer formula: ${ }^{74}$

$$
L=\frac{0.9 \lambda_{K \alpha}}{B_{2 \theta} \cos \theta_{\max }}
$$

where $L$ is the average crystal size (diameter of metal particles), $\lambda$ is the wavelength of $\mathrm{X}$ ray $(1.5406 \AA), B_{2 \theta}$ is the full width at half maximum of the peak in radians, and $\theta_{\max }$ is the Bragg angle in degree.

Lattice parameter $\left(\alpha_{f c c}\right)$ derived from Bragg's law was calculated by:

$$
\alpha_{f c c}=\frac{\sqrt{2} \lambda_{K_{\alpha}}}{\sin \theta_{\max }}
$$




\subsubsection{Inductively coupled plasma optical emission spectroscopy (ICP-OES)}

ICP-OES was employed to analyze the metal loading and bulk elements composition of as-prepared catalysts. Sample was prepared by dissolving supported catalyst of known weight (ca. $10 \mathrm{mg}$ ) in $4 \mathrm{ml}$ of fresh prepared Aqua Regia (concentrated nitric acid and hydrochloric acid in a volume ratio of 1:3). The mixture was stored for 1 day, followed by using DI water $(18.2 \Omega)$ to dilute to $250 \mathrm{ml}$ for the analysis.

\subsection{Electrochemical methods}

Electrochemical techniques include chronoamperometry (CA), cyclic voltammetry, and linear sweep voltammetry (LSV), etc. CA records current that related to Faradaic reactions under constant potential as a function of time. Cyclic voltammetry can be considered as potential swept from low to high boundaries of multiple cycles with time and the $i$-E curve is recorded directly. LSV is a single scan of potential that varies linearly with time at a slow scan rate that allows the electrochemical reactions occurring near the electrode approach a quasi-steady state. These electrochemical characterizations can be also performed with stationary electrode or with electrode that moves with respect to the electrolyte where a steady state will be attained rather quickly. Useful information about electrocatalysts and complicate electrocatalytic reactions can be obtained by deliberately designing the electrochemical experiments and detail discussions will be made in the following chapters.

\subsection{Product analysis}

The products in aqueous phase were removed periodically from outlet of AEM-based electrolysis cell reactor (Fig. 2.3 and 2.4) or AEM-based fuel cell reactor (Fig. 2.5) and analyzed by high performance liquid chromatography (HPLC, Agilent 1100) using a cation exchange column (Alltech, OA-1000) with a refractive index detector (RID, Agilent G1362A) and a variable wavelength detector (VWD, $220 \mathrm{~nm}$, Agilent G1314A).

An eluent of $5 \mathrm{mM}$ aqueous sulfuric acid at a flow rate of $0.3 \mathrm{ml} \mathrm{min}{ }^{-1}$ and column 
temperature of $60^{\circ} \mathrm{C}$ were applied for the product separation. $20 \mu 1$ of sample was injected into the HPLC system. Products were identified by comparison with authentic samples.

The term of selectivity is used to describe the relative rates of two or more competing reactions on an electrocatalyst. For a single reactant participating in two or more reactions, the selectivity for each product is defined by:

$$
\text { Selectivity }=\frac{\xi_{i}}{\Sigma \xi_{i}}
$$

where $\xi_{i}$ is the rate of increase of the extent of reaction $i$.

Therefore, the selectivity of products in the liquid phase was calculated by:

$$
\text { Selectivity }=\frac{\text { Moles of specific identified product }}{\text { Total moles of all the identified products }} \times 100 \%
$$

and the yield of product was calculated by:

$$
\text { Yield }=\text { Selectivity } \times \text { Conversion }
$$

The carbon balance, indicative of the material balance of the system, was calculated by:

$$
\text { Carbon balance }=\frac{\text { Moles of carbon in all the identified product }}{\text { Moles of carbon in the fuels initially fed }} \times 100 \%
$$

For electrochemical reactions carried out in AEM electrolysis cell reactors, the Faradaic efficiency indicates the efficiency of the system and calculated by:

$$
\text { Faradaic efficiency }=\frac{n \times F \times m o l_{\text {specific product }}}{I \times t} \times 100 \%
$$

in which $n$ is the number of electrons transferred, $F$ is the Faraday constant, $I$ is the current recorded in the experiment, and $t$ is the duration of the reaction. Detail discussions will be made in the following chapters 


\section{Chapter 3 Supported Pt, Pd and Au Anode Catalysts for Anion-Exchange Membrane-Direct Glycerol/Crude Glycerol Fuel Cells (AEM-DGFCs/DCGFCs) ${ }^{*}$}

\subsection{Background}

Glycerol has been considered as a potential fuel for direct alcohol fuel cells (DAFCs), because of its relatively low price, simple purification and storage, as well as its nontoxic, non-volatile, non-flammable and environmentally friendly properties. $39,40,48,49,75,76$ In addition, with the highly active triol structure, glycerol demonstrates a high volumetric energy density of $6.4 \mathrm{KWh} \mathrm{L}^{-1}$ (Table 1.1). Some early studies have been carried out in the electro-oxidation of glycerol on Pt, Pd, and Au based catalyst aiming to achieve high fuel cell output power densities in anion-exchange membrane-direct glycerol fuel cells (AEM-DGFCs). Matsuoka et al. first reported a peak power density of $7 \mathrm{~mW} \mathrm{~cm}{ }^{-2}$ at $50^{\circ} \mathrm{C}$ using PtRu as the anode catalyst. ${ }^{39}$ Bianchini's group has recently reported peak power density of $c a .79$ and $118 \mathrm{~mW} \mathrm{~cm}{ }^{-2}$ on $\mathrm{Pd} / \mathrm{CNT}^{40}$ and $\mathrm{Pd}-(\mathrm{Ni}-\mathrm{Zn}) / \mathrm{C}^{77}$ anode catalysts at $80^{\circ} \mathrm{C}$, respectively. On the other hand, Ilie et al. investigated the MEA fabrication methods and operation conditions (fuel concentration, flow rate, etc.) and obtained an optimized peak power density of ca. $24 \mathrm{~mW} \mathrm{~cm}$ with Pt and Pt-based bimetallic anode catalyst at $60^{\circ} \mathrm{C} .^{49}$

\footnotetext{
"The material contained in this chapter was previously published in Applied Catalysis B: Environmental 2013;136-137(0):29-39: "Supported Pt, Pd and Au nanoparticle anode catalysts for anion-exchange membrane fuel cells with glycerol and crude glycerol fuels"

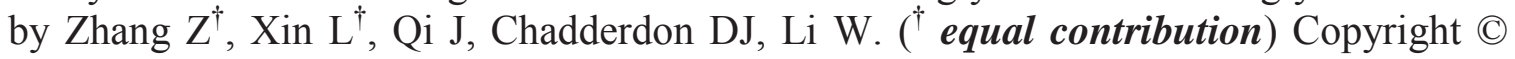
2013 Elsevier B. V. Reprint with permission shown in Appendix C
} 
However, all of these studies were based on the high price petrochemical derived high-

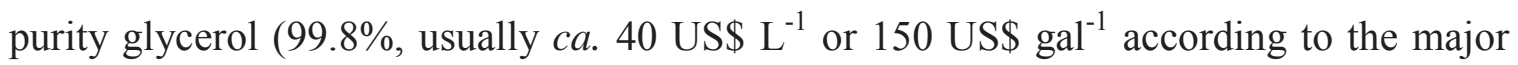
chemical suppliers). As the purification of crude glycerol is prohibitively expensive, ${ }^{78}$ it is usually sold with many impurities, including methanol, fatty acids (usually in the form of soaps), transesterification catalysts residues (as ash content), a variety of element such as $\mathrm{K}, \mathrm{Ca}, \mathrm{Mg}, \mathrm{Hg}, \mathrm{P}, \mathrm{S}$, As, etc. (in both dissolved and undissolved salts). ${ }^{79}$ Directly utilization of crude glycerol has great practical meanings for AEM-DGFCs (Fig. 3.1) as future mobile electrochemical power sources for transportation and portable electronics. Even so, little investigation has been performed on the anion-exchange membrane fuel cells (AEMFCs) with direct crude glycerol fuel, due to the concerns over the contamination and poisoning of the impurities to the fuel cell systems. Therefore, there is a clear need to firstly investigate the intrinsic activity of monometallic $\mathrm{Pt}, \mathrm{Pd}$ and $\mathrm{Au}$ catalysts toward pure glycerol oxidation and demonstrate their performances as the anode catalysts with crude glycerol fuel, so as to further develop more efficient multi-metallic catalysts for DGFCs/DCGFCs.

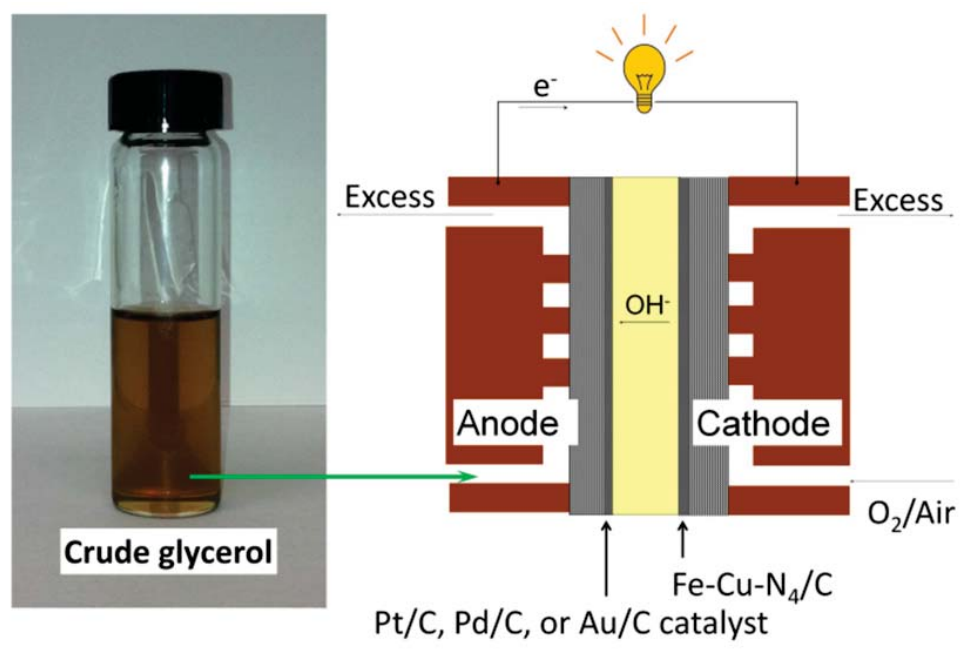

Fig. 3.1 Illustration of continuous flow-type AEM based fuel cell reactor directly fed with crude glycerol for the electricity generation.

In this chapter, carbon black supported precious metal Pt, Pd and $\mathrm{Au}$ nanoparticles were employed as the model catalysts. Their electrocatalytic activities toward pure glycerol oxidation were first compared in half cells at different temperatures. Based on the half- 
cell test results, these catalysts were further applied as the anode catalysts in AEMDGFCs. The effects on the performance of electricity generation with soybean biodiesel derived crude glycerol were evaluated at $80^{\circ} \mathrm{C}$.

\subsection{General experimental}

\subsubsection{Preparation of $\mathrm{Pt} / \mathrm{C}, \mathrm{Pd} / \mathrm{C}$ and $\mathrm{Au} / \mathrm{C}(40 \mathrm{wt} . \%)$}

The organic solution phase-based nanocapsule method was applied to prepare the carbon black supported Pt, Pd and Au nanoparticles. The detail synthesis procedures have been described in Section 2.4.2-2.4.4.

\subsubsection{Physical characterizations}

The morphology, nanostructure and metal loading of the catalysts were analyzed by TEM, XRD and ICP-OES, as described in Section 2.5.1, 2.5.3 and 2.5.4.

\subsubsection{Electrochemical tests}

\subsubsection{Half-cell tests}

Half-cell tests were conducted in a conventional three-electrode half cell (Section 2.2.1) at 25,50 or $60^{\circ} \mathrm{C}$. The testing setup is equipped with a glassy carbon $\mathrm{RDE}, \mathrm{a} \mathrm{Hg} / \mathrm{HgO} / 1.0$ $\mathrm{M} \mathrm{KOH}$ reference electrode, and a Pt coil counter electrode. Prior to tests, all the electrolytes were deaerated by purging with high-purity $\mathrm{N}_{2}(99.99 \%)$ for $30 \mathrm{~min}$. All potential in the present study were given vs. $\mathrm{Hg} / \mathrm{HgO} / 1.0 \mathrm{M} \mathrm{KOH}$ electrode $(0.098 \mathrm{~V}$ vs. SHE). Glassy carbon electrode was prepared according to Section 2.3.1. In detail, $2.0 \mathrm{mg}$ of catalyst was dispersed in $1.0 \mathrm{ml}$ of isopropanol by bath ultra-sonication until no aggregation was visible. $20 \mu \mathrm{l}$ of the ink was dropped onto the glassy carbon electrode, which yielded a catalyst loading of $c a .40 \mu \mathrm{g}_{\text {metal }} \mathrm{cm}^{-2} .10 \mu 1$ of 0.05 wt.\% AS-4 ionomer solution was then added on top to affix the catalyst particles.

A 10-cycle cyclic voltammetry test was performed on each catalyst in $1.0 \mathrm{M} \mathrm{KOH}$ with

a sweep rate of $50 \mathrm{mV} \mathrm{s}^{-1}$ and at $25^{\circ} \mathrm{C}$. The stable polarization curve obtained from the 
last cycle was used to calculate the electrochemical surface area (ECSA, $\mathrm{m}^{2} \mathrm{~g}^{-1}$ ), which was obtained according to Equation 3-1.

$$
E C S A=\frac{Q}{m \times C}
$$

where $Q$ is the total charge integrated from the wave used for ECSA calculation; $m$ is the mass of catalysts coated on the glassy carbon electrode, and $C$ is the charge capacity constant. For Pt/C catalyst, the ECSA were evaluated based on hydrogen desorption peak assuming one hydrogen atom adsorbed on one platinum atom with the pseudo-capacity of $0.210 \mathrm{mC} \mathrm{cm}^{-2} .{ }^{80}$ The ECSA of $\mathrm{Pd} / \mathrm{C}$ was obtained on the basis of the $\mathrm{PdO}$ reduction peak to avoid the multilayer hydrogen adsorption/absorption issue on Pd. A pseudocapacity of $0.405 \mathrm{mC} \mathrm{cm}^{-2}$ that is associated with the charge required for the reduction of a $1 \mathrm{~cm}^{2}$ monolayer PdO was used. ${ }^{81}$ Due to the weak hydrogen adsorption/desorption on $\mathrm{Au}$ surface, the ECSA of $\mathrm{Au} / \mathrm{C}$ was also measured from the reduction peak at $c a .0 .13 \mathrm{~V}$ vs. $\mathrm{Hg} / \mathrm{HgO} / 1.0 \mathrm{M} \mathrm{KOH}$, with a pseudo-capacity of $0.386 \mathrm{mC} \mathrm{cm}^{-2}$ for the reduction of the oxide formed on Au surface. ${ }^{82}$

To study the glycerol oxidation activity, a 10-cycle-CV test was performed on all the three catalysts in $1.0 \mathrm{M} \mathrm{KOH}+0.5 \mathrm{M}$ glycerol at the same sweep rate of $50 \mathrm{mV} \mathrm{s}^{-1}$ and at $25^{\circ} \mathrm{C}$. A linear sweep voltammetry (LSV) on each catalyst with a sweep rate of $1 \mathrm{mV} \mathrm{s} \mathrm{s}^{-1}$ and a rotation rate of $2500 \mathrm{rpm}$ was performed at different temperatures to investigate the temperature effects. The onset potential of glycerol oxidation at different temperature is defined as the potential where the inflection is observed on the quasi-steady state polarization curve. The linear polarization plot at $25^{\circ} \mathrm{C}$ was also used to study the Tafel slope and turnover frequency (TOF). The Tafel plot was achieved by plotting the potential against the logarithm of current density, which is described by the following equation $^{56}$ :

$$
\eta=2.303 \times \frac{R T}{\alpha n F} \log \left(\frac{j}{j_{0}}\right)
$$

In this equation, $\eta$ is the potential, $\alpha$ is the charge transfer coefficient, $n$ is the number of electrons transferred during the reaction, $j_{0}$ is the exchange current density, and $j$ is the 
current density obtained in the quasi-steady state scan. The quantity proceeding the logarithm is defined as Tafel slope: $2.303 \times \frac{R T}{\alpha n F}$.

The turnover frequency (TOF) of electrons is defined as follows: ${ }^{83}$

$$
T O F=\frac{j}{e N_{S}}
$$

where $N_{S}$ is the active surface atom density that calculated from the ECSA of the catalyst.

\subsubsection{AEM-DGFC single cell tests}

The electricity performance of AEM-DGFC was evaluated at $80^{\circ} \mathrm{C}$, with a high purity glycerol or crude glycerol $+\mathrm{KOH}$ solution and high purity $\mathrm{O}_{2}(99.999 \%)$ at a constant flow rate of $0.4 \mathrm{~L} \mathrm{~min}^{-1}$ under 30 psi back pressure.(Section 2.2.3)

MEA electrode was fabricated according to Section 2.3.3. At the anode, a catalyst ink containing 90 wt.\% of $\mathrm{Pt} / \mathrm{C}, \mathrm{Pd} / \mathrm{C}$, or $\mathrm{Au} / \mathrm{C}$ catalyst and 10 wt.\% of Teflon was airbrushed on a carbon cloth anode liquid diffusion layer, to obtain a catalyst loading of $1.0 \mathrm{mg}_{\text {metal }} \mathrm{cm}^{-2}$. At the cathode, $70 \mathrm{wt} . \%$ of a commercial non-PGMs catalyst $(\mathrm{Fe}-\mathrm{Cu}-$ $\mathrm{N}_{4} / \mathrm{C}$, HYPERMEC ${ }^{\mathrm{TM}}$, Acta) was blended with $30 \mathrm{wt} \%$ AS-4 anion conductive ionomer (Tokuyama Corp.), and sprayed directly onto the A201 anion-exchange membrane (Tokuyama Corp.). A 25CC carbon paper (Teflon Treated, SGL Group) was then covered on the cathode catalyst as a cathode GDL.

\subsection{Results and discussions}

\subsubsection{Physical characterizations}

The XRD patterns of $\mathrm{Pt} / \mathrm{C}, \mathrm{Pd} / \mathrm{C}$, and $\mathrm{Au} / \mathrm{C}$ catalysts were collected in the range from 15 - $100^{\circ}$, and are shown in Fig. 3.2. All of them displayed a typical face-centered cubic (FCC) pattern, with the diffraction peaks at $c a .39^{\circ}, 46^{\circ}, 67^{\circ}$, and $80^{\circ}$ assigned to the corresponding facet of (111), (200), (220), and (311), respectively. The peak around $25^{\circ}$ in all the catalysts is referred to the graphite (002) facet of the carbon supports. The average crystal size of each catalyst is calculated based on the (220) diffraction peak, 
using the Debye-Scherrer formula (Equation 2-8). The results yielded from the equation are summarized in Table 3.1, which are 1.9, 2.5, and $3.4 \mathrm{~nm}$ for $\mathrm{Pt} / \mathrm{C}, \mathrm{Pd} / \mathrm{C}$, and $\mathrm{Au} / \mathrm{C}$ catalysts, respectively.

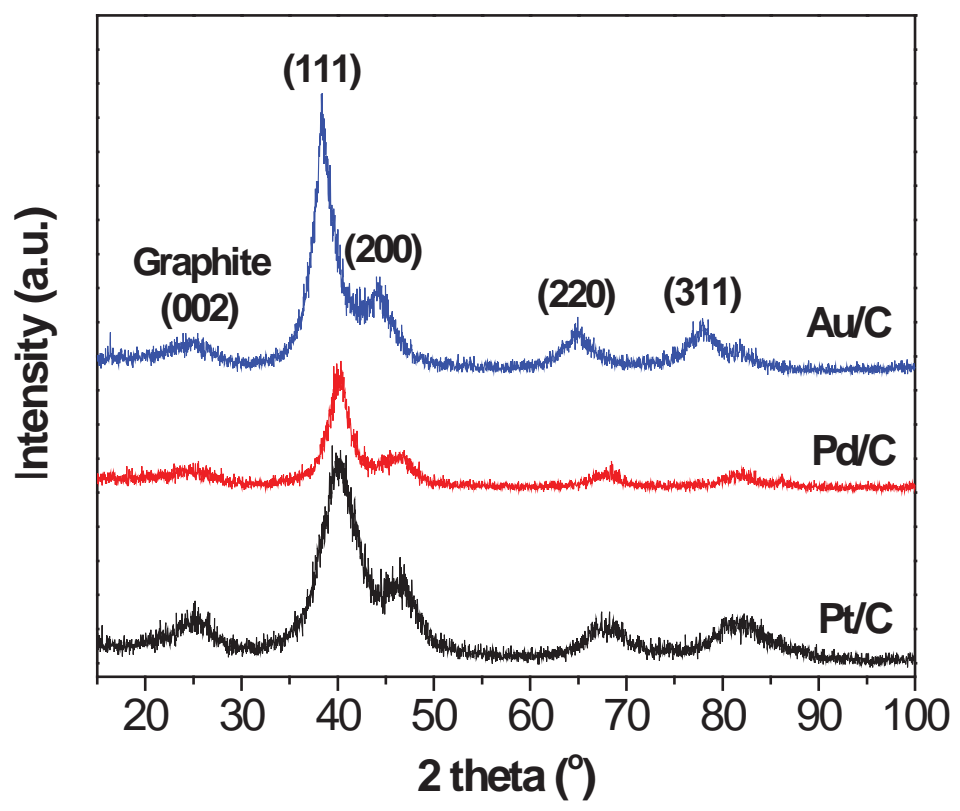

Fig. 3.2 XRD patterns of $\mathrm{Pt} / \mathrm{C}, \mathrm{Pd} / \mathrm{C}$, and $\mathrm{Au} / \mathrm{C}$ catalysts. 
Table 3.1 Summary of physical properties of $\mathrm{Pt} / \mathrm{C}, \mathrm{Pd} / \mathrm{C}$, and $\mathrm{Au} / \mathrm{C}$ catalysts.

\begin{tabular}{|c|c|c|c|c|c|}
\hline & $\begin{array}{c}\text { Metal loading } \\
\text { detected by } \\
\text { ICP-AES }\end{array}$ & $\begin{array}{c}\text { Diameter } \\
\text { calculated from } \\
\text { XRD }(\mathrm{nm})\end{array}$ & $\begin{array}{c}\text { Diameter } \\
\text { measured by } \\
\text { TEM }(\mathrm{nm})\end{array}$ & $\begin{array}{c}\text { ECSA } \\
\left(\mathrm{m}^{2} \mathrm{~g}^{-1}\right)\end{array}$ & $\begin{array}{c}\text { Active surface } \\
\text { atom density } \\
\left(\mathrm{nmol} \mathrm{cm}^{-2}\right)\end{array}$ \\
\hline $\mathrm{Pt} / \mathrm{C}$ & $38 \%$ & 1.9 & 2.4 & 41.5 & 34.9 \\
\hline $\mathrm{Pd} / \mathrm{C}$ & $37 \%$ & 2.5 & 3.4 & 48.3 & 41.2 \\
\hline $\mathrm{Au} / \mathrm{C}$ & $35 \%$ & 3.4 & 3.5 & 24.2 & 26.2 \\
\hline
\end{tabular}

The typical TEM images of $\mathrm{Pt} / \mathrm{C}, \mathrm{Pd} / \mathrm{C}$, and $\mathrm{Au} / \mathrm{C}$, and their corresponding histograms are shown in Fig. 3.3. It is evidenced that most of the catalysts are round in shape and are uniformly dispersed on carbon support with little agglomeration. The average particle sizes evaluated from TEM images are 2.4, 3.4, and $3.5 \mathrm{~nm}$ for $\mathrm{Pt} / \mathrm{C}, \mathrm{Pd} / \mathrm{C}$, and $\mathrm{Au} / \mathrm{C}$ catalysts, which are in good agreement with the results from XRD analysis. The histograms of particle sizes of these catalysts are counted from 100 randomly chosen particles in an arbitrarily chosen area, and show narrow size distribution for all the catalysts, indicating a good morphology control of the nanocapsule method for these three metal catalysts. The metal loading of $\mathrm{Pt} / \mathrm{C}, \mathrm{Pd} / \mathrm{C}$, and $\mathrm{Au} / \mathrm{C}$ catalysts evaluated by the ICP-OES (Table 3.1) are 38\%, 37\%, and 35\%, respectively, which very close to the setting ratio (40 wt.\%), indicating all the metal precursors were fully reduced by the presented synthesis method. 

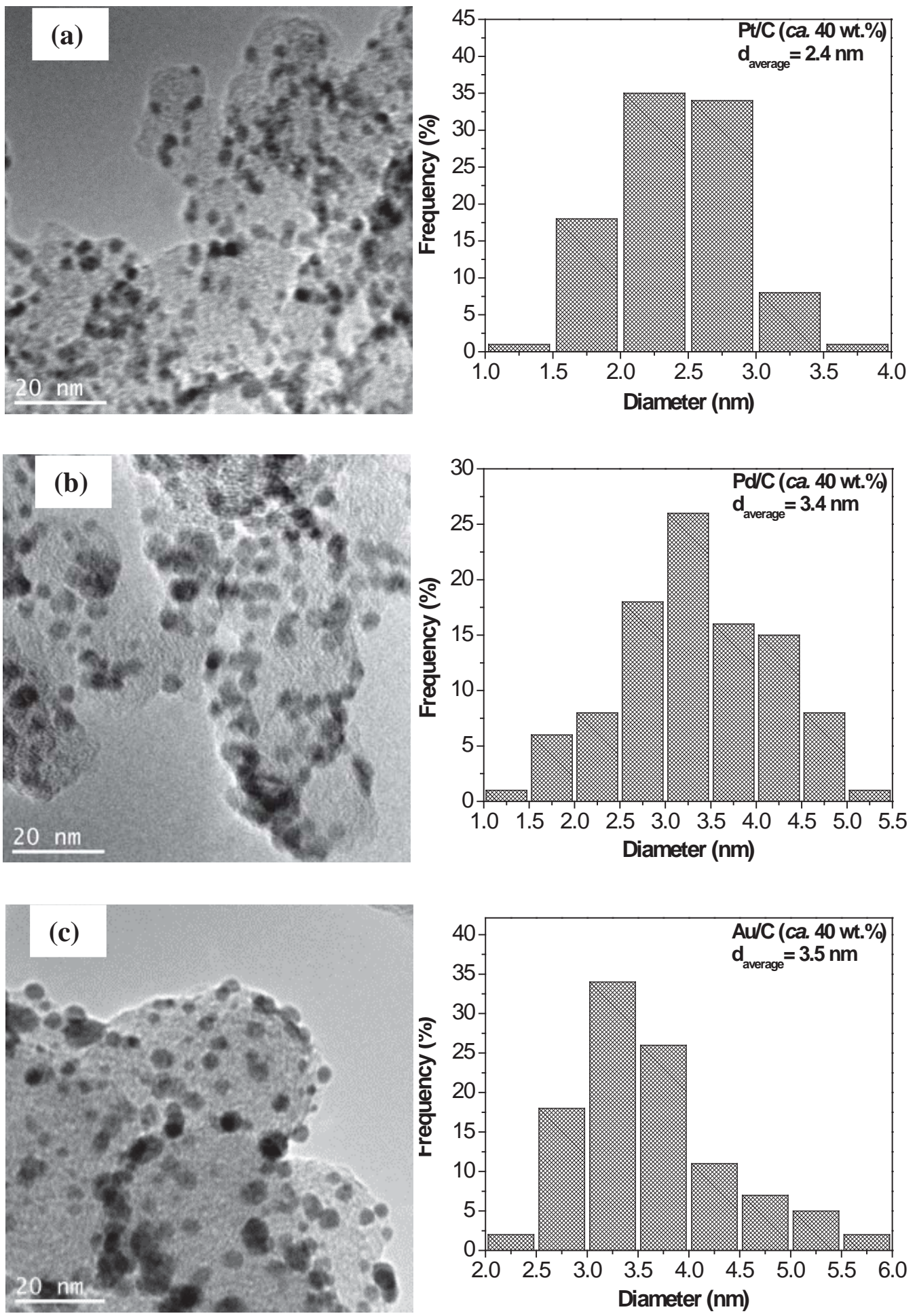

Fig. 3.3 TEM images and corresponding particle-size histograms of (a) $\mathrm{Pt} / \mathrm{C}$ ( $c a .40$ wt.\%), (b) Pd/C (ca. 40 wt.\%), and (c) Au/C catalysts (ca. 40 wt.\%). 


\subsubsection{Half-cell tests}

The cyclic voltammograms $(\mathrm{CV})$ obtained on $\mathrm{Pt} / \mathrm{C}, \mathrm{Pd} / \mathrm{C}$, and $\mathrm{Au} / \mathrm{C}$ catalysts in $\mathrm{N}_{2}$ saturated $1.0 \mathrm{M} \mathrm{KOH}$ at $25^{\circ} \mathrm{C}$ are shown in Fig. 3.4. In the $\mathrm{CV}$ plot of $\mathrm{Pt} / \mathrm{C}$, the anodic peak from $-0.9--0.45 \mathrm{~V}$ vs. $\mathrm{Hg} / \mathrm{HgO} / 1.0 \mathrm{M} \mathrm{KOH}$ is assigned to the hydrogen underpotential desorption peak, which is immediately followed by the $\mathrm{OH}^{-}$adsorption peak. ${ }^{84-87}$ However, in the $\mathrm{CV}$ plot of $\mathrm{Pd} / \mathrm{C}$, the $\mathrm{OH}^{-}$starts at even negative potentials, which covers the hydrogen underpotential desorption peak and give rise to the small peak at $c a$. $-0.35 \mathrm{~V}$ vs. $\mathrm{Hg} / \mathrm{HgO} / 1.0 \mathrm{M} \mathrm{KOH}{ }^{85,88}$ Compared to the $\mathrm{CV}$ s of $\mathrm{Pt} / \mathrm{C}$ and $\mathrm{Pd} / \mathrm{C}$, no hydrogen underpotential desorption was observed on $\mathrm{Au} / \mathrm{C}$ due to its weak adsorption ability. The ECSA of $\mathrm{Pt} / \mathrm{C}$ was obtained from the hydrogen underpotential desorption peak, which is $41.5 \mathrm{~m}^{2} \mathrm{~g}^{-1}$. The ECSAs of $\mathrm{Pd} / \mathrm{C}$ and $\mathrm{Au} / \mathrm{C}$ were calculated from their corresponding regions for reduction of a monolayer surface oxide, which are 48.3 and $24.2 \mathrm{~m}^{2} \mathrm{~g}^{-1}$, for $\mathrm{Pd} / \mathrm{C}$ and $\mathrm{Au} / \mathrm{C}$, respectively (Table 3.1). Based on the charges transferred in their identical reaction regions, the active surface atom density was calculated by the following equation:

$$
N_{s}=\frac{Q}{n F A}
$$

where $N_{S}$ is the active surface atom density, $Q$ is the total charge used for the ECSA calculation, $n$ is the number of electrons involved in the reaction, $F$ is Faraday's constant, and $A$ is the geometric area of the glassy carbon electrode $\left(0.1963 \mathrm{~cm}^{2}\right)$. The number of electrons, $n$, is 1 for the hydrogen desorption reaction on $\mathrm{Pt}$, and is 2 for the reduction of $\mathrm{PdO}$. In the case of $\mathrm{Au} / \mathrm{C}$, it is reported that the compositions of monolayer oxide on $\mathrm{Au}$ surface are $\mathrm{AuO}$ and $\mathrm{Au}(\mathrm{OH})_{2}$ in alkaline electrolyte. ${ }^{89}$ Therefore, $n$ is 2 for the reduction of Au oxides. Based on the Equation 3-4, the active surface atom densities are 34.9, 41.2, and $26.2 \mathrm{nmol} \mathrm{cm}{ }^{-2}$ for $\mathrm{Pt} / \mathrm{C}, \mathrm{Pd} / \mathrm{C}$, and $\mathrm{Au} / \mathrm{C}$, respectively (Table 3.1). 


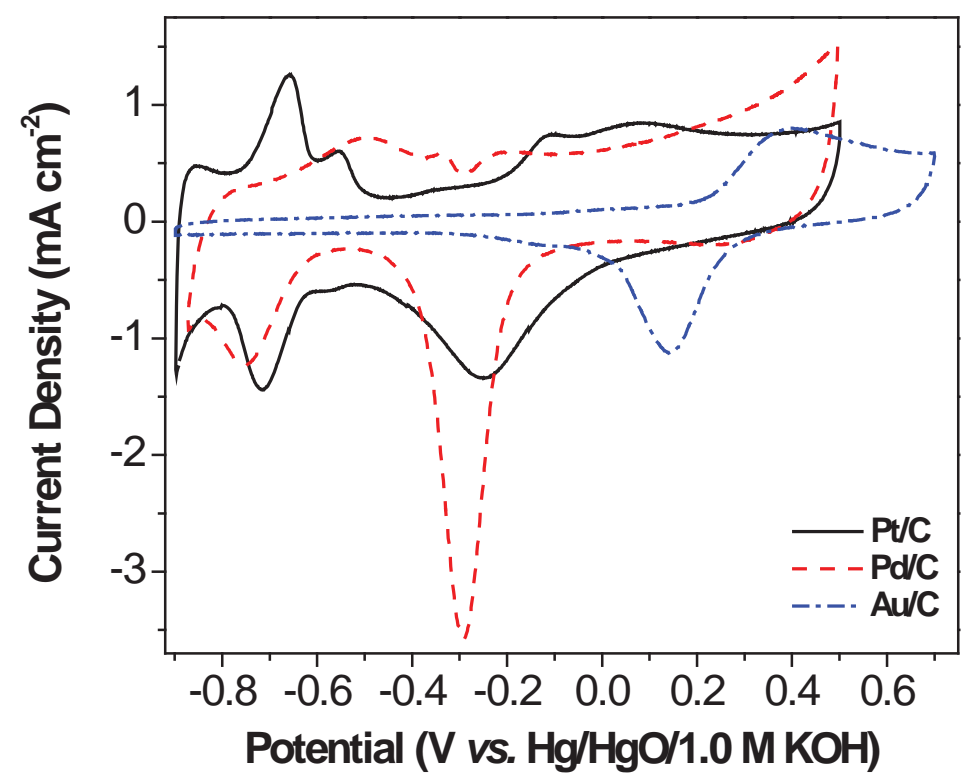

Fig. 3.4 CVs of $\mathrm{Pt} / \mathrm{C}, \mathrm{Pd} / \mathrm{C}$, and $\mathrm{Au} / \mathrm{C}$ catalysts in $1.0 \mathrm{M} \mathrm{KOH}$, at $50 \mathrm{mV} \mathrm{s}^{-1}, 25^{\circ} \mathrm{C}$.

Fig. 3.5 shows the $\mathrm{CV}$ profiles of glycerol oxidation in $1.0 \mathrm{M} \mathrm{KOH}+0.5 \mathrm{M}$ glycerol on $\mathrm{Pt} / \mathrm{C}, \mathrm{Pd} / \mathrm{C}$, and $\mathrm{Au} / \mathrm{C}$ catalysts at $25^{\circ} \mathrm{C}$. Compared to the CVs in the blank $\mathrm{KOH}$ electrolyte (in Fig. 3.4), the hydrogen adsorption/desorption peaks were totally disappeared on $\mathrm{Pt} / \mathrm{C}$ and $\mathrm{Pd} / \mathrm{C}$ when glycerol was added into the electrolyte, indicating the surface active sites on these two catalysts were covered by the adsorbed glycerol or the corresponding intermediates. As the potential increasing, the covered surface active sites were refreshed with the assistance of adsorbed $\mathrm{OH}$, which resulted in the anodic peaks on $\mathrm{Pt} / \mathrm{C}$ and $\mathrm{Pd} / \mathrm{C}$ in the course of the forward scan. It is noted that a weak shoulder peak was observed at ca. $0.25 \mathrm{~V}$ vs. $\mathrm{Hg} / \mathrm{HgO} / 1.0 \mathrm{M} \mathrm{KOH}$ on $\mathrm{Pt} / \mathrm{C}$ in the course of the forward scan, which is probably due to the glycerol oxidation on Pt oxide. Different from $\mathrm{Pt} / \mathrm{C}$ and $\mathrm{Pd} / \mathrm{C}, \mathrm{Au} / \mathrm{C}$ catalyst showed very little activity toward glycerol electro-oxidation at lower potentials. However, it demonstrated an extremely high peak current density at high potentials and a very broad active potential region. ${ }^{90,91}$ This indicates that the Au catalyst can maintain its activity in a wide applied potential range for a long time. Therefore, it can serve as the model catalyst for the study of potential controlled glycerol selective oxidation. ${ }^{92}$ It is noted that at high potentials, the current density on $\mathrm{Au} / \mathrm{C}$ became unstable. Previously, some authors assigned this instability to the complex 
kinetics of glycerol electro-oxidation on $\mathrm{Au} .{ }^{88}$ However, taking into consideration of the fast reaction rate under these high potentials, it is possible due to the mass transfer issue, which leads to the insufficient supply of $\mathrm{KOH}$ and glycerol to the electrode surface. When comparing the polarization curves on these three catalysts, it is clear that at low potential regions (e.g. $<0 \mathrm{~V}$ vs. $\mathrm{Hg} / \mathrm{HgO} / 1.0 \mathrm{M} \mathrm{KOH}$ ), $\mathrm{Pt} / \mathrm{C}$ has the highest activity towards glycerol oxidation.

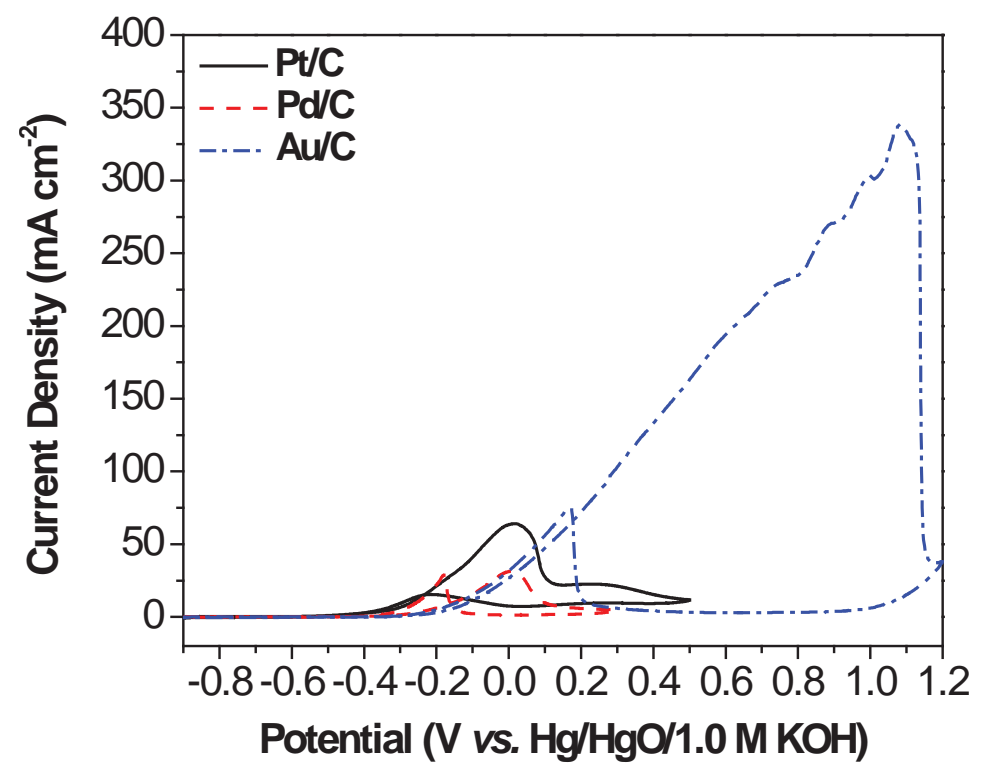

Fig. 3.5 Cyclic voltammograms of glycerol oxidation reaction on $\mathrm{Pt} / \mathrm{C}, \mathrm{Pd} / \mathrm{C}$, and $\mathrm{Au} / \mathrm{C}$ catalysts in $1.0 \mathrm{M} \mathrm{KOH}+0.5 \mathrm{M}$ glycerol, $50 \mathrm{mV} \mathrm{s}^{-1}, 25^{\circ} \mathrm{C}$.

The glycerol electro-oxidation on these three catalysts was further investigated by LSVs in $1.0 \mathrm{M}+0.5 \mathrm{M}$ glycerol at different temperatures. A slow sweep rate of $1 \mathrm{mV} \mathrm{s}^{-1}$ and a rotation rate of $2500 \mathrm{rpm}$ were applied during the test to reduce the mass transfer/diffusion issue. As shown in Fig. 3.6 (c), at $25^{\circ} \mathrm{C}$ the unstable current observed on $\mathrm{Au} / \mathrm{C}$ catalyst in Fig. 3.5 disappeared in this linear sweep, which evidenced that a better mass transfer was obtained. Therefore, it is reasonable to consider the reaction was taking place under quasi-steady states. As presented in Fig. 3.6, temperature significantly promotes the glycerol electro-oxidation on all these three catalysts. The onset potentials on these three catalysts (in Table 3.2) moved to the negative position as the working temperature, increasing from $25^{\circ} \mathrm{C}$ to $60^{\circ} \mathrm{C}$. Meanwhile, the current density increased on 
all these catalysts in the whole tested potential ranges, indicating a better kinetics was achieved at elevated temperatures. It is noted that at temperatures $>50^{\circ} \mathrm{C}$, a shoulder peak appeared at $c a$. $-0.4 \mathrm{~V}$ vs. $\mathrm{Hg} / \mathrm{HgO} / 1.0 \mathrm{M} \mathrm{KOH}$ on the $\mathrm{Pt} / \mathrm{C}$, which is probably due to the complex kinetics of glycerol oxidation. The HPLC analysis combined with half-cell voltammetry investigations on both carbon supported Pt nanoparticle catalyst ${ }^{76}$ and polycrystalline $\mathrm{Pt}$ electrode ${ }^{93,94}$ has demonstrated that at room temperature $\left(25^{\circ} \mathrm{C}\right)$, glycerol on Pt/C catalyst is first oxidized to glycerate, which is then further oxidized to glycolate, tartronate, and oxalate. Increasing temperature may lead to different reaction rate changes in these multi-step reactions and result in the formation of the shoulder peak. However, on $\mathrm{Pd} / \mathrm{C}$ and $\mathrm{Au} / \mathrm{C}$ catalysts, the polarization curves are similar at all the temperatures, indicating the reaction mechanisms on these two catalysts do not change significantly when the temperature increases. It needs to be mentioned that at $25^{\circ} \mathrm{C}, \mathrm{Pd} / \mathrm{C}$ has a higher onset potential, lower current density, and a narrower active potential region than $\mathrm{Pt} / \mathrm{C}$, which is probably due to the heavy poisoning from $\mathrm{CO}$ species on the $\mathrm{Pd} / \mathrm{C}$ catalyst. As the reaction temperature increasing, the removal of these poisonous species on $\mathrm{Pd} / \mathrm{C}$ was facilitated. As a result, at $60^{\circ} \mathrm{C}$, the peak current density increased to 68.6 $\mathrm{mA} \mathrm{cm}{ }^{-2}$, which is even higher than the peak current density on $\mathrm{Pt} / \mathrm{C}$ catalyst $(54.2 \mathrm{~mA}$ $\mathrm{cm}^{-2}$ ). However, at low potentials (e.g. $<-0.1 \mathrm{~V}$ vs. $\mathrm{Hg} / \mathrm{HgO} / 1.0 \mathrm{M} \mathrm{KOH}$ ), the current density on $\mathrm{Pt}$ is still higher than that on $\mathrm{Pd} / \mathrm{C}$. Compared to $\mathrm{Pt} / \mathrm{C}$ and $\mathrm{Pd} / \mathrm{C}$ catalyst, $\mathrm{Au} / \mathrm{C}$ shows a much higher glycerol electro-oxidation activity at high potentials. Due to the highly stable nature of $\mathrm{Au} / \mathrm{C}$, the glycerol electro-oxidation peak at $25^{\circ} \mathrm{C}$ was observed at ca. $0.59 \mathrm{~V}$ vs. $\mathrm{Hg} / \mathrm{HgO} / 1.0 \mathrm{M} \mathrm{KOH}$, with the peak current density at $117.2 \mathrm{~mA} \mathrm{~cm}^{-2}$. The kinetics of glycerol electro-oxidation on $\mathrm{Au} / \mathrm{C}$ was further facilitated at high temperatures. At temperatures $>50^{\circ} \mathrm{C}$ (Fig. 3.6 (c), the anodic current density on $\mathrm{Au} / \mathrm{C}$ continuously increases without any observation of peak current in the whole investigated potential range $(-0.9-0.8 \mathrm{~V}$ vs. $\mathrm{Hg} / \mathrm{HgO} / 1.0 \mathrm{M} \mathrm{KOH})$. 

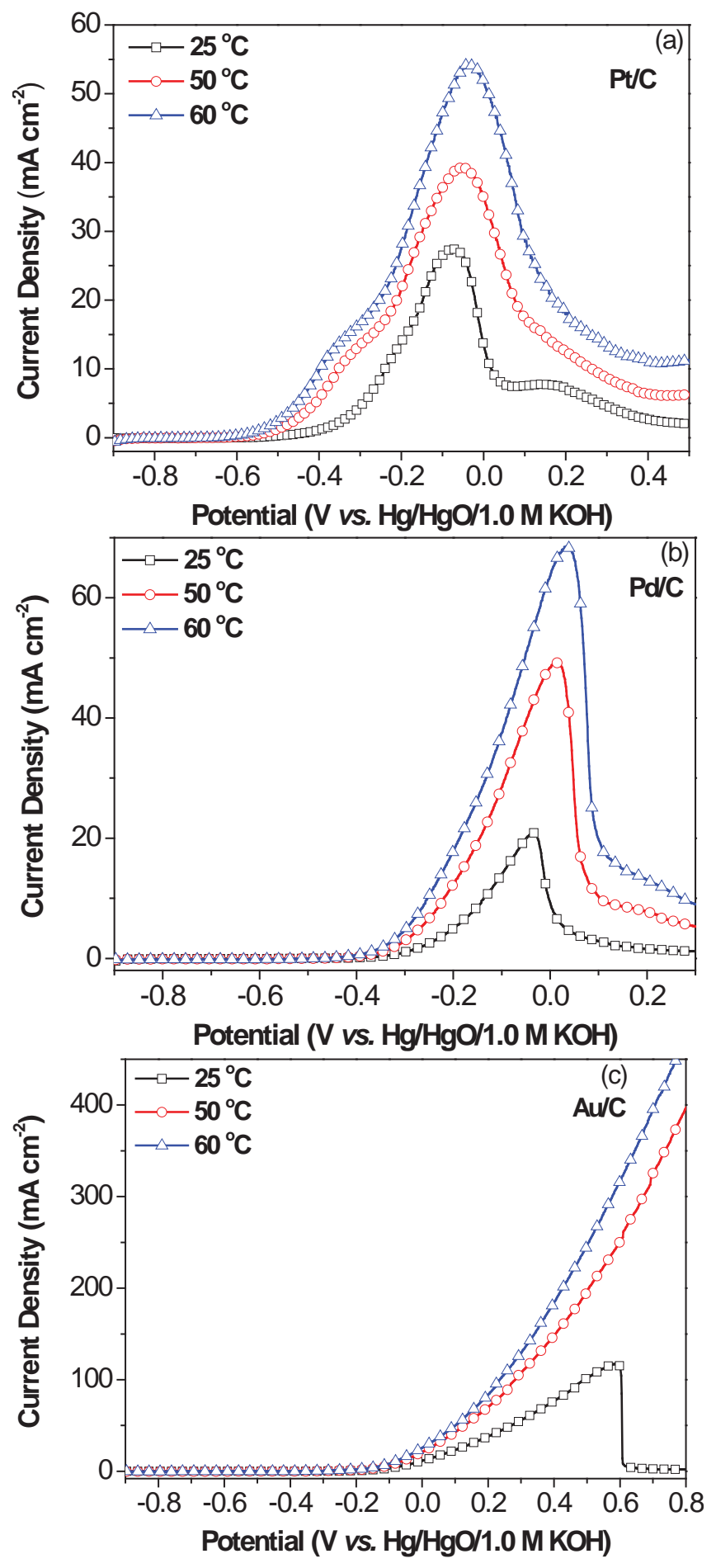

Fig. 3.6 Quasi-steady state linear scan voltammograms of glycerol oxidation on (a) Pt/C, (b) $\mathrm{Pd} / \mathrm{C}$, and (c) $\mathrm{Au} / \mathrm{C}$ catalysts in $1.0 \mathrm{M} \mathrm{KOH}+0.5 \mathrm{M}$ glycerol, $1 \mathrm{mV} \mathrm{s}^{-1}, 2500 \mathrm{rpm}$. 
Table 3.2 Onset potential, peak current density, Tafel slope, and $\boldsymbol{\alpha} \boldsymbol{n}$ on $\mathrm{Pt} / \mathrm{C}, \mathrm{Pd} / \mathrm{C}$, and $\mathrm{Au} / \mathrm{C}$ catalysts at different temperatures.

\begin{tabular}{|c|c|c|c|c|c|c|c|c|c|}
\hline & \multicolumn{3}{|c|}{$\mathrm{Pt} / \mathrm{C}$} & \multicolumn{3}{c|}{$\mathrm{Pd} / \mathrm{C}$} & \multicolumn{3}{c|}{$\mathrm{Au} / \mathrm{C}$} \\
\hline & $25^{\circ} \mathrm{C}$ & $50^{\circ} \mathrm{C}$ & $60^{\circ} \mathrm{C}$ & $25^{\circ} \mathrm{C}$ & $50^{\circ} \mathrm{C}$ & $60^{\circ} \mathrm{C}$ & $25^{\circ} \mathrm{C}$ & $50^{\circ} \mathrm{C}$ & $60^{\circ} \mathrm{C}$ \\
\hline $\begin{array}{c}\text { Onset potential } \\
(\mathrm{mV})\end{array}$ & -625 & -689 & -695 & -446 & -460 & -475 & -368 & -382 & -408 \\
\hline $\begin{array}{c}\text { Peak current } \\
\text { density (mA } \\
\left.\mathrm{cm}^{-2}\right)\end{array}$ & 27.4 & 39.4 & 54.2 & 20.9 & 49.2 & 68.6 & 117.2 & - & - \\
\hline Tafel slope & 145 & 108 & 102 & 88 & 88 & 85 & 134 & 127 & 127 \\
\hline$\alpha n$ & 0.102 & 0.148 & 0.162 & 0.168 & 0.182 & 0.194 & 0.110 & 0.126 & 0.130 \\
\hline
\end{tabular}

To further compare the kinetic activities of $\mathrm{Pt} / \mathrm{C}, \mathrm{Pd} / \mathrm{C}$ and $\mathrm{Au} / \mathrm{C}$ catalysts toward glycerol electro-oxidation, the Tafel Plots at different temperatures were investigated by plotting the potential versus the logarithm of current density, and the results are shown in

Fig. 3.7. As the electro-oxidation of glycerol is a complicated reaction that may generate more than five possible stable oxygenates in alkaline electrolytes (glycerate, tartronate, mesoxalate, glycolate, oxalate, etc.), ${ }^{76,92,94,95}$ the current density range for the Tafel plot investigation was chosen within $2 \mathrm{~mA} \mathrm{~cm}^{-2}(<10 \%$ of the peak current density on $\mathrm{Pd} / \mathrm{C}$ at $25^{\circ} \mathrm{C}$ ), in order to avoid the influences of deeper electro-oxidation reactions. As shown in Fig. 3.7 and Table 3.2, within the investigated temperature of $25-60^{\circ} \mathrm{C}$, the Tafel plots on all these three catalysts follow linear trend line, with the Tafel slopes in the range of $85-145 \mathrm{mV} \mathrm{dec}^{-1}$. The comparable values of Tafel slope indicate that the glycerol electro-oxidation mechanisms in the low current density region should be similar on these three catalysts. The comparison of Tafel plots on different catalysts clearly shows that $\mathrm{Pt} / \mathrm{C}$ needs an overpotential much lower than $\mathrm{Pd} / \mathrm{C}$ and $\mathrm{Au} / \mathrm{C}$ to obtain a certain current density, indicating that $\mathrm{Pt} / \mathrm{C}$ holds the highest catalytic activity in this low potential range. The product of charge transfer coefficient and number of transferred electrons $(\alpha n)$ are also calculated and summarized in Table 3.2. As the temperature increasing, the products $(\alpha n)$ increased on all the catalysts, indicating the kinetics is greatly facilitated at higher temperatures. 

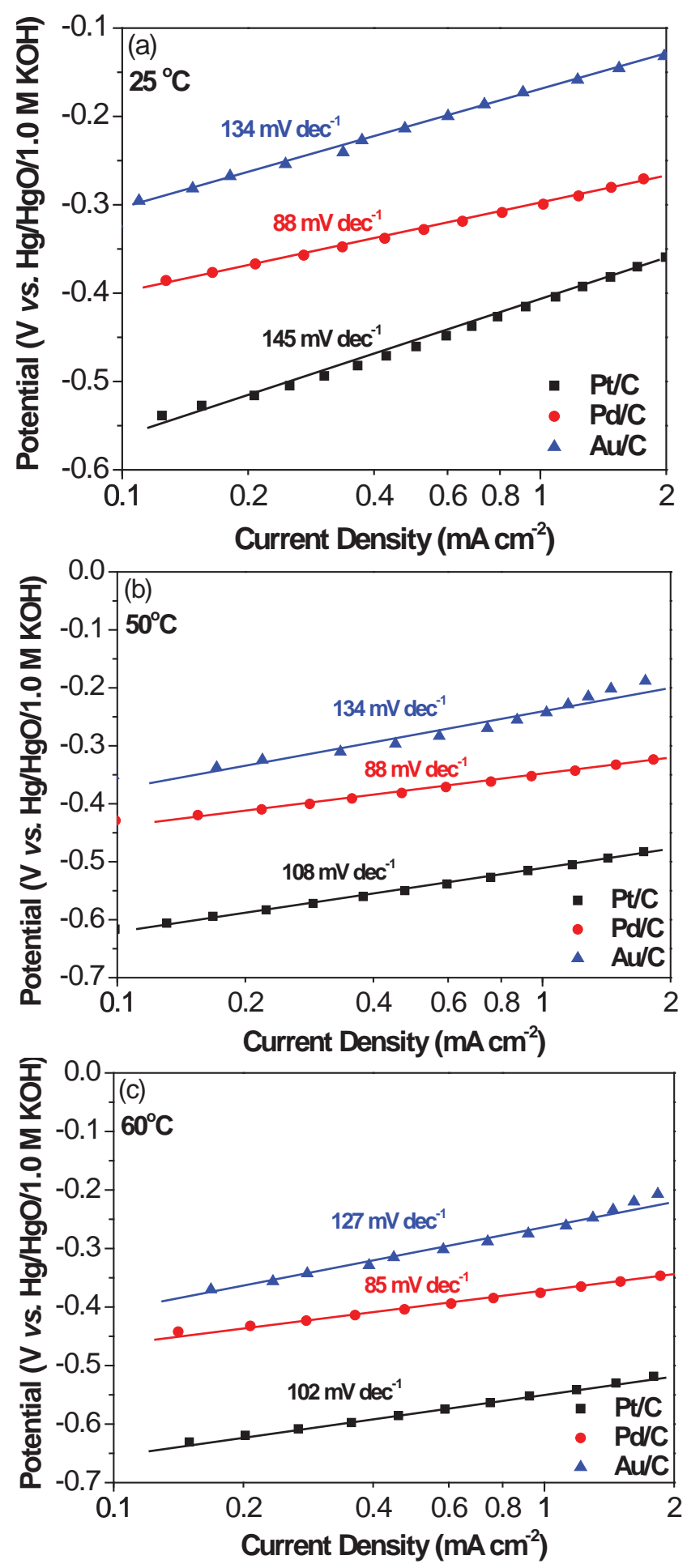

Fig. 3.7 Tafel plots of glycerol electro-oxidation on $\mathrm{Pt} / \mathrm{C}, \mathrm{Pd} / \mathrm{C}$, and $\mathrm{Au} / \mathrm{C}$ catalysts at (a) $25^{\circ} \mathrm{C}$, (b) $50^{\circ} \mathrm{C}$, and (c) $60^{\circ} \mathrm{C}$, in $1.0 \mathrm{M} \mathrm{KOH}+0.5 \mathrm{M}$ glycerol. 
Fig. 3.8 shows plots of the TOF of electrons as a function of potentials in the low potential regions, which is estimated from Equation 3-2. TOF is an absolute reaction rate, representing the number of electrons being transferred per unit time per catalyst surface active site. It directly reflects the intrinsic activity of the catalyst. It is clear that the TOF on all these three catalysts increases as the potential and temperature increasing. At low potentials, Pt atom demonstrated the highest activity based on the TOF plots at all the tested temperatures. At $-0.4 \mathrm{~V}$ vs. $\mathrm{Hg} / \mathrm{HgO} / 1.0 \mathrm{M} \mathrm{KOH}$, the reaction rate per $\mathrm{Pt}$ atom (TOF) is 16 times higher than that per Pd atom at $25^{\circ} \mathrm{C}$, and is 23 times higher at $60^{\circ} \mathrm{C}$. At $-0.3 \mathrm{~V}$ vs. $\mathrm{Hg} / \mathrm{HgO} / 1.0 \mathrm{M} \mathrm{KOH}$, the TOF on $\mathrm{Pt}$ is also $4-5$ times higher than that on $\mathrm{Pd}$ and $20-30$ times higher than that on $\mathrm{Au}$ at tested temperatures, even though $\mathrm{Au} / \mathrm{C}$ has the highest current density when potential is $>0 \mathrm{~V}$ vs. $\mathrm{Hg} / \mathrm{HgO} / 1.0 \mathrm{M} \mathrm{KOH}$ under the temperatures studied (Fig. 3.6) where both $\mathrm{Pt} / \mathrm{C}$ and $\mathrm{Pd} / \mathrm{C}$ have been oxidized and deactivated. 

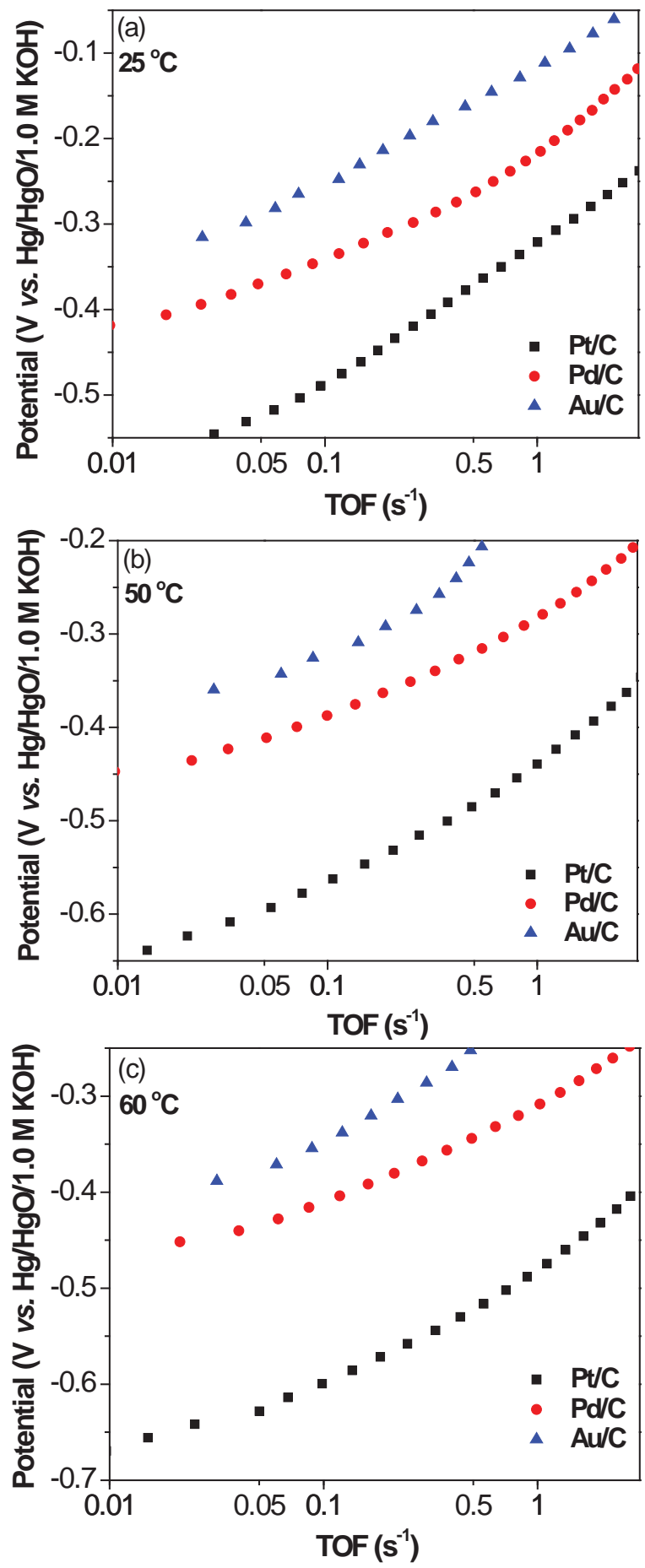

Fig. 3.8 Turnover frequencies (TOFs) of electrons for glycerol oxidation on $\mathrm{Pt} / \mathrm{C}, \mathrm{Pd} / \mathrm{C}$, and $\mathrm{Au} / \mathrm{C}$ catalyst at (a) $25^{\circ} \mathrm{C}$, (b) $50^{\circ} \mathrm{C}$, and (c) $60^{\circ} \mathrm{C}$, in $1.0 \mathrm{M} \mathrm{KOH}+0.5 \mathrm{M}$ glycerol. 


\subsubsection{Pt/C, Pd/C, and Au/C anode AEMFCs with high purity glycerol (99.8\%)}

The performances of the AEMFCs with $\mathrm{Pt} / \mathrm{C}, \mathrm{Pd} / \mathrm{C}$, and $\mathrm{Au} / \mathrm{C}$ anode catalysts were first studied with high purity glycerol fuel. As shown in Fig. 3.9, fed with $2.0 \mathrm{M} \mathrm{KOH}+1.0$ $\mathrm{M}$ glycerol, the $\mathrm{Pt} / \mathrm{C}$ anode AEMFCs demonstrated the highest performance at the cell operation temperature of both $50^{\circ} \mathrm{C}$ and $80^{\circ} \mathrm{C}$, which is consistent with the Tafel plot and TOF investigations. The cell polarization curves on $\mathrm{Pt} / \mathrm{C}$ anode are higher than that on $\mathrm{Pd} / \mathrm{C}$ anode, and are much higher than that on $\mathrm{Au} / \mathrm{C}$ anode in the whole current density range. At the fuel cell operation temperature of $50^{\circ} \mathrm{C}$ (Fig. 3.9 (a)), the open circuit voltage $(\mathrm{OCV})$ observed on $\mathrm{Pt} / \mathrm{C}$ anode AEMFC is $0.80 \mathrm{~V}$, which is $0.07 \mathrm{~V}$ higher than that on $\mathrm{Pd} / \mathrm{C}$ anode $(0.73 \mathrm{~V})$, and $0.19 \mathrm{~V}$ higher than that on $\mathrm{Au} / \mathrm{C}(0.61 \mathrm{~V})$. The $\mathrm{OCV}$ drop sequence is in good agreement with the half-cell results, with $\mathrm{Pt} / \mathrm{C}$ demonstrated the lowest onset potential (-689 $\mathrm{mV}$ vs. $\mathrm{Hg} / \mathrm{HgO} / 1.0 \mathrm{M} \mathrm{KOH})$ and $\mathrm{Au} / \mathrm{C}$ demonstrated the highest one $(-382 \mathrm{mV}$ vs. $\mathrm{Hg} / \mathrm{HgO} / 1.0 \mathrm{M} \mathrm{KOH})$. Meanwhile, the peak power density obtained on $\mathrm{Pt} / \mathrm{C}$ anode AEM fuel cell is $58.6 \mathrm{~mW} \mathrm{~cm}^{-2}$, which is also much higher than the peak power density on $\mathrm{Pd} / \mathrm{C}\left(37.4 \mathrm{~mW} \mathrm{~cm}^{-2}\right)$ and $\mathrm{Au} / \mathrm{C}\left(17.8 \mathrm{~mW} \mathrm{~cm}{ }^{-2}\right)$ anode AEMFCs. During the tests, the anode potentials were able to be monitored through a $\mathrm{Hg} / \mathrm{HgO} / 1.0 \mathrm{M} \mathrm{KOH}$ electrode (Fig. 2.5). ${ }^{76,95}$ At the peak power densities, the potentials were $c a$. $-0.45,-0.4$, and $-0.34 \mathrm{~V}$ vs. $\mathrm{Hg} / \mathrm{HgO} / 1.0 \mathrm{M} \mathrm{KOH}$ on $\mathrm{Pt} / \mathrm{C}, \mathrm{Pd} / \mathrm{C}$, and $\mathrm{Au} / \mathrm{C}$ anodes, respectively. The Tafel plot and TOF analysis obtained from half-cell tests (shown in Fig. 3.7 and 3.8) also demonstrated that at the same temperature of $50^{\circ} \mathrm{C}$ and the same potentials $(-0.45 \mathrm{~V}$ for $\mathrm{Pt} / \mathrm{C},-0.40 \mathrm{~V}$ for $\mathrm{Pd} / \mathrm{C}$, and $-0.34 \mathrm{~V}$ for $\mathrm{Au} / \mathrm{C}$, all the potentials are versus $\mathrm{Hg} / \mathrm{HgO} / 1.0 \mathrm{M} \mathrm{KOH}$ ), the $\mathrm{Pt} / \mathrm{C}$ catalyst possessed the highest intrinsic activity toward glycerol electro-oxidation in terms of both the current density and TOF of electrons. These results indicated a good consistency between the half-cell and single AEM fuel cell tests. As the fuel cell operation temperature increased to $80^{\circ} \mathrm{C}$ (Fig. 3.9 (b)), it is clear that the electricity performances over the whole tested current density range were greatly improved on all these catalysts. The peak power density of $\mathrm{Pt} / \mathrm{C}$ anode AEM fuel cell reached $124.5 \mathrm{~mW} \mathrm{~cm}^{-2}$, which is two times greater than the peak power density at $50^{\circ} \mathrm{C}\left(58.6 \mathrm{~mW} \mathrm{~cm}{ }^{-2}\right)$. The peak power density of $\mathrm{Au} / \mathrm{C}$ anode 
AEM fuel cell also shows a three-fold increase when the temperature increased from $50^{\circ} \mathrm{C}$ to $80^{\circ} \mathrm{C}$. The higher performances of $\mathrm{Pt} / \mathrm{C}, \mathrm{Pd} / \mathrm{C}$, and $\mathrm{Au} / \mathrm{C}$ anode $\mathrm{AEMFCs}$ can be attributed to the two aspects. Firstly, the kinetics of both anode and cathode are enhanced at the elevated temperatures. The half-cell investigations have demonstrated that for the glycerol oxidation reaction, both $\alpha n$ and TOF greatly increases on all these three catalysts, while the onset potentials move negatively. Meanwhile, the cathode ORR kinetics is also accelerated at higher operation temperatures. As a result, the OCVs of the AEMFCs with all these three anode catalysts increased at $80^{\circ} \mathrm{C}$. Secondly, the mass transfer is improved at higher temperatures. The conductivity of $\mathrm{OH}^{-}$ion in the AEM (A201) increases with the increasing of the cell operation temperature, which significantly reduces the internal resistance. ${ }^{43}$ In addition, the reactant diffusion is also better at higher temperature. Therefore, the mass transport limiting currents almost doubled on AEMFCs with all these three anode catalysts when the working temperature increased from $50^{\circ} \mathrm{C}$ to $80^{\circ} \mathrm{C}$. It also needs to be mentioned that the peak power density on $\mathrm{Pt} / \mathrm{C}$ anode AEM-DGFC $\left(124.5 \mathrm{~mW} \mathrm{~cm}^{-2}\right)$ is comparable to the state-of-art direct methanol $\left(168 \mathrm{~mW} \mathrm{~cm}{ }^{-2}\right)$ and ethanol $\left(160 \mathrm{~mW} \mathrm{~cm}^{-2}\right)$ AEMFCs with their optimized multi-metallic catalyst system $\left(3 \mathrm{mg}_{\mathrm{PtRu}} \mathrm{cm}^{-2}\right.$ for methanol and $1 \mathrm{mg}_{\mathrm{Pd}-(\mathrm{Ni}-\mathrm{Zn})} \mathrm{cm}^{-2}$ for ethanol) and optimized experimental conditions (i.e. fuel composition flow rate, and temperature). ${ }^{38,96}$ The performances collected on $\mathrm{Pt} / \mathrm{C}, \mathrm{Pd} / \mathrm{C}$, and $\mathrm{Au} / \mathrm{C}$ anode $\mathrm{AEM}$ DGFCs are 2-3 orders of magnitude higher than that of current biofuel cells, ${ }^{97,98}$ and are also an order of magnitude higher than that of proton-exchange membrane direct glycerol fuel cells (PEM-DGFCs) with PtRu/C anode $\left(4.0 \mathrm{mg}_{\mathrm{PtRu}} \mathrm{cm}^{-2}\right.$ ) and $\mathrm{Pt} / \mathrm{C}$ cathode $\left(4.0 \mathrm{mg}_{\mathrm{Pt}}\right.$ $\left.\mathrm{cm}^{-2}\right),{ }^{76}$ indicating that glycerol serves as an efficient liquid fuel in AEMFCs. 

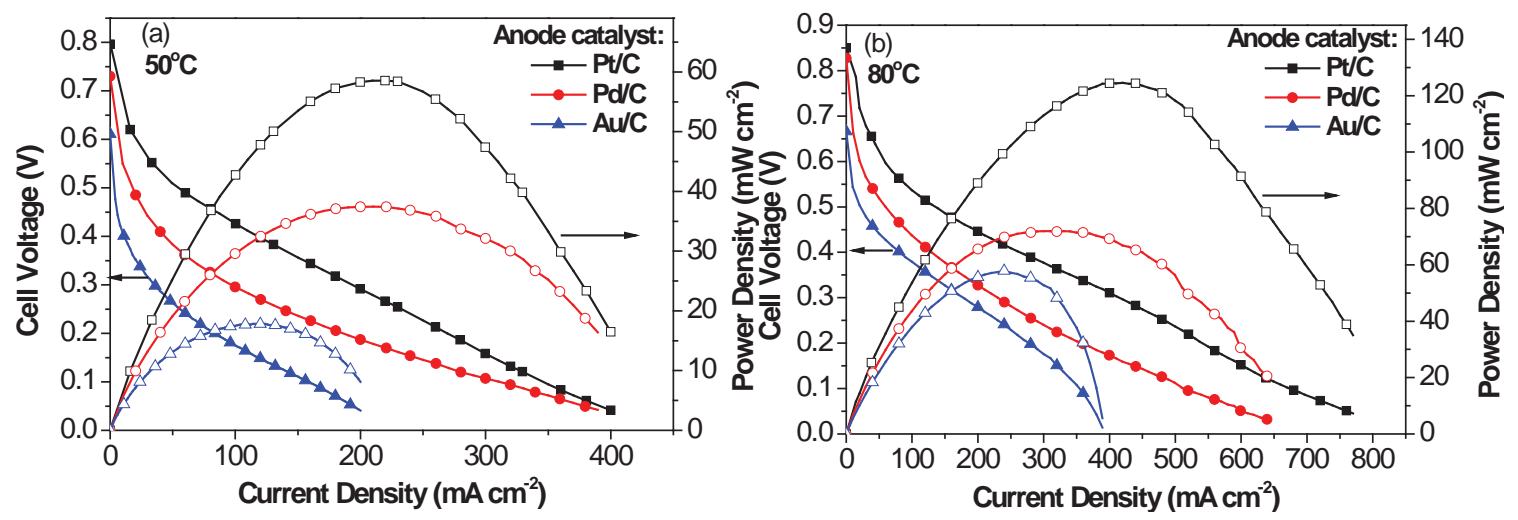

Fig. 3.9 Polarization and power density curves of $\mathrm{Pt} / \mathrm{C}, \mathrm{Pd} / \mathrm{C}$, and $\mathrm{Au} / \mathrm{C}$ anode $\mathrm{AEMFCs}$ with high purity glycerol at the operation temperature of (a) $50^{\circ} \mathrm{C}$ and (b) $80^{\circ} \mathrm{C}$; anode fuel: 2.0 M KOH + 1.0 M high purity glycerol (99.8\%).

\subsubsection{Pt/C, Pd/C, and Au/C anode AEMFCs with crude glycerol (88\%)}

Although glycerol demonstrates a high efficiency in AEMFCs, its wide application is heavily hurdled by the high cost of the high-purity glycerol fuel (ACS grade, which is usually applied in the academic research), even the price of industrial grade purified

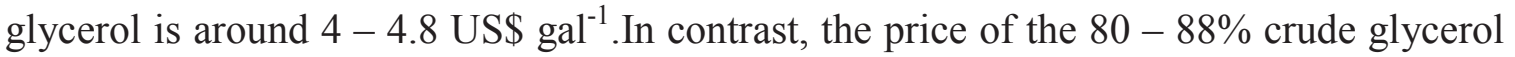
(after two simple steps of separation removing most of methanol, water, fatty acids, and

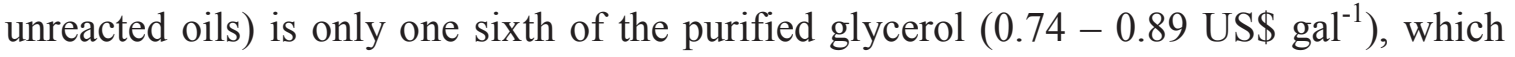
allow it serve as a more economical liquid fuel. However, it is concerning that the complicated components and multiple impurities may contaminate the fuel cell system and poison the anode catalyst. For example, the ash component may clog the pores in the liquid diffusion layer, the free fatty acids (soaps in alkaline solutions) would increase the liquid viscosity and adsorb on catalyst's surface, while the poisoning elements $(\mathrm{Ca}, \mathrm{Mg}$, $\mathrm{Hg}, \mathrm{P}, \mathrm{S}$, and As) may also deactivate the anode catalysts. Therefore, up to now, all previous AEM-DGFCs investigations were focused on the high purity glycerol fuel. None systematical work has been carried out to study the electricity performance of AEMFCs with biodiesel-derived crude glycerol.

In this work, the performances of $\mathrm{Pt} / \mathrm{C}, \mathrm{Pd} / \mathrm{C}$, and $\mathrm{Au} / \mathrm{C}$ anode $\mathrm{AEMFCs}$ were further investigated with crude glycerol fuel at $80^{\circ} \mathrm{C}$. The soy bean biodiesel derived crude glycerol contains 88.05 wt.\% of glycerol, 5.42 wt.\% of matter organic non glycerol 
(MONG), 4.16 wt.\% of moisture, $2.37 \mathrm{wt} \%$ of ash, and $628 \mathrm{ppm}$ methanol, and was used as purchased without any further treatment. As shown in Fig. 3.10 and 3.11, when 2.0 M $\mathrm{KOH}+1.0 \mathrm{M}$ crude glycerol was applied, the limiting current densities on AEMFCs with all the three anode catalyst dropped by $c a .100 \mathrm{~mA} \mathrm{~cm}$-2 than that obtained with high purity glycerol fuels (Fig. 3.9 (b)) under the same testing conditions, indicating that the ashes and high viscosity MONG components (mainly soaps) will lead to a poor mass transfer phenomenon. Meanwhile, the comparison between Fig. 3.9 (b) and Fig. 3.10 (b) and (c) also shows that the crude glycerol fuel yielded lower OCVs and peak power densities on $\mathrm{Pd} / \mathrm{C}$ and $\mathrm{Au} / \mathrm{C}$ anode AEMFCs. Comparing to the results obtained with high purity glycerol (Fig. 3.9 (b)), fed with 2.0 M KOH + 1.0 M crude glycerol, the OCVs on $\mathrm{Pd} / \mathrm{C}$ and $\mathrm{Au} / \mathrm{C}$ anode $\mathrm{AEMFCs}$ dropped by 0.08 and $0.16 \mathrm{~V}$, respectively, while the peak power density also reduced by 10.7 and $27.2 \mathrm{~mW} \mathrm{~cm}^{-2}$, correspondingly. The drop in the performances with crude glycerol fuel may have risen from two aspects. First, the MONG components (methanol and soaps) in crude glycerol may block the active site on the surface of anode catalysts and lead to the loss in the overall performance. Second, the poisoning elements may also be adsorbed on the catalysts and lead to the loss of its catalytic activity. Comparing to $\mathrm{Au} / \mathrm{C}$ and $\mathrm{Pd} / \mathrm{C}$ anode $\mathrm{AEMFCs}$, it is interesting that the both the OCV and the peak power density of $\mathrm{Pt} / \mathrm{C}$ anode fuel cell shows very little drop when switching from high purity glycerol to the crude glycerol fuel, which may indicate the highly active Pt catalyst is also highly stable in this crude glycerol system. 

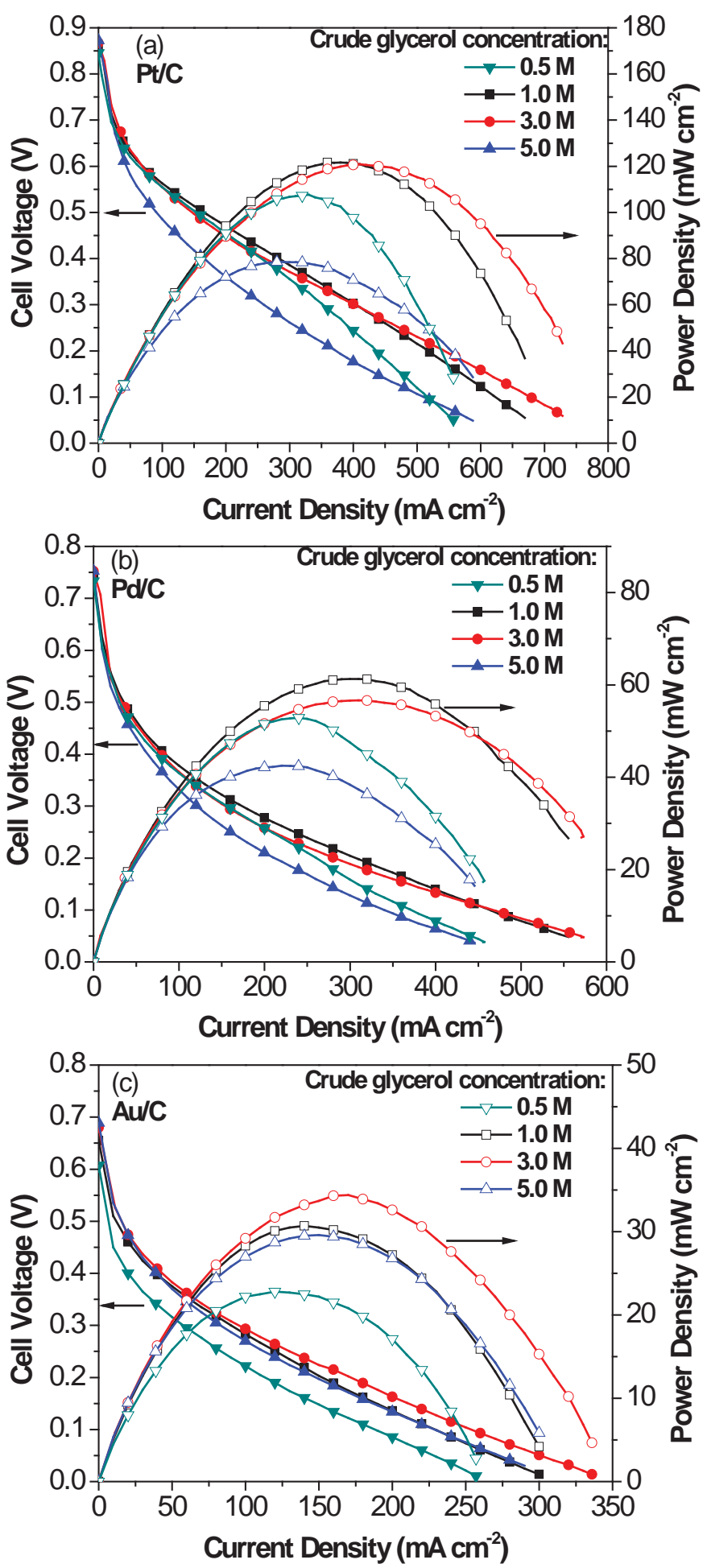

Fig. 3.10 Effect of crude glycerol concentration on fuel cell performances with (a) $\mathrm{Pt} / \mathrm{C}$, (b) $\mathrm{Pd} / \mathrm{C}$, and (c) $\mathrm{Au} / \mathrm{C}$ anode catalysts, at $80^{\circ} \mathrm{C} ; \mathrm{KOH}$ concentration: $2.0 \mathrm{M}$. 

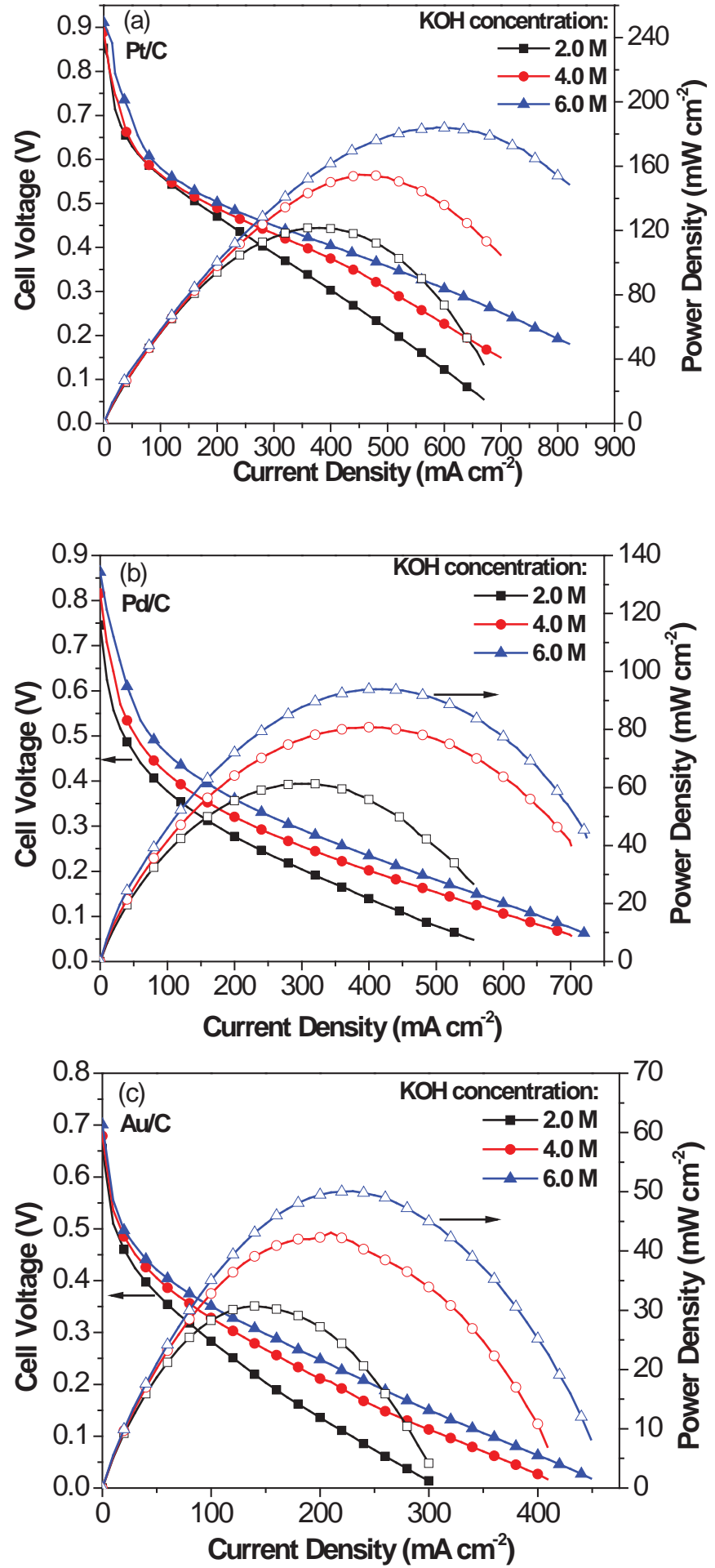

Fig. 3.11 Effect of $\mathrm{KOH}$ concentration on fuel cell performances with (a) $\mathrm{Pt} / \mathrm{C}$, (b) $\mathrm{Pd} / \mathrm{C}$, and (c) $\mathrm{Au} / \mathrm{C}$ anode catalysts, at $80^{\circ} \mathrm{C}$; crude glycerol concentration: $1.0 \mathrm{M}$. 
The effect of crude glycerol concentration on the AEMFCs with $\mathrm{Pt} / \mathrm{C}, \mathrm{Pd} / \mathrm{C}$, and $\mathrm{Au} / \mathrm{C}$ was investigated by fixing the $\mathrm{KOH}$ concentration at $2.0 \mathrm{M}$, while increasing the crude glycerol concentration from 0.5 M to 5.0 M. The results were shown in Fig. 3.10 and the OCVs summarized in Table 3.3 clearly demonstrated an increasing trend on AEMFCs with all these anode catalysts with the increasing of the crude glycerol concentration. As demonstrated in the half cell studies (Fig. 3.4 and Fig. 3.5), glycerol is adsorbed on Pt and $\mathrm{Pd}$ at very low potentials, and is further electrochemically oxidized at higher potentials with the assistance of adsorbed $\mathrm{OH}^{85,99}$ Therefore, in AEMFCs, the anode electrode potential on $\mathrm{Pt} / \mathrm{C}$ and $\mathrm{Pd} / \mathrm{C}$ are governed by the catalyst surface coverage rate of both crude glycerol and $\mathrm{OH}$. When the crude glycerol concentration increases, it will definitely reduce the adsorption of $\mathrm{OH}$. At the OCV states, the electrode reaction is infinitely slow. The catalyst surface $\mathrm{OH}$ concentration can be maintained at an appropriate level. Therefore, when the crude glycerol concentration increased from $0.5 \mathrm{M}$ to $5.0 \mathrm{M}$, small increment in OCVs is still observed on $\mathrm{Pt} / \mathrm{C}$ and $\mathrm{Pd} / \mathrm{C}$ anode $\mathrm{AEMFCs}$. For Au catalyst, the previous investigations have demonstrated that the alcohol electrooxidation on $\mathrm{Au}$ depends on the formation of highly active alkoxide in the alkaline electrolyte. $^{90,91}$

$$
H_{\beta} R-O H_{\alpha}+O H^{-} \leftrightarrows H_{\beta} R-O^{-}+H_{2} O
$$

As glycerol is a weak acid with a $\mathrm{pK}_{\mathrm{a}}=14.15$, under the same $\mathrm{pH}$ value, higher glycerol concentrations will facilitate the formation of highly reactive glycerolate. Similarly to the cases of $\mathrm{Pt} / \mathrm{C}$ and $\mathrm{Pd} / \mathrm{C}$ catalysts, the increasing of glycerolate concentration will favor its adsorption on the surface of $\mathrm{Au}$ catalyst and lead to a higher OCV on the $\mathrm{Au} / \mathrm{C}$ anode AEMFCs.

The peak power densities presented a volcano-type behavior against the crude glycerol concentration on all these three anode catalysts. The highest power densities were obtained with $3.0 \mathrm{M}$ crude glycerol with $\mathrm{Pt} / \mathrm{C}$ and $\mathrm{Au} / \mathrm{C}$ anode catalysts, while it was achieved with $1.0 \mathrm{M}$ crude glycerol with $\mathrm{Pd} / \mathrm{C}$ catalyst. On the one hand, the lower glycerol concentration will lead to lower coverage rate of glycerol on the surface of the 
catalysts (Pt and $\mathrm{Pd}$ ) or lower concentration of the highly reactive glycerolate within the catalyst layer $(\mathrm{Au})$, which further results in a lower performance. On the other side, with a lower bulk glycerol concentration, the local glycerol concentration at the catalyst layer is restricted by the fuel delivery. When the reaction rate is fast enough, a glycerol concentration gradient was built up between the catalyst surface and the bulk electrolyte. Therefore, if the bulk glycerol concentration is low, at higher current density region, the insufficient supply of fuel to the catalyst layer will become a main limitation of the power output. This phenomenon is clear on $\mathrm{Pt} / \mathrm{C}$ and $\mathrm{Pd} / \mathrm{C}$ anode $\mathrm{AEMFC}$ fed with $2.0 \mathrm{M} \mathrm{KOH}$ $+0.5 \mathrm{M}$ crude glycerol. When the current density is $>250 \mathrm{~mA} \mathrm{~cm}{ }^{-2}$, the cell output voltage dropped faster with the increasing of current density, compared to the polarization curves with higher crude glycerol concentrations. However, due to the lower kinetics of glycerol electro-oxidation on $\mathrm{Au} / \mathrm{C}$, the transport issue is less important. Compared to lower glycerol concentrations, too high crude glycerol concentration will also lead to the decrease in AEMFC performance. As is explained above, the higher crude glycerol will lead to a lower $\mathrm{OH}$ coverage on $\mathrm{Pt} / \mathrm{C}$ and $\mathrm{Pd} / \mathrm{C}$ catalyst surfaces. When the electrode deviates away from the $\mathrm{OCV}$ state, a lower coverage rate of $\mathrm{OH}$ will not be enough for the reaction, and consequently limits the AEMFC performance. Meanwhile, the products of glycerol oxidation (acids) need to be neutralized to salt form in the alkaline environment, which further consumes the $\mathrm{OH}^{-}$in the catalyst layer. In addition, a higher crude glycerol concentration will increase the viscosity of the electrolyte, which will decrease the $\mathrm{OH}^{-}$mobility, the release of products (in salt form) from the catalyst layer and increase the fuel cell internal resistance, leading to the drop of AEMFC performance. ${ }^{43,100,101}$ 
Table 3.3 Performances of AEMFCs with $\mathrm{Pt} / \mathrm{C}, \mathrm{Pd} / \mathrm{C}$, and $\mathrm{Au} / \mathrm{C}$ anode and biodiesel derived crude glycerol fuel.

\begin{tabular}{|c|c|c|c|c|c|c|c|}
\hline & & \multicolumn{2}{|r|}{$\mathrm{Pt} / \mathrm{C}$} & \multicolumn{2}{|c|}{$\mathrm{Pd} / \mathrm{C}$} & \multicolumn{2}{|c|}{$\mathrm{Au} / \mathrm{C}$} \\
\hline $\begin{array}{c}\mathrm{KOH} \\
/ \mathrm{M}\end{array}$ & $\begin{array}{c}\text { Crude } \\
\text { glycerol } \\
\text { / M }\end{array}$ & $\begin{array}{l}\mathrm{OCV} \\
/ \mathrm{V}\end{array}$ & $\begin{array}{l}\text { Peak power density } \\
\qquad / \mathrm{mW} \mathrm{cm}^{-2}\end{array}$ & $\begin{array}{l}\mathrm{OCV} \\
/ \mathrm{V}\end{array}$ & $\begin{array}{c}\text { Peak } \\
\text { power } \\
\text { density } \\
/ \mathrm{mW} \mathrm{cm}^{-2}\end{array}$ & $\begin{array}{l}\mathrm{OCV} \\
/ \mathrm{V}\end{array}$ & $\begin{array}{c}\text { Peak } \\
\text { power } \\
\text { density } \\
/ \mathrm{mWcm}^{-2}\end{array}$ \\
\hline \multirow{4}{*}{2.0} & 0.5 & 0.845 & 107.7 & 0.733 & 52.8 & 0.607 & 22.8 \\
\hline & 1.0 & 0.853 & 120.9 & 0.746 & 61.3 & 0.655 & 30.7 \\
\hline & 3.0 & 0.867 & 121.0 & 0.752 & 56.6 & 0.680 & 34.4 \\
\hline & 5.0 & 0.873 & 78.6 & 0.753 & 42.5 & 0.689 & 29.4 \\
\hline 4.0 & \multirow{2}{*}{1.0} & 0.889 & 154.8 & 0.816 & 80.8 & 0.679 & 43.1 \\
\hline 6.0 & & 0.911 & 184.2 & 0.863 & 93.9 & 0.701 & 50.1 \\
\hline
\end{tabular}

The $\mathrm{KOH}$ effects on the AEMFC performance were investigated by fixing the crude glycerol concentration at $1.0 \mathrm{M}$, while increasing the $\mathrm{KOH}$ concentration from $2.0 \mathrm{M}$ to 6.0 M, and are presented in Fig. 3.11. For Pt/C and Pd/C anode AEMFCs, the increasing of bulk $\mathrm{KOH}$ concentration will lead to a higher local $\mathrm{OH}^{-}$concentration at the catalysts layer and a higher $\mathrm{OH}$ coverage on the catalyst surface, which will facilitate the glycerol oxidation. Therefore, as summarized in Table 3.3, the OCVs on both $\mathrm{Pt} / \mathrm{C}$ and $\mathrm{Pd} / \mathrm{C}$ anode AEMFCs increased at higher $\mathrm{KOH}$ concentrations. For $\mathrm{Au} / \mathrm{C}$, a higher $\mathrm{pH}$ of the electrolyte will lead to a higher concentration of glycerolate, leading to a higher OCV on $\mathrm{Au} / \mathrm{C}$ anode AEMFC.

High $\mathrm{KOH}$ concentration will also facilitate the mass transfer in the system. Although it is reported that a higher $\mathrm{KOH}$ concentration will lead to the increase of internal resistance in an $\mathrm{AEMFC},{ }^{43,101}$ in our tested $\mathrm{KOH}$ concentration range (from $2.0 \mathrm{M}$ to $6.0 \mathrm{M}$ ), we found the internal resistance reduced at higher $\mathrm{KOH}$ concentration. When $2.0 \mathrm{M} \mathrm{KOH}$ was applied, the internal resistances on $\mathrm{Pt} / \mathrm{C}, \mathrm{Pd} / \mathrm{C}$, and $\mathrm{Au} / \mathrm{C}$ anode $\mathrm{AEMFCs}$ were 150.9, 224.9 , and $243.7 \mathrm{~m} \Omega \mathrm{cm}^{-2}$, respectively, which reduced to $134.2,151.9$, and $227.4 \mathrm{~m} \Omega$ $\mathrm{cm}^{-2}$, respectively, when $6.0 \mathrm{M} \mathrm{KOH}$ was applied. In AEMFCs with liquid anode fuels, the internal resistance mainly rises from the membrane and the cathode, the resistances of which are related with their humidification. In our test, the anode was fabricated by airbrushing a thin layer of catalyst on the carbon cloth diffusion layer. Therefore, water 
from the anode liquid can easily penetrate into the thin AEM $(28 \mu \mathrm{m})$, which allows the conducting of $\mathrm{OH}^{-}$in the membrane under good humidification at all tested current densities. The cathode catalyst was directly airbrushed on the membrane to increase the contact at the interface. As a result, all the AEMFCs in our tests are observed with very low internal resistance. In addition, the higher $\mathrm{KOH}$ concentration will facilitate the release of the anode glycerol oxidation products and maintain the local $\mathrm{pH}$ in the catalyst layer during the current density region, both of which are better for both charge transfer and mass transfer at the anode. Consequently, when the $\mathrm{KOH}$ concentration increased from 2.0 M to 6.0 M (Fig. 3.11), the limiting current density on all the AEMFCs greatly increased. Due to the better kinetics and mass transfer, the performances were also greatly enhanced. Fed with $6.0 \mathrm{M} \mathrm{KOH}+1.0 \mathrm{M}$ glycerol, the peak power densities on $\mathrm{Pt} / \mathrm{C}, \mathrm{Pd} / \mathrm{C}$, and $\mathrm{Au} / \mathrm{C}$ anode AEMFC reach 184.2, 93.9, and $50.1 \mathrm{~mW} \mathrm{~cm}^{-2}$, respectively. These exciting results may open a new avenue to efficiently utilization of biofuel waste crude glycerol as fuel for high electricity performance AEMFC.

\subsection{Conclusions}

In this work, the carbon supported Pt $(2.4 \mathrm{~nm}), \mathrm{Pd}(3.4 \mathrm{~nm})$, and $\mathrm{Au}(3.5 \mathrm{~nm})$ with small average sizes and narrow particle size distributions were prepared through a modified nanocapsule method, and served as the model catalysts for the study of glycerol electrooxidation and the electricity performance of AEMFCs with both high purity glycerol (99.8\%) and biodiesel derived crude glycerol (88 wt.\%) fuels. The half-cell tests clearly demonstrated that $\mathrm{Pt} / \mathrm{C}$ holds the highest activity in the low potential region, with a TOF 4 - 5 times higher than that on $\mathrm{Pd}$ and 20 - 30 times higher than that on $\mathrm{Au}$ at $-0.3 \mathrm{~V}$ vs. $\mathrm{Hg} / \mathrm{HgO} / 1.0 \mathrm{M} \mathrm{KOH}$. The fuel cell investigation demonstrated that the $\mathrm{Pt} / \mathrm{C}$ anode AEMFCs can yield a peak power density of $124.5 \mathrm{~mW} \mathrm{~cm}^{-2}$ with $2.0 \mathrm{M} \mathrm{KOH}+1.0 \mathrm{M}$ high purity glycerol at $80^{\circ} \mathrm{C}$, and amazingly show no drop in performance when the fuel was switched to the biodiesel derived crude glycerol, indicating that a high stability of the $\mathrm{Pt} / \mathrm{C}$ anode AEMFCs against the contamination/poisoning from the impurities in crude glycerol in high $\mathrm{pH}$ media. Tests with different crude glycerol concentrations show that an optimum crude glycerol concentration exists on $\mathrm{Pt} / \mathrm{C}, \mathrm{Pd} / \mathrm{C}$, and $\mathrm{Au} / \mathrm{C}$ anode $\mathrm{AEMFCs}$ 
at a given $\mathrm{KOH}$ concentration, while at a given crude glycerol concentration, the fuel cell performance with all the three anode catalysts increases at higher $\mathrm{KOH}$ concentration. Fed with $6.0 \mathrm{M} \mathrm{KOH}+1.0 \mathrm{M}$ crude glycerol, the Pt/C anode AEMFC exhibits a very high power density of $184.2 \mathrm{~mW} \mathrm{~cm}^{-2}$ at $80^{\circ} \mathrm{C}$. 


\section{Chapter 4 Simultaneous Generation of Mesoxalate or Tartronate and Electricity from Glycerol in Continuous Flow-type AEM-based Fuel Cell Reactors *}

\subsection{Background}

Glycerol is a key biomass-derived compound, readily available from the bio-diesel manufacture. ${ }^{9}$ In addition to working as a fuel for electricity generation, as discussed in Chapter 3, glycerol is a highly functionalized molecule featuring three hydroxyl (-OH) groups and has great potentials serving as a major building block for the production of new polymers, chemicals, pharmaceuticals, etc. ${ }^{19,102}$ A series of chemoselective catalytic conversion processes have been developed to transform glycerol into more valuable products of industrial importance. ${ }^{19,102}$ Selective partial oxidation of glycerol can lead to the formation of a large number of higher value oxygenated chemicals such as glyceric acid, dihydroxyacetone, tartronic acid, hydroxypyruvic acid, mesoxalic acid, etc. (Fig. 4.1) Among them, mesoxalic acid (140 US $\left.\$ \mathrm{~g}^{-1}\right)$ has potential applications as a complexing agent and as a precursor to the synthesis of 4-chlorophenylhydrazoned mesoxalic acid, which has been demonstrated as an anti-HIV agent, ${ }^{103}$ and its salt form (mesoxalate) has an application in the treatment of diabetes. ${ }^{104}$ Like mesoxalic acid, tartronic acid is a fine chemical and has found its medical application in the treatment of osteoporosis and obesity ${ }^{105}$, food industries ${ }^{106-108}$ and anti-corrosive protective agents ${ }^{109}$. However, the current high price of tartronic acid (1536 US\$ $\mathrm{g}^{-1}$ ) impedes the expansion of its potential market. ${ }^{19}$

\footnotetext{
"The material contained in this chapter was previously published in Applied Catalysis B: Environmental 2014;154-155:360-368 by Qi $\mathrm{J}^{\dagger}$, Xin L $\mathrm{L}^{\dagger}$, Chadderdon DJ, Qiu Y, Jiang Y, Benipal N, Liang C, Li W. ( equal contribution). Copyright (C) 2014 Elsevier B. V. And ChemCatChem 2012;4(8):1105-1114 by Xin L, Zhang Z, Wang Z, Li W. Copyright (C) 2012 John Wiley \& Sons, Inc. Reprint with permission shown in Appendix D
} 
Great progress has been made on selective oxidation of glycerol in aqueous phase with $\mathrm{O}_{2}$ or $\mathrm{H}_{2} \mathrm{O}_{2}$ oxidant. However, primary research focus are focusing on enhancing the activity and selectivity to glycerate or glyceric acid if in low $\mathrm{pH}$ aqueous solution on $\mathrm{Pt}$, $\mathrm{Pd}$ and Au-based mono- ${ }^{54,110-118}$ and bi- ${ }^{114,115,119-121}$ metallic catalysts. Yet it is still challenging to efficiently oxidize two primary - $\mathrm{OH}$ groups (to tartronate) or completely oxidize three $-\mathrm{OH}$ groups (to mesoxalate) on monometallic catalysts, the selectivity of which is mainly limited by the $\mathrm{C}-\mathrm{C}$ cleavage reaction to yield glycolic acid or oxalic acid. Nevertheless, under certain reaction conditions, the selectivity to tartronate or mesoxalate via consecutive oxidation of glycerol was found to be promoted. Prati and Hutchings groups have demonstrated that increasing the catalyst amount and decreasing the glycerol concentration can promote the tartronate formation, which could be attributed to the increasing of the ratio of glycerol to catalyst active sites. ${ }^{111,121,122}$ It was also observed that by increasing the reaction temperature and oxygen concentration, the transformation of glycerate to tartronate could be facilitated. ${ }^{111,112}$ Independent studies by Prati and Davis have reported that glycerol oxidation carried out in a fixed bed continuous up-flow reactor significantly increased the selectivity to tartronate compared with that conducted in semi-batch reactor. ${ }^{123,124}$ The preparation of mesoxalate from glycerol was then based on two step reactions combining two different catalysts, one of which was responsible for the oxidation of glycerol yielding tartronate and another was responsible for further oxidizing tartronate to mesoxalate. ${ }^{125}$ Even though research breakthroughs have been made to obtain reasonable yield of tartronate or mesoxalate, complicate multi-functional catalysts, such as Ce-Bi-Pt-Pd/Carbon ${ }^{126}$, Bi-AuPd/Activated Carbon ${ }^{127}$, Bi-Pt/Activated Carbon $^{128}$ or Ce-Bi-Pt/Carbon ${ }^{125}$ have to be used and multi-step sequential reactors were often involved. ${ }^{125,129}$ On the other hand, Au based catalysts were an inefficient catalyst to yield tartronate $(<25 \%)$ and the formation of mesoxalate has so far not been reported. ${ }^{19}$ More importantly, conventional heterogeneous catalytic oxidation of glycerol that takes place in aqueous solution cannot take advantage of the rich energy stored in the chemical bonds of glycerol, which otherwise can be directly converted to electrical energy via electrocatalytic oxidations. 
Since selective oxidation of glycerol in the aqueous phase is a redox reaction in heterogeneous catalysis where $\mathrm{O}_{2}$ functions in the same way as the ORR at the fuel cell cathodes based on DFT calculation and HPLC/MS isotope analysis, ${ }^{54}$ the study of electrocatalytic oxidation, therefore, could provide new insights into heterogeneous catalytic oxidation reactions. In this respect, exhaustive research efforts in electrochemical oxidation of glycerol have been made aiming to gain fundamental understanding of the key factors that govern the electrocatalytic oxidations. In situ FTIR spectroscopy and HPLC combined with voltammetry have been applied to probe reaction intermediates/products under a wide range of potentials in half cells. ${ }^{88,93,94,130-133}$ Employing the technique that couples the in situ sample collection during the staircase LSV with ex situ HPLC analysis, glycerate and glycolate were identified as the two dominant products on polycrystalline bulk $\mathrm{Pt}$, and $\mathrm{Au}$ in alkaline electrolyte. ${ }^{93,94}$ Tartronate was only observed as a side product with a small amount on Pt electrode, whereas on bulk $\mathrm{Au}$ electrode surface, the presence of tartronate and mesoxalate was detected as weak FTIR signals at very high potential of $>1.2 \mathrm{~V}$ vs. RHE. ${ }^{132}$ On the other hand, Simoes et al. performed the electro-oxidation of glycerol on carbon supported bimetallic PdAu, PdNi, PdBi and Trimetallic PdPtBi nanoparticle catalysts. ${ }^{88,133}$ With the assistance of spectroscopy or chromatography, they detected the formation of tartronate and mesoxalate at 0.55 and $0.85 \mathrm{~V}$ vs. RHE, respectively with the help of ad-atoms. 


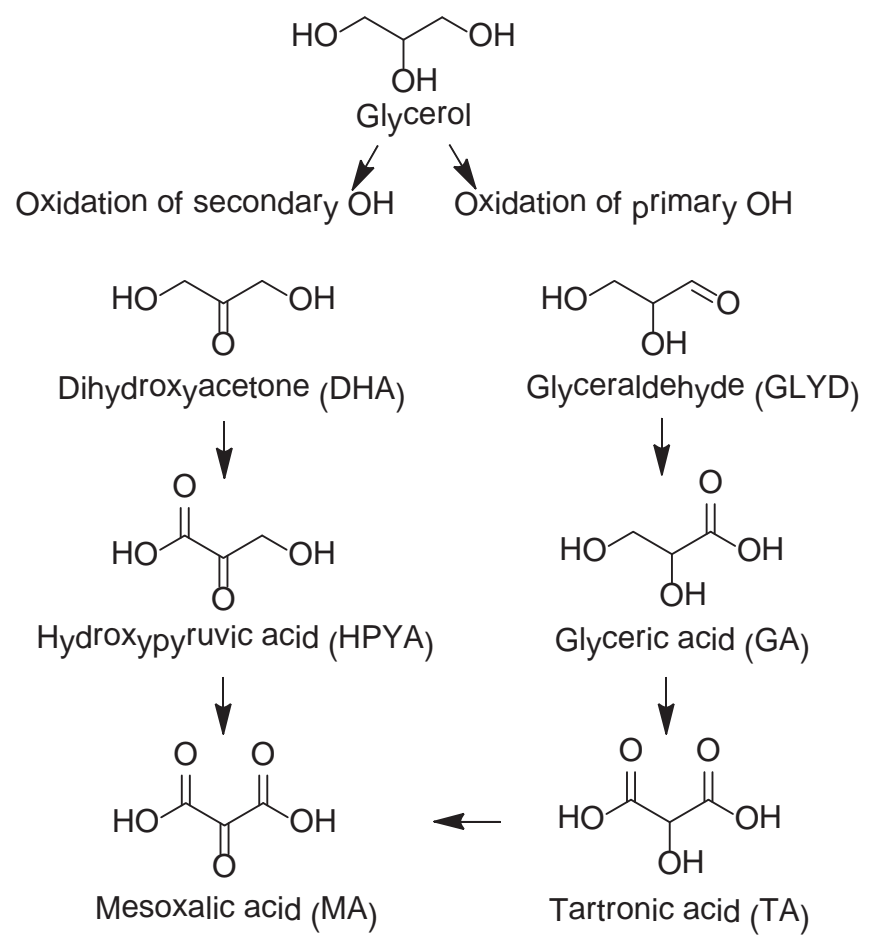

Fig. 4.1 Products obtained by the selective oxidation of glycerol.

In Chapter 3, it has introduced that tremendous progress in the electrical energy generation performance have been accomplished through rational design of electrocatalysts for AEMFCs using pure glycerol as fuel and discussed the electricity performance of AEMFCs directly using biodiesel derived crude glycerol on $\mathrm{Pt} / \mathrm{C}, \mathrm{Pd} / \mathrm{C}$ and $\mathrm{Au} / \mathrm{C}$ anode catalysts. However, complete oxidation of glycerol to carbonate in alkaline media remains the minor reaction in comparison with its partial oxidation to various carboxylates, ${ }^{77}$ which will lead to low energy density and utilization efficiency of glycerol fuel. For this reason, AEM-DGFCs may have industrial application potential only if reasonable output power density and high yield of higher valued target products can be achieved simultaneously. ${ }^{134,135}$ On the other hand, as shown in Table 4.1, chemical production does not necessarily sacrifice electricity generation efficiency. For example, the thermodynamic efficiency $(\eta)$ and reversible potential $\left(E^{0}\right)$ for partial oxidation of glycerol to mesoxalate or tartronate are $98.1 \%, 1.117 \mathrm{~V}$, and $98.4 \%, 1.170 \mathrm{~V}$, respectively, which are comparable to that for complete oxidation of glycerol to $\mathrm{CO}_{2}$ (combustion of glycerol, 98.4\%, 1.230 V). When glycerol oxidizing to mesoxalate or 
tartronate, the volumetric energy density $\left(W_{e}\right)$ of glycerol is 4.5 and $3.6 \mathrm{kWh} \mathrm{L}^{-1}$, respectively, which is also close to that of full oxidation of glycerol to $\mathrm{CO}_{2}\left(6.4 \mathrm{kWh} \mathrm{L}^{-1}\right)$. The Faradaic efficiency $\left(\eta_{e}\right)$, which is defined as the ratio of number of transferred electrons in the partial oxidation to that in the complete oxidation (combustion of glycerol), is also high (71\%, $10 \mathrm{e}^{-}: 14 \mathrm{e}^{-}$to mesoxalate and $57.1 \%, 8 \mathrm{e}^{-}: 14 \mathrm{e}^{-}$to tartronate) It is noted that both the volumetric energy density and Faradaic efficiency for the partial oxidation of glycerol to mesoxalate or tartronate are higher than that for the oxidation of ethanol (a biorenewable mono-alcohol) to acetate $\left(2.1 \mathrm{kWh} \mathrm{L}^{-1}, 33.3 \%=3 \mathrm{e}^{-}: 12 \mathrm{e}^{-}\right)-$the major product in alkaline media. Therefore, it is desirable and theoretically practical to simultaneously generate higher-valued mesoxalate or tartronate and electricity from the electro-oxidation of glycerol in AEM-DGFCs, with little effect on electricity-generation efficiency.

Table 4.1 Thermodynamic data of the electro-oxidation of biorenewable alcohols into target products.

\begin{tabular}{|c|c|c|c|c|c|c|}
\hline Fuel & Final Product & $N e^{[\mathrm{a}]}$ & $\begin{array}{l}E^{0[\mathrm{~b}]} \\
/ \mathrm{V}\end{array}$ & $\begin{array}{c}W_{e}^{[\mathrm{c}]} \\
/ \mathrm{kWh} \cdot \mathrm{L}^{-1}\end{array}$ & $\begin{array}{l}\eta_{e}{ }^{[\mathrm{d}]} \\
/ \%\end{array}$ & $\begin{array}{l}\eta^{[\mathrm{e}]} \\
/ \%\end{array}$ \\
\hline Hydrogen & $\mathrm{H}_{2} \mathrm{O}$ & 2 & 1.229 & 2.6 & 100 & 83.3 \\
\hline \multirow{2}{*}{ Ethanol } & $\mathrm{CO}_{2}$ & 12 & 1.145 & 6.4 & 100 & 96.9 \\
\hline & Acetate & 4 & 1.171 & 2.1 & 33.3 & 91.8 \\
\hline \multirow{4}{*}{ Glycerol $^{[\mathrm{f}]}$} & $\mathrm{CO}_{2}$ & 14 & 1.230 & 6.4 & 100 & 98.4 \\
\hline & Glycerate & 4 & 1.140 & 1.8 & 28.6 & 91.1 \\
\hline & Tartronate & 8 & 1.170 & 3.6 & 57.1 & 98.4 \\
\hline & Mesoxalate & 10 & 1.117 & 4.5 & 71.4 & 98.1 \\
\hline \multicolumn{7}{|c|}{$\begin{array}{l}\text { [a] } N e \text { : Number of transferred electrons. [b] } E^{0} \text { : Thermodynamic reversible potential. } \\
\text { [c] } W_{e} \text { : Volumetric energy density, liquid } \mathrm{H}_{2} \text {. [d] } \eta_{e}: \text { Faradic efficiency. [e] } \eta: \\
\text { Thermodynamic efficiency. [f] Based on predicted thermo-data from }{ }^{136} \text {. }\end{array}$} \\
\hline
\end{tabular}

In my previous collaborative research, we self-designed a continuous flow AEM-based electrolysis cell reactor (Fig. 2.3) to investigate glycerol electro-oxidation on $\mathrm{Au} / \mathrm{C}$ with carbon cloth substrate (liquid diffusion electrode), which is similar to AEM-DGFC anode structure (Fig. 2.5). It was interesting to find that tartronate with the selectivity of $>79 \%$ was produced at potential $<0.45 \mathrm{~V}$ and mesoxalate was not observed in the product profile until applied potential $\geq 0.45 \mathrm{~V}$. As shown in Fig. 4.2, a pathway of glycerol electrocatalytic oxidation was also proposed based on the products detected in the bulk 
electrolyte as a function of applied potentials. ${ }^{137}$ The current of glycerol electro-oxidation as a function of time at each applied potential is shown in Fig. 4.3. It can be observed that the current at most potentials remains stable over the course of test (1 hour), indicating little deactivation or loss of Au catalyst. However, a slight but noticeable current drop observed at the most positive potentials, 0.65 and $0.7 \mathrm{~V}$ vs. RHE tested could result from the faster reaction rates which gives rise to the more serious mass transport issue, in particularly at the cathode side where hydrogen evolution reaction occurs, as the bubbles will block the active area of the $\mathrm{Pt} /$ Vulcan Carbon $\left(1.0 \mathrm{mg}_{\mathrm{Pt}} \mathrm{cm}^{-2}\right)$ based liquid diffusion electrode (Fig. 2.3 and Section 2.3.3) from contacting fresh electrolytes. The Faradaic efficiency (calculated according Equation 2-14) of $>90 \%$ at each applied potential studied in the continuous flow AEM based electrolysis cell reactor (Fig. 4.4) confirmed the stability of $\mathrm{Au}$ anode electrode as well as little interference of $\mathrm{O}_{2}$ from OER in the system.

As shown in Equation 4.1 and 4.2, the thermodynamic potentials of glycerol oxidation to tartronate and mesoxalate under standard conditions are -0.77 and $-0.72 \mathrm{~V}$ vs. SHE in a basic electrolyte with $\mathrm{pH}$ of 14 (thermodynamic properties of some biomass compounds are obtained from reference ${ }^{136}$ ), which are very close to each other. Thermodynamically, it is possible to obtain these products simultaneously. In electrolysis, the oxidation reactions take place at the electrified catalyst-electrolyte interface close to the anode, where reaction rate, pathway and products distribution can be regulated via manipulation of the anode potential, so as to facilitate selectively formation of valuable target products.

$$
\begin{aligned}
& \text { Glycerol }+10 \mathrm{OH}^{-} \rightleftarrows \text { Tartronate }+8 \mathrm{H}_{2} \mathrm{O}+8 \mathrm{e}^{-} \quad \mathrm{E}^{\mathrm{o}}=-0.77 \mathrm{~V} \text { vs. SHE } \\
& \text { Glycerol }+12 \mathrm{OH}^{-} \rightleftarrows \text { Mesoxalate }+10 \mathrm{H}_{2} \mathrm{O}+10 \mathrm{e}^{-} \quad \mathrm{E}^{\mathrm{o}}=-0.72 \mathrm{~V} \text { vs. SHE }
\end{aligned}
$$



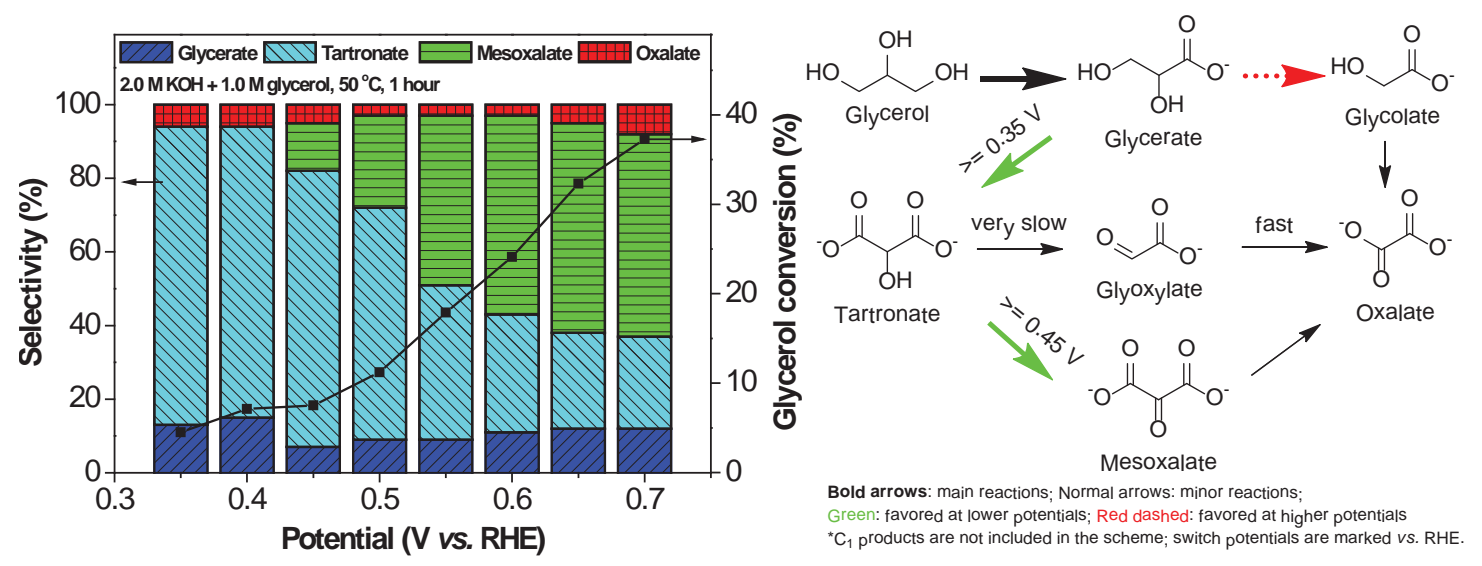

Fig. 4.2 Electrocatalytic oxidation of glycerol on $\mathrm{Au} / \mathrm{C}(40 \mathrm{wt} . \%)$ under different applied potentials in the continuous flow AEM based electrolysis cell reactor.

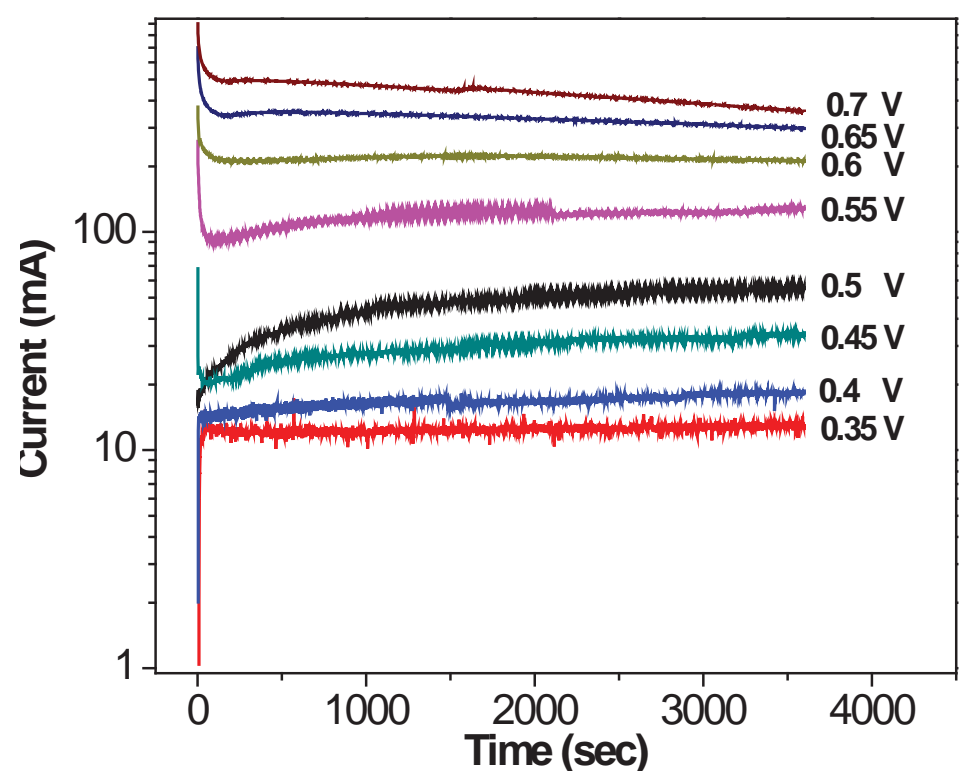

Fig. 4.3 The current of glycerol electro-oxidation on $\mathrm{Au} / \mathrm{C}(40 \mathrm{wt} . \%)$ as a function of time at different potentials (V vs. RHE) in the continuous flow AEM based electrolysis cell reactor. 


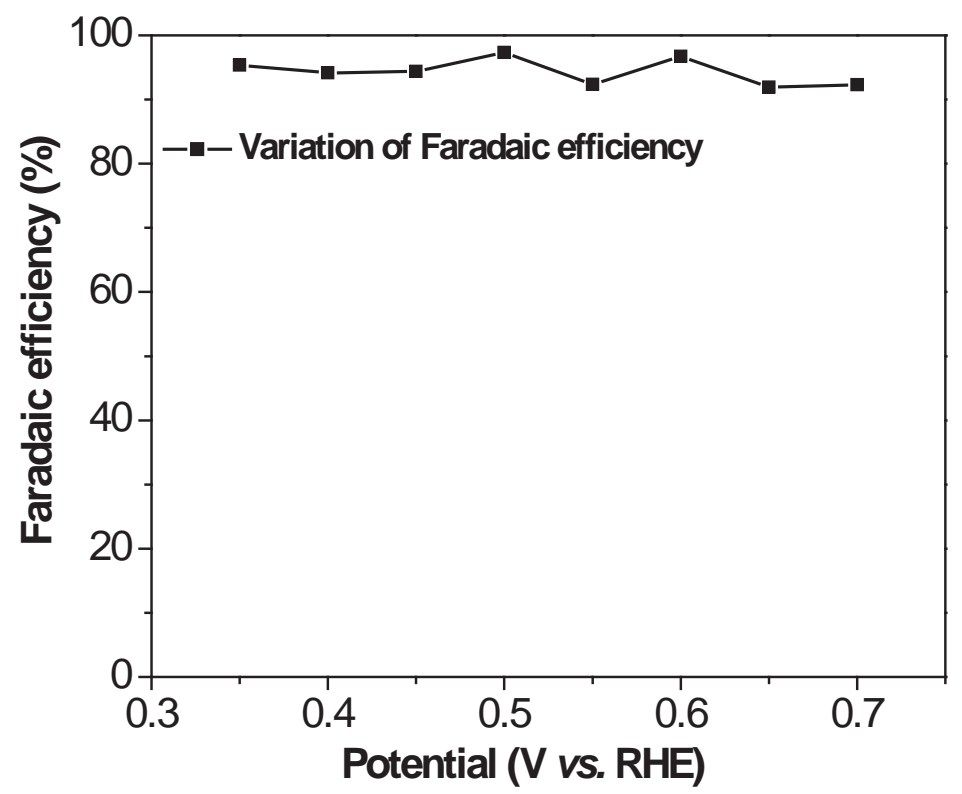

Fig. 4.4 The Faradaic efficiency of glycerol electro-oxidation on $\mathrm{Au} / \mathrm{C}$ (40 wt.\%) as a function of time at different potentials (V vs. RHE) in the continuous flow AEM based electrolysis cell reactor.

One the other hand, in the continuous flow-type AEM based electrolysis cell reactor, a porous LDE (thickness $>700 \mu \mathrm{m}$, consisting of carbon cloth substrate: $381 \mu \mathrm{m}$ and catalyst layer of $5.0 \mathrm{mg}_{\mathrm{Au}} \mathrm{cm}^{-2}, c a .40 \mathrm{wt} . \% \mathrm{Au} / \mathrm{C}: 324 \mu \mathrm{m}$, measured by micrometer) with a confined electrolyte volume was used in this study. The "holding effect" of this thick porous matrix would help retain reaction intermediate species in the catalyst layer, so that the obtained product selectivity was different from that studied on the polycrystalline Au electrode where the only glycerol oxidation product in alkaline media is glycerate, at low potentials $(\leq 0.8 \mathrm{~V}) .^{93,94}$ The different electrode structures can significantly influence reactant transport/diffusion (to catalyst surface), and therefore affect the overall reaction kinetics. In the course of glycerol oxidation, glycerate is the first stable product, as well as a reaction 'intermediate' required for the production of tartronate (Fig. 4.2). When the flat surface Au electrode was employed, the generated glycerate would irreversibly diffuse from the electrode surface to the bulk electrolyte, which will prevent the further oxidation process. In the AEM based electrolysis cell reactor, the carbon cloth can help holding/trapping the stable reaction 'intermediates' 
(glycerate, tartronate, etc.) from escaping, thus the final oxidation product generation could be better controlled by the electrode potentials.

In this chapter, the results of potential regulated selectivity obtained from AEM-based electrolysis cell reactor (Fig. 2.3) have been translated into the AEM-based fuel cell reactor (Fig. 2.5) to seek co-production of valuable tartronate or mesoxalate and electricity over $\mathrm{Au} / \mathrm{C}$ anode catalysts (Fig. 4.5). The MEA structure, electrolyte $\mathrm{pH}$, fuel flow rate and operation temperature in AEM-DGFCs have been optimized to allow fine tuning anode potential to favor the electro-oxidation of either two primary - $\mathrm{OH}$ groups of glycerol to tartronate or all three $-\mathrm{OH}$ groups to mesoxalate, while minimizing the $\mathrm{C}-\mathrm{C}$ bond cleavage (e.g. to glycolate and oxalate). It has also been found that $\mathrm{Au} / \mathrm{C}$ catalyzed glycerol partial oxidation products (glycerate, tartronate or mesoxalate) in AEMFCs are relatively stable after desorbing into bulk electrolyte, which has been further supported by studies previously carried out in the AEM-based electrolysis cell reactor.

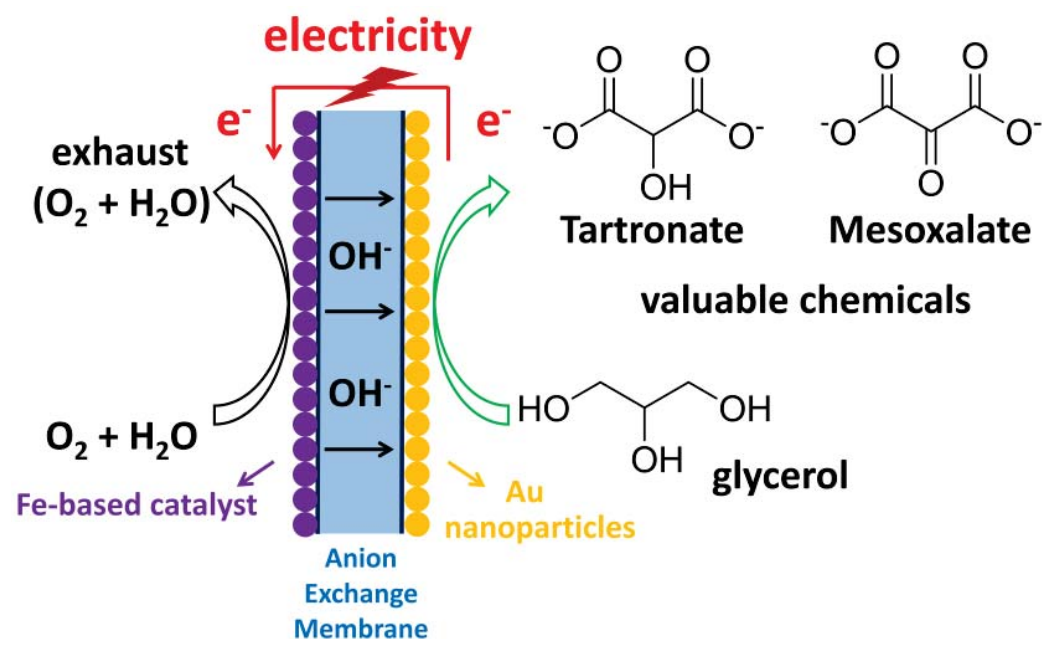

Fig. 4.5 Illustration of continuous flow AEM-based fuel cell reactor for selective electrocatalytic oxidation of glycerol for valuable tartronate or mesoxalate and electricity cogeneration. 


\subsection{General experimental}

\subsubsection{Preparation of $\mathrm{Au} / \mathrm{C}$ (40 wt.\% and 55 wt.\%)}

The organic solution phase-based nanocapsule method was applied to prepare the carbon black supported Au nanoparticles with setting loadings of 40 wt.\% and 55 wt.\%. The detail synthesis procedures have been described in Section 2.4.4.

\subsubsection{Physical characterizations}

The morphology, nanostructure and metal loading of $\mathrm{Au} / \mathrm{C}$ were analyzed by TEM, XRD and ICP-OES, as described in Section 2.5.1, 2.5.3 and 2.5.4.

\subsubsection{Electrochemical characterizations}

\subsubsection{Half-cell tests}

Half-cell tests were performed in a conventional three-electrode-cell setup (Section 2.2.1), equipped with a glassy carbon working electrode, a $\mathrm{Hg} / \mathrm{HgO} / 1.0 \mathrm{M} \mathrm{KOH}$ reference electrode and a Pt coil counter electrode. A water bath is used to hold system temperature at 25,50 , or $60^{\circ} \mathrm{C}$ throughout the tests. $2.0 \mathrm{mg} \mathrm{Au} / \mathrm{C}$ (55 wt.\%) was firstly dispersed in $1.0 \mathrm{ml}$ isopropanol by sonication to form uniform ink. Before each test, $20 \mu 1$

of the $2.0 \mathrm{mg} \mathrm{ml}^{-1}$ catalyst ink was drop-casted on the glass carbon electrode, followed by adding $10 \mu \mathrm{l}$ of 0.05 wt.\% AS-4 anion conductive ionomer (Tokuyama Corp.) on the top to bind the catalyst particles. (Section 2.3.1) Prior to tests, all the electrolytes were deaerated by purging with $\mathrm{N}_{2}$ gas $(99.99 \%)$ for $30 \mathrm{~min}$. 10-cycles of cyclic voltammetry were recorded for $\mathrm{Au} / \mathrm{C}$ catalystat 25,50 , and $60^{\circ} \mathrm{C}$ in $0.1 \mathrm{M} \mathrm{KOH}$ and the stabilized polarization curve obtained from the last cycle as reported. All potentials were reported with respect to RHE. LSVs on $\mathrm{Au} / \mathrm{C}$ catalyst with sweep rate of $1 \mathrm{mV} \mathrm{s}^{-1}$ without rotation was carried out in $0.1 \mathrm{M} \mathrm{KOH}, 0.1 \mathrm{M} \mathrm{KOH}+0.1 \mathrm{M}$ glycerol, $0.2 \mathrm{M} \mathrm{KOH}+0.1$ $\mathrm{M}$ glyceric acid, 0.3 M KOH $+0.1 \mathrm{M}$ tartronic acid and $0.1 \mathrm{M} \mathrm{KOH}+0.1 \mathrm{M}$ sodium mesoxalate monohydrate at 50 or $60^{\circ} \mathrm{C}$. Excessive $\mathrm{KOH}(0.2$ or $0.3 \mathrm{M})$ was used to neutralize glyceric acid $\left(\mathrm{pK}_{\mathrm{a}}=3.52\right)$ and tartronic acid $\left(\mathrm{pK}_{\mathrm{a}} 1=2.42, \mathrm{pK}_{\mathrm{a}} 2=4.54\right) .{ }^{138}$ 


\subsubsection{AEM-DGFC single cell tests}

Electrocatalytic selective oxidation of glycerol on $\mathrm{Au} / \mathrm{C}$ anode catalyst in AEM-DGFCs with electricity cogeneration was conducted on a Scribner fuel-cell test stand (850e). (Section 2.2.3)

MEA electrode was fabricated according to Section 2.3.3. The anode catalyst ink was made by mixing $\mathrm{Au} / \mathrm{C}$ (40 wt.\% and 55 wt.\%) catalyst power, 5 wt.\% PTFE in water suspension into iso-propanol $\left(10 \mathrm{mg}_{\text {catalyst }} \mathrm{ml}^{-1}\right.$, mass ratio PTFE : catalyst $\left.=5: 95\right)$, and sprayed onto a carbon cloth (PTFE-untreated, $381 \mu \mathrm{m}$, Fuel Cell Store) that serves as the liquid diffusion layers to achieve a loading of 1.0 or $5.0 \mathrm{mg}_{\mathrm{Au}} \mathrm{cm}^{-2}$. The cathode catalyst ink $\left(10 \mathrm{mg}_{\text {catalyst }} \mathrm{ml}^{-1}\right.$, mass ratio ionomer : catalyst $\left.=3: 7\right)$, which was made from 1propanol dispersion of a commercial non- PGMs catalyst $\left(\mathrm{Fe}-\mathrm{Cu}-\mathrm{N}_{4} / \mathrm{C}, \mathrm{HYPERMEC}^{\mathrm{TM}}\right.$, Acta) blended with an AS-4 anion conductive ionomer (Tokuyama Corp.), was airbrushed directly onto the AEM. A 25CC carbon paper (Teflon Treated, SGL Group) was employed as the cathode GDL. The evenly-sprayed carbon cloth anode and catalyst coated membrane (CCM) cathode were dried in air under room temperature overnight before use. The MEA was fabricated by directly assembling the anode, cathode and carbon paper in sequence without hot press.

During each run, $30 \mathrm{ml}$ of glycerol $+\mathrm{KOH}$ solution (glycerol : $\mathrm{Au}=1: 1300$ and 1: 6500 $\mathrm{mol} / \mathrm{mol}$ for 1.0 and $5.0 \mathrm{mg}_{\mathrm{Au}} \mathrm{cm}^{-2}$ respectively) was introduced into a plastic vessel and pumped into the anode at a flow rate of 1.0 or $4.0 \mathrm{ml} \mathrm{min}^{-1}$ through a closed loop by a peristaltic pump (Gilson Minipuls 3), while the high-purity $\mathrm{O}_{2}(99.999 \%)$ was fed into the cathode compartment at a flow rate of 0.1 or $0.4 \mathrm{~L} \mathrm{~min}^{-1}$ under a backpressure of 30 or $0 \mathrm{psig}$. The electro-oxidation was carried out by controlling the fuel cell voltage to 0.5 , 0.3 or $0.1 \mathrm{~V}$. During the reactions, the reactor temperature was controlled at $50 \mathrm{C}$ or $60 \mathrm{C}$ and the anode potential was monitored by a inserted $\mathrm{Hg} / \mathrm{HgO} / 1.0 \mathrm{M} \mathrm{KOH}$ electrode, and reported with respect to RHE (the conversion of $\mathrm{Hg} / \mathrm{HgO}$ to RHE has been discussed in Section 2.2.1. The generated current density and power density were recorded. Samples were taken after certain time and analyzed by HPLC. 


\subsubsection{Product analysis}

The glycerol electro-oxidation products were analyzed by HPLC and identified, quantified by comparison with authentic samples (Section 2.7).

The product selectivity/yield and glycerol conversion are calculated by the following equations. $^{54,110,117,124}$

$$
\begin{gathered}
\text { Selectivity of } C_{2} \text { or } C_{3} \text { product }=\frac{\text { Moles of } C_{2} \text { or } C_{3} \text { product }}{\text { Total moles of } C_{2} \text { and } C_{3} \text { products }} \times 100 \% \\
\text { Conversion of glycerol }=\left(1-\frac{\text { Concentration of glycerol at certain time }}{\text { Initial concentration of glycerol }}\right) \times 100 \%
\end{gathered}
$$

Yield of $C_{2}$ or $C_{3}$ product $=$ Selectivity of $C_{2}$ or $C_{3}$ product $\times$ Conversion of glycerol

The carbon balance is based on: ${ }^{54,124}$

$$
\text { Carbon balance }=\frac{3 M_{g_{i}}-3 \sum M_{C_{3}}-2 \sum M_{C_{2}}-\sum M_{C_{1}}-3 M_{g_{f}}}{3 M_{g_{i}}} \times 100 \%
$$

where $M_{g_{i}}$ and $M_{g_{f}}$ is the initial and final moles of glycerol in the electrolyte. $\sum M_{C_{3}}$, $\sum M_{C_{2}}$ and $\sum M_{C_{1}}$ are the total moles of $C_{3}$ (glycerate, tartronate, mesoxalate, lactate), $C_{2}$ (glycolate, glyoxylate, oxalate,) and $C_{1}$ (formate, carbonate) products, respectively. If assuming that no $\mathrm{C}-\mathrm{C}$ bond cleavage occurs through $C_{2}$ products, then $\sum M_{C_{2}}=\sum M_{C_{1}}$. Thus the equation for carbon balance calculation can be simplified to:

$$
\text { Carbon balance }=\frac{M_{g_{i}}-\sum M_{C_{3}}-\sum M_{C_{2}}-M_{g_{f}}}{M_{g_{i}}} \times 100 \%
$$

Therefore, a carbon balance of 0 means all the $C_{2}$ products generated from $\mathrm{C}-\mathrm{C}$ breaking of $C_{3}$ products do not undergo further $\mathrm{C}-\mathrm{C}$ cleavage, and the summation of all the $C_{2}$ and $C_{3}$ products and unreacted glycerol is equal to the initial glycerol. A smaller carbon 
balance value indicates less $C_{2}$ intermediates were further oxidized to $C_{1}$ products (carbon balance of 0 means no $C_{2}$ intermediates were further oxidized to $C_{1}$ products). The carbon balance under all the test conditions is less than $15 \%$, which is within the system error expected in HPLC analysis.

\subsection{Results and discussions}

\subsubsection{Physical characterizations}

TEM images (Fig. 4-6 (a) and (b)) of Au/C with different loadings (ca. 40 wt.\% and 55 wt.\%) shows similar average particle size of around $3.5 \mathrm{~nm}$ and identical size distribution of 2-6 nm. The XRD patterns (Fig. 4.6 (c)) of $c a .40 \mathrm{wt} . \%$ and $55 \mathrm{wt} . \% \mathrm{Au} / \mathrm{C}$ display the same FCC crystaline structure of Au. Both TEM and XRD characterizations indicate that the increasing of Au loading on carbon black supports do not significantly alter its physical properties. 

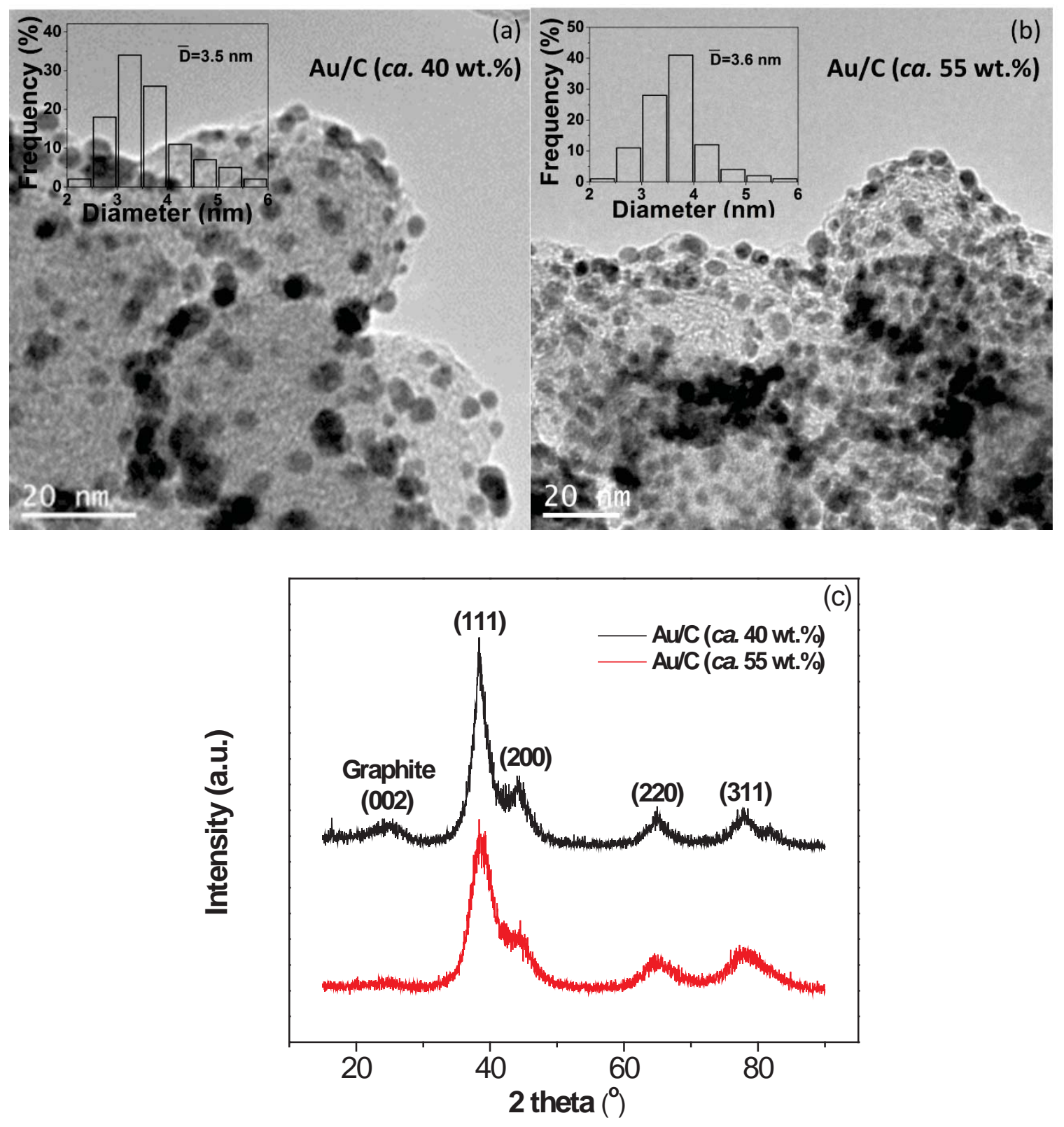

Fig. 4.6 TEM images and corresponding particle-size histograms of (a) $\mathrm{Au} / \mathrm{C}$ (ca. 40 wt.\%) and (b) Au/C (ca. 55 wt.\%); (c) XRD pattern of ca. 40 wt.\% and 55 wt.\% Au/C. 


\subsubsection{The effects of MEA structures and reaction conditions on the selectivity of tartronate and mesoxalate in AEM-DGFCs and electro-oxidation activity evaluation of main glycerol partial oxidation $\mathrm{C}_{3}$ products in half cells}

Electrocatalytic oxidation of glycerol in AEM-DGFCs could provide a new route to sustainable conversion of glycerol to value-added oxygenated chemicals with important industrial applications. The AEM-DGFCs can be envisioned as a continuous fixed-bed reactor with multiple plates, which is more prone to produce deeply oxidized products than conventional heterogeneous catalytic oxidation of glycerol in semi-batch reactor configuration. ${ }^{122-124}$ However, our reactor significantly distinguishes from heterogeneous catalytic reactors: (1) The anion-exchange membrane was introduced to separate the $\mathrm{O}_{2}$ gas phase from the catalyst-electrolyte (solid-liquid) phase, to resolve the problem of

oxygen mass transfer that was encountered by the multiphase reactor. ${ }^{124,139,140}$ (2) The LDE was not only used as a catalyst bed but also as a conductor to collect electric current. Therefore, the cogeneration of electricity and higher-value chemicals could be achieved. Considering that glycerol electro-oxidation on $\mathrm{Au} / \mathrm{C}$ in $\mathrm{AEM}-\mathrm{DGFC}$ involves complex reaction sequences, any changes in reaction conditions, such as the electrode thickness, flow rate, the reaction temperature and electrolyte $\mathrm{pH}$, could affect the anode potential, thereby influencing the final products distribution.

Electrode thickness was first optimized toward anode potential tuning for selective oxidation of glycerol in AEM-DGFCs. The different anode thicknesses (length scales) result in different timescales of which the reactants diffuse into and products diffuse out of the porous electrodes, which affect the concentration profiles of reactants and reaction intermediates available inside the electro-catalytically active region. In other words, the thicker the porous electrode is, the more reaction intermediates will be held within the confined electrolyte volume to possibly facilitate their deeper oxidation, meanwhile, the fresh reactant will be held outside of the electro-catalytically active region. As a results, a 18\% selectivity to mesoxalate was obtained with $\mathrm{Au} / \mathrm{C}$ of $c a .40$ wt.\% loading (Fig. 4.7 (a)) where the anode potential was monitored to be $0.54 \mathrm{~V}$ vs. RHE. Increasing the metal loading of $\mathrm{Au} / \mathrm{C}$ catalyst from $40 \mathrm{wt} . \%$ to $55 \mathrm{wt} . \%$ decreases the amount of carbon black 
amount on the anode (from $7.5 \mathrm{mg}$ to $4.0 \mathrm{mg}$ ), therefore decreases the thickness of the porous liquid diffusion anode (from $650 \mu \mathrm{m}$ to $597 \mu \mathrm{m}$, including the thickness of carbon cloth substrate of $381 \mu \mathrm{m}$ and catalyst layer of $269 \mu \mathrm{m}$ or $216 \mu \mathrm{m}$ measured by a micrometer), given that the same Au loading $\left(1.0 \mathrm{mg}_{\mathrm{Au}} \mathrm{cm}^{-2}\right)$ was used at the anode. Compared to the $\mathrm{Au} / \mathrm{C}\left(1.0 \mathrm{mg}_{\mathrm{Au}} \mathrm{cm}^{-2}, 40 \mathrm{wt} . \%\right)$ anode used the presented thinner porous anode structure $\left(1.0 \mathrm{mg}_{\mathrm{Au}} \mathrm{cm}^{-2}, 55 \mathrm{wt} . \%\right)$, allows more fresh glycerol from bulk electrolyte to replenish the oxidation reaction, which leads to the glycerol conversion increasing from 13.1\% (Fig. 4.7 (a)) to 14.7\% (Fig. 4.7 (b)) in $1 \mathrm{~h}$ operation. It has been discussed in Chapter 3 that higher local concentration of glycerol present at the catalystelectrolyte interface will not only negatively shift the onset potential of glycerol electrooxidation in half cell but also increase the OCV in AEM-DGFCs, as it facilitates the formation of highly reactive glyceraldehyde. The cathode non-precious $\mathrm{Fe}-\mathrm{Cu}$-based catalyst loading was also increased from $1.0 \mathrm{mg} \mathrm{cm}^{-2}$ to $3.0 \mathrm{mg} \mathrm{cm}^{-2}$ to facilitate ORR. It was observed that the measured anode potential decreases from $0.54 \mathrm{~V}$ to $0.41 \mathrm{~V}$ vs. RHE with the anode thickness decreasing and enhanced ORR. This observation can also be explained by the ease of the removal of reaction intermediates by glycerol fluxing in through the thinner porous electrode, as their presence could inhibit the oxidation of glycerol and lead to the anode potential increasing. ${ }^{141}$ 


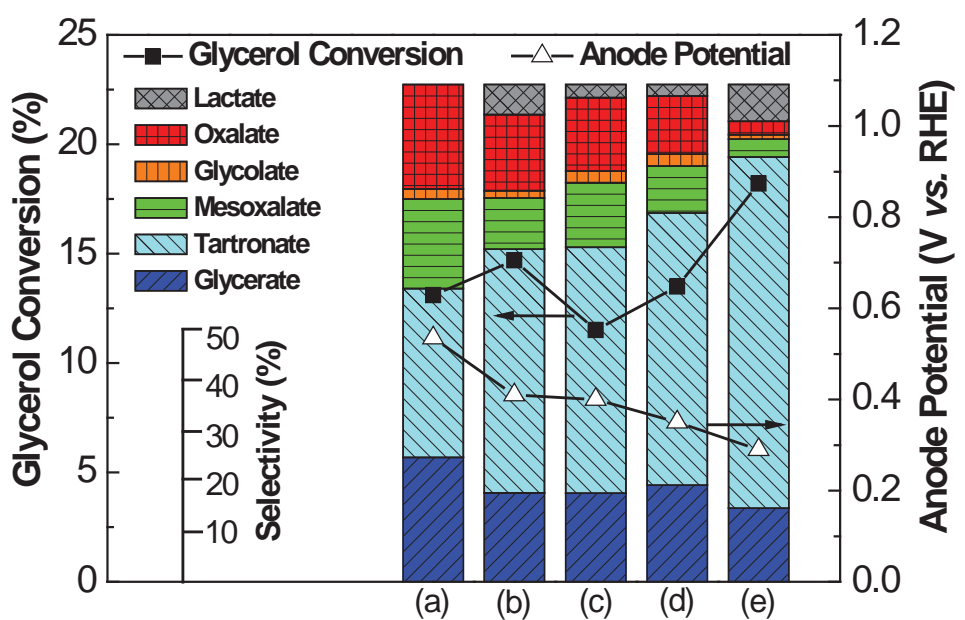

Fig. 4.7 Electro-catalytic selective oxidation of glycerol in AEM-DGFCs with different MEA structures and operation conditions: cell voltage: $0.1 \mathrm{~V}$; reaction time: $1 \mathrm{~h}$. Details of MEA structure and operation conditions (a)-(e) are listed in Table 4.2.

Table 4.2 Details of MEA structure and AEM-DGFCs operation conditions with constant cell potential of $0.1 \mathrm{~V}$.

\begin{tabular}{|c|c|c|c|c|c|}
\hline Entry & $(\mathrm{a})$ & $(\mathrm{b})$ & $(\mathrm{c})$ & $(\mathrm{d})$ & $(\mathrm{e})$ \\
\hline Membrane type & A201 & A901 & A901 & A901 & A901 \\
\hline Anode catalyst loading $/ \mathrm{mg} \mathrm{cm}^{-2}$ & 1 & 1 & 1 & 1 & 1 \\
\hline Cathode catalyst loading $/ \mathrm{mg} \mathrm{cm}^{-2}$ & 1 & 3 & 3 & 3 & 3 \\
\hline Anode catalyst metal loading $/ \mathrm{wt}^{-} \%$ & 40 & 55 & 55 & 55 & 55 \\
\hline Anode fuel flow rate $/ \mathrm{ml} \mathrm{m^{-1 }}$ & 4 & 4 & 1 & 1 & 1 \\
\hline Cathode gas flow rate $/ \mathrm{ml} \mathrm{min}^{-1}$ & 400 & 400 & 100 & 100 & 100 \\
\hline Temperature $/{ }^{\circ} \mathrm{C}$ & 50 & 50 & 50 & 60 & 60 \\
\hline $\mathrm{KOH}$ concentration $/ \mathrm{M}$ & 2 & 2 & 2 & 2 & 8 \\
\hline Back pressure $/ \mathrm{psi}$ & 30 & 30 & 0 & 0 & 0 \\
\hline
\end{tabular}

The independent LSV experiments were carried out at $50^{\circ} \mathrm{C}$ by using $\mathrm{KOH}$ solution with glycerate, tartronate, or mesoxalate (Fig. 4.8 (a)). It shows that glycerate is more difficult to be oxidized on $\mathrm{Au} / \mathrm{C}(55 \mathrm{wt} \%$ ) than glycerol as shown by its lower peak current density (e.g. $4.5 \mathrm{~mA} \mathrm{~cm}^{-2}$ vs. $23.6 \mathrm{~mA} \mathrm{~cm}^{-2}$ at $50^{\circ} \mathrm{C}$ ) and more positive onset potential (e.g. $0.82 \mathrm{~V}$ vs. ca. $0.57 \mathrm{~V}$ (vs. RHE) at $50^{\circ} \mathrm{C}$ ). It needs even higher onset potentials of 
about 1.2 and $1.3 \mathrm{~V}$ vs. RHE, respectively, for tartronate and mesoxalate adsorption and oxidation on $\mathrm{Au} / \mathrm{C}$ (55 wt.\%). This strongly indicates that desorbed glycerate, tartronate and mesoxalate are difficult to be further oxidized under the fuel cell operation conditions with relatively low anode potentials.

As will be discussed in Chapter 5, the C-C cleavage product glycolate is nearly inert on both $\mathrm{Au}$ smooth polycrystalline and nanoparticle electrodes. Therefore, lowering anode potential and enhancing mass transport using the modified thin electrode structure can promote the tartronate formation by the sequential oxidation of glycerol via adsorbed $\mathrm{C}_{3}$ reactive intermediates, while minimize its over-oxidation to mesoxalate or $\mathrm{C}-\mathrm{C}$ bond cleavage by-products (glycolate and oxalate), leading to the tartronate selectivity increasing from 34\% (Fig. 4.7 (a)) to 49\% (Fig. 4.7 (b)) in 1 h. However, the decreasing of the anode potential weakens the adsorption of glyceraldehyde, a possible unstable byproduct generated at low potential $\left(0.4 \mathrm{~V}\right.$ vs. RHE) ${ }^{94}$ The desorbed glyceraldehyde decomposes in the bulk alkaline electrolyte, which is likely responsible for the lactate detected in the final products profile (Fig. 4.7 (b)). ${ }^{91}$
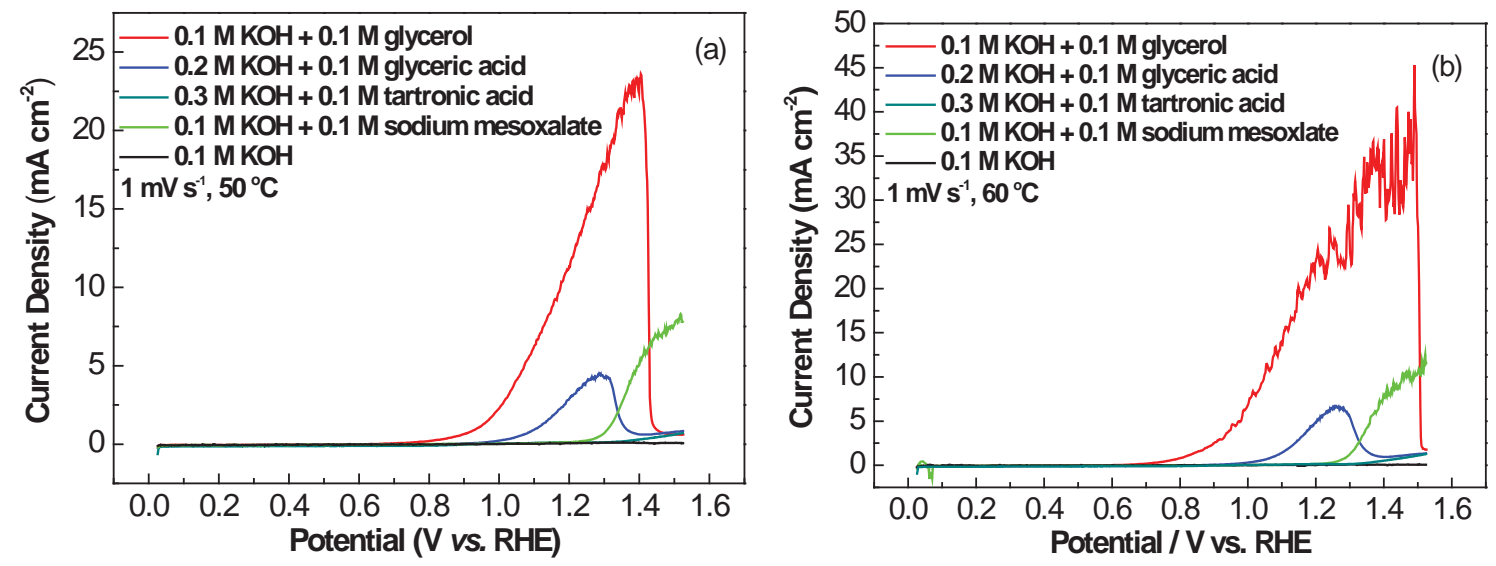

Fig. 4.8 Linear sweep voltammograms of $\mathrm{Au} / \mathrm{C}(55$ wt.\%) in $0.1 \mathrm{M} \mathrm{KOH}+0.1 \mathrm{M}$ glycerol, 0.2 M KOH +0.1 M glyceric acid, 0.3 M KOH +0.1 M tartronic acid, $0.1 \mathrm{M}$ $\mathrm{KOH}+0.1 \mathrm{M}$ sodium mesoxalate salt and $0.1 \mathrm{M} \mathrm{KOH}$ at a scan rate of $1 \mathrm{mV} \mathrm{s}^{-1}$, without rotation, (a) $50^{\circ} \mathrm{C}$, (b) $60^{\circ} \mathrm{C}$.

Glycerol fuel flow rate for the AEM-DGFC reactor was also optimized to study its effect on the reaction rate and product distribution of glycerol electro-oxidation. Under 
similar reaction conditions, the liquid flow rate was decreased from $4 \mathrm{ml} \mathrm{min}^{-1}$ to $1 \mathrm{ml}$ $\min ^{-1}$ and the results are shown in Fig. 4.7 (b) and (c). After slowing down the flow rate of $2.0 \mathrm{M} \mathrm{KOH}+1.0 \mathrm{M}$ glycerol, it is observed that the glycerol conversion drops from $14.7 \%$ to $11.5 \%$, which could also be attributed to the more intimate contact between the reaction intermediates and catalyst confined within the porous electrode through lowering the fuel flow rate. Although the fuel flow rate has a minor effect on the anode potential, the increasing of the retention time can help hold/trap the reaction intermediates within the porous matrix of the anode, therefore, glyceraldehyde is more likely to remain chemisorbed at the surface and under goes consequential oxidation to mesoxalate. This is evidenced by the mesoxalate selectivity increasing from $10 \%$ to $13 \%$ and the selectivity of the glyceraldehyde degraded by-product lactate decreasing from $6.0 \%$ to $2.6 \%$.

In order to gain insight into the influence of reaction temperature on electro-oxidation of glycerol, cyclic voltammetry was performed on $\mathrm{Au} / \mathrm{C}$ (55 wt.\%) catalyst in blank $0.1 \mathrm{M}$ $\mathrm{KOH}$ at 25,50 , and $60^{\circ} \mathrm{C}$. It is shown in Fig. 4.9 that with the temperature increasing, the onset potential where $\mathrm{Au}$ starts to adsorb $\mathrm{OH}^{-}$shifts negatively, and within the potential window investigated ( $<1.65 \mathrm{~V}$ vs. RHE), the OER activity on $\mathrm{Au} / \mathrm{C}(55 \mathrm{wt} . \%)$ is negligible at 25,50 , and $60^{\circ} \mathrm{C}$. Early studies suggested that the presence of the submonolayer of the adsorbed $\mathrm{OH}$ governs the catalytic behavior of $\mathrm{Au}$ for alcohol oxidation, ${ }^{142}$ and there is no glycerol adsorption before the onset potential of $\mathrm{Au}(\mathrm{OH})$ formation. ${ }^{91}$ The DFT results also indicated that the adsorbed $\mathrm{OH}$ will significantly lower the activation barrier for both $\mathrm{O}-\mathrm{H}$ and $\mathrm{C}-\mathrm{H}$ bond dissociation and enhance the catalytic activity of $\mathrm{Au}:{ }^{54}$

$$
\begin{gathered}
H_{\beta} R-O H_{\alpha}+O H_{a d s} \rightleftarrows H_{\beta} R-O_{a d s}+H_{2} O \\
H_{\beta} R-O H_{\alpha}+O H_{a d s} \rightleftarrows R=O_{a d s}+H_{2} O
\end{gathered}
$$

In Chapter 3, it was shown that the onset potential of the glycerol electro-oxidation on $\mathrm{Au} / \mathrm{C}(40 \mathrm{wt} . \%)$ in half cell shifts negatively, as the reaction temperature increases from $25^{\circ} \mathrm{C}$ to $60^{\circ} \mathrm{C}$, which could be attributed to the higher adsorption rate of $\mathrm{OH}^{-}$on $\mathrm{Au}$ at elevated temperatures. (Fig. 3.6 (c)) In addition, the reported voltammograms also 
indicated better electro-oxidation kinetics was achieved at higher temperatures, as shown by the increasing of the peak current density. In agreement with these prior results, it is observed that the AEM-DGFCs operated at higher temperature $\left(60^{\circ} \mathrm{C}\right)$ promotes the glycerol conversion from $11.5 \%$ (Fig. $4.7\left(\right.$ c), $50^{\circ} \mathrm{C}$ ) to13.5\% (Fig. $4.7\left(\right.$ d), $\left.60^{\circ} \mathrm{C}\right)$ in $1 \mathrm{~h}$. Moreover, it further decreases the anode potential from $0.40 \mathrm{~V}$ to $0.35 \mathrm{~V}$ vs. RHE, contributing to the increasing of tartronate selectivity to $54.8 \%$. On the other hand, the elevated reaction temperature may also promote the reaction intermediates diffusion to the bulk electrolyte, which prevents the further oxidation to mesoxalate, leading to the drop of mesoxalate selectivity from $13.0 \%$ to $9.4 \%$. The by-product lactate selectivity remains small $(2.3 \%)$, mainly due to the rapid oxidation of glycerol to glycerate via glyceraldehyde at the higher temperature.

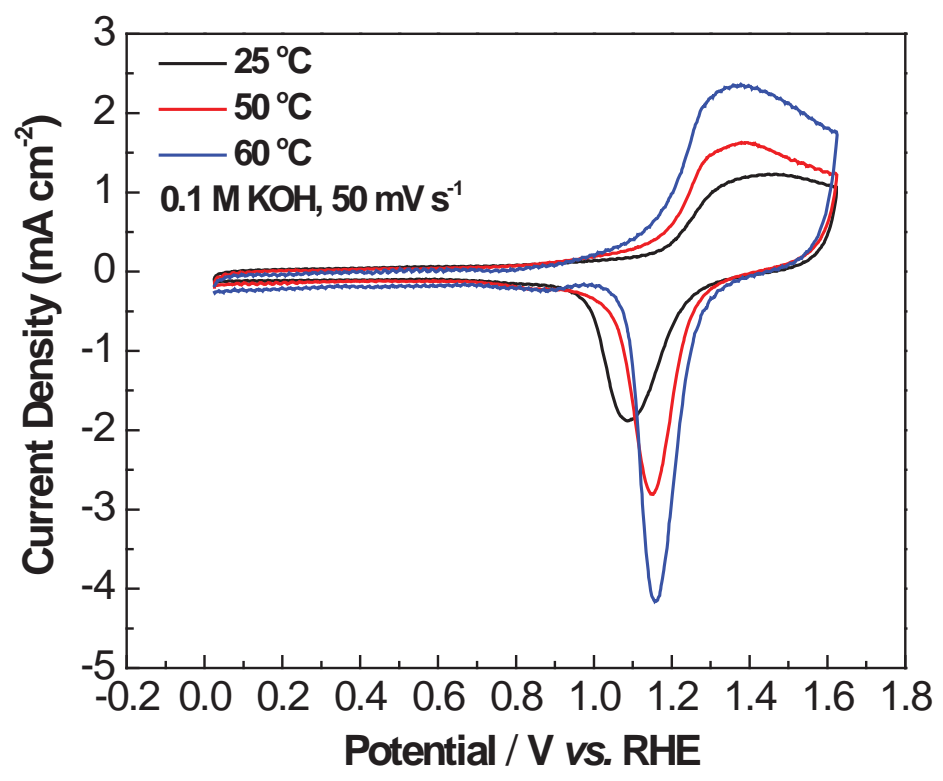

Fig. 4.9 $\mathrm{CVs}$ of $\mathrm{Au} / \mathrm{C}(55 \mathrm{wt} . \%)$ in $0.1 \mathrm{M} \mathrm{KOH}$ at 25,50 , or $60^{\circ} \mathrm{C}$, at a scan rate of 50 $\mathrm{mV} \mathrm{s}^{-1}$, without rotation.

High $\mathrm{pH}$ alkaline environment has been reported to effectively improve glycerol electrooxidation rate. ${ }^{53,76,90,92,143}$ The AEM-DGFCs fed with $8.0 \mathrm{M} \mathrm{KOH}+1.0 \mathrm{M}$ glycerol shows appreciably increasing of the tartronate selectivity from $54.8 \%$ to $70.6 \%$ and the glycerol conversion from $13.5 \%$ to $18.2 \%$ when compared to2.0 $\mathrm{M} \mathrm{KOH}+1.0 \mathrm{M}$ glycerol (Fig. 4-7 (e)). Higher $\mathrm{OH}^{-}$concentration was reported to benefit the initial base- 
catalyzed dehydrogenation of alcohol to promote the generation of highly reactive alkoxy intermediate by lowering the activation barrier: ${ }^{91}$

$$
H_{\beta} R-O H_{\alpha}+O H^{-} \rightleftarrows H_{\beta} R-O^{-}+H_{2} O \rightleftarrows H_{\beta} R-O_{a d s}+e^{-}
$$

On the other hand, higher $\mathrm{OH}^{-}$concentration in the bulk electrolyte will increase $\mathrm{OH}_{\text {ads }}$ coverage rate on $\mathrm{Au}$ surface. As aforementioned, the $\mathrm{OH}_{\text {ads }}$ will also facilitate the elimination of both $\mathrm{H}_{\alpha}$ and $\mathrm{H}_{\beta}$ of adsorbed alcohols through the metal surface catalyzed process (Equation 4-8 and 4-9). As a result, the electrolyte with higher pH $(8.0 \mathrm{M} \mathrm{KOH}$ $+1.0 \mathrm{M}$ glycerol) greatly enhances the reaction rate, giving rise to the observed higher glycerol conversion and lower anode potential ( $0.29 \mathrm{~V}$ vs. RHE). This result can be supported by my previous collaborative studies of electro-oxidation of glycerol over $\mathrm{Au} / \mathrm{C}(40 \mathrm{wt} . \%)$ in half cell, which showed that the onset potential of glycerol oxidation shifted negatively with the $\mathrm{KOH}$ concentration increasing. ${ }^{90}$ The very low anode potential favors the tartronate formation with a selectivity of $70.6 \%$ determined by HPLC analysis. A slight increase of lactate could be also attributed to this low anode potential achieved, as it weakens the adsorption of glyceraldehyde on the Au catalyst. Additionally, the increment of $\mathrm{OH}_{\text {ads }}$ on $\mathrm{Au}$ surface promotes the removal of adsorbed $\mathrm{C}_{3}$ intermediate species $^{53,88}$ to form glycerate or tartronate, before they undergo further oxidation to mesoxalate or C-C bond breaking to by-products of glycolate and oxalate. ${ }^{53,88}$

Compared with the traditional heterogeneous catalysis, electro-catalytic selective oxidation of glycerol in the AEM-DGFC reactor is a more sustainable process, in which the valuable chemicals and electrical energy can be simultaneously generated. ${ }^{55}$ The efforts will be focused on employing the optimum conditions, as listed in Table 4.2 (a) and (e), to demonstrate the high activity and selectivity to mesoxalate and high yield to tartronate for potential industrial synthesis applications. 


\subsubsection{Cogeneration of electricity and tartonate with high yield in the continuous flow-type AEM-DGFCs reactor}

The reaction profile shown in Fig. 4.10 exhibits that electro-catalytic selective oxidation of glycerol can achieve a tartronate yield of $61.8 \%(69.3 \%$ of selectivity at $89.2 \%$ glycerol conversion) after $12 \mathrm{~h}$, concurrently with energy release of $1527 \mathrm{~J}$ (constant discharging at $0.1 \mathrm{~V}$ ) in the AEM-DGFC reactor with $\mathrm{Au} / \mathrm{C}(55 \mathrm{wt} \%$ ) under the optimized conditions (Table 4.2 (e)). The maximum yields of tartronate from heterogeneous catalytic oxidation of glycerol have been reported to be $58 \%$ on $\mathrm{Ce}-\mathrm{Bi}-\mathrm{Pd}$ $\mathrm{Pt} / \mathrm{C}^{126}$ and 78\% on $\mathrm{Bi} @ \mathrm{AuPd} / \mathrm{C}^{127}$. However, mono-Au or AuPd, AuPt heterogeneous catalysts were found to be rather inefficient for tartronate production from direct glycerol oxidation $^{19}$. The high tartronate yield on $\mathrm{Au} / \mathrm{C}$ (55 wt.\%) electro-catalyst achieved may open an alternative route to sustainable electro-catalytic conversion of bio-renewable intermediates to chemicals along with electricity cogeneration. 


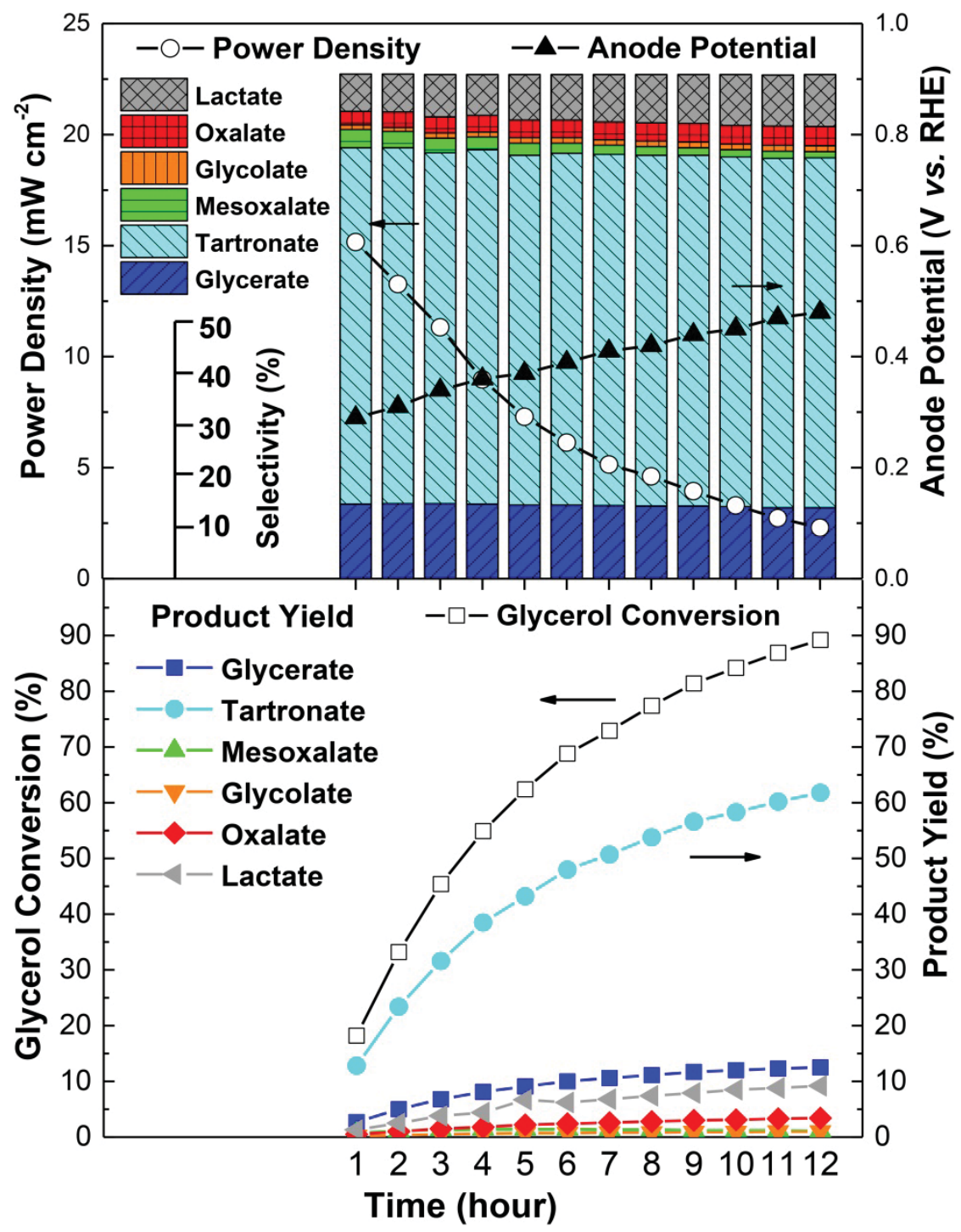

Fig. 4.10 Electro-catalytic selective oxidation of glycerol on $\mathrm{Au} / \mathrm{C}$ (55 wt.\%) in AEMDGFC under optimized condition for high yield of tartronate (Table 4.2 (e)): cell voltage: $0.1 \mathrm{~V}$; reaction time: $12 \mathrm{~h}$.

Fig. 4.10 also shows that as the reaction was prolonged to $12 \mathrm{~h}$, the glycerol conversion reached $89.2 \%$ and the tartronate selectivity only slightly decreased from $70.6 \%$ to $69.3 \%$, even though the anode potential of the AEM-DGFCs kept increasing from $0.29 \mathrm{~V}$ to 0.48 V vs. RHE. This indicates that the final products distribution in bulk electrolyte is governed by both the electro-catalytic reaction at the electrified catalyst-electrolyte interface that can be regulated by the anode potential, and the reactants/reaction intermediates/products diffusion/transport through the catalyst layer. As discussed previously, 
the MEA structure and reaction conditions of AEM-DGFCs were optimized to not only lower the anode potential so as to favor the consecutive oxidation of glycerol to tartronate with less $\mathrm{C}-\mathrm{C}$ bond cleavage or over-oxidation to mesoxalate, but also facilitate desorption of the intermediates/products off the catalytic active sites and diffusion back to the bulk electrolyte.

The LSVs performed on $\mathrm{Au} / \mathrm{C}(55 \mathrm{wt} . \%)$ in half cell at $60^{\circ} \mathrm{C}$ with alkaline electrolytes of glycerate, tartronate, mesoxalate and glycerol are shown in Fig. 4.8 (b). The results showed the electro-catalytic activity sequence of these desorbed glycerate, tartronate and mesoxalate during the glycerol electro-oxidation. Higher anode potential is needed to make them reactive on $\mathrm{Au} / \mathrm{C}$ (55 wt.\%) electrode. In addition, previous studies by Lamy et al. have found that the glycolate and oxalate cannot be oxidized on Au electrode in alkaline solution in the potential range of $0-1.0 \mathrm{~V}$ vs. RHE, which is within the fuel cell anode potential window. ${ }^{142}$ For this reason, the products presented in the bulk electrolyte are more difficult to re-adsorb and further oxidize on the Au catalyst as compared with glycerol, resulting in the relatively stable products distribution in the bulk electrolyte and no apparent change in the product selectivity from $1 \mathrm{~h}$ to $12 \mathrm{~h}$. In particular, the relatively low activity (onset potential and peak current density) of electro-oxidation "desorbed" tartronate may account for its high selectivity.

However, as glycerol was continuously converted, increasing concentrations of glycerate and tartronate will accumulate in the product mixture solution. It is reported that the adsorption of glycerate or tartronate during the glycerol oxidation could strongly deactivate metal catalysts in the heterogeneous catalysis system, which is attributed to the formation of ketonic species. ${ }^{141,144}$ To investigate the influence of the product salts on the rate of glycerol electro-oxidation, equal molar glyceric acid was added to a $0.1 \mathrm{M}$ glycerol solution. Additional $\mathrm{KOH}$ was also added to neutralize the glyceric acid in order to maintain a close base to reactant ratio of around 1:1 (mol: mol). Chronoamperometries (CAs) were carried out on $\mathrm{Au} / \mathrm{C}(55 \mathrm{wt} . \%$ ) at $0.8 \mathrm{~V}$ vs. RHE, where the electro-oxidation proceeds slowly so that the mass transport effect is negligible. Fig. 4.11 (a) shows that the oxidation current density of $0.1 \mathrm{M}$ glycerol remains at $c a .0 .28 \mathrm{~mA} \mathrm{~cm}^{-2}$ after $1800 \mathrm{~s}$ 
test, while with addition of $0.1 \mathrm{M}$ glycerate, it is significantly lower and drops rapidly to $0.014 \mathrm{~mA} \mathrm{~cm}^{-2}$. The controlled CA experiment using $0.2 \mathrm{M} \mathrm{KOH}+0.1 \mathrm{M}$ glyceric acid showed no current generation on $\mathrm{Au} / \mathrm{C}(55 \mathrm{wt} . \%)$ under the same test conditions, which suggests that the decreased reaction rate is not due to the competitive electro-oxidation of glycerate, but rather due to the inhibitory effect of glycerate. It is worth to mention that the adsorbed glycerate could be washed off with copious deionized water and the active sites of $\mathrm{Au} / \mathrm{C}$ (55 wt.\%) can be recovered, as evidenced by the similar broad peaks correlated to the reduction of $\mathrm{AuO}_{\mathrm{x}}$ during the cyclic voltammetry in $1.0 \mathrm{M} \mathrm{KOH}$ before and after CV tests (Fig. 4.11 (b)). The mechanism of the inhibition of supported metal catalysts by reaction intermediates/products formed in the course of the electro-oxidation of glycerol is still elusive and currently under study. Nevertheless, the deactivation of $\mathrm{Au} / \mathrm{C}$ (55 wt.\%) will cause the activity loss of the glycerol electro-oxidation and is responsible for the increasing of the anode potential in AEM-DGFCs with the elongated reaction time, as shown in Fig. 4.10. As a result of anode potential increasing, the selectivites to $\mathrm{C}-\mathrm{C}$ cleavage products glycolate and oxalate, were increased from $0.8 \%$ (after $1 \mathrm{~h}$ ) to $1.2 \%$ (after $12 \mathrm{~h}$ ) and $2.5 \%$ (after $1 \mathrm{~h}$ ) to $3.8 \%$ (after $12 \mathrm{~h}$ ), respectively. 

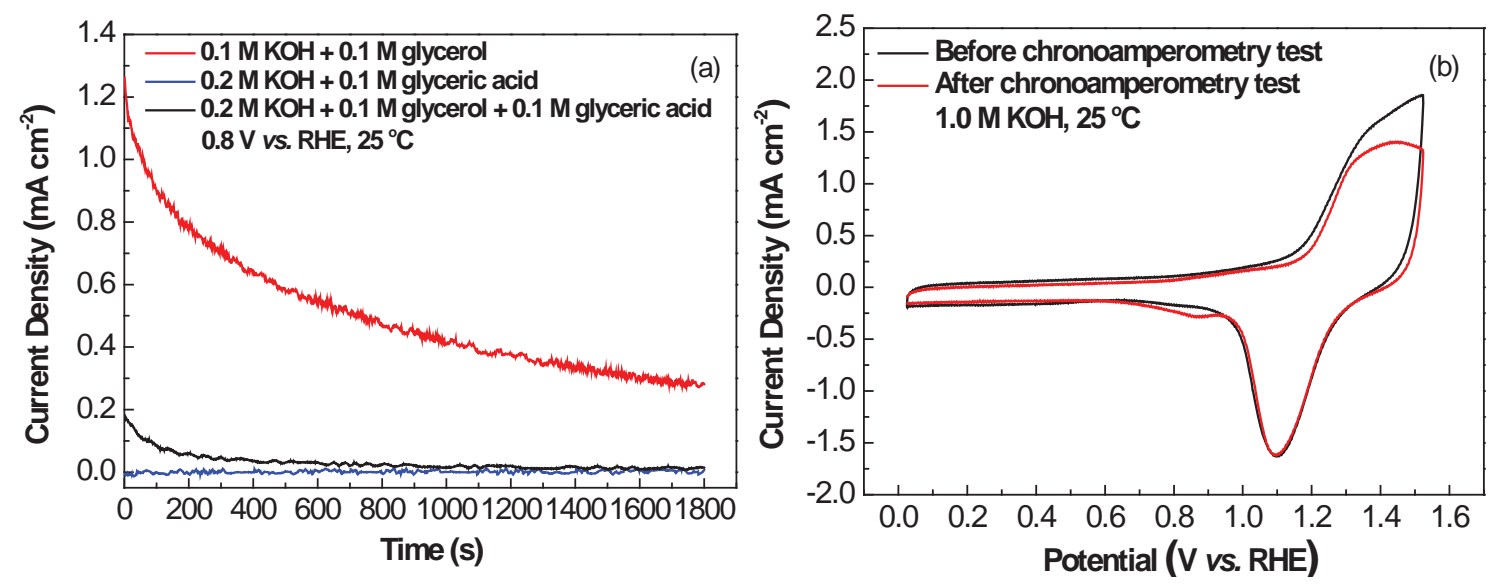

Fig. 4.11 (a) Influence of glycerate on the chronoameperometric activity of glycerol oxidation on $\mathrm{Au} / \mathrm{C}(55 \mathrm{wt} . \%)$ at $0.8 \mathrm{~V}$ vs. RHE, $25^{\circ} \mathrm{C}$; (b) cyclic voltammograms of $\mathrm{Au} / \mathrm{C}$ (55 wt.\%) before and after chronoamperometry tests with the addition of glyceric acid, used $\mathrm{Au} / \mathrm{C}(55 \mathrm{wt} . \%)$ catalyst was washed with deionized water before there cycle test, $1.0 \mathrm{M} \mathrm{KOH}, 25^{\circ} \mathrm{C}$.

\subsubsection{Cogeneration of electricity and mesoxalate with high selectivity in the continuous flow-type AEM-DGFCs reactor}

In light of the reaction condition in Table 4.2 (a), the electro-catalytic selective oxidation of glycerol aiming at cogeneration of electricity and mesoxalate was conducted by continuously looping $2.0 \mathrm{M} \mathrm{KOH}+1.0 \mathrm{M}$ glycerol from a plastic vessel into the anode compartment of an AEM-DGFC reactor for $2 \mathrm{~h}$, at $50^{\circ} \mathrm{C}$.

A constant fuel cell voltage $(0.5,0.3$, or $0.1 \mathrm{~V})$ was applied by controlling the outer circuit resistance and electricity was simultaneously generated. Fig. 4.12 (a) shows the glycerol oxidation product distribution and electricity-generation performance on an $\mathrm{Au} / \mathrm{C}$ (40 wt.\%) anode with a loading of $1.0 \mathrm{mg}_{\mathrm{Au}} \mathrm{cm}^{-2}$. During the oxidation, the average anode potentials were monitored by using an $\mathrm{Hg} / \mathrm{HgO}$ electrode and the values (reported vs. RHE) are given in parentheses (Fig. 4.12) with their corresponding fuel cell operating voltages. Fig. 4.12 (a) and Table 4.3 show that the selectivity for mesoxalate was well controlled by the fuel cell operating voltage (anode potentials): At $0.5 \mathrm{~V}$, which was close to the OCV, the anode potential was $0.47 \mathrm{~V}$ vs. RHE, and no mesoxalate was detected. Instead, selectivities of 26,49 , and $25 \%$ were obtained for glycerate, tartronate, and 
oxalate, respectively, with $3.5 \%$ glycerol conversion, which agrees very well with the results from AEM based electrolysis cell where a switch potential of $0.45 \mathrm{~V}$ vs. RHE was required for the conversion of glycerol to mesoxalate on $\mathrm{Au} / \mathrm{C}$ (40 wt.\%). When the fuel cell operating voltage was decreased to $0.3 \mathrm{~V}$, the anode potential increased to $0.51 \mathrm{~V}$ vs. RHE and mesoxalate was appeared in the final mixture of products with a selectivity of $19 \%$ at $7.4 \%$ glycerol conversion. Moreover, electricity was generated with a peak power density of $14.8 \mathrm{~mW} \mathrm{~cm}^{-2}$. The yield of mesoxalate seemed to suppress the selectivity for tartronate from $49 \%$ to $39 \%$. When the fuel cell voltage was further decreased to $0.1 \mathrm{~V}$, which was sufficiently low to approach the limiting current density during the steady state discharging, the anode potential increased to $0.58 \mathrm{~V}$ vs. RHE and lower selectivity of mesoxalate (12\%) was observed. Under the higher anode potential ( $0.58 \mathrm{~V}$ vs. RHE), glycerol conversion within $2 \mathrm{~h}$ ramped up to $20 \%$ and a small amount of glycolate (3\%) was yielded. At a cell voltage of $0.1 \mathrm{~V}$, the anode potential gradually increased in the course of the reaction owing to the continuous consumption of glycerol, while at higher fuel cell operating voltages $(0.5$ and $0.3 \mathrm{~V})$ where the monitor anode potential is relatively low compared to that at $0.1 \mathrm{~V}$, the glycerol consumption was $<7.4 \%$, which affects the anode potential to a lesser extent. Thus, the anode potentials that were monitored at higher cell voltages were quite stable with minor variations. 

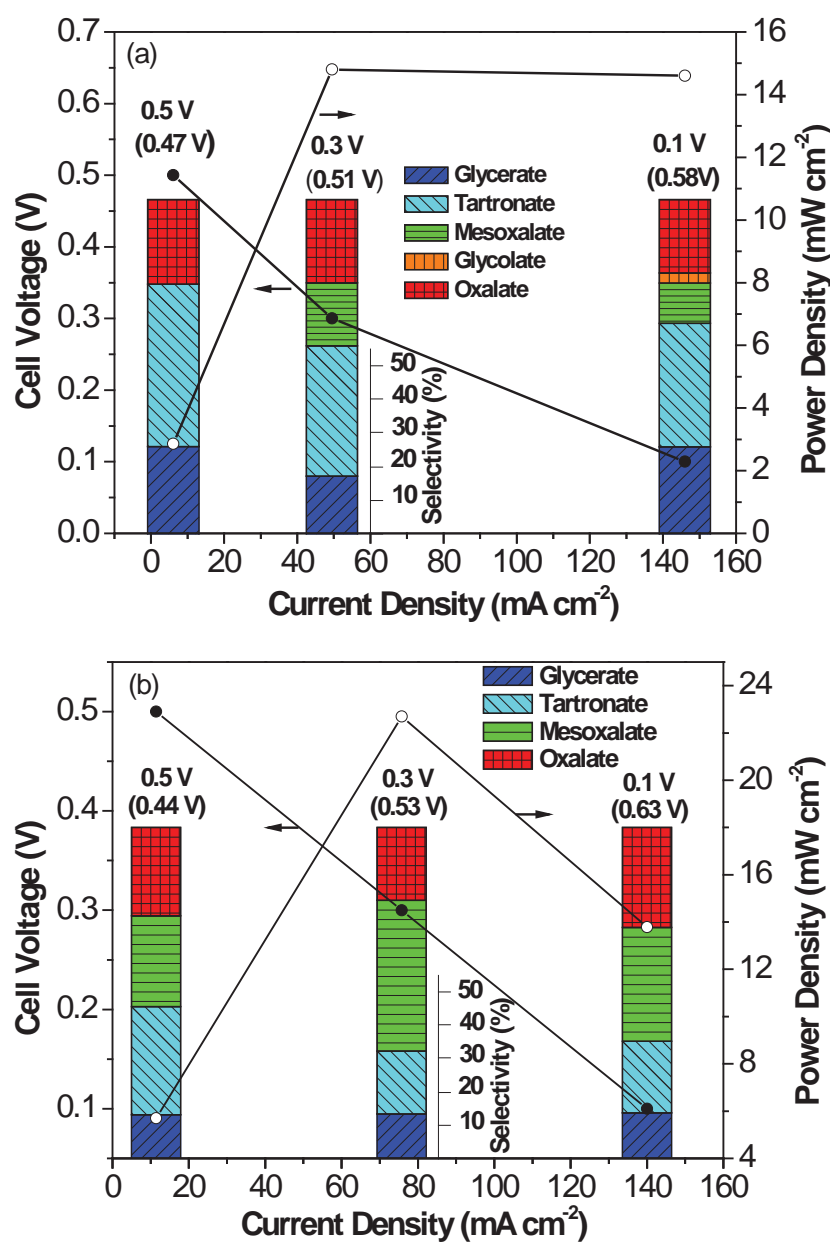

Fig. 4.12 Product selectivity and the generation of electricity from electro-catalytic selective oxidation of glycerol on (a) $\mathrm{Au} / \mathrm{C}$ (40 wt.\%), $1.0 \mathrm{mg}_{\mathrm{Au}} \mathrm{cm}^{-2}$, and (b) $\mathrm{Au} / \mathrm{C}$ (40 wt.\%), $5.0 \mathrm{mg}_{\mathrm{Au}} \mathrm{cm}^{-2}$ in AEM-DGFC reactors, $50{ }^{\circ} \mathrm{C}$, reaction time: $2 \mathrm{~h}$.

Table 4.3 Electrocatalytic selective oxidation of glycerol on Au/C (40 wt.\%) in AEMDGFC reactors at different fuel cell operation voltages.

\begin{tabular}{|c|c|c|c|c|c|c|c|c|c|c|}
\hline \multirow{2}{*}{$\begin{array}{c}\text { Anode } \\
\text { Catalyst }\end{array}$} & \multirow{2}{*}{$\begin{array}{c}\text { Cell } \\
\text { Voltage } \\
\text { / V }\end{array}$} & \multirow{2}{*}{$\begin{array}{l}\text { Anode } \\
\text { potential } \\
\text { / V vs. } \\
\text { RHE }\end{array}$} & \multicolumn{5}{|c|}{ Selectivity / \% } & \multirow{2}{*}{$\begin{array}{c}\text { Glycerol } \\
\text { Conversion } \\
/ \%\end{array}$} & \multirow{2}{*}{$\begin{array}{c}\text { Carbon } \\
\text { Balance } \\
/ \%\end{array}$} & \multirow{2}{*}{$\begin{array}{c}\text { Power } \\
\text { Density } \\
/ \mathrm{mW} \mathrm{cm}^{-2}\end{array}$} \\
\hline & & & GA & TA & MA & GLA & $\mathrm{OA}$ & & & \\
\hline \multirow{3}{*}{$\begin{array}{c}\mathrm{Au} / \mathrm{C}(40 \\
\text { wt. } \%) \\
1.0 \mathrm{mg}_{\mathrm{Au}} \mathrm{cm}^{-2} \\
\end{array}$} & 0.5 & 0.47 & 26 & 49 & 0 & 0 & 25 & 3.5 & 0.43 & 2.9 \\
\hline & 0.3 & 0.51 & 17 & 39 & 19 & 0 & 25 & 7.4 & 0.51 & 14.8 \\
\hline & 0.1 & 0.58 & 26 & 37 & 12 & 3 & 22 & 20.0 & 0.78 & 14.6 \\
\hline \multirow{3}{*}{$\begin{array}{c}\mathrm{Au} / \mathrm{C}(40 \\
\text { wt. } \%) \\
5.0 \mathrm{mg}_{\mathrm{Au}} \mathrm{cm}^{-2}\end{array}$} & 05 & 045 & 13 & 32 & 28 & 0 & 27 & 32 & 12 & 57 \\
\hline & 0.3 & 0.53 & 13 & 19 & 46 & 0 & 22 & 7.2 & 2.0 & 22.7 \\
\hline & 0.1 & 0.63 & 14 & 22 & 34 & 0 & 30 & 12.5 & 0.4 & 13.8 \\
\hline
\end{tabular}


To further investigate the effects of reaction time, and the corresponding increase in anode potential, on mesoxalate selectivity, the reaction time was prolonged to $6 \mathrm{~h}$. The same reaction conditions were used Table 4.2 (a) at the fuel cell operating voltage of 0.1 $\mathrm{V}$. The anode potential increased from $0.50 \mathrm{~V}$ vs. RHE at $30 \mathrm{~min}$ to $0.63 \mathrm{~V}$ vs. RHE over the $6 \mathrm{~h}$ reaction, as shown in Fig. 4.13 (a). As a result, the initial selectivity for mesoxalate $(22 \%)$ could not be maintained. The concentration of mesoxalate decreased after $2 \mathrm{~h}$, thereby leading to the drop in selectivity (Fig. 4.13 (b)), whilst the concentrations of tartronate, glycolate and oxalate gradually increased, with a corresponding increase in their selectivity. These results confirmed that the oxidation of glycerol into deeper-oxidized mesoxalate underwent a metal-surface-catalyzed step, as proposed by Davis et al. ${ }^{54,117}$ In electrolysis, this step would be enhanced on a polarized $\mathrm{Au}$ surface. Herein, the degree of positive polarization on $\mathrm{Au}$ increased as the anode potential increased, which promoted the formation of tartronate from the oxidation of glycerate. Tartronate is an important intermediate that is directly oxidized into mesoxalate. ${ }^{128}$ This process was favored within a mild anode potential range on $\mathrm{Au} / \mathrm{C}$. It is suggested that the formation of mesoxalate was accompanied by its decarboxylation into oxalate, as supported by the studies in electrolysis cell reactor (Fig. 4.2), which could be accelerated at higher anode potentials. The accumulation of glycolate presumably resulted from the $\mathrm{C}-\mathrm{C}$ bond cleavage of glycerate at higher anode potentials. In sharp contrast to $\mathrm{Au} / \mathrm{C}$, my previous collaborative work has demonstrated that $\mathrm{Pt} / \mathrm{C}$ catalyzes glycerol electro-oxidation more actively, generating higher peak power density while yielding more $\mathrm{C}-\mathrm{C}$ bond breaking $\mathrm{C}_{2}$ and $\mathrm{C}_{1}$ product (glycolate, oxalate, formate and carbonate). The different electro-catalytic activities between $\mathrm{Pt}$ and $\mathrm{Au}$ were attributed to binding energy between metal catalysts and the hydroxyl and oxygenated functional groups. $^{76}$ 

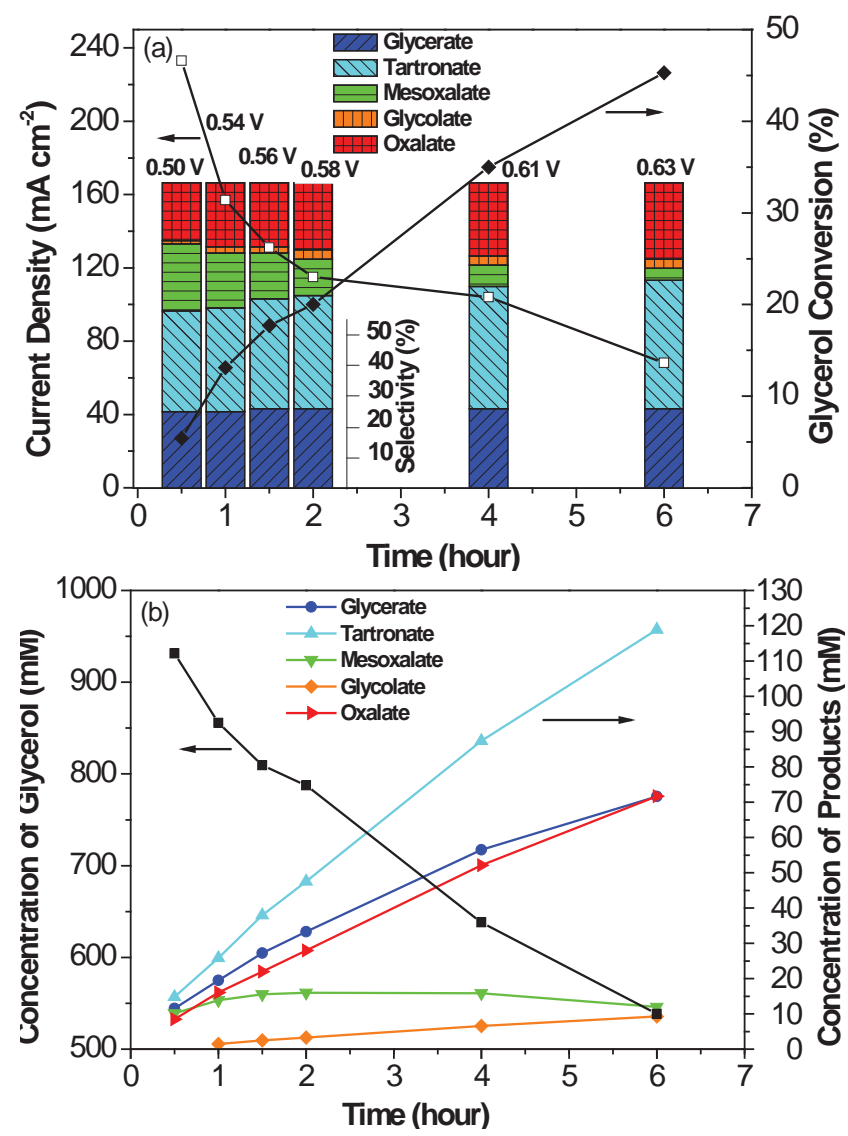

Fig. 4.13 (a) Product selectivity and electricity generation, and (b) products and glycerol concentrations from electro-catalytic selective oxidation of glycerol on $\mathrm{Au} / \mathrm{C}$ (40 wt.\%) from 0.5 to 6 hours in AEM-DGFC reactor, $50^{\circ} \mathrm{C}$. The cell operation voltage was set at $0.1 \mathrm{~V}$.

Interestingly, when the loading of $\mathrm{Au} / \mathrm{C}(40 \mathrm{wt} . \%)$ anode was increased to $5.0 \mathrm{mg}_{\mathrm{Au}} \mathrm{cm}^{-}$ ${ }^{2}$, considerable higher selectivity to mesoxalate (46\%) with a glycerol conversion of $7.2 \%$ was obtained along with an output peak power density of $22.7 \mathrm{~mW} \mathrm{~cm}^{-2}$ at fuel cell voltage of $0.3 \mathrm{~V}$. Glycerol conversions on both the Au-loaded anodes $\left(1.0 \mathrm{mg} \mathrm{cm}^{-2}\right.$ and $5.0 \mathrm{mg} \mathrm{cm}{ }^{-2}$ ) were comparable at each cell voltage studied; however, different product distributions were observed. Compared with the anode with $1.0 \mathrm{mg}_{\mathrm{Au}} \mathrm{cm}^{-2}$, the selectivity to mesoxalate by using the anode with $5.0 \mathrm{mg}_{\mathrm{Au}} \mathrm{cm}^{-2}$ increased significantly (from $0 \%$ to $28 \%$ ) at $0.5 \mathrm{~V}$, whilst the selectivity for tartronate dropped from $49 \%$ to $32 \%$. As the cell potential was further lowered to $0.3 \mathrm{~V}$, a significant amount of mesoxalate was produced with a selectivity of $46 \%$, whilst the selectivity for tartronate dropped to $19 \%$. These 
results indicated that the production of mesoxalate in this AEM-DGFC reactor might follow a sequential oxidation process starting from glycerol, that is, glycerol $\rightarrow$ glycerate $\rightarrow$ tartronate $\rightarrow$ mesoxalate, which has been demonstrated in heterogeneous catalysis systems in low-pH media. ${ }^{128,145}$ A very high mesoxalate achieved was resulted from that the increasing of the anode electrode thickness allows more glycerate and tartonate that are the important intermediates preceding the production of mesoxalate retain inside the active Au porous matrix, therefore, provided with the suitable anode potential $(0.53 \mathrm{~V}$ vs. RHE, as shown in Fig. 4.12 (b)), the selectivity of $46 \%$ for mesoxalate in the AEMDGFC reactor is expected.

It also indicated that the average selectivity of each reaction intermediate (glycerate or tartronate) should exceed $77 \%$ ! However, further decreasing the cell potential to $0.1 \mathrm{~V}$ led to a decrease in the selectivity for mesoxalate, but an increase in the selectivity for oxalate. Compared to the anode with $1.0 \mathrm{mg}_{\mathrm{Au}} \mathrm{cm}^{-2}$, no glycolate was observed with 5.0 $\mathrm{mg}_{\mathrm{Au}} \mathrm{cm}^{-2}$ at the anode, which indicated that high Au loading (glycerol to Au: 1: 6500 mol : mol) favored the oxidation of the $\mathrm{C}_{3}$ hydroxyl groups without breaking their $\mathrm{C}-\mathrm{C}$ bonds. We also observed that the carbon balance remained within $2.0 \%$ (Table 4.3) by using the anode with $5.0 \mathrm{mg}_{\mathrm{Au}} \mathrm{cm}^{-2}$, thereby suggesting that, despite large amounts of fully oxidized $\mathrm{C}_{3}$ product (mesoxalate) being produced, negligible quantities of $\mathrm{C}_{2}$ products were broken into $\mathrm{C}_{1}$ products. The higher yield of mesoxalate would also result in a higher Faradaic efficiency of the fuel cell and greater utilization of glycerol fuel.

The stability of the $\mathrm{Au} / \mathrm{C}$ (40 wt.\%) anode AEM-DGFC reactor was investigated over 10 runs with an operation time of $2 \mathrm{~h}$ for glycerol oxidation with $2.0 \mathrm{M} \mathrm{KOH}+1.0 \mathrm{M}$ glycerol under the same test conditions (Fig. 4.14). The anode catalyst loading was maintained at $5.0 \mathrm{mg}_{\mathrm{Au}} \mathrm{cm}^{-2}$, whilst the cathode catalyst loading was increased to $2.0 \mathrm{mg}$ $\mathrm{cm}^{-2}$ to minimize the effect of the loss of catalytic activity. The fuel-cell operating voltage was fixed at $0.3 \mathrm{~V}$, at which the $\mathrm{Au} / \mathrm{C}$ anode AEM-DGFC generated the highest selectivity for mesoxalate, as well as the highest power density. After each run, the anode was cleaned by flushing with deionized water until the OCV was $<0.01 \mathrm{~V}$. The glycerol conversion and selectivity for mesoxalate increased to $10 \%$ and $49 \%$, respectively, 
presumably owing to the increase in catalyst loading at the cathode (Fig. 4.14). The selectivity for each product remained almost constant over the 10 runs, thereby indicating that the catalytic activity and selectivity on $\mathrm{Au} / \mathrm{C}(40 \mathrm{wt} . \%)$ was stable over repeated cycles. Meanwhile, the $\mathrm{Au} / \mathrm{C}$ (40 wt.\%) anode also showed good stability against deactivation; the glycerol conversion stabilized at about $10 \%$ and the power density remained steady at about $27.6 \mathrm{~mW} \mathrm{~cm}^{-2}$. The internal resistances during the reactions were stable at about $142 \Omega \mathrm{m} \mathrm{cm}^{2}$, as shown in Fig. 4.15, thus indicating that no structural changes of either the anode or cathode catalyst electrode occurred, and no decomposition of the AEM occurred, even after 10 runs (a total operation time of $20 \mathrm{~h}$ ).

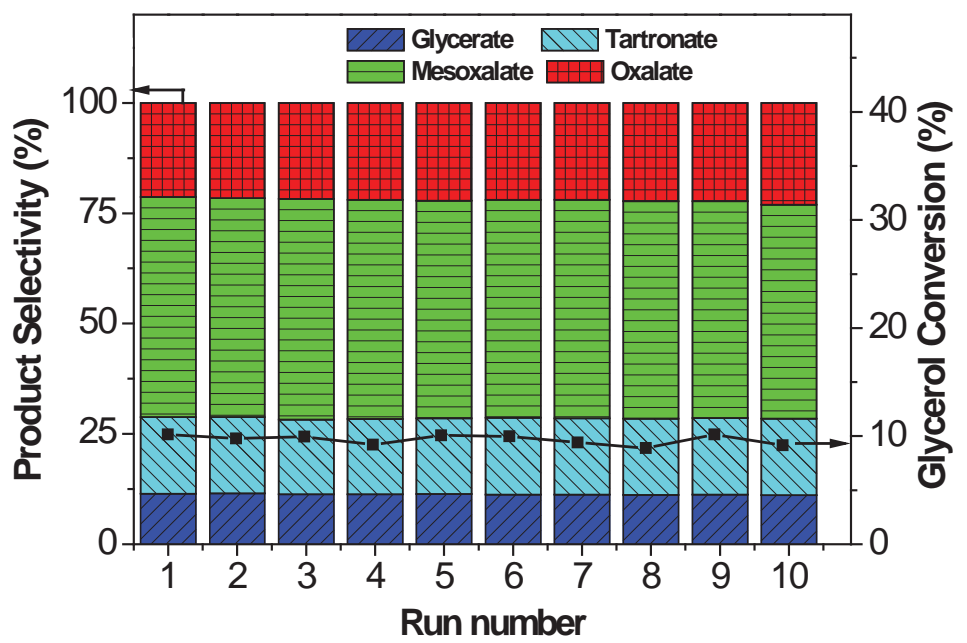

Fig. 4.14 Stability test of Au/C (40 wt.\%) anode AEM-DGFC with $2.0 \mathrm{M} \mathrm{KOH}+1.0 \mathrm{M}$ glycerol at the cell operation voltage of $0.3 \mathrm{~V}$ and $50^{\circ} \mathrm{C}$. Anode catalyst loading: $5.0 \mathrm{mg}_{\mathrm{Au}}$ $\mathrm{cm}^{-2}$; cathode catalyst loading: $2.0 \mathrm{mg} \mathrm{cm}^{-2}$. 


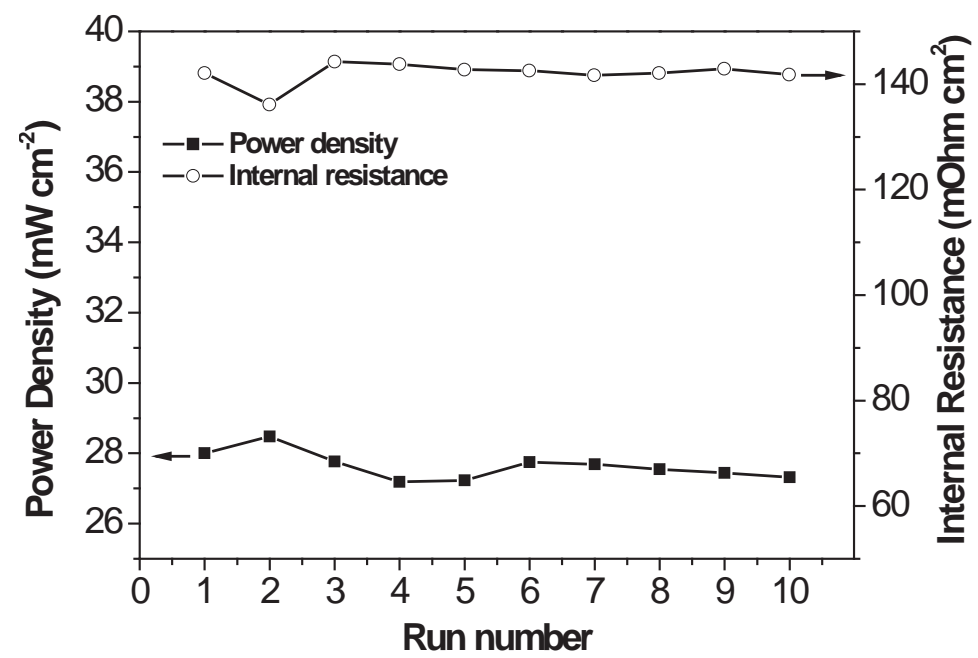

Fig. 4.15 Power density and internal resistance plots in AEM-DGFC with 2.0 M KOH + 1.0 M glycerol during the stability test. Conditions: Anode: $5.0 \mathrm{mg}_{\mathrm{Au}} \mathrm{cm}^{-2}$; Cathode: 2.0 $\mathrm{mg} \mathrm{cm}{ }^{-2}$; Run time: 2 hours, 10 runs; Fuel cell operation voltage: $0.3 \mathrm{~V} ; 50^{\circ} \mathrm{C}$.

\subsection{Conclusions}

Electro-catalytic selective oxidation of glycerol over Au nanoparticle catalysts to tartronate with a high yield of $61.8 \%$ with cogeneration of electrical energy of $1527 \mathrm{~J}$ for $12 \mathrm{~h}$ or to mesoxalate of a high selectivity of $46 \%$ for $2 \mathrm{~h}$ with cogeneration of power density of $22.7 \mathrm{~mW} \mathrm{~cm}^{-2}$ has been achieved in a stable $5 \mathrm{~cm}^{2}$ AEM-DGFC continuous flow reactors. The MEA structure and reaction conditions were found to be able to strongly influence tartronate and mesoxalte selectivity during the glycerol electrooxidation. Rational optimization of the MEA structure, flow rate, oxidation temperature as well as the electrolyte $\mathrm{pH}$ could not only tune the anode potentials to either $<0.45 \mathrm{~V}$ or $\geq 0.45 \mathrm{~V}$ in favor of tartronate and mesoxalate production, respectively, but also improve the mass transport of the reactant and products/intermediates, so as to improve the reaction kinetics and desorption rate of targeted products off the active sites. The half-cell study on electro-oxidation of $\mathrm{C}_{3}$ products (glycerate, tartronate and mesoxalate) shows they are less active than glycerol on $\mathrm{Au} / \mathrm{C}$, therefore, they are not likely to be further oxidized upon diffusion into the bulk electrolyte. Particularly, the lowest electrooxidation activity of both tartronate and mesoxalate may be related with their high selectivity and yield. 


\section{Chapter 5 Electrocatalytic Selective Oxidation of Ethylene Glycol (EG): Reaction Pathway Investigation via On-line Sample Collection System Collected to Three-electrode Half Cells}

\subsection{Background}

Chapter $\mathbf{4}$ has proposed the electrode potential dependent reaction pathway of glycerol electro-oxidation on supported gold catalysts based upon the products identified in the bulk electrolyte away from the catalyst deposited carbon cloth electrode after long term chronoamperometries under various potentials applied. Aiming to elucidate the electrocatalytic reaction sequence, products generated close to the electrode layers of thin porous matrix structure need to be on-line collected in conjunction with electrochemical tests. Herein, ethylene glycol (EG), that is the simplest polyol featuring two primary alcohol groups, was chosen as the model molecule and its selective electro-oxidation on $\mathrm{Au} / \mathrm{C}$ and $\mathrm{Pt} / \mathrm{C}$ was studied.

Compared to methanol fuel, EG has advantages of high volumetric energy density (5.9 $\mathrm{kWh} \mathrm{L}^{-1}$ vs. $4.8 \mathrm{kWh} \mathrm{L}^{-1}$, Table 1.1), high boiling point $\left(197^{\circ} \mathrm{C}\right.$ vs. $\left.65^{\circ} \mathrm{C}\right)$ and low toxicity, which makes it an attractive fuel for DAFCs. ${ }^{35,75,146}$ Additionally, recent studies found that EG can be directly produced from catalytic conversion of biomass-related cellulose with high yields (Fig. 5.1). ${ }^{147,148}$ This provides new opportunities for sustainable widespread applications of direct EG fuel cells (DEGFCs). However, the slow kinetics of

\footnotetext{
*The material contained in this chapter was previously published in Applied Catalysis BEnvironmental 2012;125:85-94: "Electrocatalytic oxidation of ethylene glycol (EG) on supported Pt and Au catalysts in alkaline media: Reaction pathway investigation in threeelectrode cell and fuel cell reactors" by Xin L, Zhang Z, Qi J, Chadderdon D, Li W. Copyright (C) 2013 Elsevier B. V. Reprint with permission shown in Appendix E
} 
electro-oxidation of small alcohols remains a long-standing scientific issue to developing efficient DAFCs. ${ }^{35,149,150} \mathrm{Pt}$ and Au have been investigated as catalysts for the electro-

oxidation of EG for decades, ${ }^{54,151-157}$ and Pt exhibits higher electrocatalytic activity than $\mathrm{Au}$. Furthermore, it has been found that in acid electrolyte, $\mathrm{CO}$ or $\mathrm{CO}-$ like intermediates may strongly adsorb on the active sites of $\mathrm{Pt}$, resulting in catalyst poisoning; while $\mathrm{Au}$ is nearly inactive to EG electro-oxidation in acid media due to its weak adsorption capability. However, when high $\mathrm{pH}$ electrolyte is used, the high concentration of $\mathrm{OH}^{-}$in the electrolyte and adsorbed hydroxyl on the Pt or Au surface are able to greatly facilitate the de-protonation of alcohols, and thus significantly lower the energy barrier of alcohol oxidation reactions. ${ }^{54,91}$ Therefore, the alkaline media can improve the kinetics of EG electro-oxidation on both $\mathrm{Pt}$ and $\mathrm{Au}$, and even make $\mathrm{Au}$ a possible anode catalyst for DEGFCs.

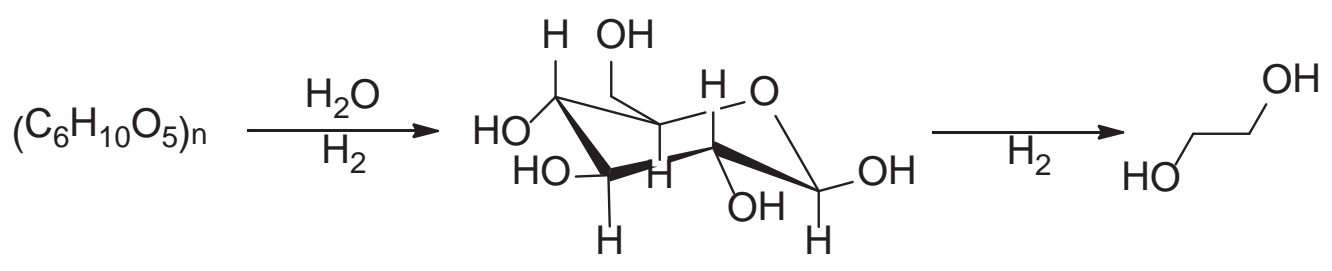

Cellulose

Glucose

Ethylene glycol

Fig. 5.1 Ni- $\mathrm{W}_{2} \mathrm{C} / \mathrm{AC}$ catalyzed conversion of cellulose into polyols. ${ }^{147}$

The electro-oxidation of EG is a complex reaction, involving various successive and parallel pathways. To design efficient anode electrocatalysts for DEGFCs, it is of primary importance to understand the mechanisms of EG electro-oxidation on metal catalysts. A variety of analysis techniques, such as FTIR spectroscopy, ${ }^{158}$ HPLC, ${ }^{156,159}$ and differential electrochemical mass spectrometry (DEMS), ${ }^{160}$ etc. have been developed to analyze the reaction intermediates on catalyst surfaces and/or in liquid electrolyte, thus to investigate the reaction pathways of EG electro-oxidation. With mass-spectroscopic investigation, reaction intermediates/products such as glycolaldehyde, glycolate, glyoxal, glyoxylate, oxalate, formate and $\mathrm{CO}$ were examined on a polycrystalline $\mathrm{Pt}$ electrode during the electro-oxidation of EG in alkaline electrolyte, ${ }^{154}$ while Christensen and coworkers used in situ FTIR spectroscopy to study the electro-oxidation of EG in alkaline 
media and found that glycolate, oxalate and carbonate were the main products on $\mathrm{Pt}$ electrode. ${ }^{153}$ Analyses of the alkaline electrolyte solution after electro-oxidation of EG on $\mathrm{Au}$ electrode were also performed by combining HPLC and FTIR analyses. It was reported that at potentials less than $1.13 \mathrm{~V}$ vs. RHE, glycolate was the only product, whereas at potentials greater than $1.13 \mathrm{~V}$, glycolate could be further oxidized to glyoxylate, oxalate and formate. ${ }^{151,152}$ In addition, Weaver and co-workers proposed the $\mathrm{C}-\mathrm{C}$ bond cleavage on $\mathrm{Pt}$ involved the short-lived surface intermediates, whereas on $\mathrm{Au}$, it occurred involving long-lived solution-phase intermediates. ${ }^{158}$ Based on HPLC analysis results, two parallel pathways were proposed regarding the EG electro-oxidation on Pt in alkaline media: a non-poisoning pathway which yielded oxalate without $\mathrm{C}-\mathrm{C}$ bond scission, and a poisoning pathway which produced adsorbed $\mathrm{CO}$ species via the rupture of $\mathrm{C}-\mathrm{C}$ bond of $\mathrm{C}_{2}$ intermediates. ${ }^{156}$ However, the pathways of EG electro-oxidation on $\mathrm{Pt}$ and $\mathrm{Au}$ in alkaline media are still unclear, in particular, the detailed pathway of $\mathrm{C}-\mathrm{C}$ bond cleavage process. Recently, Koper's group developed an elegant on-line collection offline HPLC analysis system. Combined with electrochemical voltammetry, they investigated the products of electro-oxidation of glycerol and some primary alcohols in situ generated close to the electrode surfaces in liquid electrolyte under accurately controlled potentials, and gained new insights into the oxidation pathways. ${ }^{93,94}$ Currently, there is a clear need to examine the acquired reaction pathways in real fuel cell reactors, so as to help the development of more efficient anode catalysts for DEGFCs.

In this chapter, a self-designed on-line sample collection system, linked to a conventional three-electrode cell setup was employed to study the electrocatalytic selective oxidation of EG. Through a combined study of staircase LSV and cyclic voltammetry on supported $\mathrm{Pt}$ or $\mathrm{Au}$ nanoparticle catalysts $(\mathrm{Pt} / \mathrm{C}$ and $\mathrm{Au} / \mathrm{C})$ in alkaline solution of EG, glycolate, and oxalate, the detailed reaction sequence of EG electrooxidation on $\mathrm{Pt} / \mathrm{C}$ and $\mathrm{Au} / \mathrm{C}$ catalysts in high $\mathrm{pH}$ media was obtained. It further examined the catalytic functions (reactivity and selectivity) of $\mathrm{Pt} / \mathrm{C}$ and $\mathrm{Au} / \mathrm{C}$ anode catalysts in the continuous flow-type AEM-DEGFC reactors, and it was observed that the product distributions from EG electro-oxidation in AEM-DEGFCs are closely consistent with the 
results obtained from the electro-chemical study in the three electrode cell with the online sample collection system.

\subsection{General experimental}

\subsubsection{Preparation of $\mathrm{Au} / \mathrm{C}(40$ wt.\%) and $\mathrm{Pt} / \mathrm{C}(40$ wt.\%)}

The $\mathrm{Au} / \mathrm{C}(40 \mathrm{wt} . \%)$ and Pt/C (40 wt.\%) were synthesized through a modified organic solution-phase reduction method developed in our group. The detail synthesis procedures have been described in Section 2.4.4 and Section 2.4.2.

\subsubsection{Physical characterizations}

The morphology, nanostructure and metal loading of the catalysts were analyzed by TEM, XRD and ICP-OES, as described in Section 2.5.1, 2.5.3 and 2.5.4.

\subsubsection{Electrochemical tests}

\subsubsection{Half-cell tests}

Half-cell tests were performed in a conventional three-electrode-cell setup (Section 2.2.1), equipped with a glassy carbon working electrode, a $\mathrm{Hg} / \mathrm{HgO} / 1.0 \mathrm{M} \mathrm{KOH}$ reference electrode and a Pt coil counter electrode. $2.0 \mathrm{mg} \mathrm{Au} / \mathrm{C}$ or $\mathrm{Pt} / \mathrm{C}(40 \mathrm{wt} . \%)$ was firstly dispersed in $1.0 \mathrm{ml}$ isopropanol by sonication to form uniform ink. Before each test, $20 \mu \mathrm{l}$ of the $2.0 \mathrm{mg} \mathrm{ml}^{-1}$ catalyst ink was drop-casted on the glass carbon electrode, followed by adding $20 \mu \mathrm{l}$ of $0.05 \mathrm{wt} \% \mathrm{AS}-4$ anion conductive ionomer (Tokuyama Corp.) on the top to bind the catalyst particles. (Section 2.3.1)

To investigate the EG oxidation pathways, staircase linear scans with an increment of $100 \mathrm{mV} 10 \mathrm{~min}^{-1}$ were used for 1.0 M KOH + 0.5 M EG, 1.0 M KOH + 0.5 M glycolic acid, and 1.5 $\mathrm{M} \mathrm{KOH}+0.5 \mathrm{M}$ oxalic acid solutions. The instantaneous oxidation products at different potentials were on-line collected through a self-designed needle that was positioned within $0.5 \mathrm{~mm}$ of the center of the working electrode surface. ${ }^{76}$ The needle configurations were cleaned with copious de-ionized water before use. The flow 
rate of sample collection was controlled by a peristaltic pump at $50 \mu 1 \mathrm{~min}^{-1}$. At each potential, $0.5 \mathrm{ml}$ of sample was collected in $10 \mathrm{~min}$ and stored in a $2 \mathrm{ml}$ screw cap vial (Agilent) for HPLC analysis. All voltages were reported with respect to RHE.

\subsubsection{AEM-DEGFC single cell tests}

The AEM-DEGFC tests were performed on the Scribner Fuel Cell System 850e (Section 2.2.3). MEA electrode was fabricated according to Section 2.3.3. The anode catalyst ink was made by mixing water-dispersed 10 wt.\% of PTFE and $\mathrm{Au} / \mathrm{C}$ (or Pt/C) powder. The ink was sprayed onto carbon cloth that was used as the anode LDE with a loading of $1.0 \mathrm{mg}_{\text {metal }} \mathrm{cm}^{-2}$. For the cathode, a commercial non-PGMs HYPERMEC ${ }^{\mathrm{TM}}$ catalyst $\left(\mathrm{Fe}-\mathrm{Cu}-\mathrm{N}_{4} / \mathrm{C}\right.$, Acta) blended with AS-4 anion conductive ionomer (Tokuyama Corp.) was directly sprayed onto the AEM (Tokuyama A201, $28 \mu \mathrm{m}$ ) with a loading of $1.0 \mathrm{mg} \mathrm{cm}{ }^{-2}$. 25CC carbon paper (SGL Group) was applied as the cathode GDL. The MEA was fabricated by mechanically sandwiching the anode, AEM, and cathode together. 1.0 M or 0.1 M EG in 2.0 M KOH was fed into the anode compartment at $4 \mathrm{ml}$

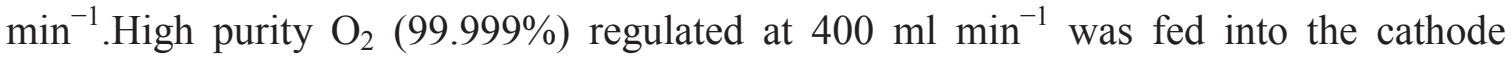
compartment under a back pressure of 30 psi. After the MEA was fully activated by fast operating the voltage from the OCV to $0.1 \mathrm{~V}$ for 30 cycles, the polarization curves of the AEM-DEGFCs were obtained by scanning current and collecting the respective voltage and power density. The studies of electrocatalytic selective oxidation of EG and glycolate were carried out by looping $55 \mathrm{ml}$ of EG or glycolate alkaline electrolyte from a plastic fuel vessel into the anode compartment at $50^{\circ} \mathrm{C}$ and with the same $\mathrm{O}_{2}$ flow rate and back pressure at the cathode compartment. The EG oxidation was performed for $2 \mathrm{~h}$ for each constant voltage. During the tests, the anode potential was monitored by a $\mathrm{Hg} / \mathrm{HgO} / 1.0 \mathrm{M}$ $\mathrm{KOH}$ electrode, and reported with respect to RHE. In the meantime, the current density and power density generated were recorded. The temperatures of anode fuel, cathode humidifier, and fuel cell were kept at $50^{\circ} \mathrm{C}$. Samples were collected after the $2 \mathrm{~h}$ reaction period for HPLC analysis 


\subsubsection{Product analysis}

The glycerol electro-oxidation products were analyzed by HPLC and identified, quantified by comparison with authentic samples (Section 2.7).

The product selectivity and EG conversion are calculated by the following equations:

$$
\begin{gathered}
\text { Selectivity of } C_{2} \text { or } C_{1} \text { product }=\frac{\text { Moles of } C_{2} \text { or } C_{1} \text { product }}{\text { Total moles of } C_{2} \text { and } C_{1} \text { products }} \times 100 \% \\
\text { Conversion of } E G=\left(1-\frac{\text { Concentration of } E G \text { at certain time }}{\text { Initial concentration of } E G}\right) \times 100 \%
\end{gathered}
$$

The carbon balance is based on:

$$
\text { Carbon balance }=\frac{2 M_{E G_{i}}-2 \sum M_{C_{2}}-\sum M_{C_{1}}-2 M_{E G_{f}}}{2 M_{E G_{i}}} \times 100 \%
$$

Assuming that no formate was further oxidized to carbonate $\left(\mathrm{CO}_{2}\right.$ combined with $\mathrm{OH}^{-}$ in high $\mathrm{pH}$ electrolyte), then $\sum M_{C_{2}}=\sum M_{C_{1}}$.

Therefore,

$$
\text { Carbon balance }=\frac{M_{E G_{i}}-\sum M_{C_{2}}-1 / 2 \sum M_{C_{1}}-M_{E G_{f}}}{M_{E G_{i}}} \times 100 \%
$$

where $M_{E G_{i}}$ and $M_{E G_{f}}$ is the initial and final moles of EG in the electrolyte. $\sum M_{C_{2}}$, and $\sum M_{C_{1}}$ are the total moles of $C_{2}$ (glycolate, glyoxylate, oxalate), and $C_{1}$ (formate, carbonate) products, respectively. A smaller carbon balance indicates less formate was further oxidized to carbonate.

\subsection{Results and discussions}

\subsubsection{Physical characterizations}

The XRD patterns of $\mathrm{Pt} / \mathrm{C}$ and $\mathrm{Au} / \mathrm{C}$ catalysts have been shown in Fig. 3.2 and discussed in Section 3.3.1, and both display a typical face-centered cubic (FCC) structure. 
Typical TEM images of $\mathrm{Pt} / \mathrm{C}$ and $\mathrm{Au} / \mathrm{C}$ and their corresponding size histograms have been shown in Fig. 3.3 (a) and (c) and discussed in the Section 3.3.1.

\subsubsection{Electrocatalytic selective oxidation of $\mathrm{EG}$ on $\mathrm{Pt} / \mathrm{C}$ and $\mathrm{Au} / \mathrm{C}$ catalysts in three- electrode cells with an on-line sample collection system}

Fig. 5.2 shows the staircase linear scans for electro-oxidation of $\mathrm{EG}$ on $\mathrm{Pt} / \mathrm{C}$ and $\mathrm{Au} / \mathrm{C}$ in alkaline solution, alongside the products distribution as a function of applied potential. The onset potential of $0.5 \mathrm{M} \mathrm{EG}$ oxidation in $1.0 \mathrm{M} \mathrm{KOH}$ solution on $\mathrm{Pt} / \mathrm{C}$ is $0.3 \mathrm{~V}$ vs. RHE, which is around $400 \mathrm{mV}$ more negative than that on $\mathrm{Au} / \mathrm{C}(0.7 \mathrm{~V}$ vs. RHE). The peak current density obtained on $\mathrm{Pt} / \mathrm{C}\left(38 \mathrm{~mA} \mathrm{~cm}^{-2}\right)$ is also higher than that on $\mathrm{Au} / \mathrm{C}(15$ $\mathrm{mA} \mathrm{cm}{ }^{-2}$ ). As expected, $\mathrm{Pt} / \mathrm{C}$ exhibits a higher activity toward EG oxidation compared with $\mathrm{Au} / \mathrm{C}$ in alkaline media, due to the stronger adsorption of hydroxyl group and better electro-catalytic properties of $\mathrm{Pt}^{88,151}$ Whereas, a reasonable catalytic activity toward EG oxidation on $\mathrm{Au}$ needs a higher applied potential to achieve a sufficient degree of coverage of adsorbed $\mathrm{OH}$ to facilitate the $H_{\beta}$ abstraction. ${ }^{88,91,151}$ It was reported that the $\mathrm{OH}^{-}$adsorption was enhanced in alkaline media, which initiated at $0.4 \mathrm{~V}$ and $0.6 \mathrm{~V}$ vs. RHE on Pt and Au, respectively. ${ }^{88,161}$ This is in good agreement with the onset potential of oxidation of $0.5 \mathrm{M} \mathrm{EG}$ in 1.0 M KOH solution on Pt/C (ca. $0.3 \mathrm{~V}$ vs. RHE) and $\mathrm{Au} / \mathrm{C}$ (ca. 0.7 V vs. RHE), as shown in Fig. 5.2 (a) and (b).

During the staircase linear scans, the instantaneous oxidation products at different potentials were on-line collected through a self-designed needle positioned near the center of $\mathrm{Pt} / \mathrm{C}(\mathrm{Au} / \mathrm{C})$ deposited working electrode, and analyzed by HPLC. Fig. 5.2 (a) shows that on the $\mathrm{Pt} / \mathrm{C}$ catalyst, only glycolate, oxalate and formate were detected as the stable products in liquid electrolyte, which can represent the local products distribution near the working electrode surface during the sweep of the applied potentials. The first observed product, glycolate, was detected since $0.3 \mathrm{~V}$ vs. RHE, which is in agreement with the observed onset potential. This suggests that the on-line sample collection system is able to effectively catch the instant oxidation products generated near the catalyst surfaces. As the potential increases, the concentration of glycolate steeply ramps up until 
$0.9 \mathrm{~V}$ vs. RHE, which corresponds to the potential of peak current density in staircase linear voltammetry. It has been demonstrated that at $c a .0 .85 \mathrm{~V}$ vs. RHE, Pt starts to form surface oxide, which blocks the active sites of $\mathrm{Pt}^{93,94}$ Therefore, the concentration of glycolate, along with the current density in voltammetry, decreases while the potential is higher than $0.9 \mathrm{~V}$ vs. RHE. Oxalate and formate were also observed as products with relatively low concentrations starting from $0.6 \mathrm{~V}$ vs. RHE. The concentration of oxalate reaches its peak at $1.0 \mathrm{~V}$ vs. RHE, and subsequently decreases at higher applied potentials. Interestingly, the concentration of formate first increases slowly until $0.9 \mathrm{~V}$ vs. RHE, where the highest current density is obtained, and then its concentration starts to decrease due to the formation of $\mathrm{PtO}_{\mathrm{x}}$. As the applied potential reaches $1.1 \mathrm{~V}$ vs. RHE, the concentration of formate increases again, and its accelerated increasing from $1.5 \mathrm{~V}$ to $1.7 \mathrm{~V}$ vs. RHE may count for the slight increase in current density.
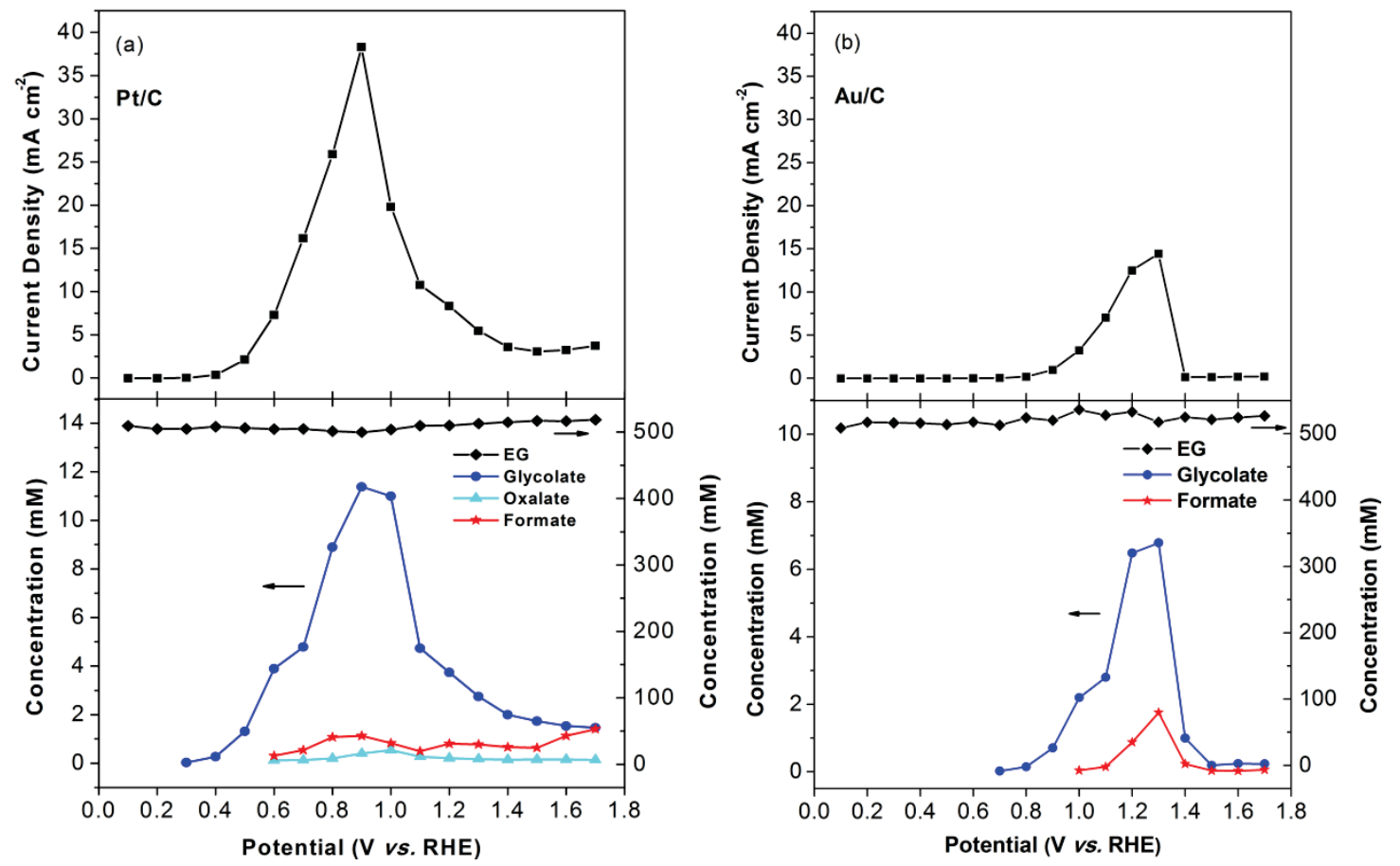

Fig. 5.2 Voltammograms and product concentrations of electrocatalytic selective oxidation of $\mathrm{EG}$ on (a) $\mathrm{Pt} / \mathrm{C}$, (b) $\mathrm{Au} / \mathrm{C}$ in $1.0 \mathrm{M} \mathrm{KOH}+0.5 \mathrm{M} \mathrm{EG}$ in a three-electrode cell with an on-line sample collection system.

Different from Pt/C, only two products - glycolate and oxalate were detected on $\mathrm{Au} / \mathrm{C}$ in the potential region investigated. As shown in Fig. 5.2 (b), the appearance of the 
dominant product glycolate, commences at $0.7 \mathrm{~V}$ vs. RHE and shows its peak concentration at $1.3 \mathrm{~V}$ vs. RHE, potential corresponding to the peak current density of EG oxidation. At an applied potential higher than $1.3 \mathrm{~V}$ vs. RHE, which has been reported the onset potential of surface $\mathrm{Au}$ oxide formation, ${ }^{82,88,94}$ the concentration of glycolate decreases sharply. It implies that $\mathrm{AuO}_{\mathrm{x}}$ is nearly inactive to $\mathrm{EG}$ oxidation under the experiment conditions performed in this study. The concentration profile of formate has a similar trend as that of glycolate, except that it begins to be detected as a product at $1.0 \mathrm{~V}$, which is $300 \mathrm{mV}$ more positive than glycolate. A significant difference between EG oxidation on $\mathrm{Au} / \mathrm{C}$ and $\mathrm{Pt} / \mathrm{C}$ is that oxalate is absent from the product distribution profile on $\mathrm{Au} / \mathrm{C}$ over the whole range of applied potentials.

Based on the results discussed above, it is clear that glycolate is an important reaction intermediate in the process of EG oxidation on both $\mathrm{Pt} / \mathrm{C}$ and $\mathrm{Au} / \mathrm{C}$ catalysts. In order to gain deep insights to the pathways of electro-oxidation of EG in alkaline solution, glycolate was used as a reactant in independent cyclic voltammetry experiments, which were conducted with a scan rate of $50 \mathrm{mV} \mathrm{s}^{-1}$. The CVs of $0.5 \mathrm{M}$ glycolic acid oxidation on $\mathrm{Pt} / \mathrm{C}$ and $\mathrm{Au} / \mathrm{C}$ in $1.0 \mathrm{M} \mathrm{KOH}$ are shown in Fig. 5.3 (a) and (b). Compared with the $\mathrm{CV}$ s recorded in only 1.0 M KOH, Pt/C with addition of $0.5 \mathrm{M}$ glycolic acid produced a 3 orders of magnitude higher peak current density. On the contrary, nearly no current was generated from glycolate oxidation on $\mathrm{Au} / \mathrm{C}$ at a potential of less than $1.2 \mathrm{~V}$ vs. $\mathrm{RHE}$, and only a very small oxidation current was detected on $\mathrm{Au} / \mathrm{C}$ at a potential of greater than 1.2 V vs. RHE in 1.0 M KOH solution + 0.5 M glycolic acid. This observation agrees well with the results reported by Kadirgan et al. that glycolate is the only product on $\mathrm{Au}$ at potential below $1.13 \mathrm{~V}$ vs. RHE, whereas at potentials above $1.13 \mathrm{~V}$, glycolate could be further oxidized to glyoxylate, oxalate and formate, based on liquid chromatography (HPLC) and infrared spectroscopy (FTIR) analysis. ${ }^{151,152}$ It can be concluded that $\mathrm{Pt} / \mathrm{C}$ is much more active than $\mathrm{Au} / \mathrm{C}$ for the electrocatalytic oxidization of glycolate in alkaline media, and the only product is oxalate. The CV of $0.5 \mathrm{M}$ oxalic acid oxidation in $1.5 \mathrm{M}$ $\mathrm{KOH}$ on $\mathrm{Pt} / \mathrm{C}$ was also tested, and compared with that of a blank 1.0 M KOH (Fig. 5.3 
(c)). Their similar CVs suggest that oxalate is a stable reaction product, and $\mathrm{Pt}$ is nearly inert to its further oxidation ( $\mathrm{C}-\mathrm{C}$ bond cleave of oxalate to carbonate).
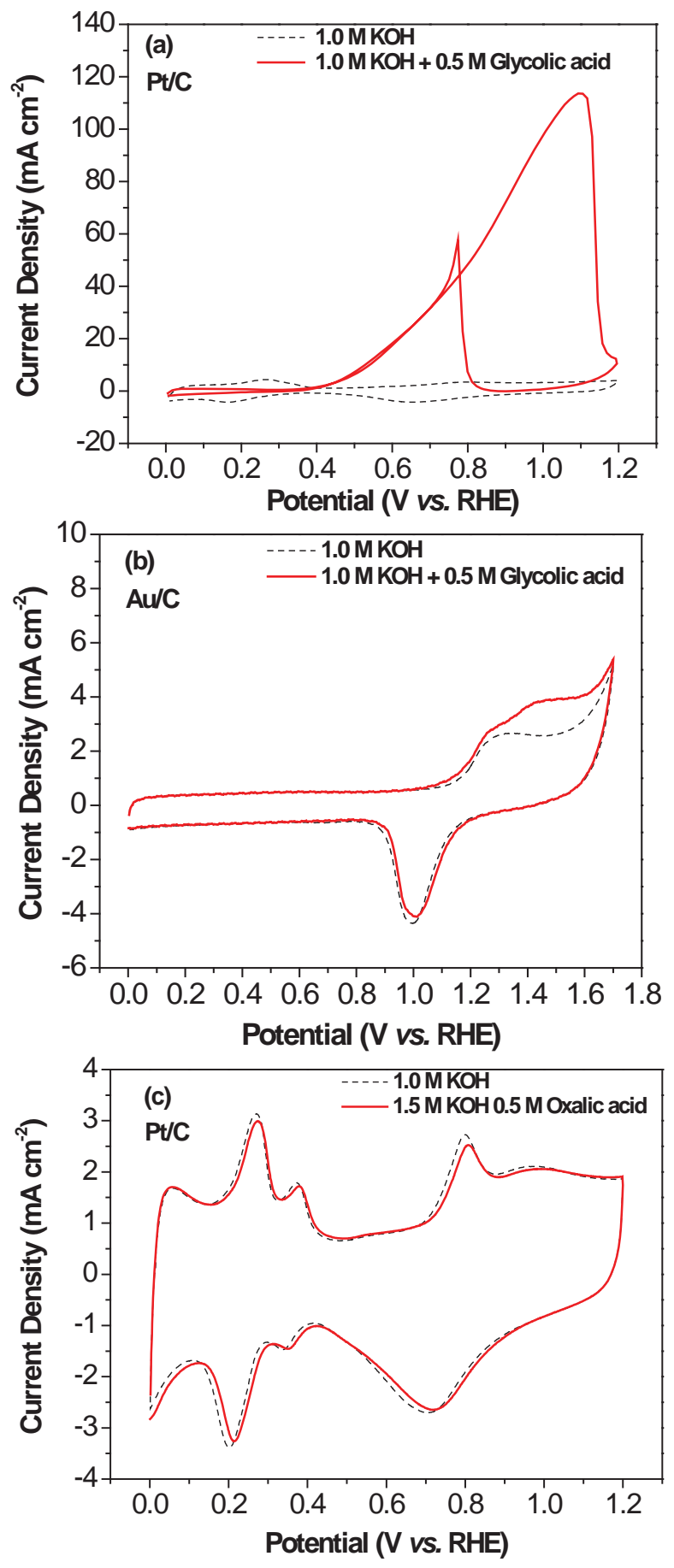

Fig. 5.3 CVs of (a) $\mathrm{Pt} / \mathrm{C}$ and (b) $\mathrm{Au} / \mathrm{C}$ in $1.0 \mathrm{M} \mathrm{KOH}+0.5 \mathrm{M}$ glycolic acid, and (c) $\mathrm{Pt} / \mathrm{C}$ in $1.5 \mathrm{M}+0.5 \mathrm{M}$ oxalic acid with a scan rate of $50 \mathrm{mV} \mathrm{s}^{-1}$, room temperature. 
The staircase linear scan voltammetry was conducted in $1.0 \mathrm{M} \mathrm{KOH}$ solution $+0.5 \mathrm{M}$ glycolic acid on Pt/C. The results shown in Fig. 5.4 indicate that on Pt/C, the peak current density produced from glycolate oxidation $\left(8.5 \mathrm{~mA} \mathrm{~cm}^{-2}\right)$ is smaller than that produced from 1.0 M KOH + 0.5 M EG solution $\left(38 \mathrm{~mA} \mathrm{~cm}^{-2}\right)$, although the oxidations of both EG and glycolate have the same onset potential of $0.4 \mathrm{~V}$ vs. RHE. This indicates that $\mathrm{Pt} / \mathrm{C}$ has higher activity toward EG oxidation than glycolate oxidation. However, their different product distributions may account for the difference in their produced current densities. Compared to the 4-electrons-transfer from glycolate oxidation to oxalate, oxalate and formate produced from EG oxidation involve 8- and 6-electrons-transfer, respectively; this will contribute to the higher generated current. The current density of glycolate oxidation features two peaks: the bigger one centered at $0.8 \mathrm{~V}$ vs. RHE can be attributed to its oxidation on clean Pt surface, while the smaller one centered at $1.1 \mathrm{~V}$ vs. RHE is due to the catalytic activity of $\mathrm{PtO}_{\mathrm{x}}$ at high potentials ( $>1.0 \mathrm{~V}$ vs. RHE). 


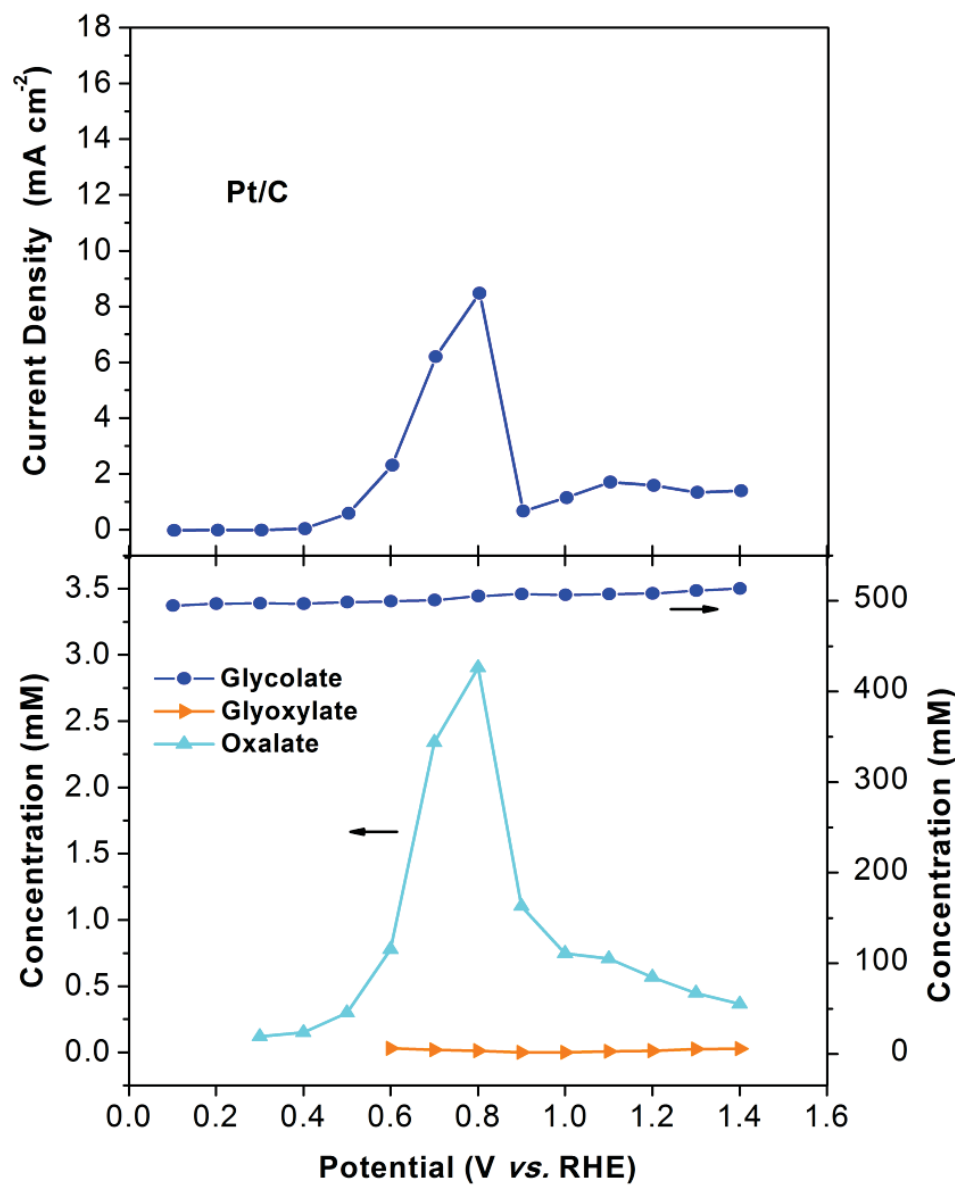

Fig. 5.4 Voltammogram and product concentrations of electrocatalytic selective oxidation of glycolate on $\mathrm{Pt} / \mathrm{C}$ in $1.0 \mathrm{M} \mathrm{KOH}+0.5 \mathrm{M}$ glycolic acid in a three-electrode cell with an on-line sample collection system.

Samples were collected during the staircase linear scan and analyzed by HPLC. The major product, oxalate starts to appear at $0.3 \mathrm{~V}$ vs. RHE and its concentration increases until $0.8 \mathrm{~V}$ vs. RHE, beyond which it drops until 1.0 V vs. RHE because of the surface oxide formation. Then, a small peak is shown at $1.1 \mathrm{~V}$ vs. RHE, suggesting $\mathrm{PtO}_{\mathrm{x}}$ is catalytically active toward glycolate oxidation at higher potentials, after which the concentration of oxalate decreases. A very small amount of glyoxylate was detected from $0.6 \mathrm{~V}$ vs. RHE, which is $300 \mathrm{mV}$ behind the oxalate detection. Glyoxylate is a reaction intermediate for glycolate oxidation to oxalate. However, it has been found that the oxidation of aldehyde group proceeds much faster than hydroxyl group ${ }^{162}$. Thus, the glyoxylate was not detected until higher potentials are applied (i.e. $>0.6 \mathrm{~V}$ vs. RHE), at 
which more glycolate was generated and participated into the reaction, and thus glyoxylate can be caught by the on-line collection system. Compared with the product distribution of EG oxidation on $\mathrm{Pt} / \mathrm{C}$, the absence of formate in the whole applied potentials suggests the $\mathrm{C}_{1}$ product formate was not derived from the further oxidation of glycolate, but rather derived from direct C-C bond breaking of EG on the Pt surface at relative high potential (e.g. $>0.6 \mathrm{~V}$ vs. RHE). On the contrary, $\mathrm{Au} / \mathrm{C}$ is inert to the glycolate oxidation, and no products, such as glyoxylate, oxalate and formate, were detected in the entire potential range ( $0-1.7 \mathrm{~V}$ vs. RHE) by using HPLC analysis, suggesting that on $\mathrm{Au} / \mathrm{C}$, glycolate is a fairly stable reaction intermediate for $\mathrm{EG}$ oxidation under the investigated experimental conditions.

\subsubsection{Proposed pathways for electro-oxidation of EG on $\mathrm{Pt} / \mathrm{C}$ and $\mathrm{Au} / \mathrm{C}$ in alkaline media}

Based on the results obtained from our three-electrode cell with the on-line sample collection system, it is proposed reaction pathways for $\mathrm{EG}$ oxidation on $\mathrm{Pt} / \mathrm{C}$ and $\mathrm{Au} / \mathrm{C}$ in alkaline solution, as shown in Fig. 5.5. It has been reported that glycolaldehyde is the first intermediate formed on Pt via the solution and metal catalyzed steps. ${ }^{54,91}$ Previous electrochemical in situ FTIR study also examined the adsorbed glycolaldehyde on Pt electrode during EG electro-oxidation. ${ }^{158}$ However, glycolaldehyde is not stable in alkaline solution and will decompose through non-Faradaic reaction. ${ }^{91}$ In order to clarify the role of glycolaldehyde in EG electro-oxidation, comparison experiments were carried out using $10 \mathrm{mM}$ glycolaldehyde $+1.0 \mathrm{M} \mathrm{KOH}$ with and without the applied potentials ( $0.6 \mathrm{~V}$ or $0.9 \mathrm{~V}$ vs. RHE) in the absence of oxygen. Samples were taken out after $10 \mathrm{~min}$ and immediately neutralized with equal moles of $\mathrm{H}_{2} \mathrm{SO}_{4}$, this is in agreement with the sample withdraw intervals (10 min for each potential) during the online sample collection process in the three-electrode cell experiments. Various glycolaldehyde decomposition products including formate, glycerate, erythrose etc. were detected by HPLC, regardless of the potentials applied. It is interesting to find that the concentration of formate generated in 10 min with and without the applied potential ( $0.6 \mathrm{~V}$ or $0.9 \mathrm{~V}$ vs. RHE) were nearly the same: no potential applied: $2.3 \mathrm{mM}, 0.6 \mathrm{~V}$, and $2.4 \mathrm{mM}, 0.9 \mathrm{~V}$. It suggests that 
in alkaline media formate was not favorably produced by further electro-oxidizing glycolaldehyde on $\mathrm{Pt} / \mathrm{C}$ catalyst, but merely a glycolaldehyde decomposition product. Furthermore, it was shown in Fig. 5.2 (a) that in the whole studied potential ranges (0.3$1.7 \mathrm{~V}$ vs. RHE) during the electro-oxidation of $\mathrm{EG}$ on $\mathrm{Pt} / \mathrm{C}$ in alkaline solution, other glycolaldehyde decomposition products (such as glycerate, erythrose etc.) were not observed in liquid electrolyte by the HPLC analysis. Therefore, the absence of these products from the non-Faradaic reaction of glycolaldehyde strongly indicates that the dominant reaction intermediate (glycolaldehyde) formed on the surface of $\mathrm{Pt} / \mathrm{C}$ was readily further oxidized to glycolate, starting at $0.3 \mathrm{~V}$ vs. RHE, without any noticeable desorption to form "glycolaldehyde in solution-phase", therefore its decomposition reaction would not occur.

Subsequently, two reaction pathways proceed in parallel for electro-oxidation of EG at potentials $>0.6 \mathrm{~V}$ vs. RHE: (1) the hydroxyl group of glycolate is oxidized to produce glyoxylate, which is rapidly oxidized to oxalate; (2) EG directly dissociates its C-C bond to form formate, which possibly generates adsorbed $\mathrm{CO}$ species, and finally carbonate, according to previous in situ FTIR spectroscopic ${ }^{151,153,158,159}$ and DEMS ${ }^{163}$ studies. Interestingly, $\mathrm{PtO}_{\mathrm{x}}$ also shows activity to promote the $\mathrm{EG}$ oxidation to oxalate through stepwise oxidation of EG without $\mathrm{C}-\mathrm{C}$ breaking, and to formate through the direct dissociation of EG at higher potential range of $>1.0 \mathrm{~V}$ vs. RHE. Neither Pt nor $\mathrm{PtO}_{\mathrm{x}}$ demonstrates activity to the oxidation of oxalate (Fig. 5.3 (c)). On Au/C, the oxidation of EG occurs at $0.7 \mathrm{~V}$ vs. RHE, which is $400 \mathrm{mV}$ more positive than that on $\mathrm{Pt} / \mathrm{C}$. Similar to $\mathrm{Pt} / \mathrm{C}$, the glycolaldehyde decomposition products on $\mathrm{Au} / \mathrm{C}$ were absent from the product profile. The higher onset potential of EG oxidation on $\mathrm{Au} / \mathrm{C}$ possibly makes the glycolaldehyde a quite reactive intermediate, which is quickly oxidized to glycolate, thus, cannot be detected in the electrolyte. This is similar to glycerol electro-oxidation: no glyceraldehyde but only glycerate was detected from glycerol oxidation ${ }^{94}$. Its first product, glycolate, is very difficult to be further oxidized. As the applied potential is higher than $1.0 \mathrm{~V}$ vs. RHE, where $\mathrm{OH}_{\mathrm{ads}}$ starts to accumulate on the Au surface, the C-C bond of EG is directly broken to yield formate. 


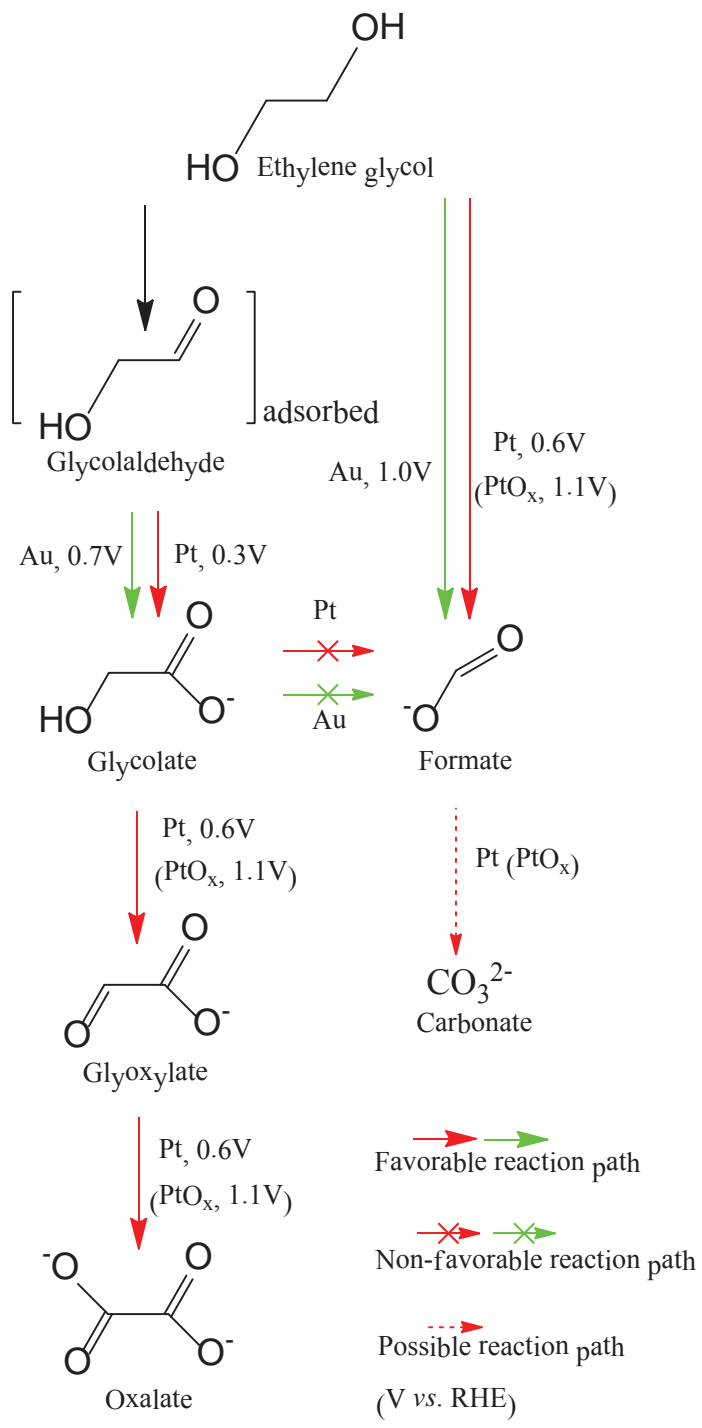

Fig. 5.5 The proposed pathways for electrocatalytic selective oxidation of $\mathrm{EG}$ on $\mathrm{Au} / \mathrm{C}$ and $\mathrm{Pt} / \mathrm{C}$ in alkaline media, the starting potentials (vs. RHE) for observed reaction paths are marked.

Extensive studies have been conducted to investigate their EG oxidation pathways on Pt and Au electrodes, ${ }^{50,152,154-156,164}$ however, detailed reaction paths still need to be clarified. It has been generally accepted that two reaction pathways proceed on $\mathrm{Pt} / \mathrm{C}$ : a poisoning path that involves $\mathrm{C}-\mathrm{C}$ breaking of $\mathrm{C}_{2}$ chemicals to produce $\mathrm{CO}$, and a non-poisoning path that stops at oxalate. The presented results confirmed that oxalate is a fairly stable oxidation product that hurdles further $\mathrm{C}-\mathrm{C}$ scission to $\mathrm{C}_{1}$ products on $\mathrm{Pt} / \mathrm{C}$. Furthermore, it is found that the $\mathrm{C}-\mathrm{C}$ bond cleavage is not a favorable process on other $\mathrm{C}_{2}$ reaction 
intermediates, such as glycolate and glyoxalate, while the successive oxidation of hydroxyl $(-\mathrm{OH})$ or carbonyl $(\mathrm{C}=\mathrm{O})$ to deeper-oxidized chemicals is a dominant process. It is clarified that the $\mathrm{C}-\mathrm{C}$ bond cleavage mainly occurs on $\mathrm{EG}$ both for $\mathrm{Pt} / \mathrm{C}$ and $\mathrm{Au} / \mathrm{C}$. This may be due to its symmetric structure and a favorable $\mathrm{O}$ bridge adsorption on the catalyst surface. ${ }^{130}$ Predominant cleavage of the C-C linkage of EG to yield solely formate has been observed on $\mathrm{NiO}$ film in $0.5 \mathrm{M} \mathrm{KOH}$ at very high potential (i.e. $>1.4 \mathrm{~V}$ vs. RHE) using electrochemical FTIR. ${ }^{158}$ Koper's group found that dissociation of C-C bond of glycerate to form glycolate on both $\mathrm{Au}$ and Pt electrodes in relatively high potentials. This also occurs on the $\mathrm{C}-\mathrm{C}$ containing two adjacent -OH groups. ${ }^{94}$ Combining the presented new observations, it is hypothesize that $\mathrm{C}-\mathrm{C}$ bond cleavage is a common process that occurs on vicinal diol compounds, such as EG and glycerate, on both Pt and Au catalysts in relatively high potentials (i.e. $0.6 \mathrm{~V}$ vs. RHE for Pt and $1.0 \mathrm{~V}$ vs. RHE for $\mathrm{Au})$.

\subsubsection{Electrocatalytic selective oxidation of EG in continuous flow-type AEM- DEGFC reactors with $\mathrm{Pt} / \mathrm{C}$ and $\mathrm{Au} / \mathrm{C}$ anode catalysts}

In order to examine the proposed reaction pathway, AEM-DEGFCs were employed to further investigate electrocatalytic selective oxidation of EG. The polarization and power density curves are shown in Fig. 5.6. Compared with $\mathrm{Pt} / \mathrm{C}$, the fuel cell electricity performance is much lower when using $\mathrm{Au} / \mathrm{C}$ anode catalyst. In detail, when fed with 2.0 $\mathrm{M} \mathrm{KOH}+1.0 \mathrm{M} \mathrm{EG}$ into the anode compartment, the AEM-DEGFC with the $\mathrm{Pt} / \mathrm{C}$ anode catalyst yields an OCV of $0.868 \mathrm{~V}$ and a peak power density of $71.0 \mathrm{~mW} \mathrm{~cm}{ }^{-2}$ at $259 \mathrm{~mA}$ $\mathrm{cm}^{-2}$ at $50^{\circ} \mathrm{C}$, while for the AEM-DEGFC with the $\mathrm{Au} / \mathrm{C}$ anode catalyst, an OCV of $0.478 \mathrm{~V}$ and a peak power density of $7.3 \mathrm{~mW} \mathrm{~cm}^{-2}$ at the current density of $60 \mathrm{~mA} \mathrm{~cm}{ }^{-2}$ were achieved. Around $400 \mathrm{mV}$ greater $\mathrm{OCV}$ obtained on $\mathrm{Pt} / \mathrm{C}$ than on $\mathrm{Au} / \mathrm{C}$ closely agrees with the $400 \mathrm{mV}$ more negative onset potential observed on $\mathrm{Pt} / \mathrm{C}$ compared with $\mathrm{Au} / \mathrm{C}$ in the three-electrode cell setup, where the same concentration ratio of $\mathrm{KOH}$ to $\mathrm{EG}$ (2:1) was used (Fig. 5.2). In addition, the higher fuel cell peak power density obtained on $\mathrm{Pt} / \mathrm{C}$ as compared with $\mathrm{Au} / \mathrm{C}$ is also consistent with higher generated current density from EG oxidation on Pt/C observed in the staircase linear scan voltammetry (Fig. 5.2). It is 
observed that the fuel cell voltage dropped more rapidly when the EG concentration was switched from 1.0 $\mathrm{M}$ to $0.1 \mathrm{M}$, in a fixed $2.0 \mathrm{M} \mathrm{KOH}$ electrolyte, giving rise to the decreased power density of $25 \mathrm{~mW} \mathrm{~cm}$ and $1.3 \mathrm{~mW} \mathrm{~cm}^{-2}$ on $\mathrm{Pt} / \mathrm{C}$ and $\mathrm{Au} / \mathrm{C}$, respectively. Furthermore, the limiting current density also decreased from $539 \mathrm{~mA} \mathrm{~cm}^{-2}$ to $134 \mathrm{~mA} \mathrm{~cm}{ }^{-2}$ on $\mathrm{Pt} / \mathrm{C}$, and $114 \mathrm{~mA} \mathrm{~cm}^{-2}$ to $26 \mathrm{~mA} \mathrm{~cm}{ }^{-2}$ on $\mathrm{Au} / \mathrm{C}$. This can be reasoned as that the diluted EG cannot provide sufficient reactant to the catalyst active sites, especially in the high current density region, where a high mass transfer rate is needed.

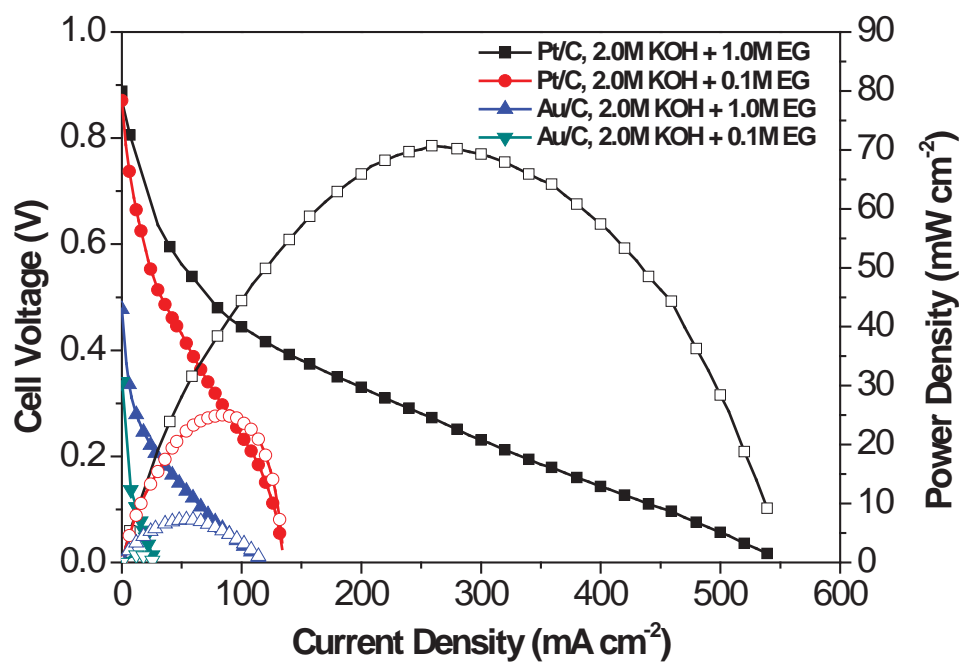

Fig. 5.6 Polarization and power density curves of AEM-DEGFC at $50^{\circ} \mathrm{C}$. Anode: $\mathrm{Pt} / \mathrm{C}$ or $\mathrm{Au} / \mathrm{C}\left(40 \mathrm{wt} \%\right.$ ), $1.0 \mathrm{mg}_{\text {metal }} \mathrm{cm}^{-2}$, cathode: $\mathrm{Fe}-\mathrm{Cu}-\mathrm{N}_{4} / \mathrm{C}$ (Acta 4020 ), $1.0 \mathrm{mg}_{\text {cat }} \mathrm{cm}^{-2}$. Membrane: Tokuyama A201, $28 \mu \mathrm{m}, 2.0 \mathrm{M} \mathrm{KOH}+1.0 \mathrm{M} \mathrm{EG}$ or $2.0 \mathrm{M} \mathrm{KOH}+0.1 \mathrm{M}$ EG, $\mathrm{O}_{2}: 0.4 \mathrm{~L} \min ^{-1}, 30 \mathrm{psi}$.

The product distribution and electricity generation from electrocatalytic selective oxidation of EG was investigated in the AEM-DEGFC reactors with $\mathrm{Pt} / \mathrm{C}$ or $\mathrm{Au} / \mathrm{C}$ anode catalyst. The EG oxidation was performed by applying different constant fuel cell voltages, while the anode potential was monitored in situ and reported with respect to RHE. The oxidation products were analyzed by HPLC after each $2 \mathrm{~h}$ reaction. As the fuel cell operation voltage was controlled at $0.5 \mathrm{~V}, 0.3 \mathrm{~V}$ and $0.1 \mathrm{~V}$, the average power density and current density of an AEM-DEGFC with the $\mathrm{Pt} / \mathrm{C}$ within $2 \mathrm{~h}$ reaction were $21.4 \mathrm{~mW} \mathrm{~cm}^{-2}$ at $42.7 \mathrm{~mA} \mathrm{~cm}^{-2}, 53.0 \mathrm{~mW} \mathrm{~cm}^{-2}$ at $177.1 \mathrm{~mA} \mathrm{~cm}^{-2}$, and $33.2 \mathrm{~mW} \mathrm{~cm}^{-2}$ at 
332.1 $\mathrm{mA} \mathrm{cm}^{-2}$, respectively, as shown in Fig. 5.7 (a) and summarized in Table 5.1. These current density and power density are slightly lower than the values observed in regular I-V scan with open circuit of fuel (Fig. 5.6). This is due to the gradual decrease of EG concentration during the $2 \mathrm{~h}$ reaction with closed circuit of fuel. In addition, the on-line monitored anode potential is $0.39 \mathrm{~V}, 0.44 \mathrm{~V}$ and $0.49 \mathrm{~V}$ (vs. RHE) on Pt/C at the fuel cell operation voltage of $0.5 \mathrm{~V}, 0.3 \mathrm{~V}$ and $0.1 \mathrm{~V}$, respectively, when the AEMDEGFC reactor is fed with 2.0 M KOH + 1.0 M EG. Fig. 5.7 (a) and Table 5.1 also summarize the oxidation products from $\mathrm{EG}$ oxidation in basic environment on $\mathrm{Pt} / \mathrm{C}$ under different operation voltages. Glycolate was observed as the major product, with a selectivity of $83.0-95.0 \%$ in the whole fuel cell operation voltage range. Meanwhile, oxalate and formate also appeared in the final products profiles. This observation is consistent with the product distributions examined from the three-electrode cell system, where all glycolate, oxalate and formate were found at relatively low applied potentials $(<0.6 \mathrm{~V}$ vs.RHE). (Fig. 5.2 (a)) Furthermore, it is interesting to note that the fuel cell operation voltage (anode potential) is able to tune the product distributions. With the fuel cell voltage decreasing, the selectivity to glycolate drops from $95.0 \%$ at $0.5 \mathrm{~V}$ to $83.0 \%$ at $0.1 \mathrm{~V}$. Conversely, the selectivity to oxalate and formate increase from $1.3 \%$ to $12.3 \%$, and $3.7 \%$ to $4.7 \%$, respectively. The carbon balance for the AEM-DEGFC operated at 0.5 $\mathrm{V}, 0.3 \mathrm{~V}$, and $0.1 \mathrm{~V}$ are $3.4 \%, 5.5 \% .8 .8 \%$, respectively. The high carbon balance at low fuel cell operation voltages indicates that formic acid may be further oxidized to $\mathrm{CO}$, or carbonate on the active $\mathrm{Pt} / \mathrm{C}$ catalyst. These products escaped the identification of HPLC, but have been probed as the reaction intermediates/products by using the FTIR spectroscopy. ${ }^{151,154,158,165}$ 

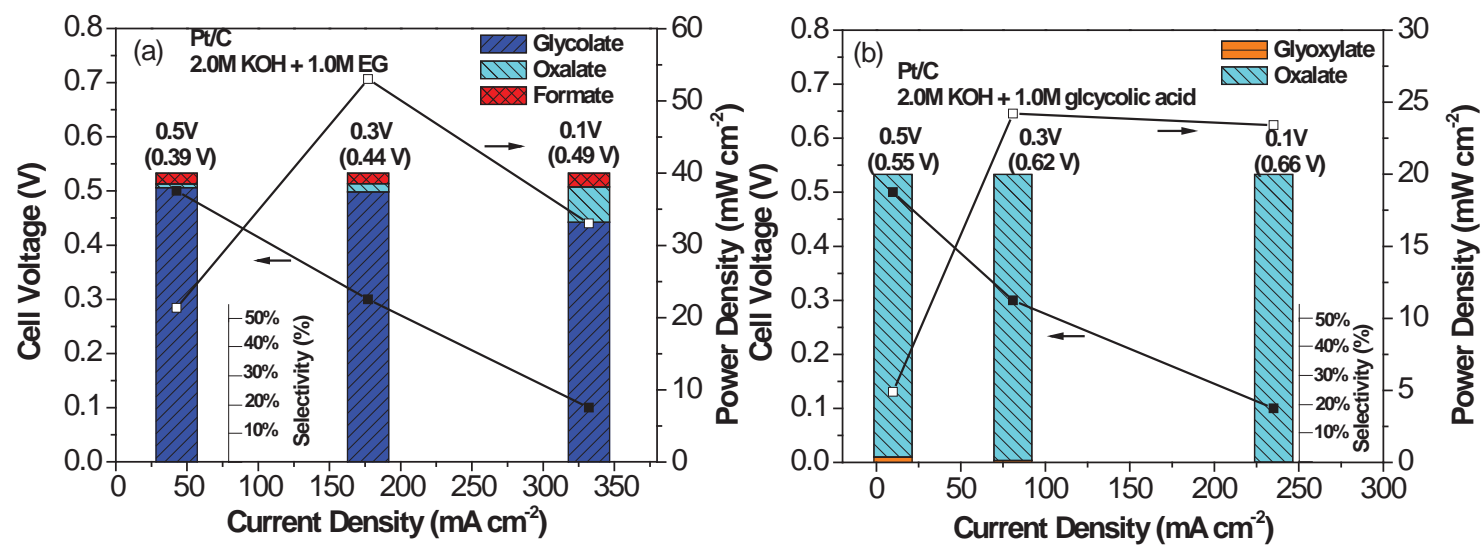

Fig. 5.7 Product selectivity and electricity generation from electrocatalytic selective oxidation of EG or glycolate on Pt/C with (a) $2.0 \mathrm{M} \mathrm{KOH}+1.0 \mathrm{M} \mathrm{EG}$ or (b) $2.0 \mathrm{M} \mathrm{KOH}$ $+1.0 \mathrm{M}$ glycolic acid in AEM-DEGFC reactors for an operation duration of $2 \mathrm{~h}$ at $50^{\circ} \mathrm{C}$. Anode potential (vs. RHE) is marked in parentheses.

Table 5.1 Electrocatalytic selective oxidation of EG on $\mathrm{Pt} / \mathrm{C}$ in AEM-DEGFC reactor with $2.0 \mathrm{M} \mathrm{KOH}+1.0 \mathrm{M}$ or $0.1 \mathrm{M} \mathrm{EG}$ at different fuel cell operation voltages for $2 \mathrm{~h}$, $50^{\circ} \mathrm{C}$.

\begin{tabular}{|c|c|c|c|c|c|c|c|c|c|}
\hline \multirow{2}{*}{$\begin{array}{c}\mathrm{Pt} / \mathrm{C} \\
(40 \text { wt.\%) }\end{array}$} & \multirow{2}{*}{$\begin{array}{l}\text { Cell } \\
\text { Voltage } \\
\text { / V }\end{array}$} & \multirow{2}{*}{$\begin{array}{c}\text { Anode } \\
\text { Voltage } \\
\text { / V vs. RHE }\end{array}$} & \multicolumn{4}{|c|}{ Selectivity / \% } & \multirow{2}{*}{$\begin{array}{c}\text { EG } \\
\text { Conversion } \\
/ \%\end{array}$} & \multirow{2}{*}{$\begin{array}{l}\text { Power } \\
\text { Density } \\
/ \mathrm{mWcm}^{-2}\end{array}$} & \multirow{2}{*}{$\begin{array}{c}\text { Carbon } \\
\text { Balance } \\
/ \%\end{array}$} \\
\hline & & & $\mathrm{C}_{2}$ Acids & GLA & $\mathrm{OA}$ & FA & & & \\
\hline \multirow{3}{*}{$\begin{array}{c}2.0 \mathrm{M} \\
\mathrm{KOH} \\
+ \\
1.0 \mathrm{M} \mathrm{EG}\end{array}$} & 0.5 & 0.39 & 96.3 & 95.0 & 1.3 & 3.7 & 10.6 & 21.4 & 3.4 \\
\hline & 0.3 & 0.44 & 96.4 & 93.5 & 2.9 & 3.6 & 31.6 & 53.0 & 5.5 \\
\hline & 0.1 & 0.49 & 95.3 & 83.0 & 12.3 & 4.7 & 51.7 & 33.2 & 8.8 \\
\hline \multirow{3}{*}{$\begin{array}{c}2.0 \mathrm{M} \\
\mathrm{KOH} \\
+ \\
0.1 \mathrm{M} \mathrm{EG}\end{array}$} & 0.5 & 0.43 & 94.7 & 92.7 & 2.0 & 5.3 & 39.3 & 11.7 & 3.2 \\
\hline & 0.3 & 0.54 & 91.8 & 80.2 & 11.6 & 8.2 & 94.9 & 24.0 & 16.5 \\
\hline & 0.1 & 0.71 & 91.4 & 62.2 & 29.2 & 8.7 & 99.7 & 10.0 & 25.0 \\
\hline
\end{tabular}

In order to elucidate the reaction pathway of intermediate glycolate in EG oxidation on $\mathrm{Pt} / \mathrm{C}$ in AEM-DEGFC reactor, 2.0 $\mathrm{M} \mathrm{KOH}+1.0 \mathrm{M}$ glycolic acid was applied as fuel. It seems that on $\mathrm{Pt} / \mathrm{C}$ more energy is needed to oxidize glycolate than EG, which is evidenced by the higher anode potential $(0.55-0.66 \mathrm{~V}$ vs. RHE) and lower peak power density $\left(24.2 \mathrm{~mW} \mathrm{~cm}^{-2}\right)$, as observed in Fig. 5.7 (b) and Table 5.2. It is also shown that oxalate with a selectivity of $>98 \%$ was obtained, along with production of a small amount 
of glyoxylate $\left(<2 \%\right.$ selectivity). In this study, $100 \%$ selectivity to $\mathrm{C}_{2}$ products was achieved without detection of any formate even at the fuel cell voltage of $0.1 \mathrm{~V}$, at which the anode potential is as high as $0.66 \mathrm{~V}$ vs. RHE and the conversion of glycolate reaches $38.7 \%$. The appearance of glyoxylate is due to the partial oxidation of glycolate, and its selectivity decreasing from $2.0 \%$ to $0.2 \%$ with the fuel cell potential decreasing from 0.5 $\mathrm{V}$ to $0.1 \mathrm{~V}$ is because of its further fast oxidation to oxalate. Moreover, the carbon balance calculated generally closes to less than $5 \%$, which is within the system error expected in HPLC analysis. Based on the observed results, it is suggested that in AEMDEGFCs, glycolate oxidation does not produce formate, but produces oxalate, which exactly matches the proposed pathways of EG oxidation on $\mathrm{Pt} / \mathrm{C}$ catalyst in threeelectrode cell (Fig. 5.2 (a) and Fig. 5.5). The C-C bond cleavage occurs directly from EG (not glycolate) on $\mathrm{Pt} / \mathrm{C}$ under fuel cell operations.

Table 5.2 Electrocatalytic selective oxidation of glycolate on Pt/C in AEM-DEGFC with $2.0 \mathrm{M} \mathrm{KOH}+1.0 \mathrm{M}$ glycolic acid at different fuel cell operation voltages for $2 \mathrm{~h}, 50^{\circ} \mathrm{C}$.

\begin{tabular}{|c|c|c|c|c|c|c|c|c|c|}
\hline \multirow{2}{*}{$\begin{array}{c}\mathrm{Pt} / \mathrm{C} \\
(40 \text { wt.\%) }\end{array}$} & \multirow{2}{*}{$\begin{array}{c}\text { Cell } \\
\text { Voltage } \\
\text { / V }\end{array}$} & \multirow{2}{*}{$\begin{array}{c}\text { Anode } \\
\text { Voltage } \\
\text { / V vs. RHE }\end{array}$} & \multicolumn{4}{|c|}{ Selectivity /\% } & \multirow{2}{*}{$\begin{array}{c}\text { GLA } \\
\text { Conversion } \\
/ \%\end{array}$} & \multirow{2}{*}{$\begin{array}{l}\text { Power } \\
\text { Density } \\
/ \mathrm{mWcm}^{-2}\end{array}$} & \multirow{2}{*}{$\begin{array}{c}\text { Carbon } \\
\text { Balance } \\
/ \%\end{array}$} \\
\hline & & & $\begin{array}{c}\mathrm{C}_{2} \\
\text { Acids }\end{array}$ & GLO & $\mathrm{OA}$ & FA & & & \\
\hline \multirow{3}{*}{$\begin{array}{c}2.0 \mathrm{M} \\
\mathrm{KOH} \\
+ \\
1.0 \mathrm{M} \\
\text { GLA }\end{array}$} & 0.5 & 0.55 & 100 & 2.0 & 98.0 & 0 & 0.4 & 4.9 & 4.0 \\
\hline & 0.3 & 0.62 & 100 & 0.8 & 99.2 & 0 & 15.3 & 24.2 & 4.1 \\
\hline & 0.1 & 0.66 & 100 & 0.2 & 99.8 & 0 & 38.7 & 23.4 & 4.5 \\
\hline
\end{tabular}

In sharp contrast to $\mathrm{Pt} / \mathrm{C}, \mathrm{Au} / \mathrm{C}$ is much less active to the $\mathrm{EG}$ electro-oxidation in the AEM-DEGMFC with 2.0 M KOH $+1.0 \mathrm{M} \mathrm{EG}$ fuel under the working conditions, as evidenced by its lower peak power density $\left(4.8 \mathrm{~mW} \mathrm{~cm}^{-2}\right.$ at $\left.47.9 \mathrm{~mA} \mathrm{~cm}{ }^{-2}\right)$ and lower EG conversion $(3.6 \%$ at $0.3 \mathrm{~V}$, and $10.4 \%$ at $0.1 \mathrm{~V})$. The on-line monitored anode potentials are $0.60 \mathrm{~V}$ and $0.69 \mathrm{~V}$ for the fuel cell voltage operated at $0.3 \mathrm{~V}$ and $0.1 \mathrm{~V}$, respectively, which are obviously higher than that observed on Pt/C, as shown in Fig. 5.8 and Table 5.3. However, it is found that on $\mathrm{Au} / \mathrm{C}, \mathrm{EG}$ is oxidized to glycolate with nearly $100 \%$ selectivity, and no oxalate has been detected in the final products. The overall carbon balance for the EG oxidation is far less than 5\%, which clearly indicates Au is 
inactive to further oxidation of formate. In addition, 2.0 M KOH +1.0 M glycolic acid was also used as the anode fuel, but no electricity was generated, confirming that the collected formic acid from EG oxidation does not come from the $\mathrm{C}-\mathrm{C}$ bond dissociation of glycolate but from direct $\mathrm{C}-\mathrm{C}$ bond breaking of EG under fuel cell operations. Therefore, the results further confirm the pathways of EG electro-oxidation on $\mathrm{Au} / \mathrm{C}$ in alkaline electrolyte proposed in light of the studies performed in the three-electrode cell with the on-line sample collection system (Fig. 5.5): on $\mathrm{Au} / \mathrm{C}$ catalyst, the stepwise oxidation of EG without breaking the $\mathrm{C}-\mathrm{C}$ bond stops at the formation of glycolate, and the yield of formate results from direct $\mathrm{C}-\mathrm{C}$ bond scission of EG itself at relatively high anode potentials in fuel cells.

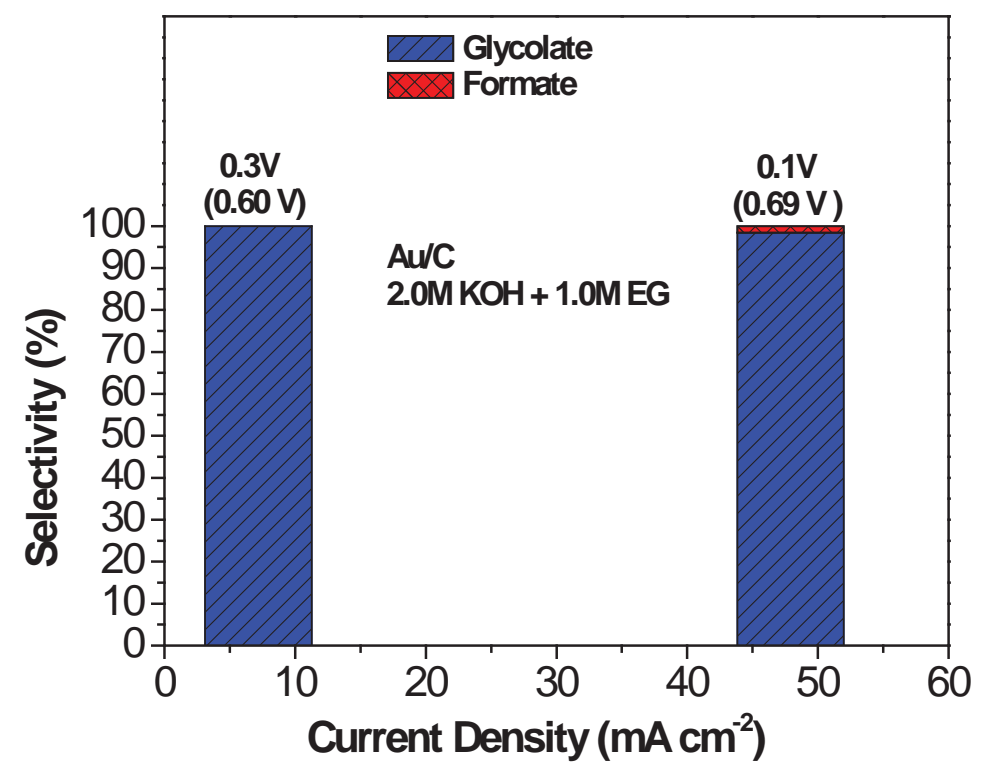

Fig. 5.8 Product selectivity and electricity generation from electrocatalytic selective oxidation of $\mathrm{EG}$ on $\mathrm{Au} / \mathrm{C}$ with $2.0 \mathrm{M} \mathrm{KOH}+1.0 \mathrm{M} \mathrm{EG}$ in the AEM-DEGFC reactor for the operation duration of $2 \mathrm{~h}$ at $50^{\circ} \mathrm{C}$. Anode potential (vs. RHE) is marked in parentheses. 
Table 5.3 Electrocatalytic selective oxidation of EG on Au/C in AEM-DEGFC with 2.0 $\mathrm{M} \mathrm{KOH}+1.0 \mathrm{M}$ or $0.1 \mathrm{M} \mathrm{EG}$ at different fuel cell operation voltages for $2 \mathrm{~h}, 50^{\circ} \mathrm{C}$.

\begin{tabular}{|c|c|c|c|c|c|c|c|c|c|}
\hline \multirow{2}{*}{$\begin{array}{c}\mathrm{Au} / \mathrm{C} \\
(40 \mathrm{wt} . \%)\end{array}$} & \multirow{2}{*}{$\begin{array}{c}\text { Cell } \\
\text { Voltage } \\
\text { / V }\end{array}$} & \multirow{2}{*}{$\begin{array}{c}\text { Anode } \\
\text { Voltage } \\
\text { / V vs. RHE }\end{array}$} & \multicolumn{4}{|c|}{ Selectivity / \% } & \multirow{2}{*}{$\begin{array}{c}\text { EG } \\
\text { Conversion } \\
/ \%\end{array}$} & \multirow{2}{*}{$\begin{array}{c}\text { Power } \\
\text { Density } \\
/ \mathrm{mWcm}^{-2}\end{array}$} & \multirow{2}{*}{$\begin{array}{c}\text { Carbon } \\
\text { Balance } \\
/ \%\end{array}$} \\
\hline & & & $\begin{array}{c}\mathrm{C}_{2} \\
\text { Acids }\end{array}$ & GLA & OA & FA & & & \\
\hline \multirow{2}{*}{$\begin{array}{c}2.0 \mathrm{M} \\
\mathrm{KOH} \\
+ \\
1.0 \mathrm{M} \mathrm{EG}\end{array}$} & 0.3 & 0.60 & 100 & 100 & 0 & 0 & 3.6 & 2.2 & 0.5 \\
\hline & 0.1 & 0.69 & 98.4 & 98.4 & 0 & 1.6 & 10.4 & 4.8 & 0.6 \\
\hline $\begin{array}{c}2.0 \mathrm{M} \\
\mathrm{KOH} \\
+ \\
0.1 \mathrm{M} \mathrm{EG}\end{array}$ & 0.1 & 0.77 & 99.0 & 99.0 & 0 & 1.0 & 20.9 & 1.0 & 1.7 \\
\hline
\end{tabular}

When EG concentration decreases from 1.0 M to $0.1 \mathrm{M}$, it is observed that the current density and power density significantly decreased on both $\mathrm{Pt} / \mathrm{C}$ and $\mathrm{Au} / \mathrm{C}$, together with the anode potential shifts more positively, as shown in Fig. 5.9 and Tables 5.1 and Table 5.3. This suggests that the EG oxidation is related to the ratio of $-\mathrm{RO}_{\mathrm{ads}}$ and $\mathrm{OH}_{\mathrm{ads}}$ coverage on the catalyst surface. It is also noted that the EG conversion is strongly affected by its concentration in the feeding fuel. The EG conversion in $2.0 \mathrm{M} \mathrm{KOH}+0.1$ $\mathrm{M}$ EG is much higher than that obtained in 2.0 M KOH + 1.0 M EG. Particularly, on Pt/C, the EG conversion at fuel cell operation voltages of $0.5,0.3$ and $0.1 \mathrm{~V}$ increases from $10.6 \%, 31.6 \%$ and $51.7 \%$ with $1.0 \mathrm{M}$ EG to $39.3 \%, 94.9 \%$ and $99.7 \%$ with $0.1 \mathrm{M} \mathrm{EG}$, and on $\mathrm{Au} / \mathrm{C}$, the $\mathrm{EG}$ conversion at fuel cell operation voltage of $0.1 \mathrm{~V}$ increases from $10.4 \%$ to $20.9 \%$. Meanwhile, decreasing EG concentration also leads to a lower selectivity of $\mathrm{C}_{2}$ products on $\mathrm{Pt} / \mathrm{C}$, which further confirms that high applied potential facilitates C-C bond breaking of EG. Still, no oxalate was observed from $0.1 \mathrm{M}$ EG electro-oxidation on $\mathrm{Au} / \mathrm{C}$ anode catalyst in AEM-DEGFC, which suggests that the EG concentration does not apparently change the reaction pathways. The EG oxidation pathways proposed according to the study combining the three-electrode cell, on-line sample collection, and HPLC analysis has been well verified by theAEM-DEGFC reactor investigations. This approach is able to not only supplement the previous spectroscopic findings, but also potentially produce new findings on the pathways of electro-oxidation of biorenewable polyols (i.e. glycerol and sorbitol, etc.) on nanostructured metallic catalysts. 

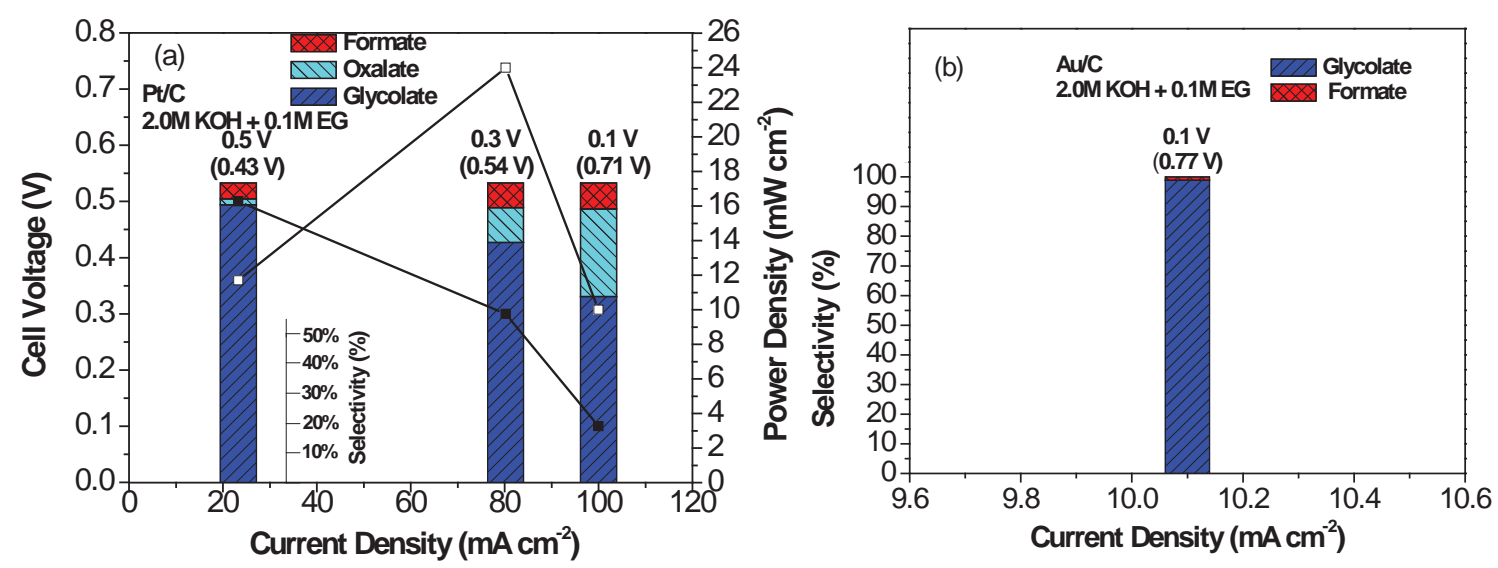

Fig. 5.9 Product selectivity and electricity generation from electrocatalytic selective oxidation of EG on Pt/C (a) and $\mathrm{Au} / \mathrm{C}$ (b) with $2.0 \mathrm{M} \mathrm{KOH}+0.1 \mathrm{M}$ EG in AEM-DEGFC reactors for an operation duration of $2 \mathrm{~h}$ at $50^{\circ} \mathrm{C}$. Anode potential (vs. RHE) is marked in parentheses.

\subsection{Conclusions}

In this chapter, electrocatalytic selective oxidation of EG was studied on $\mathrm{Pt} / \mathrm{C}$ and $\mathrm{Au} / \mathrm{C}$ catalysts in alkaline electrolyte. The three-electrode cell with on-line sample collection system showed that glycolate, oxalate and formate were sequentially produced from EG oxidation on $\mathrm{Pt} / \mathrm{C}$ with increasing staircase LSV, while only glycolate and formate were examined on $\mathrm{Au} / \mathrm{C}$. It was clarified that formate was produced favorably from direct $\mathrm{C}-\mathrm{C}$ bond cleavage of EG on both $\mathrm{Pt} / \mathrm{C}$ and $\mathrm{Au} / \mathrm{C}$. Further oxidation of glycolate to oxalate occurs only on $\mathrm{Pt} / \mathrm{C}$ but not on $\mathrm{Au} / \mathrm{C}$ at the specified test conditions. Electrocatalytic selective oxidation of EG in the AEM-DEGFCs with $\mathrm{Pt} / \mathrm{C}$ and $\mathrm{Au} / \mathrm{C}$ anode catalysts showed consistent results with the three-electrode cell tests. The AEM-DEGFCs with $\mathrm{Pt} / \mathrm{C}$ anode demonstrated a peak power density of $71.0 \mathrm{~mW} \mathrm{~cm}{ }^{-2}$, which is much higher than that obtained on $\mathrm{Au} / \mathrm{C}$ anode (only $7.3 \mathrm{~mW} \mathrm{~cm}^{-2}$ ) at $50^{\circ} \mathrm{C}$, this is consistent with more negative onset potential and higher generated current density for electro-oxidation of $\mathrm{EG}$ on $\mathrm{Pt} / \mathrm{C}$ than on $\mathrm{Au} / \mathrm{C}$ obtained in the three-electrode cell setup. With fuel cell operation voltage decreasing (anode potential increasing), deeper-oxidized products oxalate and formate were generated in the $\mathrm{Pt} / \mathrm{C}$ anode AEM-DEGFC with increased selectivity, and no formate was examined when glycolate was employed as fuel. On $\mathrm{Au} / \mathrm{C}$ anode catalyst, very high selectivity of $>98 \%$ to glycolate was achieved. The AEM- 
DEGFCs results confirmed the EG electro-oxidation pathways proposed by using the online sample collection system, which is anticipated to be used to explore the reaction sequences for electro-oxidation of other polyols. 


\section{Chapter 6 Electrocatalytic Selective Oxidation of 1,2- Propanediol in the Continuous Flow AEM-based Electrolysis Cell Reactor: Potential Controlled Electro- oxidation Mechanism Determination via Combined Experimental and Theoretical DFT Studies}

\subsection{Background}

Chapter $\mathbf{4}$ and $\mathbf{5}$ have shown that tuning electrode potential can affect the reactivity of possible reaction steps of electrocatalytic selective oxidation of glycerol and EG, respectively, thereby enabling good control over the selectivity of final product. However, it is still difficult to determine the reaction mechanism because there are numerous elementary oxidation steps that involve many possible intermediates which cannot be detected or quantified through conventional experimental approaches. On the other hand, understanding the electrocatalytic mechanisms can help future rational catalyst design to improving the conversion of biomass to valuable chemicals of industrial significance. In this chapter, 1,2-propanediol, a $\mathrm{C}_{3}$ alcohol containing one primary and one secondary $\mathrm{OH}$ groups on vicinal carbons, was chosen as a model polyol to study its electrocatalytic oxidation mechanisms on $\mathrm{Au} / \mathrm{C}$ by combining experimental results obtained on continuous flow AEM based electrolysis cell reactor (Fig. 2.3) and theoretical DFT calculations.

Biorenewable 1,2-propanediol can be produced from catalytic dehydration/hydrogenation of glycerol whose availability is sustained by the biodiesel industry. ${ }^{166}$ Further oxidation of 1,2-propanediol through primary -OH group can yield lactic acid, ${ }^{167}$ which is a useful intermediate for the production of food additives and polylactide, a biodegradable polymer. ${ }^{9}$ Oxidation of both the primary and secondary alcohol groups of 1,2-propanediol can lead to pyruvic acid formation that finds its application in both pharmaceutical and food processing industries. ${ }^{168}$ Fig. 6.1 summarizes the key industrial products derived from 1,2-propanediol. 


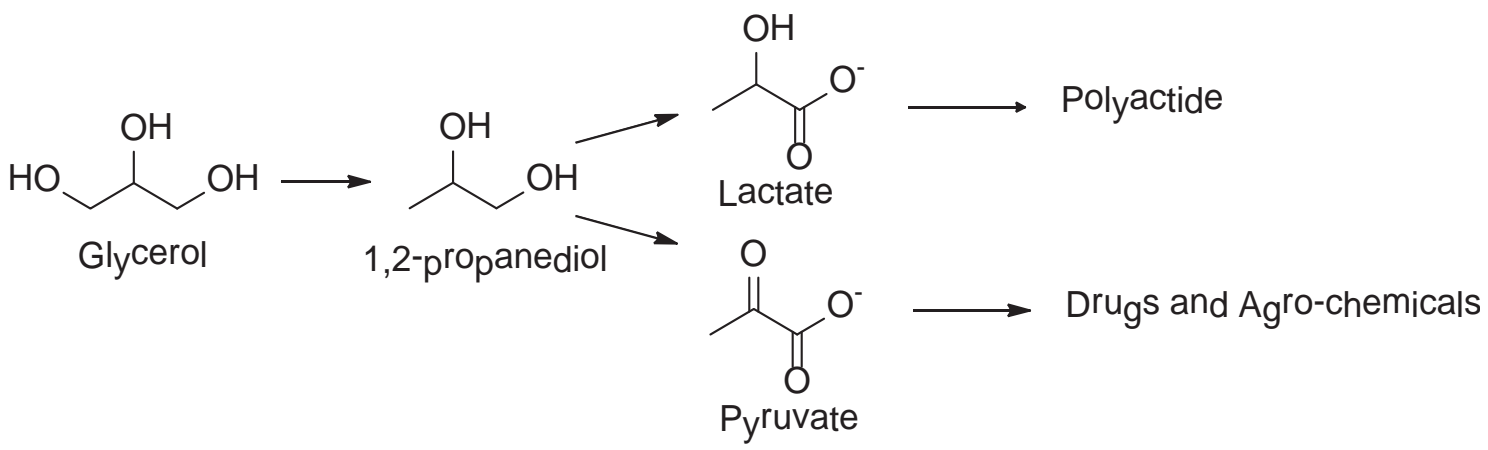

Fig. 6.1 Important industrial products derived from 1,2-propanediol.

Electrocatalysis sparks many interests as another central process that plays an important role in sustainable generation of electricity and chemicals in fuel cells. Studies of electrocatalytic oxidation of 1,2-propanediol have been performed on platinum nanoparticle and planar electrodes with a focus only on electricity performance, which have also shown that basic conditions could give enhanced activity. ${ }^{46}$ The analysis of thermodynamic reversible potential for 1,2-propanediol electro-oxidation indicates that the thermodynamic potentials of interested products (lactate and pyruvate, Equation 6-1 and 6-2) are very similar and also close to $\mathrm{C}-\mathrm{C}$ bond breaking byproducts (acetate, formate and carbonate, Equation 6-3 - 6-5). To realize the cogeneration of valuable chemicals and electricity in a fuel cell system, knowledge of selective electrocatalytic oxidation of 1,2-propanediol with varying the electrode potential should be obtained.

$$
1,2-\text { Propanediol }+5 \mathrm{OH}^{-} \leftrightarrows \text { Lactate }+4 \mathrm{H}_{2} \mathrm{O}+4 \mathrm{e}^{-} \quad \mathrm{E}^{\mathrm{o}}=-0.75 \mathrm{~V} \text { vs. SHE }
$$

$$
1,2-\text { Propanediol }+7 \mathrm{OH}^{-} \leftrightarrows \text { Pyruvate }+6 \mathrm{H}_{2} \mathrm{O}+6 \mathrm{e}^{-} \quad \mathrm{E}^{\mathrm{o}}=-0.80 \mathrm{~V} \text { vs. SHE }
$$

$$
1,2-\text { Propanediol }+5.50 \mathrm{H}^{-} \leftrightarrows 1.5 \text { Acetate }+2 \mathrm{H}_{2} \mathrm{O}+4 \mathrm{e}^{-} \quad \mathrm{E}^{\mathrm{o}}=-0.88 \mathrm{~V} \text { vs. SHE }
$$

$$
1,2-\text { Propanediol }+13 \mathrm{OH}^{-} \leftrightarrows 3 \text { Formate }+9 \mathrm{H}_{2} \mathrm{O}+10 \mathrm{e}^{-} \quad \mathrm{E}^{\mathrm{o}}=-0.61 \mathrm{~V} \text { vs. SHE }
$$




$$
1,2-\text { Propanediol }+22 \mathrm{OH}^{-} \leftrightarrows 3 \text { Carbonate }+15 \mathrm{H}_{2} \mathrm{O}+16 \mathrm{e}^{-} \quad \mathrm{E}^{\mathrm{o}}=-0.75 \mathrm{~V} \text { vs. SHE }
$$

\subsection{General experimental}

\subsubsection{Preparation of $\mathrm{Au} / \mathrm{C}(40 \mathrm{wt} . \%)$}

The organic solution phase-based nanocapsule method was applied to prepare the carbon black supported Au nanoparticles with setting loadings of $40 \mathrm{wt} . \%$. The detail synthesis procedures have been described in Section 2.4.4.

\subsubsection{Physical characterizations}

The morphology, nanostructure and metal loading of $\mathrm{Au} / \mathrm{C}$ were analyzed by TEM, XRD and ICP-OES, as described in Section 2.5.1, 2.5.3 and 2.5.4.

\subsubsection{Electrocatalytic selective oxidation of 1,2-propanediol in AEM based electrolysis cell reactor}

Electrocatalytic selective oxidation of 1,2-propanediol was conducted in the custom designed continuous flow AEM based electrolysis cell reactor (Fig. 2.3) that is constructed with a MEA-type electrode. Au/C (40 wt.\%, $5.0 \mathrm{mg}_{\mathrm{Au}} \mathrm{cm}^{-2}$ ) based working electrode and Pt/C (40 wt.\%, Fuel Cell Store, $1.0 \mathrm{mg}_{\mathrm{Pt}} \mathrm{cm}^{-2}$ ) based counter electrode were fabricated by airbrushing catalyst mixed with 5 wt.\% PTFE in water suspension into isopropanol onto carbon cloths (PTFE-untreated, $381 \mu \mathrm{m}$, Fuel Cell Store) that serves as the liquid diffusion layers, and assembled with a solid anion-exchange membrane (A201, 28 $\mu \mathrm{m}$, Tokuyama Corp.).During each run, $25 \mathrm{ml}$ of 2.0 M KOH + 1.0 M 1,2-propanediol was introduced into a plastic vessel and close-looped into the compartment of working electrode at the rate of $1.0 \mathrm{ml} \mathrm{min}^{-1}$, at the same time, $2.0 \mathrm{M} \mathrm{KOH}$ was cycled through the compartment of counter electrode. The reactor temperature was controlled at $50^{\circ} \mathrm{C}$. The potentials were applied by the potentiostats on the $\mathrm{Au} / \mathrm{C}$ based working electrode and controlled with respect to a $\mathrm{Hg} / \mathrm{HgO} / 1.0 \mathrm{M} \mathrm{KOH}$ reference electrode that was inserted into the compartment of working electrode. All the electrochemical data in this chapter 
was converted to values versus RHE as reported according to Equation 2-1.1,2propanediol electrocatalytic selective oxidation were performed at constant applied potentials ranging from $0.35 \mathrm{~V}-0.75 \mathrm{~V}$ vs. RHE, each for 1 hour. The Faradaic efficiency (calculated according Equation 2-14) of $>90 \%$ at each applied potential studied in the continuous flow AEM based electrolysis cell reactor (Fig. 6.1) confirmed the stability of $\mathrm{Au}$ anode electrode as well as little interference of $\mathrm{O}_{2}$ from OER in the system. Subsequently, liquid products were withdrawn from the system and sent for analysis.

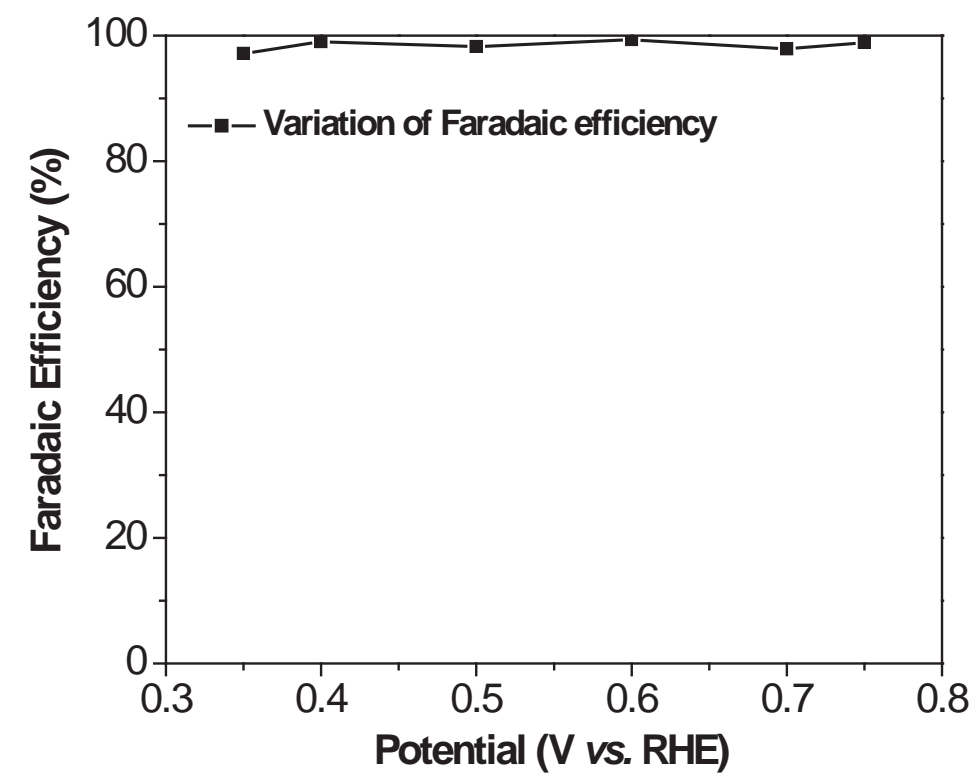

Fig. 6.2 The Faradaic efficiency of 1,2-propanediol electro-oxidation on $\mathrm{Au} / \mathrm{C}$ (40 wt.\%) as a function of time at different potentials (V vs. RHE) in the continuous flow AEM based electrolysis cell reactor.

\subsubsection{Product analysis}

The 1,2-propanediol electro-oxidation products were analyzed by HPLC and identified, quantified by comparison with authentic samples (Section 2.7).

The product selectivity and 1,2-propanediol conversion are calculated by the following equations:

$$
\text { Selectivity of } C_{2} \text { or } C_{3} \text { product }=\frac{\text { Moles of } C_{2} \text { or } C_{3} \text { product }}{\text { Total moles of } C_{2} \text { and } C_{3} \text { products }} \times 100 \%
$$


Conversion of $1,2-$ propanediol $=\left(1-\frac{\text { Concentration of } 1,2-\text { propanediol at certain time }}{\text { Initial concentration of } 1,2 \text {-propanediol }}\right) \times 100 \%$

The carbon balance is based on:

$$
\text { Carbon balance }=\frac{3 M_{P D O_{i}}-3 \sum M_{C_{3}}-2 \sum M_{C_{2}}-\sum M_{C_{1}}-3 M_{P D O_{f}}}{3 M_{P D O_{i}}} \times 100 \%
$$

where $M_{P D O_{i}}$ and $M_{P D O_{f}}$ is the initial and final moles of 1,2-propanediol in the electrolyte. $\sum M_{C_{3}}, \sum M_{C_{2}}$ and $\sum M_{C_{1}}$ are the total moles of $C_{3}$ (lactate, pyruvate), $C_{2}$ (acetate) and $C_{1}$ (formate, carbonate) products, respectively. If assuming that no $\mathrm{C}-\mathrm{C}$ bond cleavage occurs through $C_{2}$ product (acetate), then $\sum M_{C_{2}}=\sum M_{C_{1}}$. Thus the equation for carbon balance calculation can be simplified to:

$$
\text { Carbon balance }=\frac{M_{P D O_{i}}-\sum M_{C_{3}}-\sum M_{C_{2}}-M_{P D O_{f}}}{M_{g P D O_{i}}} \times 100 \%
$$

Therefore, a carbon balance of zero means all the $C_{2}$ products generated from C-C breaking of $C_{3}$ products do not undergo further $\mathrm{C}-\mathrm{C}$ cleavage, and the summation of all the $C_{2}$ (acetate) and $C_{3}$ products and unreacted 1,2-propanediol is equal to the initial 1,2propanediol. A smaller carbon balance value indicates less $C_{2}$ intermediate (acetate) were further oxidized to $C_{1}$ products (carbon balance of 0 means no $C_{2}$ intermediates were further oxidized to $C_{1}$ products). The carbon balance under all the test conditions is less than $5 \%$, which is within the system error expected in HPLC analysis.

\subsubsection{DFT simulations of 1,2-propanediol electrocatalytic oxidation on Au (111) surface}

DFT calculation was performed by our collaborator, Prof. Dr. Michael Janik and his undergraduate student Brian Brady at Pennsylvania State University on the Vienna Ab Initio Simulation Program (VASP), a plane-wave pseudopotential package. ${ }^{169}$ The exchange and correlation energies were calculated using Perdew-Wang functional (PW91)

form of the generalized gradient approximation (GGA). ${ }^{170}$ Computational details are 
presented in Brady B. (2014), Determining the Electrocatalytic Oxidation Mechanism for Lactic Acid and Pyruvic Acid from 1,2-Propanediol using Density Functional Theory. (Baccalaureate Degree Thesis)

\subsection{Results and discussions}

\subsubsection{Physical characterizations}

The XRD patterns of $\mathrm{Au} / \mathrm{C}$ catalysts have been shown in Fig. 3.2 and discussed in the Section 3.3.1, and displayed a typical face-centered cubic (FCC) structure. Typical TEM images of $\mathrm{Au} / \mathrm{C}$ and their corresponding size histograms have been shown in Fig. 3.3 (c) and discussed in the Section 3.3.1.

\subsubsection{Electrocatalytic selective oxidation of 1,2-propanediol Au/C (40 wt.\%) in the continuous flow AEM based electrolysis cell reactor}

The conversion of 1,2-propanediol and electrocatalytic oxidation product profiles (selectivity and concentration) under different applied potentials for $1 \mathrm{~h}$ at $50^{\circ} \mathrm{C}$ were shown in Fig. 6.3. It clearly shows a shift in product selectivity as the applied potential was increased, indicating the electrode potential strongly regulates the selectivity of oxidation products.(Fig. 6.3 (a)) At $0.35 \mathrm{~V}$ vs. RHE, the selectivity of lactate and pyruvate in the electrolysis cell were 51.7 and $18.6 \%$, respectively, at 1,2-propanediol conversion of $3.5 \%$. With the increasing of potentials applied on the working electrode, the selectivity of lactate gradually decreased to $33.2 \%$ at $0.75 \mathrm{~V}$ vs. RHE $(1,2-$ propanediol conversion of $12.5 \%$ ), while the increasing selectivity to pyruvate was observed, achieving $55.9 \%$ at $0.75 \mathrm{~V}$ vs. RHE. In addition, the absolute concentration of products also increased with electrode potential increasing. (Fig. 6.3 (b)) The experimental results suggest that at relatively low electrode potential, the polarization of catalyst surface is weak and can only allow the oxidation primary $-\mathrm{OH}$ to form an aldehyde (-CHO) or acid (-COOH). As the polarization of Au-based electrode becomes more positive, the surface catalyzed oxidation of both primary and secondary $-\mathrm{OH}$ groups is more favorable, leading to pyruvate being a dominant product. 

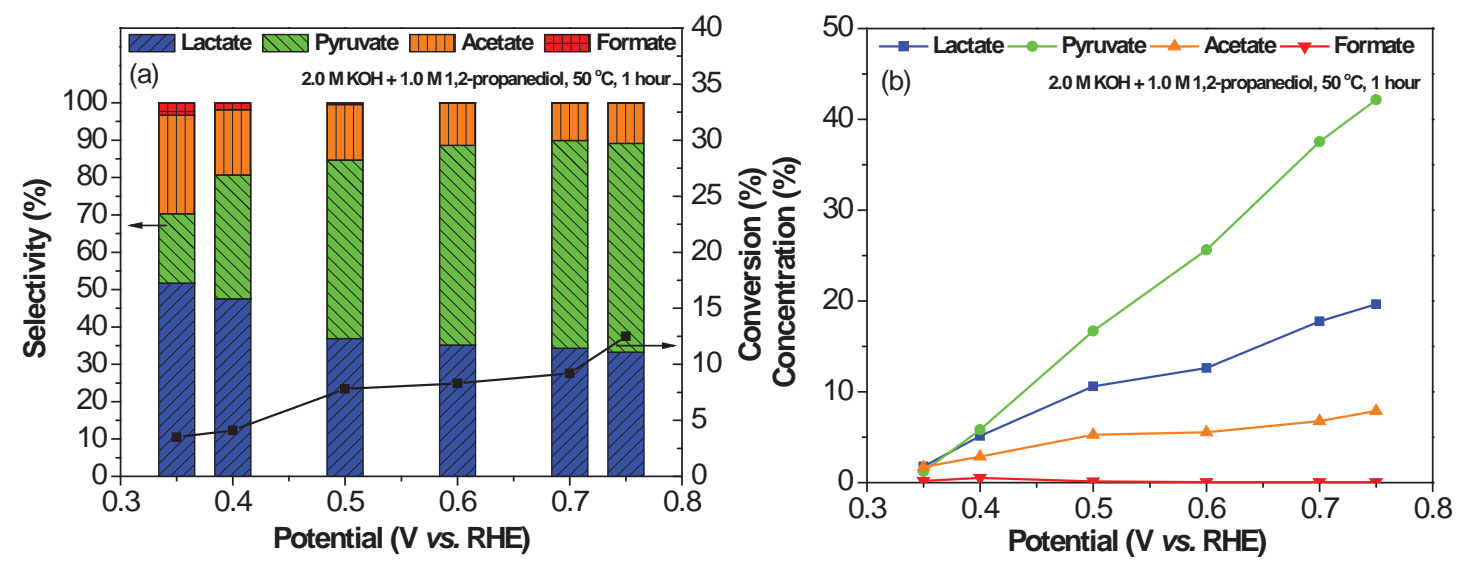

Fig. 6.3 Electrocatalytic selective oxidation of 1,2-propanedio (2.0 M KOH + 1.0 M 1,2propanediol) on $\mathrm{Au} / \mathrm{C}(40 \mathrm{wt} \%$ ) in the continuous flow AEM based electrolysis cell reactor, (a) selectivity and conversion versus different applied potentials (V. vs. RHE), (b) concentration versus different applied potentials (V. vs. RHE). Reaction time: 1 h. $50^{\circ} \mathrm{C}$.

\subsubsection{Electrocatalytic oxidation mechanism determination for lactic acid and pyruvic acid from 1,2-propanediol using density functional theory (DFT)}

The electrocatalytic selective oxidation of 1,2-propanediol was studied using DFT that considers the Gibbs free energies of all likely conformations of reactants, intermediates and products over $\mathrm{Au}(111)$ surface at varied potentials $(0 \mathrm{~V}, 0.5 \mathrm{~V}$ and $0.75 \mathrm{~V})$. The reaction energy diagram was provided in Fig. 6.4 that highlighted the preferred pathway during the course of the reaction. $\left(1 \mathrm{eV}=1.6 \times 10^{-19} \mathrm{~J}\right)$ The electro-oxidation of the alcohol in alkaline media undergoes the initial de-protonation step catalyzed by $\mathrm{OH}^{-}$in the electrolyte, followed by metal-catalyzed $\mathrm{C}-\mathrm{H}$ and $\mathrm{C}-\mathrm{C}$ bonds breaking steps where the $\mathrm{Au}$ catalyst is needed. ${ }^{91}$ Therefore, DFT calculation was performed starting with the adsorption of alkoxy (R-O) on $\mathrm{Au}(111)$ ensuing solution-mediated de-protonation step. Since hydroxyacetone was not detected under our experimental conditions, the electrooxidation of 1,2-propanediol through $\mathrm{O}_{2}$ binding (secondary - $\mathrm{OH}$ ) pathway was excluded in this dissertation. From Fig. 6.4, it depicts that the activation energy for each oxidation step decreases as potential increases from $0 \mathrm{~V}$ to $0.75 \mathrm{~V}$. At lower potential $(0 \mathrm{~V})$, high energy barrier between lactic acid and pyruvic acid makes further oxidation of lactic acid unfavorable. With increasing potential, the energy of this transition state decreases and the free-energy pathway is then downhill to favor the formation of pyruvic acid. The 
preliminary DFT computational results explains the high yield of pyruvate obtained at higher electrode potentials in experimental results fairly well (Fig. 6.3) However, the reaction mechanism related to $\mathrm{C}-\mathrm{C}$ bond breaking is still elusive in the current DFT study and future work should be focused on it.

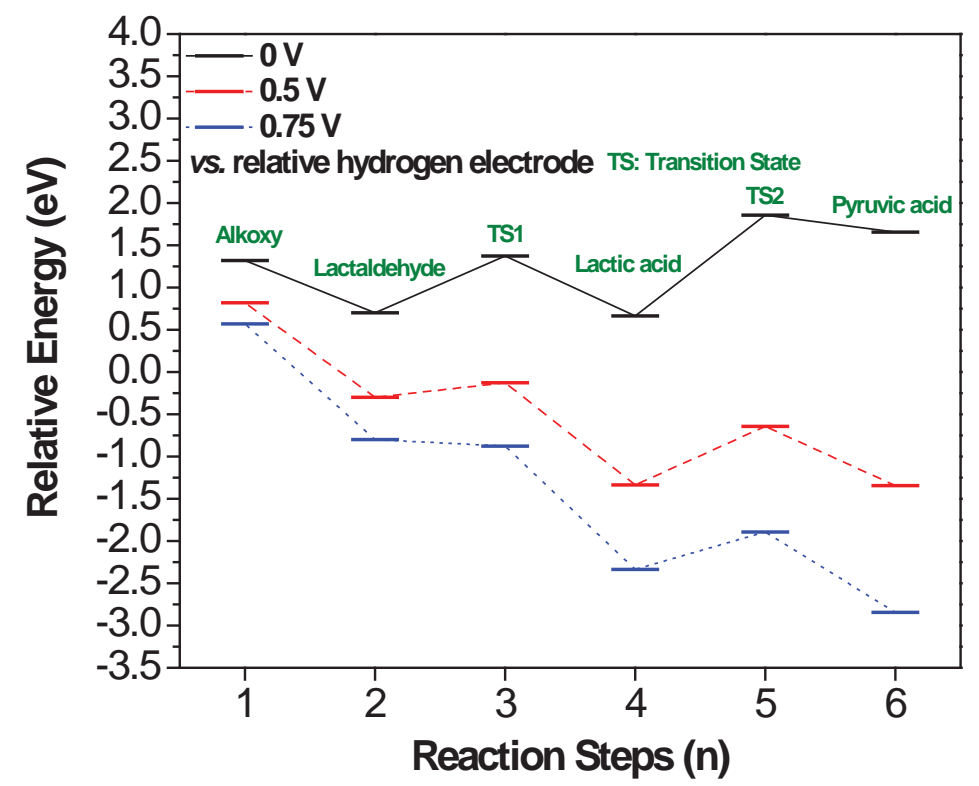

Fig. 6.4 Reaction energy diagram at various potentials (vs. relative hydrogen electrode). Relative energy is the value that compared to the energy of single gas phase 1,2propanediol molecule, the $\mathrm{Au}(111)$ surface, and water molecules at zero potentials.

\subsection{Conclusions}

In this chapter, electrocatalytic oxidation of biorenewable 1,2-propanediol on $\mathrm{Au} / \mathrm{C}$ catalyst was carried out in the continuous flow AEM based electrolysis cell to produce lactate and pyruvate. The experiments show that the increasing of electrode potential can promote both the conversion of 1,2-propanediol and the production of pyruvate. The selectivity of pyruvate increases from $18.6 \%$ at $0.35 \mathrm{~V}$ vs. RHE with 1,2-propanediol conversion of $3.5 \%$ to $55.9 \%$ at $0.75 \mathrm{~V}$ vs. RHE with 1,2-propanediol conversion of $12.5 \%$. To determine and explain the mechanisms of potential-regulated electrocatalytic oxidation reaction, DFT calculations were performed by our collaborators. The reaction energy diagrams developed show that there is a high energy step for the transformation of lactate to pyruvate, which requires a high electrode potential to overcome, thereby 
explaining the dominant product of pyruvate at high potentials observed in experiments. Future researches should extend the DFT model to study the reaction steps involving C-C bond breaking, so as to deepen the understanding the mechanisms of electrocatalytic oxidation of 1,2-propanediol on $\mathrm{Au} / \mathrm{C}$. The acquired knowledge of the reaction mechanisms through combined experimental and theoretical DFT studies will lead to rational catalyst design for enhanced activity and controlled selectivity. 


\section{Chapter 7 Electrocatalytic reduction of Levulinic Acid (to Valeric Acid or $\gamma$-Valerolactone)*}

\subsection{Background}

Renewable electricity based on PV cell and wind power, although attractive, has an intermittent nature that requires the development of efficient energy storage devices. Current electrical energy storage techniques include pumped-storage hydropower (PSH), compressed-air energy storage (CAES), batteries, flywheels, and electrolysis of water to hydrogen (electro-hydrogen) for fuel cells, and so forth. ${ }^{171}$ In general, they serve to capture renewable electrical energy generated during off-peak hours and convert them into the forms of gravitational potential energy (with $\mathrm{PSH}$ ), molecular potential energy (with CAES), electrical potential energy (with batteries) or kinetic energy (with flywheels), and to release electrical energy during peak demand. PSH has a high efficiency (70-85\%) and long storage duration; however, the large amount of land required for the construction of a hydro dam and reservoir can increase construction costs and lower overall feasibility. CAES also has a high efficiency (70-89\%), long storage duration, and has attracted extensive attention recently, but it can only be constructed in areas with favorable geography because it needs to be used in conjunction with a gas turbine plant. Batteries are primarily for short-term storage and have more limited energy storage capacities, that is, $\mathrm{Li}$ ion batteries have an effective practical energy density of only $0.35 \mathrm{kWh} \mathrm{kg}^{-1}$, which is approximately $20 \%$ that of gasoline $\left(13 \mathrm{kWh} \mathrm{kg}^{-1}\right.$, however, if considering its tank-to-wheel efficiency (including Carnot efficiency) of $12.6 \%$, the

\footnotetext{
${ }^{*}$ The material contained in this chapter was previously published in ChemSusChem 2013;6(4):674-686 by Xin L, Zhang Z, Qi J, Chadderdon DJ, Qiu Y, Warsko KM, Li W. Copyright (C) 2013 John Wiley \& Sons, Inc. And Green Chemistry 2014;16(3):1305-1315 by Qiu $\mathrm{Y}^{\dagger}$, Xin $\mathrm{L}^{\dagger}$, Chadderdon DJ, Qi J, Liang C, Li W. (' equal contribution). Copyright (C) Royal Society of Chemistry 2014. Reprint with permission shown in Appendix F
} 
energy density of gasoline becomes $\left.1.7 \mathrm{kWh} \mathrm{kg}^{-1}\right) .{ }^{172}$ Production of $\mathrm{H}_{2}$ through electrolysis of water (electro-hydrogen) for $\mathrm{H}_{2}$-PEMFCs is another sustainable energy cycle option. ${ }^{34,57,173,174}$ Low-temperature $\mathrm{H}_{2}$-based PEMFCs can directly convert chemical energy stored in $\mathrm{H}_{2}$ into electricity without limitation of the Carnot cycle. ${ }^{175}$ However, a high loading of noble metals (i.e., $>0.6 \mathrm{mg}$ of Pt per electrode) is required in PEMFCs to facilitate the sluggish ORR at the cathode; this is a longstanding scientific issue, which dramatically decreases the energy conversion efficiency. ${ }^{176-179}$ Although the theoretical thermodynamic efficiency of a $\mathrm{H}_{2}$-PEMFCs is $83 \%$ under standard conditions, the operating voltage must be significantly decreased for a high power output, that is, $0.65 \mathrm{~V}$. Unfortunately, the resulting thermo-efficiency is only about $44 \%$. Considering the electrical current efficiency for $\mathrm{H}_{2}$ production in a PEM based electrolysis cell is around $70 \%$, the overall energy efficiency of fuel cell + electrolysis cell based on the hydrogen cycle is only $30 \% .{ }^{171}$ This does not even include the energy loss from fuel cells to mechanic motors (to wheels). In addition, both fuel (consumption of $\mathrm{H}_{2}$ ) and electrolysis (generation of $\mathrm{H}_{2}$ ) cells have to employ very expensive precious metals, such as $\mathrm{Pt}$ (for the ORR) ${ }^{176}$ and $\mathrm{IrO}_{2}$ or $\mathrm{RuO}_{2}$ (for the OER) ${ }^{180}$. In an acidic-electrolyte environment, the durability of both the catalyst (even noble metals) and membrane (even C - F backbone polymers) still needs improvement to achieve widespread application of PEMFCs in automobiles. ${ }^{31}$ Furthermore, storage and transportation of $\mathrm{H}_{2}$ have encountered significant challenges compared with well-established liquid fuel pipeline systems.

Although active R\&D activities are still under way to achieve higher efficiency based on the current electrical energy storage techniques, seeking new electrochemistry-based energy storage methods should be simultaneously promoted in order to diversify and secure our energy future. The electro-biorefinery process presented in this chapter can capture overproduced renewable electricity in the form of chemical potential energy; this can be achieved by employing electrocatalytic processes to convert abundant, cheap biomass-derived compounds into biofuel-related compounds with higher energy densities that are suitable for further upgrading and blending in gasoline or diesel. 
Abundant and renewable ligno-cellulosic biomass is expected to occupy a significant position in our future energy landscape; thus it has great potential to serve as feedstock to produce chemicals, polymers, and biofuels. ${ }^{6,22,181}$ One of the most important components derived from ligno-cellulosic biomass is highly polymerized cellulose (DP 7000-15 000), which can be employed as a sustainable source to produce levulinic acid through dilute acid-catalyzed hydrolysis processes. ${ }^{10,182}$ Levulinic acid can be further upgraded to a wide range of value-added chemicals and fuel additives, ${ }^{10,183}$ and has been identified as one of the top abundant, renewable building-block biomass compounds by the USDOE. ${ }^{14}$ The hydrolysis of waste cellulose to levulinic acid is carried out in 0.1-0.5 M sulfuric acid aqueous solution; equal molar levulinic acid and formic acid (levulinic acid : formic acid $=$ mol: mol $=1: 1$ ) can be cheaply produced at yields of $70 \%$ and $50 \%$, respectively. ${ }^{26,184}$

Levulinic acid, although considered a promising feedstock for chemicals and biofuel production, has excess oxygen functionalities. Thus, effective processes are needed to remove oxygen in the hydroxyl, ketone, aldehyde, and carboxylic groups of levulinic acid or its derivatives ( $\gamma$-valerolactone $(\mathrm{gVL})$, valeric acid, etc.) to upgrade them to high energy density transportation fuels (gasoline, jet, and diesel fuels) or fuel additives.

Unfortunately, both the by-product formic acid and the residual sulfuric acid that remained in the hydrolysis downstream will bring some complexities to the subsequent transformation of LA to biodegradable chemicals or fuel additives during heterogeneous catalytic processes. $^{10,185}$ The hydrogenation of levulinic acid to $\mathrm{GVL}^{23,186-188}$ and valeric acid $^{21,189}$, using Pt, Pd or Ru based mono- or bi-functional catalysts, have been investigated through heterogeneous catalytic processes. It has been reported that formic acid can rapidly deactivate the noble metal catalysts, and has negative effects on deoxygenation of levulinic acid. For example, fed with a levulinic acid + formic acid mixture stream, GVL was produced in low yield over $\mathrm{Ru} / \mathrm{C}$, which was mainly due to the poisoning effect of formic acid. ${ }^{186,187}$ Thus, novel processing routes and advanced catalysts have recently been explored to remove or utilize the by-product formic acid. For example, a continuous dual bed tubular reactor was developed where $\mathrm{Ru}-\mathrm{P} / \mathrm{SiO}_{2}$ and 
$\mathrm{Ru} / \mathrm{TiO}_{2}$ catalysts fixed separately in this two-stage process are responsible for the decomposition of formic acid and hydrogenation of levulinic acid, respectively. ${ }^{186}$ Dumesic and co-workers have also designed bimetallic $\mathrm{RuSn}_{4} / \mathrm{C}$ and $\operatorname{RuRe}(3: 4) / \mathrm{C}$ catalysts that demonstrate sufficient stability to tolerate acidic conditions for GVL synthesis, through which levulinic acid together with formic acid can be fed into the reactor and formic acid is directly self-decomposed to $\mathrm{CO}_{2}$ and $\mathrm{H}_{2} \cdot{ }^{24,188}$ It not only successfully utilizes the formic acid as a hydrogen source, avoiding the external petroleum-derived hydrogen supply, but also mitigates the greenhouse gas emission, because the generated $\mathrm{CO}_{2}$ can be effectively captured and treated for other applications. ${ }^{189,190}$ On the other hand, the residual sulfuric acid in the downstream has also been found to deteriorate the metallic catalysts for hydrogenation of the levulinic acid to GVL; ${ }^{191,192}$ thus, novel strategies need to be developed to separate levulinic acid and formic acid from aqueous sulfuric acid. Direct esterification of levulinic acid and formic acid using alcohols and butane has been developed to produce hydrophobic levulinic acid and formic acid ester, which automatically separate from residual aqueous sulfuric acid, and can then be recycled for cellulose dehydration. ${ }^{23,193-195}$ Although attractive, the above mentioned heterogeneous catalysis processes often requires the operating temperatures and pressures are as high as $370-420 \mathrm{~K}$ and $10-30$ bar, respectively. ${ }^{22}$ The safety issues associated with pressurized hydrogen gas involved under these conditions will arise from this biofuel upgrading rout that needs special hydrogen management and robust and robust reactor design. In addition, the removal and reuse of $\mathrm{H}_{2} \mathrm{SO}_{4}$, despite providing possible solutions, still need the subsequent separation and recovery of target products, which accounts for a large portion of the working capital. ${ }^{192}$ Therefore, exploring alternative and sustainable strategies of upgrading the cellulose hydrolysis downstream to biofuel (intermediates) is still necessary to supplement the current heterogeneous catalytic hydrogenation processes.

Regarding renewable electricity utilization, environmental conservation and economic feasibility, electrocatalytic hydrogenation $(\mathrm{ECH})$ mitigates several concerns associated with the conventional heterogeneous catalytic hydrogenation of biomass-derived 
oxygenates, which are, in most cases, the demand for pressurized hydrogen gas, elevated temperatures and energy-intense separation processes. Electrocatalysis has been investigated for the reduction of biomass derived lactic acid ${ }^{196}$, acetone ${ }^{197}$, furfural ${ }^{198-201}$, $\mathrm{HMF}^{202}$, glucose ${ }^{203}$ and bio-oil derived phenolic compounds ${ }^{204}$ in aqueous solution. In this chapter, levulinic acid was chosen as a model biomass derived compound. It will first study the effects of applied potential, electrolyte $\mathrm{pH}$ on $\mathrm{ECH}$ of levulinic acid in both batch-type three-electrode cell reactor and continuous flow-type AEM or PEM based electrolysis cell reactor. (Fig. 7.1) Additionally, the molecular structure effects on the electrocatalytic reduction of hydroxyl, ketone, and aldehyde groups of biomass-relevant compounds in terms of reactivity, selectivity, and reaction pathway are also thoroughly investigated. Next, a green integrated electrocatalytic strategy will be developed by coupling AEM based electrolysis cell and PEM based fuel cell reactors to process realistic raw biomass feed stock: the downstream of acid-catalyzed cellulose hydrolysis is simulated by preparing a sulfuric acid aqueous solution of equal molar levulinic acid and formic acid so that the effects of each coupled components on upgrading levulinic acid to valeric biofuel intermediates will be examined. (Fig. 7.2)

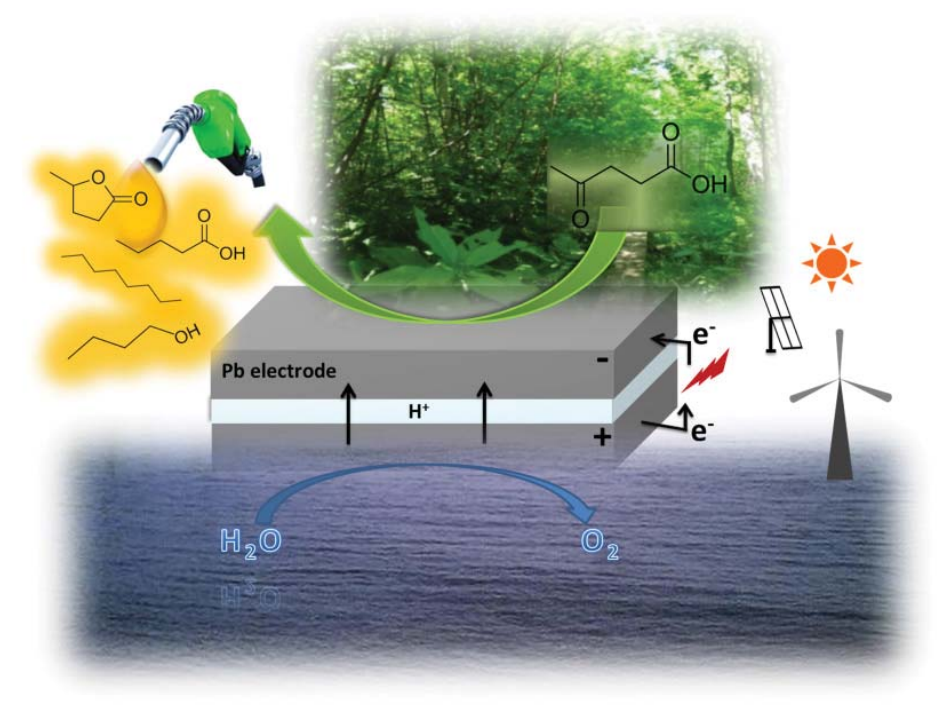

Fig. 7.1 Illustration of selective electrocatalytic hydrogenation of levulinic acid to valeric biofuels with renewable electricity storage. 


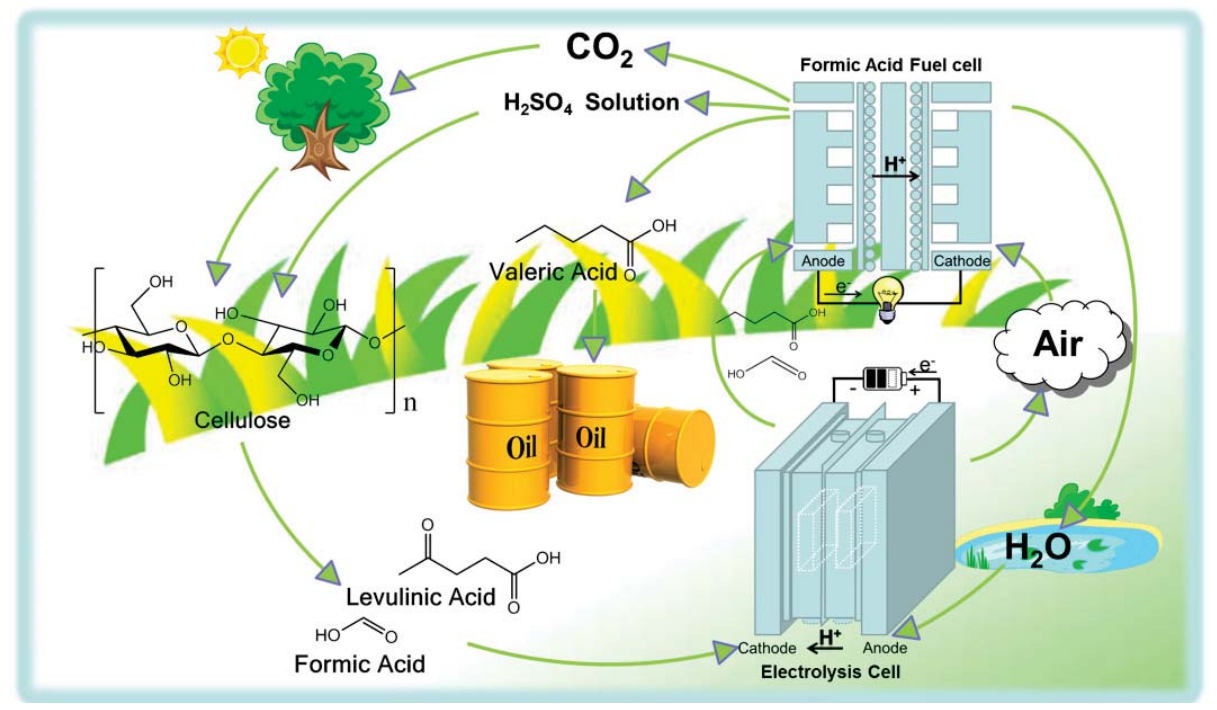

Fig. 7.2 Illustration of integrated electrocatalytic processing of levulinic acid and formic acid to produce biofuel intermediate valeric acid.

\subsection{General experimental}

\subsubsection{Preparation of electrode materials}

Prior to experiments, $\mathrm{Pb}$ (99.9\%, Rotometals Inc., United States) and $\mathrm{Cu}$ (99.9\%, Small Parts Inc., United States) metal electrodes underwent pretreatment procedures according to Section 2.3.2 to remove surface impurities and oxides.

The carbon black supported Pd (ca. 40 wt.\%) was synthesized by a modified organic solution phase reduction method, and has been discussed in Section 2.4.3.

\subsubsection{Physical characterizations}

The morphology, nanostructure and metal loading of $\mathrm{Pd} / \mathrm{C}$ were analyzed by TEM, XRD and ICP-OES, as described in Section 2.5.1, 2.5.3 and 2.5.4.

The surface of $\mathrm{Pb}$ and $\mathrm{Cu}$ electrodes was characterized by a SEM equipped with EDS as described in Section 2.5.2 


\subsubsection{Electrochemical tests}

\subsubsection{Half-cell tests}

Half-cell tests were performed in a conventional three-electrode-cell setup (Section 2.2.1), equipped with a glassy carbon working electrode, a reference electrode and a $\mathrm{Pt}$ coil counter electrode.

As for the $\mathrm{ECH}$ conducted in the batch-type half-cell reactor, $\mathrm{Pb}$ or $\mathrm{Cu}$ metal plate was used as working electrode and the electrochemical data was recorded versus $\mathrm{Ag} / \mathrm{AgCl}$ (in saturated $\mathrm{KCl}$ solution) reference electrode and reported with respect to RHE. Cathodic cyclic voltammetry scans were firstly performed for 20 cycles from -0.35 to -1.6 and 0.35 to $-1.5 \mathrm{~V}$ vs. RHE on a $\mathrm{Pb}$ electrode in a solution at $\mathrm{pH} 0$ and 7.5 , respectively, whereas the scan range was -0.35 to $-1.1 \mathrm{~V}$ vs. $\mathrm{RHE}$ on a $\mathrm{Cu}$ electrode in a solution of $\mathrm{pH}$ $\cong 0$. The scan rate was $50 \mathrm{mV} \mathrm{s}^{-1}$. The cyclic voltammetry scans were taken to ensure that the surface $\mathrm{CuO}_{\mathrm{x}}$ and $\mathrm{PbO}_{\mathrm{x}}$ was reduced. The last stabilized CV curve was reported. The upper limits of the cyclic voltammetry scan ranges were selected to be within the potentials at which the dissolution of $\mathrm{Pb}$ and $\mathrm{Cu}$ metals would not occur. Buffer solutions of $\mathrm{K}_{2} \mathrm{HPO}_{4}$ and $\mathrm{KH}_{2} \mathrm{PO}_{4}$ with or without the addition of levulinic acid were prepared with 18.2 $\mathrm{M} \Omega$ deionized water and the $\mathrm{pH}$ of this neutral electrolyte was adjusted to $c a$. 7.5. The acidic electrolyte was prepared by applying the precursors (levulinic acid, GVL, pyruvic acid, and glyoxylic acid) in $0.5 \mathrm{~m} \mathrm{H}_{2} \mathrm{SO}_{4}$. The $\mathrm{pH}$ of the acidic electrolyte was set to be $c a$. zero. Next, a fresh $55 \mathrm{ml}$ of electrolyte was loaded into the three-necked glassware and CA was carried out to study the potential effect on the product distribution during the ECH process.

To investigate the effects of valeric acid present in the electrolyte on the electrocatalytic oxidation of formic acid over $\mathrm{Pd} / \mathrm{C}$, half-cell tests were conducted by using $\mathrm{Pd} / \mathrm{C}$ coated glassy carbon electrode as working electrode and a reversible hydrogen reference electrode (Hydroflex $\left.{ }^{\circledR}\right)$. All testing electrolytes were de-aerated with high purity $\mathrm{N}_{2}$ (99.99\%) for $30 \mathrm{~min}$ before use. Prior to the experiments, $2.0 \mathrm{mg} \mathrm{Pd} / \mathrm{C}$ was ultrasonically dispersed in $1.0 \mathrm{ml}$ isopropanol and $10 \mu \mathrm{l}$ of Nafion proton exchange ionomer solution (5 
$\mathrm{wt} \%, 1100 \mathrm{EW}$, Ion Power, Inc.) to form uniform ink. $80 \mu \mathrm{l}$ of the catalyst ink was dropcasted onto the glassy carbon electrode. The activity of formic acid electro-oxidation on $\mathrm{Pd} / \mathrm{C}$ was measured by carrying out cyclic voltammetry in $0.5 \mathrm{M} \mathrm{H}_{2} \mathrm{SO}_{4}$ aqueous solution mixed with $1.0 \mathrm{M}$ formic acid or $1.0 \mathrm{M}$ formic acid + valeric acid $(0.1-0.3 \mathrm{M})$ in the potential region between $0.1 \mathrm{~V}$ and $1.2 \mathrm{~V}$ (vs. RHE) at a scan rate of $50 \mathrm{mV} \mathrm{s}^{-1}, 25^{\circ} \mathrm{C}$ and $2000 \mathrm{rpm}$. CVs recorded in the same potential window using either blank $0.5 \mathrm{M} \mathrm{H}_{2} \mathrm{SO}_{4}$ or $0.5 \mathrm{M} \mathrm{H}_{2} \mathrm{SO}_{4}$ with different carboxylic acids, including acetic acid, propionic acid, butyric acid and valeric acid, were employed to determine the ECSA change. Twenty CVs were recorded under each condition and the final CV was reported.

\subsubsection{Continuous flow-type electrolysis cell tests}

The selective ECH of levulinic acid was also carried out in the continuous flow solidpolymer electrolyte membrane (AEM or PEM) based electrolysis cell reactors constructed with $\mathrm{Pb}$ or $\mathrm{Cu}$ foil electrode. (Section 2.2.2 and Fig. 2.3) During each run, 55 $\mathrm{ml}$ of $0.2 \mathrm{M}, 0.5 \mathrm{M}$ and $1.0 \mathrm{M}$ levulinic acid with or without an equal concentration of formic acid in $0.5 \mathrm{M} \mathrm{H}_{2} \mathrm{SO}_{4}$ or $0.2 \mathrm{M}$ pure levulinic acid in $\mathrm{K}_{2} \mathrm{HPO}_{4} / \mathrm{KH}_{2} \mathrm{PO}_{4}$ buffer solution was fed into the cathode chamber in a closed loop by a peristaltic pump at $30 \mathrm{ml}$ $\mathrm{min}^{-1}$, while the electrolyte of same $\mathrm{pH}$ without levulinic acid was quickly pumped into the anode chamber to remove the $\mathrm{O}_{2}$ that was produced during the OER on the Pt foil electrode. After certain time of reaction under different applied potentials, the products were sampled and analyzed by HPLC. ICP-OES was performed to examine the stability of the $\mathrm{Pb}$ electrode after prolonged reaction.

\subsubsection{Proton exchange membrane-direct formic acid fuel cell (PEM-DFAFC) study}

Electrocatalytic oxidation removal of formic acid in the solution of valeric acid $+0.5 \mathrm{M}$ $\mathrm{H}_{2} \mathrm{SO}_{4}$ was tested on a Scribner Fuel Cell system 850e of a fuel cell fixture setup similar to Fig. 2.5. The anode electrode composed of $70 \mathrm{wt} . \% \mathrm{Pd} / \mathrm{C}$ catalyst and $30 \mathrm{wt} . \%$ Nafion ionomer was sprayed onto a PTFE-untreated carbon cloth liquid diffusion layer to obtain

a catalyst loading of $3.0 \mathrm{mg}_{\mathrm{Pd}} \mathrm{cm}^{-2}$. At the cathode, catalyst slurry containing $70 \mathrm{wt} . \%$ of $\mathrm{Pt} / \mathrm{C}$ (Fuel Cell Store, $40 \mathrm{wt} . \%$ ) and $30 \mathrm{wt} . \%$ of Nafion ionomer was sprayed onto a 
PTFE-treated carbon cloth GDL to obtain a catalyst loading of $3.0 \mathrm{mg}_{\mathrm{Pt}} \mathrm{cm}^{-2}$. Finally, a 5 wt.\% Nafion solution was sprayed onto the surface of both the anode and the cathode (1.0 $\mathrm{mg}$ Nafion $\mathrm{cm}^{-2}$ ) to form a thin Nafion layer. The MEA was constructed by hot pressing the anode, the cathode and the pre-treated Nafion membrane (N117, Ion Power, Inc.) under a pressure of $140 \mathrm{~atm}$ at $135^{\circ} \mathrm{C}$ for $3 \mathrm{~min}^{205} 1.0 \mathrm{M}$ formic acid with or without the addition of $0.3 \mathrm{M}$ valeric acid in $0.5 \mathrm{M} \mathrm{H}_{2} \mathrm{SO}_{4}$ was pumped into the anode compartment at $1 \mathrm{ml} \mathrm{min}{ }^{-1}$, while high purity $\mathrm{O}_{2}(99.999 \%)$ regulated at $400 \mathrm{ml} \mathrm{min}^{-1}$ was fed into the cathode compartment under ambient pressure. The polarization curves of the PEMDFAFC were collected by scanning current at $30^{\circ} \mathrm{C}$. Electrocatalytic oxidation of formic acid was performed for 6 hours at a fuel cell voltage of $0.1 \mathrm{~V}$. Samples were withdrawn every $1 \mathrm{~h}$ and analyzed by HPLC.

\subsubsection{Product analysis}

The products from the selective ECH of organic compounds and oxidation removal of formic acid were analyzed by HPLC and identified, quantified by comparison with authentic samples (Section 2.7).Faradaic efficiency, selectivity, yield and carbon balance of the reactions were calculated according to Equation 2-10 - 2-14.

\subsection{Results and Discussion}

\subsubsection{Thermodynamics and kinetics of the $\mathrm{ECH}$ reaction}

From a thermodynamic point of view, the reversible potential of the hydrogenation of levulinic acid to valeric acid is around $500 \mathrm{mV}$ more positive than that of the hydrogen evolution reaction (HER) across the entire $\mathrm{pH}$ range, as shown in Fig. 7.3. This indicates that, since levulinic acid reduction involves $\mathrm{H}_{2} \mathrm{O}$ and $\mathrm{H}^{+}$, the reversible potentials varies in accordance with the $\mathrm{pH}$ of the electrolyte. In addition, the boundary region where the forms of the stable acids (levulinic acid and valeric acid) and salt (levulinate and valerate) exist in the electrolyte is also shown; this is dependent on the electrolyte $\mathrm{pH}$. At $\mathrm{pH} \cong 0$ at room temperature, the thermodynamically stable forms are levulinic acid and valeric acid as the ratio of $\left[\mathrm{CH}_{3} \mathrm{CO}\left(\mathrm{CH}_{2}\right)_{2} \mathrm{COOH}\right]$ to $\left[\mathrm{CH}_{3} \mathrm{CO}\left(\mathrm{CH}_{2}\right) 2 \mathrm{COO}^{-}\right]$and 
$\left[\mathrm{CH}_{3}\left(\mathrm{CH}_{2}\right)_{3} \mathrm{COOH}\right]$ to $\left[\mathrm{CH}_{3}\left(\mathrm{CH}_{2}\right)_{3} \mathrm{COO}^{-}\right]$are 42000 and 66000 , respectively. Therefore, the $\mathrm{ECH}$ of $\mathrm{CH}_{3} \mathrm{CO}\left(\mathrm{CH}_{2}\right)_{2} \mathrm{COOH}$ to $\mathrm{CH}_{3}\left(\mathrm{CH}_{2}\right)_{3} \mathrm{COOH}$ in aqueous solution is given in Equation 7-1 with respect to SHE:

$$
\mathrm{CH}_{3} \mathrm{CO}\left(\mathrm{CH}_{2}\right)_{2} \mathrm{COOH}+4 \mathrm{H}^{+}+4 \mathrm{e}^{-} \rightleftarrows \mathrm{CH}_{3}\left(\mathrm{CH}_{2}\right)_{3} \mathrm{COOH}+\mathrm{H}_{2} \mathrm{O} \mathrm{E}^{\circ}=+0.54 \text { vs. SHE }
$$

At a $\mathrm{pH}$ value of $\mathrm{ca}$. 7.5 , the salt-to-acid ratios are $\left[\mathrm{CH}_{3} \mathrm{CO}\left(\mathrm{CH}_{2}\right)_{2} \mathrm{COO}^{-}\right.$ ]$/\left[\mathrm{CH}_{3} \mathrm{CO}\left(\mathrm{CH}_{2}\right)_{2} \mathrm{COOH}\right]=2400$ and $\left[\mathrm{CH}_{3}\left(\mathrm{CH}_{2}\right)_{3} \mathrm{COO}^{-}\right] /\left[\mathrm{CH}_{3}\left(\mathrm{CH}_{2}\right)_{3} \mathrm{COOH}\right]=1500$, respectively; therefore, valerate $\left(\mathrm{CH}_{3}\left(\mathrm{CH}_{2}\right)_{3} \mathrm{COO}^{-}\right)$is predominantly produced from levulinate $\left(\mathrm{CH}_{3} \mathrm{CO}\left(\mathrm{CH}_{2}\right)_{2} \mathrm{COO}^{-}\right)$, as shown in Equation 7-2:

$$
\mathrm{CH}_{3} \mathrm{CO}\left(\mathrm{CH}_{2}\right)_{2} \mathrm{COO}^{-}+3 \mathrm{H}_{2} \mathrm{O}+4 \mathrm{e}^{-} \rightleftarrows \mathrm{CH}_{3}\left(\mathrm{CH}_{2}\right)_{3} \mathrm{COO}^{-}+4 \mathrm{OH}^{-} \mathrm{E}^{\circ}=+0.08 \text { vs. SHE }
$$

As shown in Fig. 7.3, the ECH of levulinic acid to valeric acid is a thermodynamically favorable reaction compared to HER. However, HER kinetically proceeds faster on the metal electrode compared with the ECH reactions, and therefore, the actual electrolysis potentials for ECH of levulinic acid and HER are very similar depending on the electrode materials. Previous works have provided the mechanism of the HER, ${ }^{206}$ which proceeds through the steps shown in Equations 7-3 - 7-7:

Volmer step:

$$
\begin{gathered}
\mathrm{H}^{+}+\mathrm{e}^{-} \rightarrow \mathrm{H}_{\text {ads }} \text { (in acid) } \\
\mathrm{H}_{2} \mathrm{O}+\mathrm{e}^{-} \rightarrow \mathrm{H}_{\mathrm{ads}}+\mathrm{OH}^{-} \text {(in base) }
\end{gathered}
$$

Tafel step:

$$
2 \mathrm{H}_{\mathrm{ads}} \rightarrow \mathrm{H}_{2}
$$

Heyrovsky step:

$$
\mathrm{H}_{\mathrm{ads}}+\mathrm{H}^{+}+\mathrm{e}^{-} \rightarrow \mathrm{H}_{2} \text { (in acid) }
$$




$$
\mathrm{H}_{2} \mathrm{O}+\mathrm{e}^{-} \rightarrow \mathrm{H}_{\text {ads }}+\mathrm{OH}^{-} \text {(in base) }
$$

The adsorbed hydrogen generated from the Volmer step serves as the hydrogen source for subsequent ECH steps. The Tafel and Heyrovsky steps facilitate the HER, which are unwanted side reactions that reduce the surface adsorbed hydrogen density and consume the applied electrical energy (decrease the Faradaic efficiency). Since the electrochemical steps in Equations 7-3 - 7-7 govern the availability of adsorbed hydrogen, it is expected that the ECH selectivity and reaction rate will be affected by the applied potential, the electrolyte $\mathrm{pH}$, and the metal catalyst.

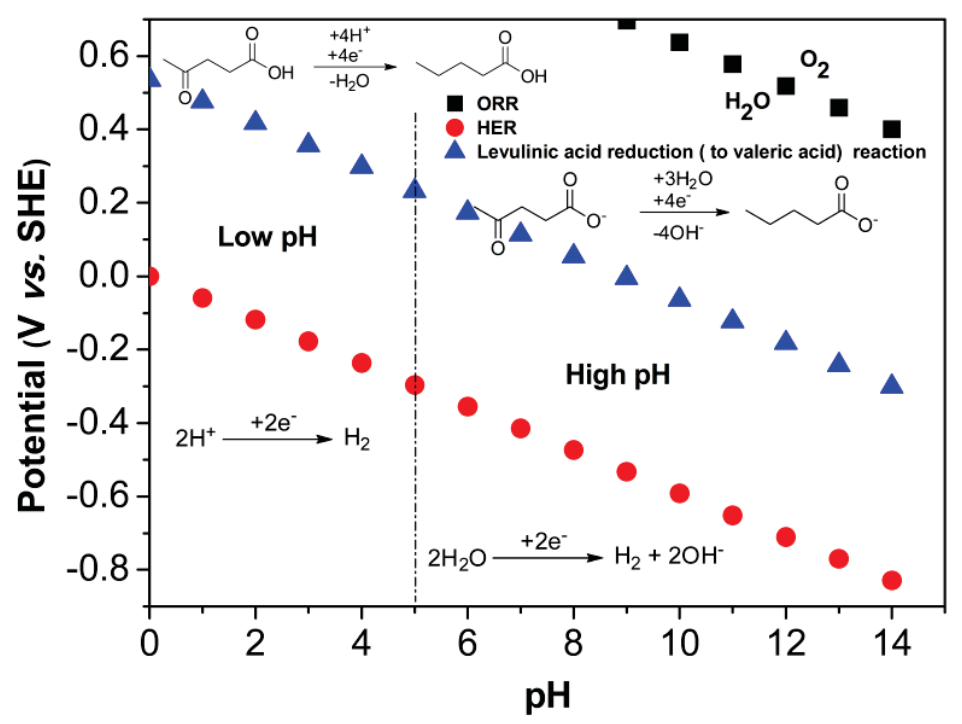

Fig. 7.3 Theoretical potential for the ORR, HER, and electrochemical hydrogenation of levulinic acid to valeric acid as a function of $\mathrm{pH}$.

Fig. 7.4 shows $\mathrm{CVs}$ of the $\mathrm{ECH}$ of levulinic acid on pretreated $\mathrm{Pb}$ and $\mathrm{Cu}$ electrodes. The cyclic voltammetry scan was performed in a $0.5 \mathrm{M} \mathrm{H}_{2} \mathrm{SO}_{4}$ with or without $0.2 \mathrm{M}$ levulinic acid at a scan rate of $50 \mathrm{mV} \mathrm{s}^{-1}$. From the $\mathrm{CVs}$ of the $\mathrm{Pb}$ electrode with or without the addition of $0.2 \mathrm{M}$ levulinic acid, it is clear that the onset potential is over 200 $\mathrm{mV}$ more positive and the cathodic current is significantly greater with $0.2 \mathrm{M}$ levulinic acid than that without levulinic acid. In sharp contrast, the HER in $0.5 \mathrm{M} \mathrm{H}_{2} \mathrm{SO}_{4}$ on $\mathrm{Cu}$ occurs at $-0.4 \mathrm{~V}$ vs. RHE, which is $700 \mathrm{mV}$ more positive compared with $-1.1 \mathrm{~V}$ vs. RHE for $\mathrm{Pb}$. However, in the absence and presence of $0.2 \mathrm{M}$ levulinic acid, the cathodic 
current density remains almost the same on the $\mathrm{Cu}$ electrode, indicating that the adsorption of levulinic acid or charge transfer due to the ECH of levulinic acid is suppressed by the very fast HER on $\mathrm{Cu}$. The product analysis shown in Table 7.1 (entry 8) confirms that the conversion of levulinic acid is zero on the $\mathrm{Cu}$ electrode, indicating that electrons transferred are all attributed to the HER. According to the Faraday Law, ${ }^{207}$ the net current flow during the electrochemical reaction can be proportionally attributed to the amount of levulinic acid converted in the given time period. Valuable information about the extent of the ECH of levulinic acid accompanied by the HER is provided by cyclic voltammetry experiments. However, product analysis needs to be carried out under different reaction conditions to investigate the extent of the levulinic acid ECH reaction and to further elucidate reaction pathways.

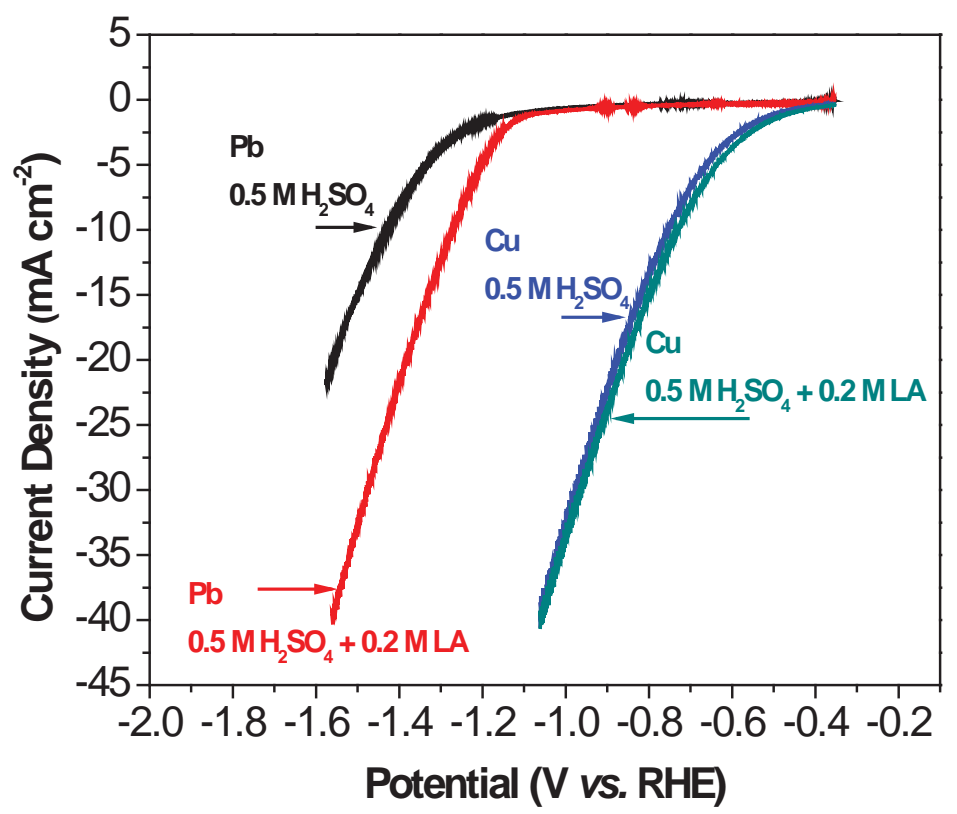

Fig. 7.4 $\mathrm{CVs}$ of the $\mathrm{ECH}$ of levulinic acid on $\mathrm{Pb}$ and $\mathrm{Cu}$ in an acidic electrolyte $(\mathrm{pH} \cong 0)$ at a scan rate of $50 \mathrm{mV} \mathrm{s}^{-1}$, room temperature, and ambient pressure.

7.3.2 Potential-/pH- regulated selective ECH of levulinic acid to valeric acid and GVL on a $\mathrm{Pb}$ electrode in batch-type half-cell reactors

Selective ECH of levulinic acid was conducted in a batch-type half-cell reactor with 55 $\mathrm{mL}$ of electrolyte. CA was carried out under different applied voltages for $1 \mathrm{~h}$. As 
summarized in Fig. 7.5 and Table 7.1, the selective production of GVL and valeric acid on a $\mathrm{Pb}$ electrode was governed by the extent of polarization of the $\mathrm{Pb}$ electrode, which could be controlled by the applied potential. At $-1.1 \mathrm{~V}$ vs. RHE, which is close to the onset potential of levulinic acid $\mathrm{ECH}$ on the $\mathrm{Pb}$ electrode, $81.5 \%$ selectivity to valeric acid (18.5\% to GVL) was observed at a Faradaic efficiency of $27.9 \%$ and levulinic acid conversion of $1.2 \%$. When the applied voltage decreased to $-1.3 \mathrm{~V}$ vs. RHE, the valeric acid selectivity increased to $94.1 \%$ (5.9\% to GVL), while the ECH Faradaic efficiency and levulinic acid conversion increased to $83.8 \%$ and $6.7 \%$, respectively. When the applied potential further decreased to $-1.5 \mathrm{~V}$ vs. RHE, the selectivity of valeric acid increased to $97.0 \%$ and the conversion of levulinic acid jumped to $20.3 \%$ after $1 \mathrm{~h}$ reaction, while the Faradaic efficiency slightly dropped to $78.3 \%$. The results demonstrate that the $\mathrm{ECH}$ of levulinic acid $\left(\mathrm{CH}_{3} \mathrm{CO}\left(\mathrm{CH}_{2}\right)_{2} \mathrm{COOH}\right)$ might involve a serial four-electron pathway through the reaction intermediate 4-hydroxypentanoic acid $\left(\mathrm{CH}_{3} \mathrm{COH}(\mathrm{CH} 2)_{2} \mathrm{COOH}_{\text {ads }}\right)$, the presence of which was proposed by Dumesic's group. ${ }^{189}$ The adsorbed 4-hydroxypentanoic acid can be further reduced to valeric acid $\left(\mathrm{CH}_{3}\left(\mathrm{CH}_{2}\right)_{3} \mathrm{COOH}\right)$ or desorbed into the bulk electrolyte to form GVL. The more negative the potential applied, the higher the selectivity of valeric acid that can be achieved with less GVL detected. 


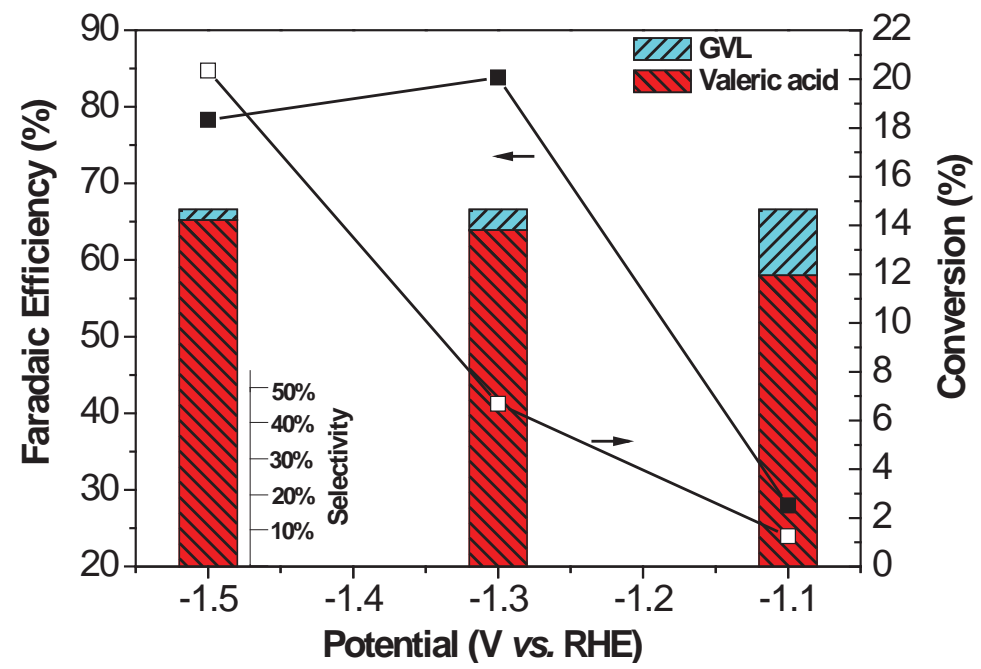

Fig. 7.5 Selective ECH of levulinic acid on a $\mathrm{Pb}$ electrode in a batch-type half-cell reactor under different applied potentials; the Faradaic efficiency is related to the liquid products (valeric acid + GVL); reaction conditions: $0.5 \mathrm{M} \mathrm{H}_{2} \mathrm{SO}_{4}+0.2 \mathrm{M}$ levulinic acid, room temperature, ambient pressure, $1 \mathrm{~h}$.

The variation of Faradaic efficiency at different applied potential observed in Fig. 7.5 is consistent with the CV (Fig. 7.4) and Tafel plot (Fig. 7.6). Within the voltage range close to the onset potential at which the degree of $\mathrm{Pb}$ polarization is insufficient for levulinic acid reduction, the ECH of levulinic acid proceeds slowly. Thus, only a slight difference in the cathodic current density was observed with and without levulinic acid was observed, leading to a lower Faradaic efficiency (27.9 \%). With more negative applied voltage potentials, the availability of surface $\mathrm{H}_{\mathrm{ads}}$ atoms increases. The $\mathrm{ECH}$ of levulinic acid accelerates, as illustrated in Fig. 7.4, when the slope of the CV curve in the presence of levulinic acid becomes steeper than the blank electrolyte as the applied potential becomes more negative. However, the more negative the applied potential is, the unwanted HER is more competitive, proceeding through Tafel or Heyrovsky steps (Equation 7-5 and 7-6). This is supported by the increasing Tafel slope due to the mass transport issue arising from hydrogen gas bubbles generated on the $\mathrm{Pb}$ electrode surface as the applied potential becomes higher than $-1.4 \mathrm{~V}$ vs. RHE, as shown in Fig. 7.6 (a) and (b). Therefore, the measured Faradaic efficiency reaches a maximum at $-1.3 \mathrm{~V}$ vs. RHE $(83.8 \%)$ and decreases to $78.3 \%$ at $-1.5 \mathrm{~V}$ vs. RHE. 

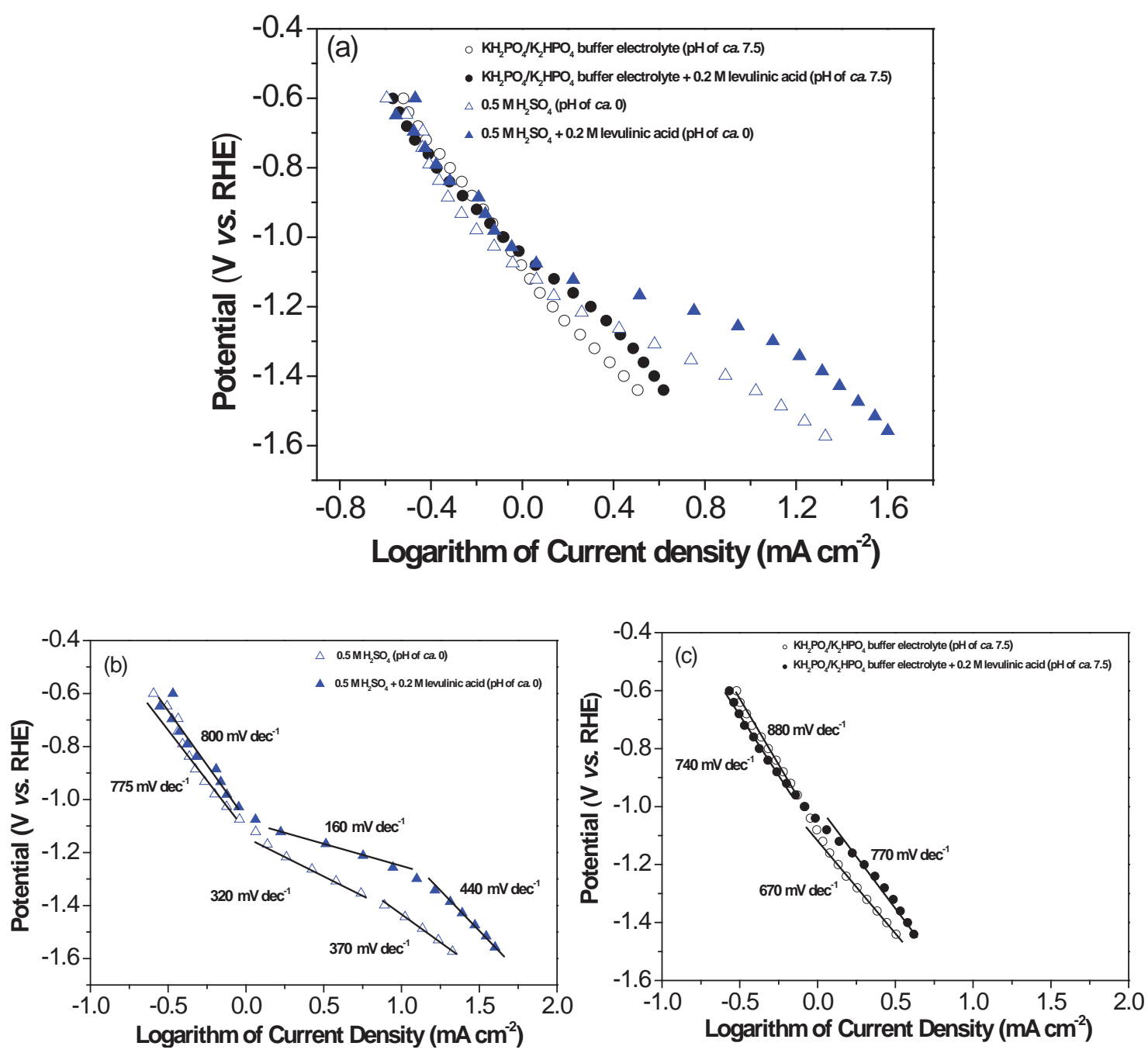

Fig. 7.6 Tafel plot of $\mathrm{ECH}$ of levulinic acid on $\mathrm{Pb}$ electrode as a function of $\mathrm{pH}$, room temperature and ambient pressure.

To evaluate the energy efficiency of the levulinic acid ECH reaction, the electricity consumption (EC) is defined in Equation 7-8:

$$
\text { Electricity consumption }=\frac{\text { Electrical energy input }}{\text { Unit product }}=\frac{\text { ExI } \times \text { t } / 1000}{\text { Unit product }}
$$

in which $E$ is the applied potential (in V vs. RHE) that only accounts for the cathodic reactions; $I$ is the current (in A); $t$ is the reaction time (in hour); and $\mathrm{EC}$ is given in $\mathrm{kWh} \mathrm{mol}_{\text {product }}^{-1}$ or $\mathrm{kWh} \mathrm{L}_{\text {product. }}^{-1}$ A lower $\mathrm{EC}$ value means that the production of the target product (e.g. valeric acid) requires a smaller amount of electrical energy input. The 
introduction of EC combines the Faradaic efficiency, the overpotential, and product yield (conversion $\times$ selectivity) to quantify the energy efficiency of the $\mathrm{ECH}$ process. Based on the ECH reaction carried out in the half-cell reactor, the lowest EC of 1.6 kWh mol ${ }_{\text {valeric acid }}^{-1}$ was achieved at $-1.3 \mathrm{~V}$ vs. RHE, as shown in Table 7.1 and Fig. 7.7. Thus, with an electricity input of $1.6 \mathrm{kWh}, 1 \mathrm{~L}$ of valeric acid with a higher energy density (25.9 MJ L-1 , compared with LA of $24.0 \mathrm{MJ} \mathrm{L}^{-1}$ ) can be produced. Based on the current industrial electricity rate of $\$ 0.068 \mathrm{kWh}^{-1}$ in the US, including demand charges, all other end-use costs and state and local taxes, ${ }^{208-210}$ the cost of the electricity is only $\$ 0.42$ for the production of 1 gallon of valeric acid from levulinic acid. In addition, the conversion of levulinic acid to valeric acid results in removal of the oxygen content in the biomass-derived oxygenate compound. Less-oxygen-containing valeric acid is an important biofuel precursor for the next step of upgrading to valeric biofuels. ${ }^{21}$

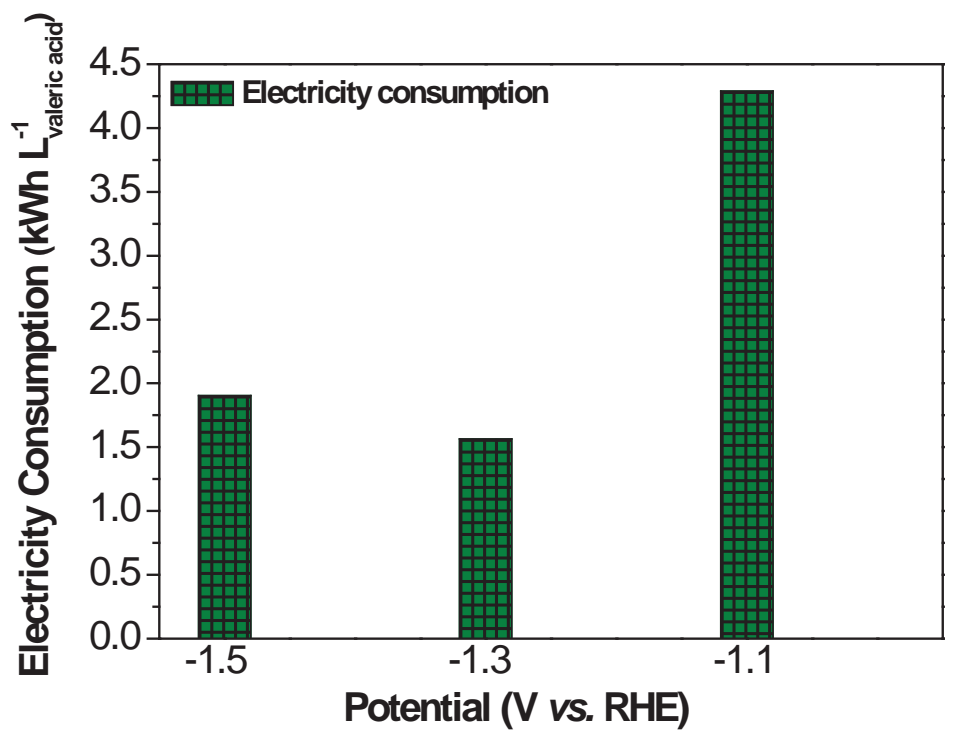

Fig. 7.7 EC of selectivity $\mathrm{ECH}$ of levulinic acid to $\mathrm{VA}$ on $\mathrm{Pb}$ electrode in aqueous solution as a function of applied potentials, reaction condition: $0.5 \mathrm{M} \mathrm{H}_{2} \mathrm{SO}_{4}+0.2 \mathrm{M}$ levulinic acid, room temperature and ambient pressure, reaction time: $1 \mathrm{~h}$.

The dependence of $\mathrm{pH}$ on the selectivity for $\mathrm{ECH}$ of levulinic acid on the $\mathrm{Pb}$ electrode was also investigated in the half-cell reactor with $0.2 \mathrm{M}$ levulinic acid $+0.5 \mathrm{M} \mathrm{H}_{2} \mathrm{SO}_{4}$ ( $\mathrm{pH} \cong 0)$ or $\mathrm{K}_{2} \mathrm{HPO}_{4} / \mathrm{KH}_{2} \mathrm{PO}_{4}$ buffer solution $(\mathrm{pH} \cong 7.5)$ as the electrolyte. Fig. 7.8 presents the $\mathrm{CV}$ curves of $\mathrm{ECH}$ of levulinic acid as a function of $\mathrm{pH}$. The observed 
current density in neutral electrolyte is generally much lower than that in acid medium, regardless of the addition of levulinic acid. This is probably due to the different kinetics and pathways for the ECH reactions in acid and neutral environments. Thus, the hydrogenation rate and selectivity would be expected to be a function of the electrolyte pH. Table 7.1 (entries 4 and 6) shows that the ketone group of levulinic acid can be fully reduced to $-\mathrm{CH}_{2}$ - by a four-electron-transfer reduction to valeric acid in low $\mathrm{pH}$ electrolyte (high $\mathrm{H}^{+}$concentration), whereas it is partially reduced to $-\mathrm{OH}$ in neutral electrolyte and involves only two-electron-transfer reduction. A selectivity of $100 \%$ to GVL at a levulinic acid conversion of $4.8 \%$ was achieved, although the EC in neutral electrolyte $\left(10.8 \mathrm{kWh} \mathrm{L}_{\mathrm{GVL}}{ }^{-1}\right)$ is much higher than that in acidic electrolyte $(1.6 \mathrm{kWh}$ $\left.\mathrm{L}_{\text {valeric acid }}{ }^{-1}\right)$.

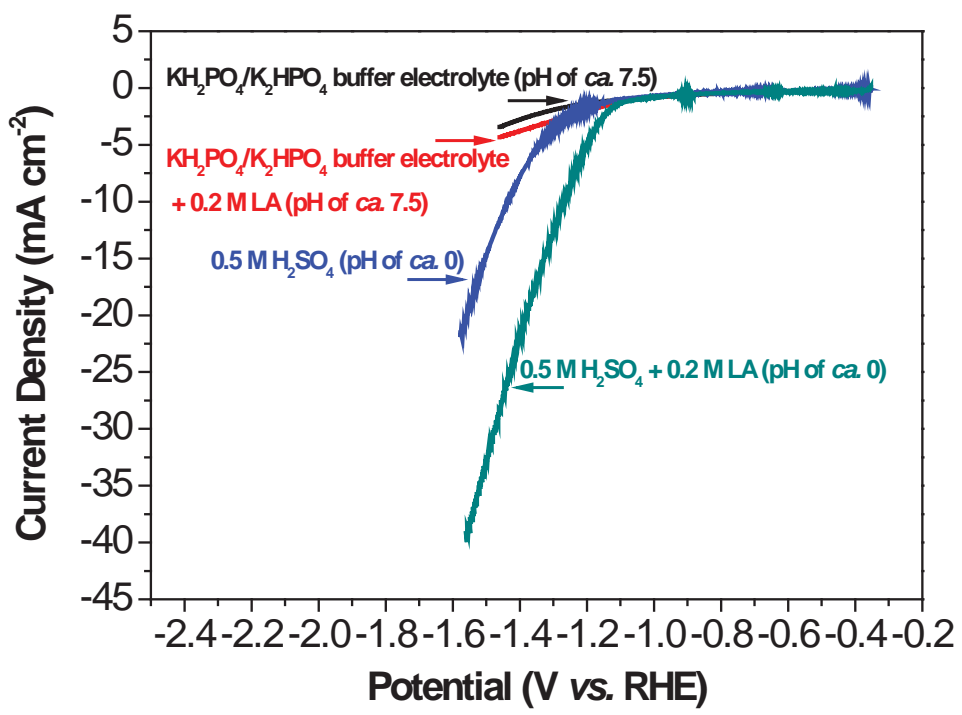

Fig. 7.8 CVs of ECH of levulinic acid on a $\mathrm{Pb}$ electrode as a function of $\mathrm{pH}$ at $50 \mathrm{mV} \mathrm{s}^{-1}$, room temperature, and ambient pressure.

The kinetic behavior of levulinic acid $\mathrm{ECH}$ on the $\mathrm{Pb}$ electrode in acid and neutral electrolytes was further revealed by the analysis of Tafel plots. Fig. 7.6 shows that both HER and ECH of levulinic acid proceed faster and require a lower overpotential to obtain a certain current density in the acidic electrolyte than those in the neutral solution. The number of electrons transferred in the acidic electrolyte with the presence of levulinic acid is twice of that in a blank $0.5 \mathrm{M}$ solution of $\mathrm{H}_{2} \mathrm{SO}_{4}$, leading to a four-electron- 
transfer reaction that favors the production of valeric acid. In comparison, ECH of levulinic acid on a Pb electrode involves two-electron-transfer (the same as the HER) to generate GVL in a neutral environment. It can also be inferred from the Tafel slope investigation that the energy required for the reactants to adsorb on the $\mathrm{Pb}$ electrode at a lower $\mathrm{pH}$ is lower than that at higher $\mathrm{pH}$, resulting in an increase in the production rate of $\mathrm{H}_{\text {ads }}$ atoms as well as molecular hydrogen. The higher coverage of $\mathrm{H}_{\text {ads }}$ atoms and levulinic acid on the $\mathrm{Pb}$ electrode in an acidic electrolyte could lower the energy barrier for complete reduction of the ketone group of levulinic acid to $-\mathrm{CH}_{2}$ - by a four-electrontransfer pathway. In the neutral electrolyte, both leuvlinic acid and monoatomic hydrogen adsorb weakly on the $\mathrm{Pb}$ electrode; therefore, only the partial reduction product GVL (by a two-electron-transfer pathway) was observed.

\subsubsection{Selective ECH of levulinic acid on a Pb electrode in the continuous flow-type AEM or PEM based electrolysis cell reactors}

The ECH of levulinic acid was also conducted in a custom-made continuous flow AEM or PEM based electrolysis cell reactors where the applied potential on the cathode was controlled by using a potentiostat, as illustrated in Fig. 2.4. In constrast to the half-cell setup, which is regarded to be a batch reactor, the electrolysis cell can be considered as a fixed-bed continuous flow reactor. Interestingly, it is observed amazing consistency in the $\mathrm{pH}$-dependent product selectivity between the batch and flow reactors, as shown in Table 7.1 (entries 4-7). At $\mathrm{pH} \cong 0$, the selectivity for valeric acid and GVL in the PEM based electrolysis cell reactor is 95.0 and $5.0 \%$, respectively; these values are in good agreement with the values achieved in a half-cell reactor: 94.5 and $5.5 \%$. At $\mathrm{pH} \cong 7.5$, $\mathrm{ECH}$ of levulinic acid in both reactors yields $100 \%$ selectivity to GVL. 
Table 7.1 ECH of levulinic acid in bath-type half-cell and flow-type electrolysis cell reactors.

\begin{tabular}{|c|c|c|c|c|c|c|c|c|c|c|}
\hline Entry & $\begin{array}{c}\text { Reactor } \\
\text { configuration }\end{array}$ & Electrode & Solvent & $\mathrm{pH}$ & $\begin{array}{c}E \\
\text { / V vs. } \\
\text { RHE }\end{array}$ & $\begin{array}{c}\text { Reaction } \\
\text { time } \\
/ \mathrm{h}\end{array}$ & $\begin{array}{c}\mathrm{EC} \\
/ \mathrm{kWh} \\
\mathrm{L}_{\mathrm{VA}}^{-1}\end{array}$ & $\begin{array}{c}\text { Selectivity }^{[\mathrm{a}]} \\
/ \%\end{array}$ & $\begin{array}{l}\text { Faradaic } \\
\text { efficienc }^{[\mathrm{b}]} \\
\quad / \%\end{array}$ & $\begin{array}{c}\text { Conversion } \\
/ \%\end{array}$ \\
\hline 1 & Half cell & $\mathrm{Pb}$ & $\mathrm{H}_{2} \mathrm{O} / \mathrm{H}_{2} \mathrm{SO}_{4}$ & 0 & -1.5 & 1 & 1.9 & 97.0 (to VA) & 78.3 & 20.3 \\
\hline 2 & Half cell & $\mathrm{Pb}$ & $\mathrm{H}_{2} \mathrm{O} / \mathrm{H}_{2} \mathrm{SO}_{4}$ & 0 & -1.3 & 1 & 1.6 & 94.1 (to VA) & 83.8 & 6.7 \\
\hline 3 & Half cell & $\mathrm{Pb}$ & $\mathrm{H}_{2} \mathrm{O} / \mathrm{H}_{2} \mathrm{SO}_{4}$ & 0 & -1.1 & 1 & 4.3 & 81.5 (to VA) & 27.9 & 1.2 \\
\hline 4 & Half cell & $\mathrm{Pb}$ & $\mathrm{H}_{2} \mathrm{O} / \mathrm{H}_{2} \mathrm{SO}_{4}$ & 0 & -1.3 & 2 & 1.6 & 94.5 (to VA) & 84.2 & 12.7 \\
\hline 5 & flow cell & $\mathrm{Pb}$ & $\mathrm{H}_{2} \mathrm{O} / \mathrm{H}_{2} \mathrm{SO}_{4}$ & 0 & -1.3 & 2 & 1.5 & 95.0 (to VA) & 86.5 & 18.6 \\
\hline 6 & Half cell & $\mathrm{Pb}$ & $\mathrm{H}_{2} \mathrm{O} /$ Buffer & 7.5 & -1.3 & 2 & $\begin{array}{c}10.8 \\
\text { (to } \\
\text { GVL) }\end{array}$ & 100 (to GVL) & 6.2 & 1.3 \\
\hline 7 & flow cell & $\mathrm{Pb}$ & $\mathrm{H}_{2} \mathrm{O} /$ Buffer & 7.5 & -1.3 & 2 & $\begin{array}{l}4.0 \text { (to } \\
\text { GVL) }\end{array}$ & 100 (to GVL) & 18.2 & 4.5 \\
\hline 8 & Half cell & $\mathrm{Cu}$ & $\mathrm{H}_{2} \mathrm{O} / \mathrm{H}_{2} \mathrm{SO}_{4}$ & 0 & -0.8 & 1 & $\infty$ & $0^{[\mathrm{c}]}$ & $0^{[\mathrm{d}]}$ & 0 \\
\hline
\end{tabular}

In addition, the ECH of levulinic acid conducted in the electrolysis cell demonstrates higher Faradaic efficiency and levulinic acid conversion than the half-cell reactor, as shown in Table 7.1 (entries 4-7) and Fig. 7.9. In neutral electrolyte ( $\mathrm{pH} \cong 7.5)$, the $\mathrm{ECH}$ of levulinic acid performed in the electrolysis cell reactor gives a higher Faradaic efficiency of $18.2 \%$ and a conversion of $4.5 \%$, with respect to 6.2 and $1.3 \%$, respectively, obtained in a half-cell reactor under the same reaction conditions. Table 7.1 (entries 6 and 7) shows the specific EC for the ECH process evaluated in both reactors at $\mathrm{pH} \cong 7.5$. It only requires $4.0 \mathrm{kWh}$ to produce $1 \mathrm{~L} \mathrm{GVL}$ in the electrolysis cell reactor, which is less than half of the electrical energy input of $10.8 \mathrm{kWh}$ for the production of $1 \mathrm{~L} \mathrm{GVL}$ obtained in the half-cell reactor. On the other hand, in acidic electrolyte, during the $6 \mathrm{~h}$ reaction, the conversion of levulinic acid achieved in the electrolysis cell reactor at $-1.3 \mathrm{~V}$ vs. RHE is also generally $7 \%$ higher than that in the half-cell reactor under identical reaction conditions. Notably, the Faradaic efficiency of the half-cell reactor decreases much faster than that in the electrolysis cell reactor. After the $6 \mathrm{~h}$ reaction, the Faradaic efficiency dropped to only $57.2 \%$ in the half-cell reactor, while a higher Faradaic efficiency of $76.7 \%$ was still maintained in the electrolysis cell reactor. Better performance of the electrolysis cell reactor versus the half-cell reactor could be attributed to the custom design and optimized operation conditions in the electrolysis cell reactor. 
The large electrode area $\left(6.5 \mathrm{~cm}^{2}\right)$ and the small cathode chamber volume $(12 \mathrm{ml})$ along with the fast flow rate of $30 \mathrm{ml} \mathrm{min}{ }^{-1}$ were optimized to ensure a sufficient supply of levulinic acid to the $\mathrm{Pb}$ electrode surface, while avoiding the mass transport issue caused by hydrogen gas bubbles striking the $\mathrm{Pb}$ electrode. When ECH of levulinic acid is conducted in an acidic environment, in which the reaction proceeds faster than that in neutral electrolyte, as the reaction time was extended to more than $2 \mathrm{~h}$, the HER started to dominate because depletion of levulinic acid generates more hydrogen bubbles on the $\mathrm{Pb}$ electrode surface. Interference from gas bubbles, preventing a fresh supply of levulinic acid to the catalyst surface, is much more serious in the batch-type half-cell reactor, even though the stirring rate has been optimized to minimize such mass transport issues 


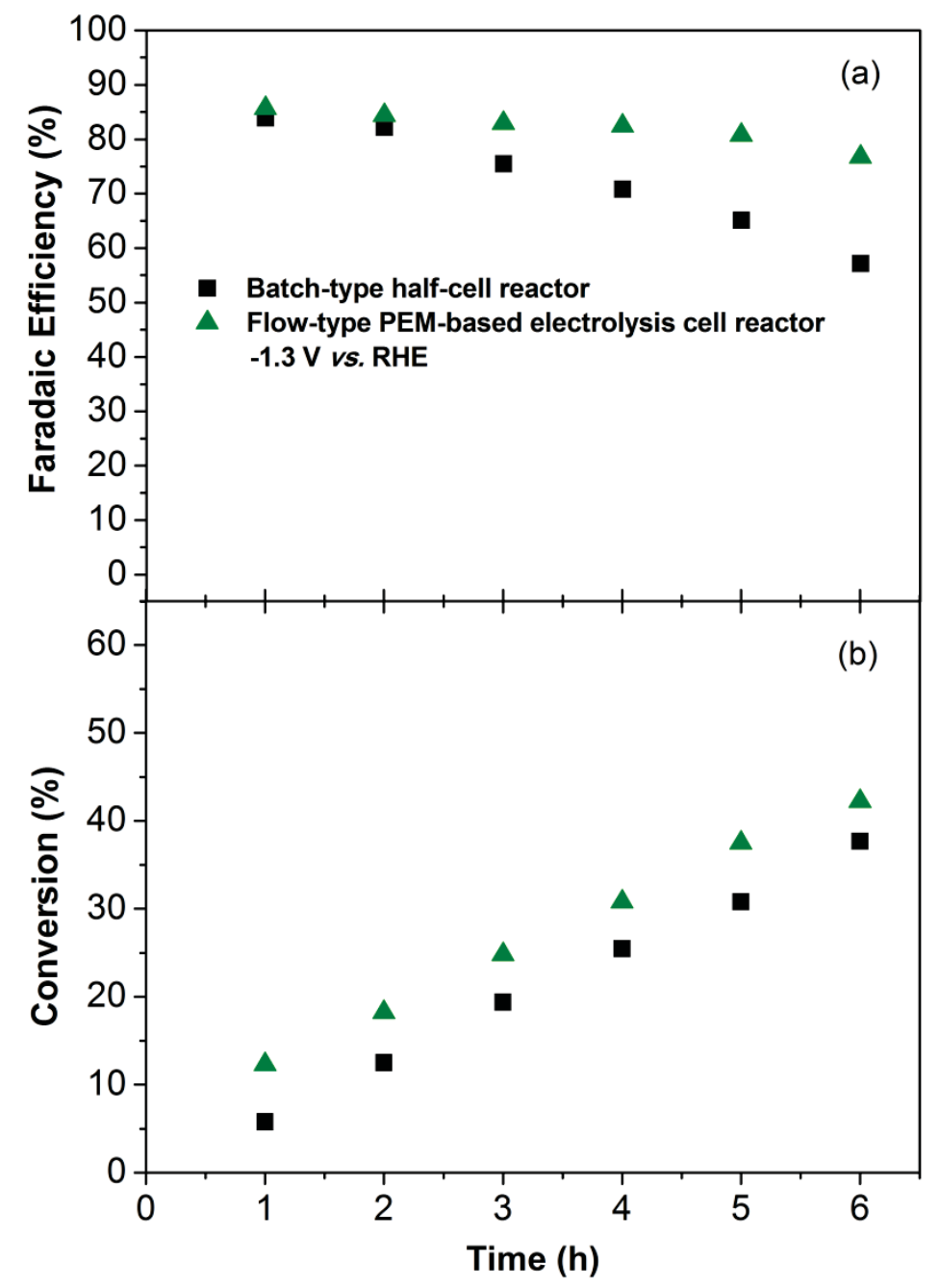

Fig. 7.9 (a) Faradaic efficiency and (b) Conversion versus time at an applied potential of $-1.3 \mathrm{~V}$ vs. RHE for the batch-type half-cell reactor and flow-type PEM-based electrolysis cell reactor with a $\mathrm{Pb}$ electrode. Reaction conditions: $0.2 \mathrm{M}$ levulinic acid $+0.5 \mathrm{M} \mathrm{H}_{2} \mathrm{SO}_{4}$, room temperature, and ambient pressure. The Faradaic efficiency is related to the liquid products (valeric acid + GVL).

To investigate the durability of the $\mathrm{Pb}$ electrode in acidic solution, the $\mathrm{ECH}$ of levulinic acid performed in the PEM-based electrolysis cell reactor was extended to 20 or $10 \mathrm{~h}$ at applied potentials of -1.3 and $-1.5 \mathrm{~V}$ vs. RHE, respectively. Liquid reactor effluent was collected at certain time intervals and the reactant and product concentrations were analyzed by using an HPLC system. Fig. 7.10 shows that, after continuous reaction for 20 or $10 \mathrm{~h}$, the conversion of levulinic acid at -1.3 and $-1.5 \mathrm{~V}$ vs. RHE can reach 91.1 and 
$96.8 \%$, respectively. The reaction rate was provided to investigate the $\mathrm{ECH}$ reactions versus time in the electrolysis cell reactor, which is defined:

$$
\text { Reaction rate }=\frac{\text { Converted levulinic acid }}{\text { Reaction time }} \times 100 \%
$$

As shown in Fig. 7.11, the reaction rate is generally higher at $-1.5 \mathrm{~V}$ than at $-1.3 \mathrm{~V}$ vs. RHE, which could be due to more negative potential that activates the ECH of levulinic acid. In addition, it is observed that the initial rate can reach up to 1.7 and $2.8 \mathrm{mmol} \mathrm{h}^{-1}$ at $-1.3 \mathrm{~V}$ and $-1.5 \mathrm{~V}$ vs. RHE, respectively. The reaction rate decreases quickly in the first three hours and tends to be steady in the subsequent hours. The initial high rate of reaction could be attributed to the sufficient levulinic acid available at the beginning of the reaction and with the depletion of the reactant (levulinic acid), the reaction slows down. However, this is probably not the only reason leading to the fast decreasing of the reaction rate at the beginning of the reaction. Deeper study on the reaction kinetics is still in progress. 


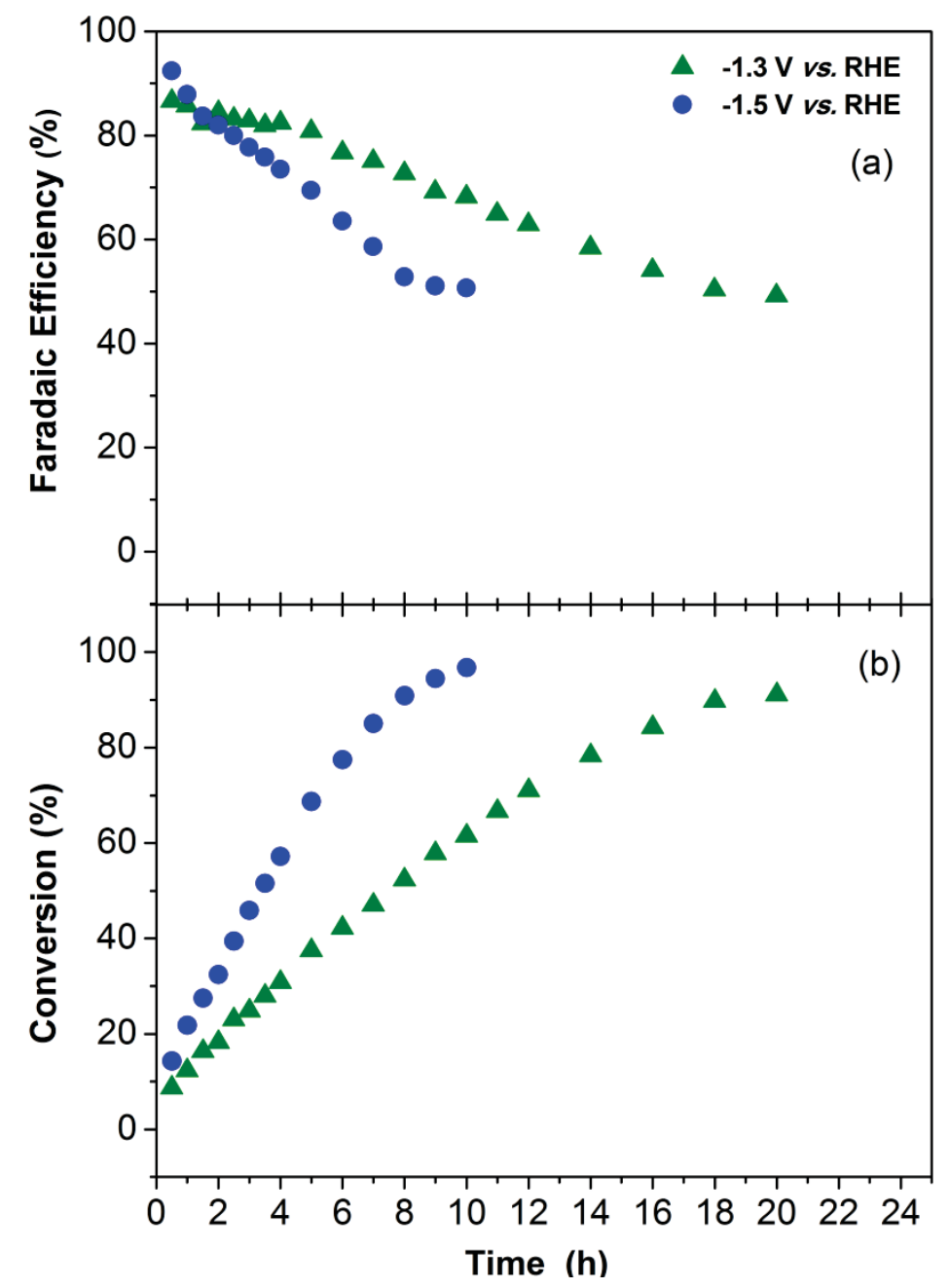

Fig. 7.10 (a) Faradaic efficiency and (b) Conversion of levulinic acid ECH versus time at applied potentials of -1.3 and $-1.5 \mathrm{~V}$ vs. RHE on a Pb electrode in the flow-type PEMbased electrolysis cell reactor. Reaction conditions: $0.2 \mathrm{M}$ levulinic acid $+0.5 \mathrm{M} \mathrm{H}_{2} \mathrm{SO}_{4}$, room temperature, and ambient pressure. The Faradaic efficiency is related to the liquid products (valeric acid $+\mathrm{GVL}$ ). 


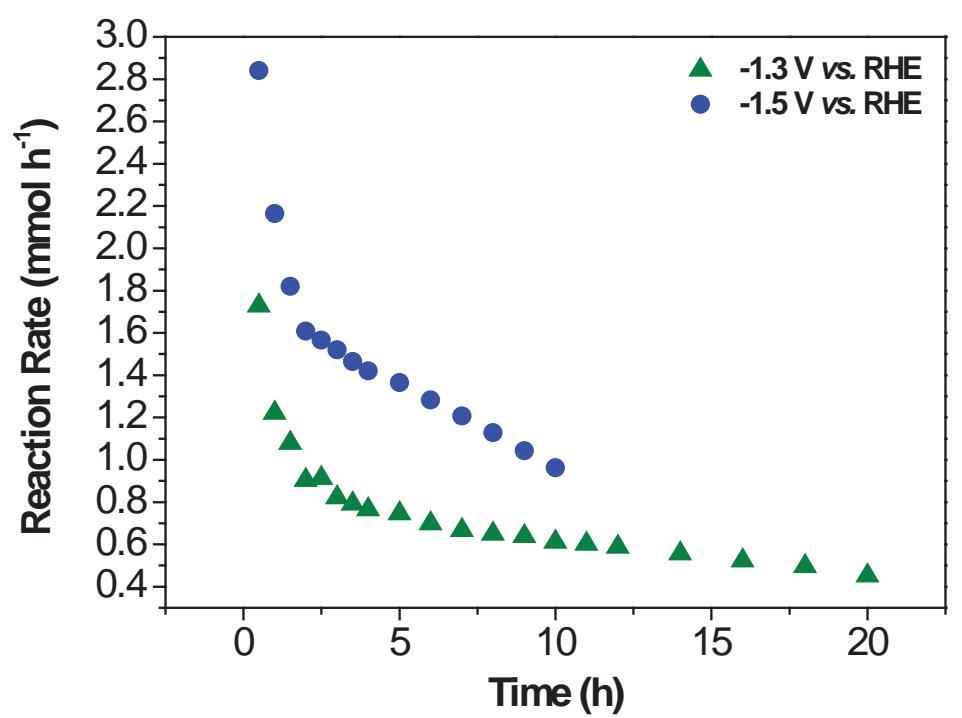

Fig. 7.11 Reaction rate versus time at the applied potential of $-1.3 \mathrm{~V}$ and $-1.5 \mathrm{~V}$ vs. RHE for the flow-type PEM-based electrolysis cell reactor with $\mathrm{Pb}$ electrode. Reaction condition: $0.2 \mathrm{M}$ levulinic acid $+0.5 \mathrm{M} \mathrm{H}_{2} \mathrm{SO}_{4}$, room temperature and ambient pressure.

In addition, as the conversion of levulinic acid increases, the Faradaic efficiency is observed to decrease because the HER becomes more competitive as more levulinic acid is converted. However, Fig. 7.12 demonstrates that the selectivities to valeric acid and GVL are almost constant at 93.3 and $6.7 \%$, respectively, at $-1.3 \mathrm{~V}$ vs. RHE after $20 \mathrm{~h}$, and at 96.9 and $3.1 \%$, respectively, at $-1.5 \mathrm{~V}$ vs. RHE after $10 \mathrm{~h}$ reaction. ICP-OES analysis indicated that no measurable quantities of $\mathrm{Pb}$ ions $(<2 \mathrm{ppm})$ were detected in the liquid reactor effluent after reaction for 20 and $10 \mathrm{~h}$. In addition, no clear difference was observed in the $\mathrm{CV}$ curves carried out in blank $0.5 \mathrm{M} \mathrm{H}_{2} \mathrm{SO}_{4}$ before and after prolonged reaction (Fig. 7.13). Therefore, these results suggest good stability of the Pb electrode and that no detectable $\mathrm{Pb}$ leaching occurred during the extended reaction study in low-pH electrolyte $(\mathrm{pH} \cong 0)$ at negative potentials $(<1.3 \mathrm{~V}$ vs.RHE). 

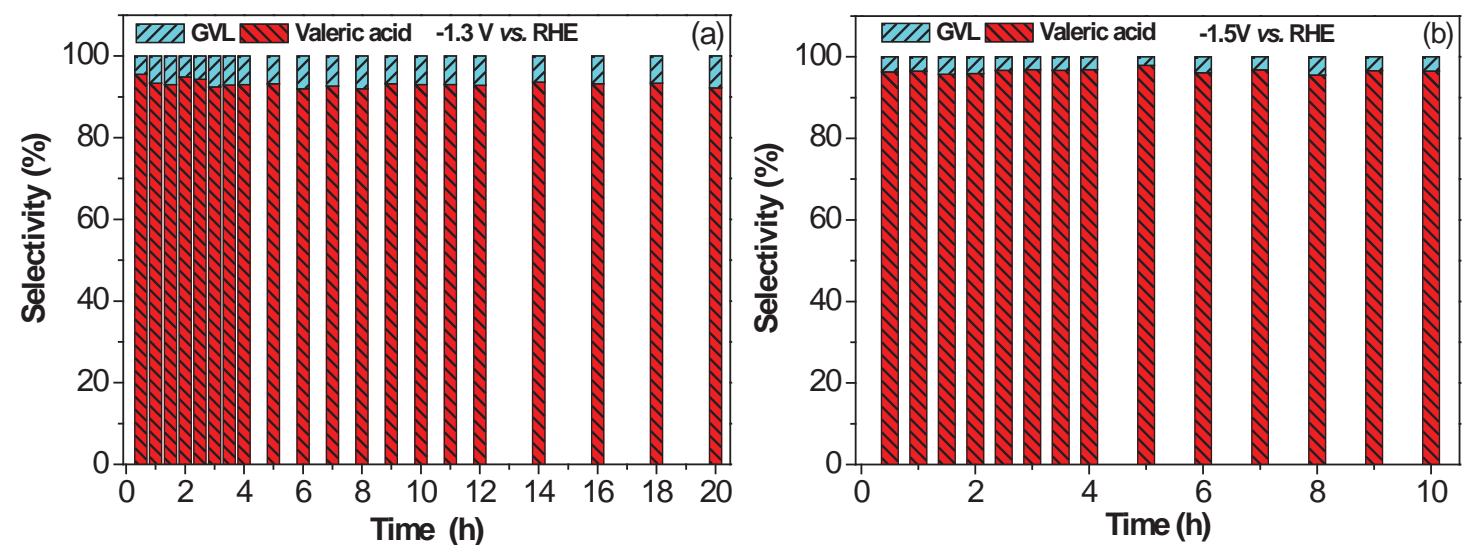

Fig. 7.12 Selectivity of levulinic acid ECH versus time at applied potentials of (a) -1.3 and (b) $-1.5 \mathrm{~V}$ vs. RHE on a Pb electrode in the flow-type PEM-based electrolysis cell reactor. Reaction conditions: $0.2 \mathrm{M}$ levulinic acid $+0.5 \mathrm{M} \mathrm{H}_{2} \mathrm{SO}_{4}$, room temperature, and ambient pressure. The Faradaic efficiency is related to the liquid products (valeric acid + GVL).

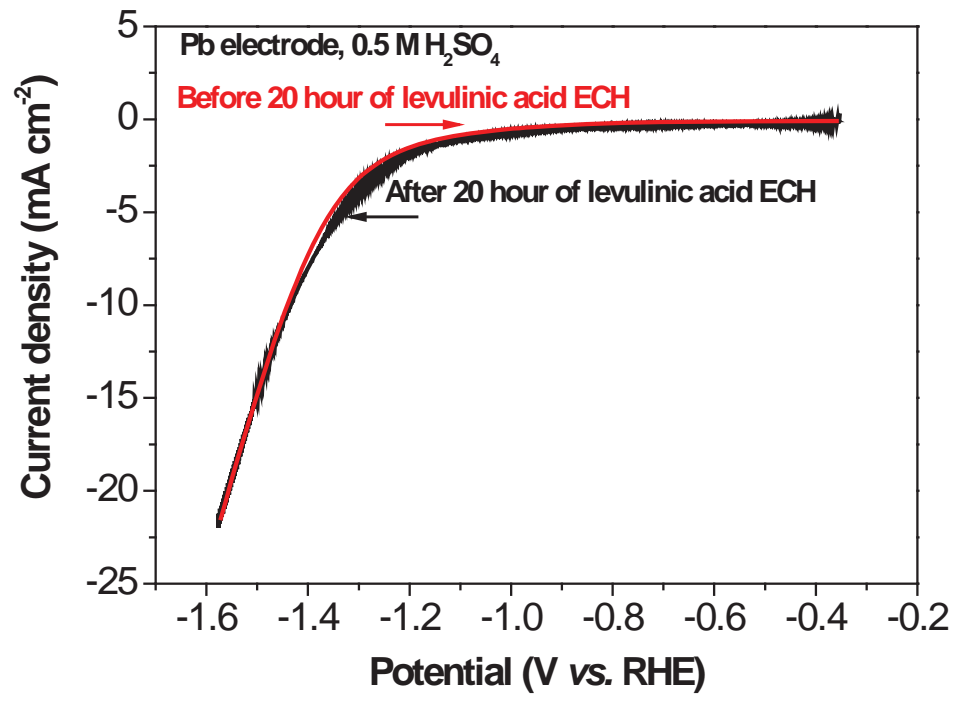

Fig. 7.13 Cyclic voltammetry scan conducted in $0.5 \mathrm{M} \mathrm{H}_{2} \mathrm{SO}_{4}$ on $\mathrm{Pb}$ electrode before and after the ECH of levulinic acid for 20 hours in the flow-type PEM-based electrolysis cell reactor. Scan rate: $50 \mathrm{mV} \mathrm{s}^{-1}$, room temperature and ambient pressure.

Significantly, it is exciting to observe that the yield of valeric acid could reach up to 84.0 and $93.4 \%$ at -1.3 and $-1.5 \mathrm{~V}$ vs. RHE, respectively, as shown in Fig. 7.14. Meanwhile, EC analysis shows that even though the ECH of levulinic acid proceeds faster and the yield of valeric acid is higher at $-1.5 \mathrm{~V}$ than that at $-1.3 \mathrm{~V}$ vs. RHE, the EC at $-1.5 \mathrm{~V}$ vs.RHE is greater than that at $-1.3 \mathrm{~V}$ vs.RHE, mainly due to the $200 \mathrm{mV}$ higher 
overpotential required to accelerate the reaction. Thus, there is a trade-off between the product yield, reaction rate, and the EC; all of which need to be taken into consideration during practical ECH operation. The high yield of valeric acid achieved in the PEMbased electrolysis cell reactor will significantly reduce the cost of subsequent energyintensive processes for the separation of target products. Additionally, it has been reported that levulinic acid can be produced by a simple and costefficient acid-catalyzed hydrolysis of waste cellulosic materials by $\mathrm{H}_{2} \mathrm{SO}_{4}{ }^{9}{ }^{9,15,211,212}$ However, the presence of $\mathrm{H}_{2} \mathrm{SO}_{4}$ will dramatically deactivate the catalysts employed to heterogeneously reduce levulinic acid ${ }^{24}$. Some energy-intensive processes, such as solvent extraction combined with distillation, are required to separate levulinic acid from $\mathrm{H}_{2} \mathrm{SO}_{4}$ before the catalytic hydrogenation of levulinic acid; thus making the overall process complicated and costly ${ }^{23}$. The introduction of flow-type PEM-based electrolysis cell reactor presented herein offers a feasible strategy to directly use outlet streams of the cellulosic hydrolysis process (levulinic acid+aqueous $\mathrm{H}_{2} \mathrm{SO}_{4}$ ); this could reduce the capital costs required to upgrade levulinic acid to a biofuel. Another big issue is the need for pressurized molecular hydrogen in the chemical catalytic reduction of levulinic acid. The ECH of levulinic acid conducted in the electrolysis cell reactor does not require an external molecular hydrogen source, therefore it can be operated in low temperatures and atmosphere pressures. Taken together, the flow-type PEM-based electrolysis cell reactor is particularly suited for sustainable processing of biorenewable compounds under continuous operation and the whole process is viable for scaleup. 


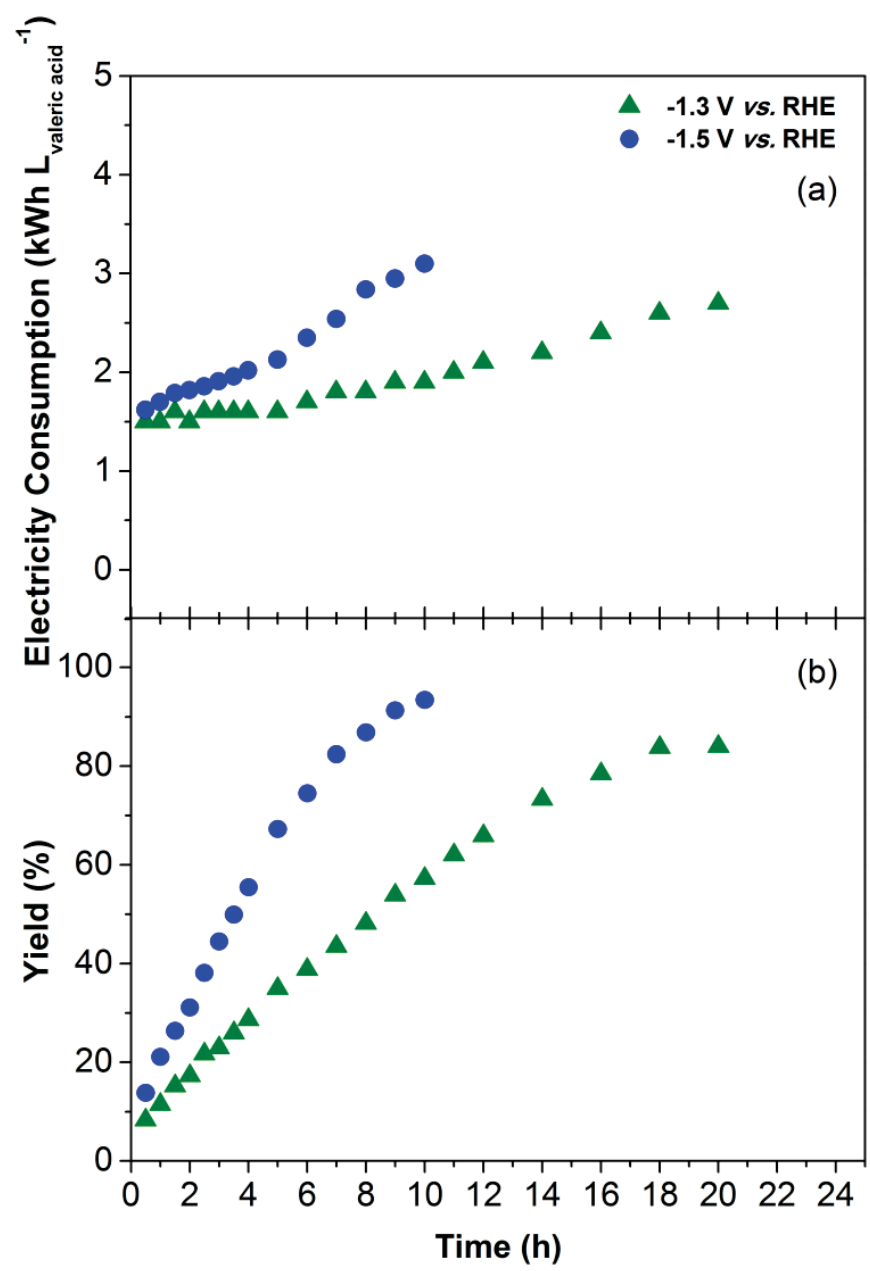

Fig. 7-14 (a) EC and (b) yield of VA versus time at applied potentials of -1.3 and $-1.5 \mathrm{~V}$ vs. RHE on a Pb electrode in the PEM-based electrolysis cell reactor. Reaction conditions: $0.2 \mathrm{M}$ levulinic acid $+0.5 \mathrm{M} \mathrm{H}_{2} \mathrm{SO}_{4}$, room temperature, and ambient pressure. The Faradaic efficiency is related to the liquid products (valeric acid $+\mathrm{GVL}$ ).

Additionally, the electrolysis cell reactor provides a new strategy to store renewable electricity produced by PV cells and wind power into liquid fuel compounds by taking advantage of the chemical potential differences (Table 7.2) between levulinic acid $(2.42$ $\left.\mathrm{MJ} \mathrm{mol}^{-1}\right)$ and valeric acid (2.84 $\mathrm{MJ}$ mol-1) or GVL (2.65 $\left.\mathrm{MJ} \mathrm{mol}^{-1}\right)$ to capture electrical energy during off-peak hours. Off-peak electricity can be used to efficiently convert levulinic acid into valeric acid or GVL, which can be further upgraded to hydrocarbon fuels, such as octane and valeric biofuels..$^{21,190,191}$ The efficiency of converting applied 
electricity into stored chemical energy in a specific product (valeric acid or GVL) for $\mathrm{ECH}$ of levulinic acid is calculated by energy storage efficiency (ESE):

$$
E S E=\frac{\text { Moles (specific identified product }) \times \Delta_{C} H_{\text {levulinic acid } \rightarrow \text { valeric acid or } G V L}^{\circ}}{E \times I \times t / 1000}
$$

in which $E$ is the applied potential (in V vs. RHE) which only accounted for the cathodic reaction, the future exploration of efficient OER electrocatalysts will be required in order to promote the ESE of the single cells, I is the current (in A), $t$ is the reaction time (in hour), and $\Delta_{C} H_{\text {levulinic acid } \rightarrow \text { valeric acid or GVL }}^{\circ}$ is the difference in the standard enthalpy change of combustion between levulinic acid and valeric acid or GVL (in $\mathrm{kJ} \mathrm{mol}^{-1}$ ). A higher ESE means that more electrical energy is stored in more energetic fuel compounds.

Table 7.2 Physical properties of valeric biofuel-related compounds

\begin{tabular}{|c|c|c|c|c|c|c|c|c|c|}
\hline \multirow{2}{*}{ Compound } & \multirow{2}{*}{$\begin{array}{l}\text { b.p.p. }{ }^{[\mathrm{a}]} \\
/{ }^{\mathrm{O}} \mathrm{C}\end{array}$} & \multirow{2}{*}{$\underset{/{ }^{\circ} \mathrm{C}}{\operatorname{m.p}}$} & \multirow{2}{*}{$\begin{array}{l}\text { State } \\
\text { at } \\
\operatorname{STP}^{[b]}\end{array}$} & \multirow{2}{*}{$\begin{array}{l}\text { Molar mass } \\
\text { / } \mathrm{g} \mathrm{mole}^{-1}\end{array}$} & \multirow{2}{*}{$\begin{array}{l}\text { Density } \\
/ \mathrm{Kg} \mathrm{L}^{-1}\end{array}$} & \multirow{2}{*}{$\begin{array}{c}\text { Solubility } \\
\text { limit } \\
/ \mathrm{g} \mathrm{L}^{-1}\end{array}$} & \multicolumn{3}{|c|}{ Energy Density $(W e)$} \\
\hline & & & & & & & $\mathrm{MJ} \mathrm{mol}^{-1}$ & $\mathrm{MJ} \mathrm{L}^{-1}$ & $\mathrm{MJ} \mathrm{kg}^{-1}$ \\
\hline $\begin{array}{l}\text { Valeric } \\
\text { acid }\end{array}$ & 186 & -35 & liquid & 102.1 & 0.93 & $40^{[\mathrm{c}]}$ & 2.84 & 25.9 & 27.8 \\
\hline $\begin{array}{c}\gamma- \\
\text { valerolacto } \\
\text { ne }\end{array}$ & 208 & -31 & liquid & 100.1 & 1.05 & $\geq 100^{[\mathrm{d}]}$ & 2.65 & 27.8 & 26.5 \\
\hline $\begin{array}{l}\text { Levulinic } \\
\text { acid }\end{array}$ & 246 & 34 & solid & 116.2 & 1.15 & Miscible $^{[\mathrm{e}]}$ & 2.42 & 24.0 & 20.8 \\
\hline
\end{tabular}

[a] b.p. = boiling point; m.p.= melting point. [b] STP: standard condition for temperature $(298.15 \mathrm{~K})$ and pressure $(100 \mathrm{kPa})$. [c] Data from Material Safety Data Sheet (MSDS) by SIGMA-ALDRICH. [d] Data from http://en.wikipedia.org/wiki/ $\gamma$-Valerolactone. [e] Data from MSDS by ACROS ORGANICS.

Fig. 7.15 shows the ESE of selective ECH of levulinic acid to valeric acid or GVL in the PEM-based electrolysis cell reactor on a $\mathrm{Pb}$ electrode in aqueous solution with different $\mathrm{pH}$ values at an applied potential of $-1.3 \mathrm{~V}$ vs. $\mathrm{RHE}$. At $\mathrm{pH} \cong 0,70.8 \%$ of the electrical energy is directly stored in valeric acid (with 95\% selectivity), whereas $16.7 \%$ of electrical energy is stored in GVL (with $100 \%$ selectivity) at $\mathrm{pH} \cong 7.5$. A detailed calculation of ESE is tabulated in Table 7.3. The ESE obtained at $\mathrm{pH} \cong 0$ is significantly greater than the ESE achieved at $\mathrm{pH} \cong 7.5$. This result is within the expectations because the relative reaction rate ratio of $\mathrm{ECH}$ to HER is greater in an acidic electrolyte than that 
in a neutral electrolyte and the current density recorded at $\mathrm{pH} \cong 0$ is about $40 \%$ higher than that at $\mathrm{pH} \cong 7.5$ in the flow-type electrolysis cell reactor.

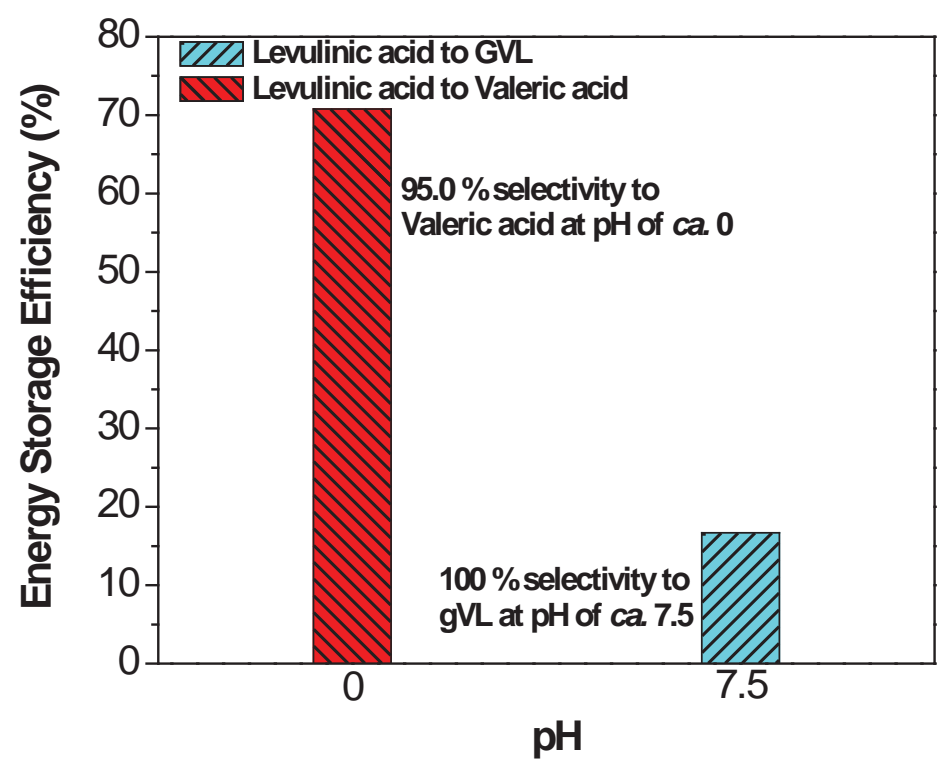

Fig. 7.15 ESE of the selective ECH of levulinic acid to valeric acid or GVL on a Pb electrode in the PEM-based electrolysis cell reactor at different $\mathrm{pH}$ values. Reaction conditions: 0.2 M levulinic acid, room temperature, ambient pressure, $-1.3 \mathrm{~V}$ vs. RHE, 2 h.

Table 7.3 The calculation for ESE the PEM-based electrolysis cell reactor.

\begin{tabular}{|c|c|c|c|c|c|}
\hline & $(1)$ & $(2)$ & $(3)$ & $(4)$ & \multirow{3}{*}{ Energy storage efficiency / \% } \\
\hline & \multicolumn{3}{|c|}{$\begin{array}{l}\text { Energy density } \\
/ \mathrm{KJ} \mathrm{mol}^{-1}\end{array}$} & \multirow{2}{*}{$\begin{array}{l}\text { Electricity } \\
\text { consumption } \\
/ \mathrm{KJ} \mathrm{mol}^{-1}\end{array}$} & \\
\hline $\begin{array}{l}-1.3 \mathrm{Vs} . \\
\text { RHE }\end{array}$ & LA & VA & GVL & & \\
\hline $\mathrm{pH} \cong 0$ & \multirow{2}{*}{2420} & \multirow{2}{*}{2840} & \multirow{2}{*}{2650} & 593.0 (to VA) & {$[(2)-(1)] /(4) \times 100 \%=70.8 \%$ (to VA) } \\
\hline $\mathrm{pH} \cong 7.5$ & & & & 1377.6 (to GVL) & {$[(3)-(1)] /(4) \times 100 \%=16.7 \%$ (to GVL) } \\
\hline
\end{tabular}

\subsubsection{Reaction pathway and molecular structure effects on ECH of oxygenates containing ketone or aldehyde groups}

Based on the results obtained from the half-cell and electrolysis cell reactors, the reaction pathway for the ECH of levulinic acid is proposed in Fig. 7.16. As discussed before, the ketone group in levulinic acid is able to be selectively reduced to -OH (two- 
electron transfer) or fully reduced to $-\mathrm{CH}_{2}$ - (four-electron- transfer): Lower overpotentials favor the production of GVL ( $18.5 \%$ selectivity to GVL at $-1.1 \mathrm{~V}$ vs. RHE), whereas higher overpotentials facilitate the formation of valeric acid (97\% selectivity to valeric acid at $-1.5 \mathrm{~V}$ vs. RHE). At low applied potentials, both the ketone group of levulinic acid and monoatomic hydrogen adsorb weakly on the $\mathrm{Pb}$ electrode, resulting in the slower reaction rate and lower current density observed (Fig. 7.17). According to the proposed sequential mechanism for ECH of levulinic acid on a Pb electrode (Fig. 7.16 (a)), the reaction intermediate (4-hydroxypetanoic acid) is more weakly adsorbed on the $\mathrm{Pb}$ electrode surface than levulinic acid. This can be supported by the experiment using the esterification intermediate GVL as a feedstock, for which the CV curve of the ECH of 0.2 $\mathrm{M} \mathrm{GVL}$ on $\mathrm{Pb}$ in $0.5 \mathrm{M} \mathrm{H}_{2} \mathrm{SO}_{4}$ does not show any difference compared with the blank $\mathrm{CV}$ curve recorded in $0.5 \mathrm{M} \mathrm{H}_{2} \mathrm{SO}_{4}$ electrolyte (Fig. 7.17). The product analysis shown in Table 7.4 further confirms that the conversion of GVL under identical conditions to the ECH of levulinic acid is zero, and 100\% electron transfer is attributed to the HER. The results indicate that GVL is a relatively stable product under ECH conditions and further hydrogenation will not proceed, as long as it is produced and desorbed from the metal catalyst surface. Because the adsorption strength of 4-hydroxypentanoic acid is weaker than levulinic acid, it is easily replaced by levulinic acid before it reacts with the surfaceadsorbed $\mathrm{H}$ atoms for further dehydration and hydrogenation to produce valeric acid. As 4-hydroxypentanoic acid desorbs from the $\mathrm{Pb}$ electrode surface, it subsequently undergoes internal esterification (not an electrochemical reaction) to form the five $\mathrm{C}$-ring compound GVL. With increasing applied potential, a more negatively polarized $\mathrm{Pb}$ electrode will perhaps not only facilitate the interaction of the $\mathrm{C}=\mathrm{O}$ (ketone) group of levulinic acid with the $\mathrm{Pb}$ electrode surface, but also increase the concentration of surface $\mathrm{H}_{\mathrm{ads}}$ atoms. Thus, a more negative potential could accelerate the hydrogenation of the $\mathrm{C}=\mathrm{O}$ (ketone) group of levulinic acid to $-\mathrm{CH}_{2}$ - with less desorbed GVL. 
(a)

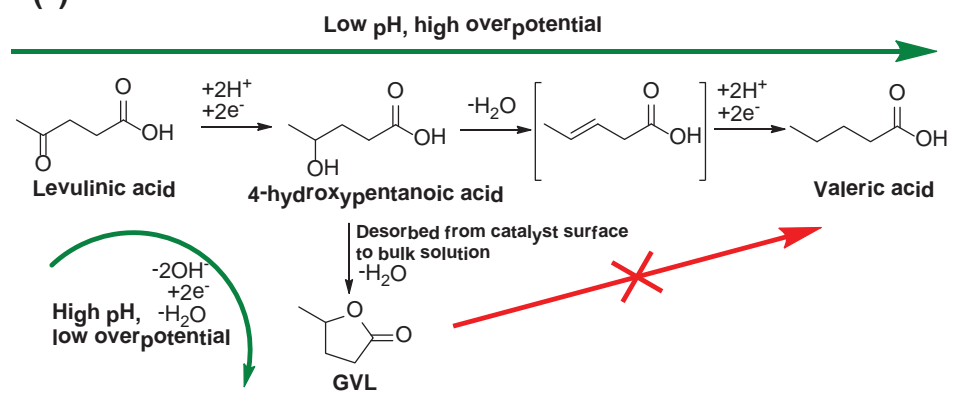

(b)

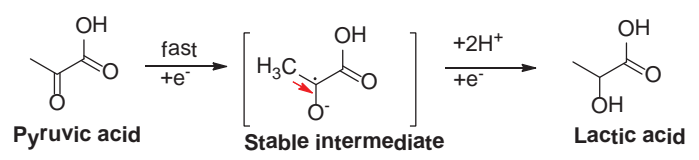

(c)

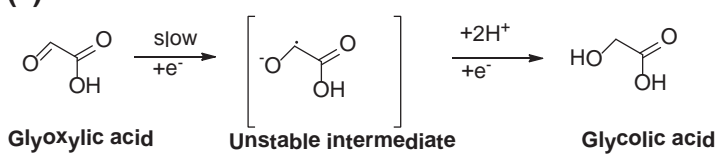

Fig. 7.16 Proposed reaction pathways for the ECH of (a) levulinic acid, (b) pyruvic acid, and (c) glyoxylic acid on $\mathrm{Pb}$.

It has also been demonstrated that the $\mathrm{pH}$ value can be used to control the final product distribution. Selectivities of $95 \%$ to valeric acid in acidic electrolyte $(\mathrm{pH} \cong 0)$ and $100 \%$ to GVL in neutral electrolyte $(\mathrm{pH} \cong 7)$ were obtained (Fig. 7.16 (a)). The effect of electrolyte $\mathrm{pH}$ on product selectivity was also revealed by the Tafel plot investigation (Fig. 7.6), which showed that four-electron transfer was involved in the ECH of levulinic acid in acidic electrolyte, resulting in the formation of valeric acid, whereas only twoelectron transfer was observed in neutral electrolyte $(\mathrm{pH} \cong 7.5)$, leading to the production of GVL. 


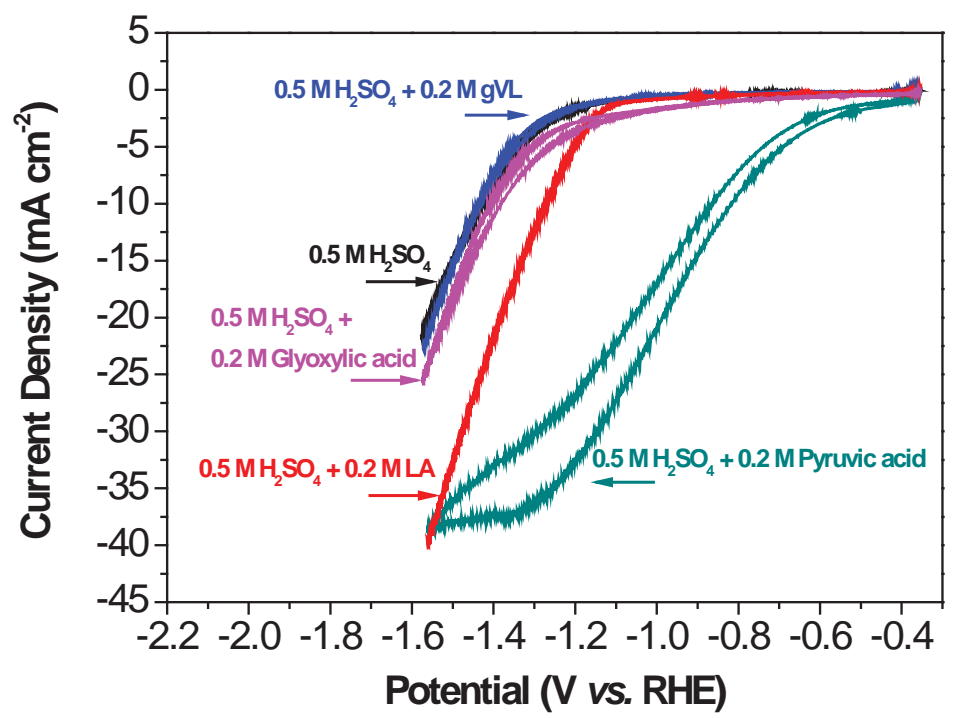

Fig. 7.17 CVs of the ECH of biomass compounds containing ketone or aldehyde groups on a $\mathrm{Pb}$ electrode in acidic electrolyte at a scan rate of $50 \mathrm{mV} \mathrm{s}^{-1}$, room temperature, and ambient pressure.

To gain insight into structural effects on $\mathrm{C}=\mathrm{O}$ reduction pathways, pyruvic acid and glyoxylic acid, which contain ketone or aldehyde groups, were also studied. Fig. 7.17 demonstrates the half-cell $\mathrm{CVs}$ of the $\mathrm{ECH}$ of these oxygenates on $\mathrm{Pb}$ in an acidic electrolyte. A cyclic voltammetry scan in $0.2 \mathrm{M}$ pyruvic acid $+0.5 \mathrm{M} \mathrm{H}_{2} \mathrm{SO}_{4}$ gave a 700 $\mathrm{mV}$ more positive onset potential and significantly greater current density than that conducted in $0.2 \mathrm{M}$ levulinic acid electrolyte; this indicates $\mathrm{Pb}$ has a higher electrocatalytic activity towards the ECH of pyruvic acid than that of levulinic acid. In sharp contrast, with $0.2 \mathrm{M}$ glyoxylic $+0.5 \mathrm{M} \mathrm{H}_{2} \mathrm{SO}_{4}$, the $\mathrm{ECH}$ reaction rate was much slower on $\mathrm{Pb}$ than that with $0.2 \mathrm{M}$ levulinic acid, as evidenced by the smaller current density observed in the CV curves. 
Table 7.4 ECH of biomass compounds containing ketone or aldehyde group in half cell reactor on $\mathrm{Pb}(\mathrm{pH} \cong 0)$.

\begin{tabular}{|c|c|c|c|c|}
\hline $\begin{array}{l}\text { Biomass } \\
\text { compound }\end{array}$ & 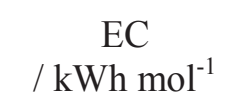 & $\begin{array}{l}\text { Selectivity } \\
\quad / \%\end{array}$ & $\begin{array}{c}\text { Faradic efficiency }^{[\mathrm{a}]} \\
\qquad / \%\end{array}$ & $\begin{array}{c}\text { Conversion } \\
/ \%\end{array}$ \\
\hline LA & $\begin{array}{c}0.29 \\
\text { (to VA) }\end{array}$ & $\begin{array}{c}95.0 \\
\text { (to VA) }\end{array}$ & 57.1 & 51.3 \\
\hline GVL & $\infty$ & $0^{[\mathrm{b}]}$ & $0^{[\mathrm{c}]}$ & 0.0 \\
\hline Pyruvic acid & $\begin{array}{c}0.14 \\
\text { (to lactic acid) }\end{array}$ & $\begin{array}{c}100 \\
\text { (to lactic acid) }\end{array}$ & 56.1 & 89.6 \\
\hline Glyoxylic acid & $\begin{array}{l}3.23 \\
\text { (to glycolic } \\
\text { acid) }\end{array}$ & $\begin{array}{c}100 \\
\text { (to glycolic acid) }\end{array}$ & 2.5 & 1.6 \\
\hline \multicolumn{5}{|c|}{$\begin{array}{l}\text { Reaction conditions: chronoamperometry of }-1.5 \mathrm{~V} \text { vs. RHE was performed for } 4 \mathrm{~h} \text { in } 0.5 \mathrm{M} \\
\mathrm{H}_{2} \mathrm{SO}_{4}+0.2 \mathrm{M} \text { biomass compounds, room temperature; } \mathrm{LA}=\text { levulinic acid, } \mathrm{GVL}=\gamma- \\
\text { valerolacetone, VA = valeric acid. [a] Faradaic efficiency takes account the sum of electrons } \\
\text { transferred during the ECH of LA to VA and gVL. [b] No products in liquid phase are } \\
\text { detected. [c] All electrons transferred are attributed to HER. }\end{array}$} \\
\hline
\end{tabular}

It is interesting to observe that the ketone groups in pyruvic and glyoxylic acid can be only reduced to $-\mathrm{OH}$ through a two-electron- transfer reaction compared with the $\mathrm{ECH}$ of levulinic acid on $\mathrm{Pb}$ in an acidic electrolyte, resulting in $100 \%$ selectivity to lactic acid and glycolic acid, respectively (Table 7.4). However, 89.6\% conversion of pyruvic acid after $4 \mathrm{~h} \mathrm{ECH}$ reaction is much higher than the conversion of both levulinic acid and glyoxylic acid, whose conversion are only 51.3 and $1.6 \%$ respectively. This also agrees well with the cyclic voltammetry experiment, in which the ECH of pyruvic acid exhibited the greatest current density. The EC value for the target product, given by the yield, Faradaic efficiency, and applied potential, determines the specific energy consumption. As expected, the EC value for the conversion of pyruvic acid into lactic acid $(0.14 \mathrm{kWh}$ $\mathrm{mol}_{\text {lactic acid }}{ }^{-1}$ ) is lower than both values for valeric acid (from levulinic acid reduction) and glycolic acid (from glyoxylic acid reduction), the EC values of which are $0.29 \mathrm{kWh}$ $\mathrm{mol}_{\text {valeric acid }}{ }^{-1}$ and $3.23 \mathrm{kWh} \mathrm{mol}_{\text {glycolic acid }}{ }^{-1}$, respectively, as shown in Table 7.4 and Fig. 7.18. These results indicate that the final products may be influenced by the molecular structure of the oxygenated compounds. As illustrated in Fig. 7.16, the ketone radical anion could be stabilized by the neighboring electron-donating $\mathrm{CH}_{3}$ - group, thereby 
favoring its formation, whereas the lack of $\mathrm{CH}_{3}$ - attached to the aldehyde group of glyoxylic acid makes the intermediate unstable ${ }^{213}$, leading to the slower reaction rate of glyoxylic acid hydrogenation on $\mathrm{Pb}$. On the other hand, the presence of the two-carbon chain $\left(-\mathrm{CH}_{2}-\mathrm{CH}_{2}-\right)$ allows the dehydration step and subsequent hydrogenation to valeric acid, as demonstrated in Fig. 7.16 (a).

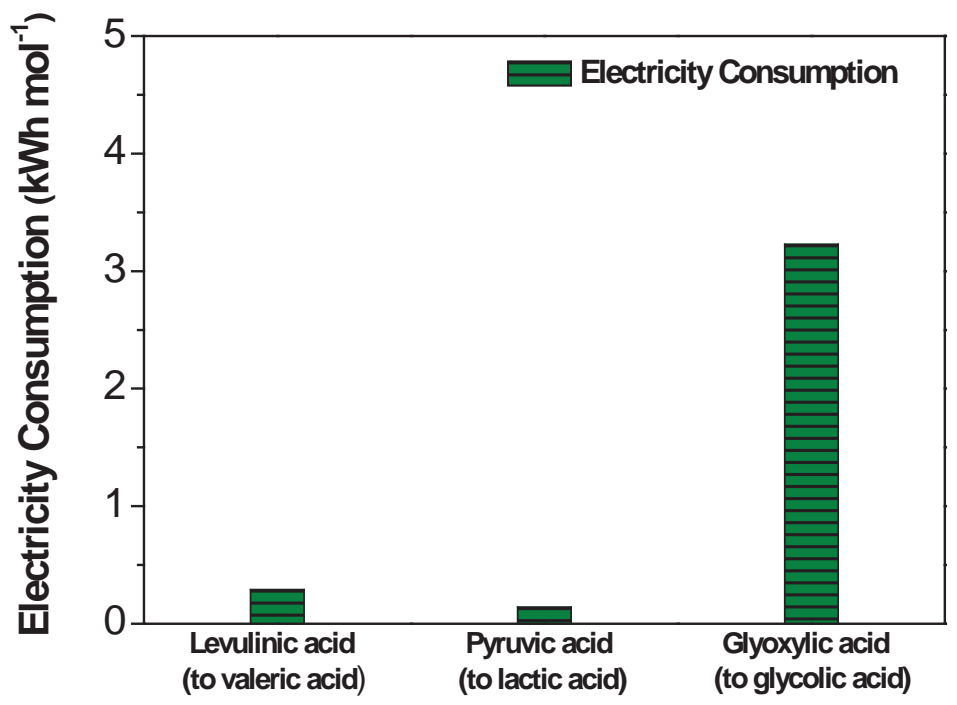

Fig. 7.18 EC of selective ECH of levulinic acid, pyruvic acid and glyoxylic acid on $\mathrm{Pb}$ electrode in aqueous solution at the applied potential of $-1.5 \mathrm{~V}$ vs. RHE, reaction conditions: $0.5 \mathrm{M} \mathrm{H}_{2} \mathrm{SO}_{4}+0.2 \mathrm{M}$ reactants, room temperature and ambient pressure, reaction time: $4 \mathrm{~h}$.

The work discussed above has successfully demonstrates that valeric acid with high yield of $>90 \%$ can be produced from ECH of pure biomass platform compound levulinic acid in the continuous flow-type PEM-based electrolysis cell reactor. However, it is well known that most biorefinery downstreams are often very complex, containing lots of components besides the main targeted feedstock compound. Therefore, it would be more desirable and practical to investigate the effects of the "impurities" (the coupled components in the biorefinery streams), such as adsorption and catalytic behavior, on the electrocatalysts as well as the proposed electro-biorefinery process so that to explore green electrocatalytic routes to directly process the biorefinery streams to fuels and chemicals. To this end, efforts were made to integrate ECH of levulinic acid in the PEMbased electrolysis cell reactor with electrocatalytic oxidation of formic acid in the PEM- 
DFAFC reactor by using the simulated downstream of the acid-catalyzed cellulose hydrolysis process equal molar of levulinic acid and formic acid in sulfuric acid solution, as shown in Fig. 7.19, and investigate the effects of each coupled component through this integrated process.

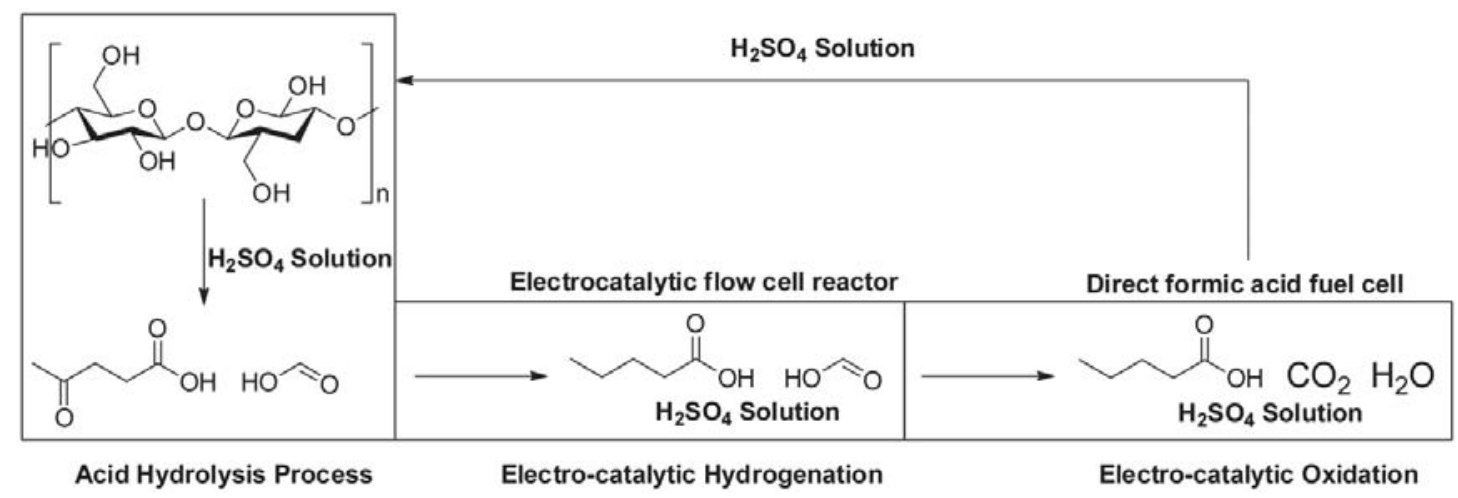

Fig. 7.19 Schematic flow diagram of coupling the electrolysis cell reactor and PEMDFAFC reactor, using downstream of cellulose acid hydrolysis (levulinic acid + formic acid $+\mathrm{H}_{2} \mathrm{SO}_{4}$ ) as feedstock.

\subsubsection{ECH of levulinic acid + formic acid in the continuous flow-type PEM-based electrolysis cell reactors}

The aqueous-phase ECH of levulinic acid and levulinic acid + formic acid was carried out in a custom-designed PEM-based electrolysis cell reactor with a $\mathrm{Pb}$ electrode. Levulinic acid and formic acid with a molar ratio of $1: 1$ in $\mathrm{H}_{2} \mathrm{SO}_{4}$ aqueous solution was circulated in a closed loop to the cathode chamber of the reactor at room temperature. As a control experiment, the same concentration of levulinic acid (0.2 M, 0.5 M, and 1.0 M) without the addition of formic acid was also tested under identical conditions. Section 7.3.2 and 7.3.3 have investigated the CVs of the $\mathrm{ECH}$ of levulinic acid on a $\mathrm{Pb}$ electrode in $0.5 \mathrm{M} \mathrm{H}_{2} \mathrm{SO}_{4}$. In the presence of $0.2 \mathrm{M}$ levulinic acid, the onset potential is over 200 $\mathrm{mV}$ more positive and the cathodic reduction current is greater than that without levulinic acid. However, an optimized potential is required to yield a significant amount of target products at an appreciable rate ${ }^{196,197,200,214}$. Thus, all the presented electrocatalysis studies are conducted at an optimized applied potential of $-1.5 \mathrm{~V}$ vs. RHE, because as the applied potential is set more negative, the relative $\mathrm{ECH}$ rate 

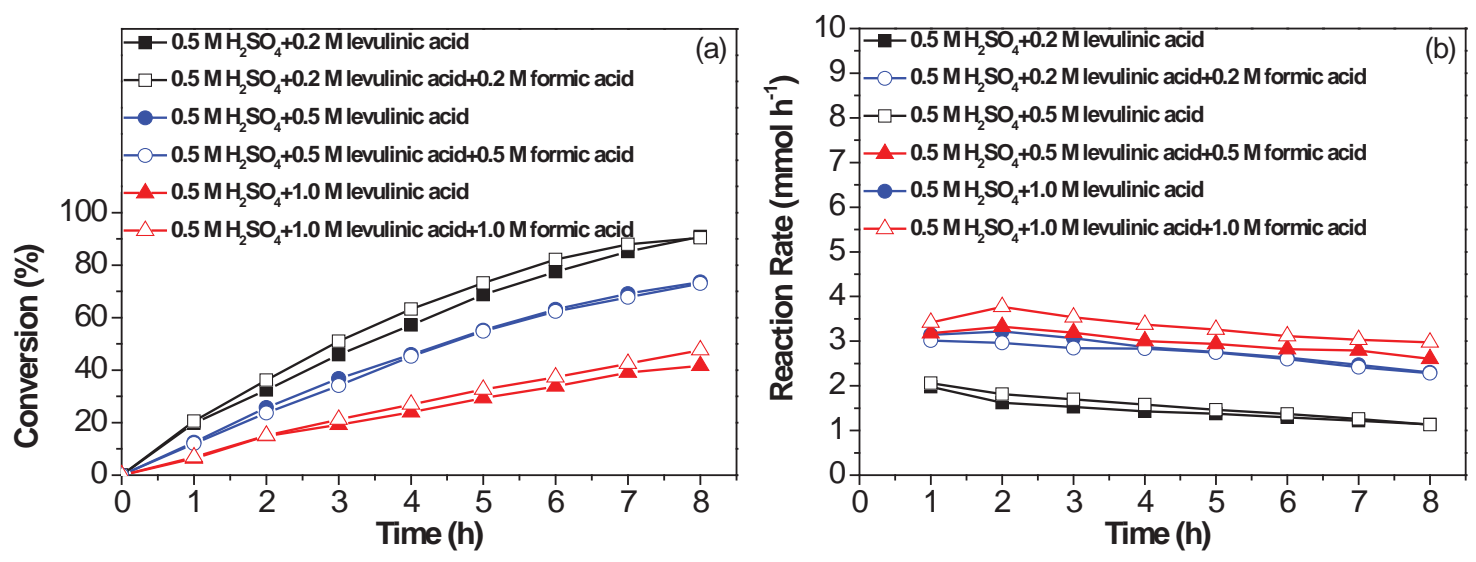

Fig. 7.20 (a) Conversion and (b) reaction rate of ECH of levulinic acid in $0.5 \mathrm{M} \mathrm{H}_{2} \mathrm{SO}_{4}$ aqueous solution at $-1.5 \mathrm{~V}$ vs. RHE on a Pb electrode in the PEM-based electrolysis cell reactor under ambient pressure and room temperature.

Fig. 7.20 presents the levulinic acid conversion and reaction rate vs. time for various feed compositions over a $\mathrm{Pb}$ electrode in the PEM-based electrolysis cell reactor. The reactant and products collected at certain time intervals were analyzed by HPLC. Fig. 7.20 (a) shows that levulinic acid conversions of $90.9 \%, 73.6 \%$ and $41.7 \%$ can be obtained after 8 hours electro-hydrogenation reaction with levulinic acid concentration fed at $0.2 \mathrm{M}, 0.5 \mathrm{M}$ and $1.0 \mathrm{M}$, respectively. The conversion decreases with the increasing of the initial levulinic acid concentration, since the geometry of a $\mathrm{Pb}$ electrode involved in the catalytic process governs the electrocatalytic efficiency. ${ }^{215}$ In this respect, the active surface of a $\mathrm{Pb}$ electrode intimately interacting with the levulinic acid aqueous solution cannot provide sufficient reaction sites to afford hydrogenation of levulinic acid with higher concentrations. Nonetheless, the reaction rate of $0.5 \mathrm{M}$ levulinic acid is generally higher than that of $0.2 \mathrm{M}$ levulinic acid, as shown in Fig. 7.20 (b). However, further increase of levulinic acid concentration to $1.0 \mathrm{M}$ does not help to increase the reaction rate, which may be due to the insufficient quantity of adsorbed hydrogen for the complete hydrogenation of all the levulinic acid present in the solution. Importantly, it is demonstrated in Fig. 7.20 that both the conversion and reaction rate of levulinic acid do not decrease in the presence of formic acid in the course of 8 hours of reaction, suggesting that formic acid has no "inhibition effect" on levunilic acid electrohydrogenation. For example, fed with equal molar formic acid and levulinic acid mixture 
streams ( $0.2 \mathrm{M}, 0.5 \mathrm{M}$ and $1.0 \mathrm{M})$, levulinic acid conversion of $90.4 \%, 73.1 \%$ and $47.6 \%$ is desirably obtained; the results strongly resemble that of pure levulinic acid fed. In order to examine whether formic acid is nearly inert on a $\mathrm{Pb}$ electrode at an applied potential of $-1.5 \mathrm{~V}$ vs. RHE, the formic acid concentration was quantified each hour using HPLC. As seen in Fig. 7.21, the formic acid concentration undergoes no significant change during the long run time. There are no unidentified side product peaks in the liquid chromatographs either. The slight diminishing of formic acid concentration ( $c a$. $10 \%$ ) is probably a result of the evaporation of the formic acid during 8 hours of reaction, which can be supported by the blank experiment without applying a potential of $-1.5 \mathrm{~V}$ vs. RHE

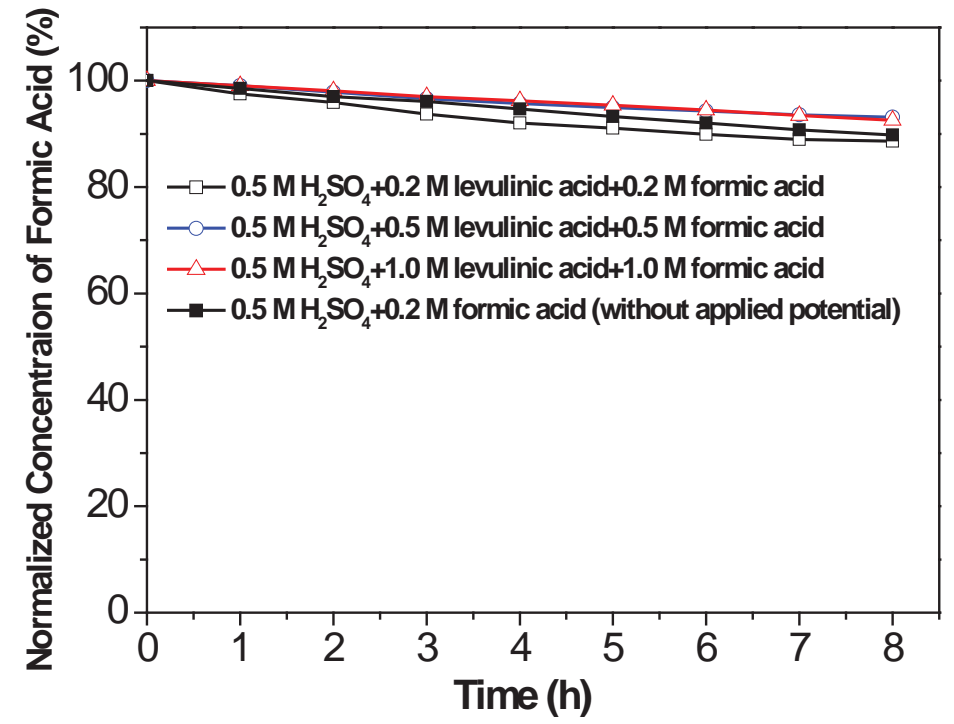

Fig. 7.21 Normalized concentration of formic acid during 8 hour ECH of levulinic acid at $-1.5 \mathrm{~V}$ vs. RHE on a Pb electrode in the PEM-based electrolysis cell reactor under ambient pressure and room temperature.

Furthermore, the selectivity of valeric acid and GVL can be regulated by the applied potential ( $-1.5 \mathrm{~V}$ vs. RHE) and almost remains constant during the 8 hour reaction, as shown in Fig. 7.22. However, with the levulinic acid concentration increasing from $0.2 \mathrm{M}$ to $1.0 \mathrm{M}$, the selectivity of valeric acid decreases from $96.5 \%$ to $86.3 \%$, while the selectivity of GVL increases from $3.5 \%$ to $13.7 \%$ (Fig. 7.22). At higher concentration of levulinic acid, protons in solution are presumably more quickly consumed for levulinic 
acid hydrogenation, resulting in the $\mathrm{pH}$ increasing near the cathode surface. Higher local $\mathrm{pH}$ likely affects the adsorption behavior and reaction energies of the substrates and makes the ECH of levulinic acid to valeric acid via four-electron transfer relatively difficult (Fig. 7.16 (a)). It was demonstrated here that the selectivity to valeric acid can be slightly increased by co-feeding levulinic acid along with the formic acid, especially when a higher concentration of levulinic acid was employed, which is observed that the selectivity of valeric acid ramps up from $86.3 \%$ in $1.0 \mathrm{M}$ levulinic acid to $89.8 \%$ in $1.0 \mathrm{M}$ levulinic acid $+1.0 \mathrm{M}$ formic acid solution (Fig. 7.22). In the presence of strong sulfuric acid $\left(\mathrm{pK}_{\mathrm{a}}=-3\right)$, formic acid $\left(\mathrm{pK}_{\mathrm{a}}=3.77\right)$ and levulinic acid $(\mathrm{pKa}=4.59)$ are preferably in neutral molecules without de-protonation in the aqueous solution. Therefore, it is suggested that the amount of protons originating from formic acid is negligible; however, the presence of formic acid probably diluted the levulinic acid aqueous solution, so that the availability of adsorbed hydrogen in proximity to levulinic acid was enhanced, thus facilitating the conversion of levulinic acid to valeric acid.

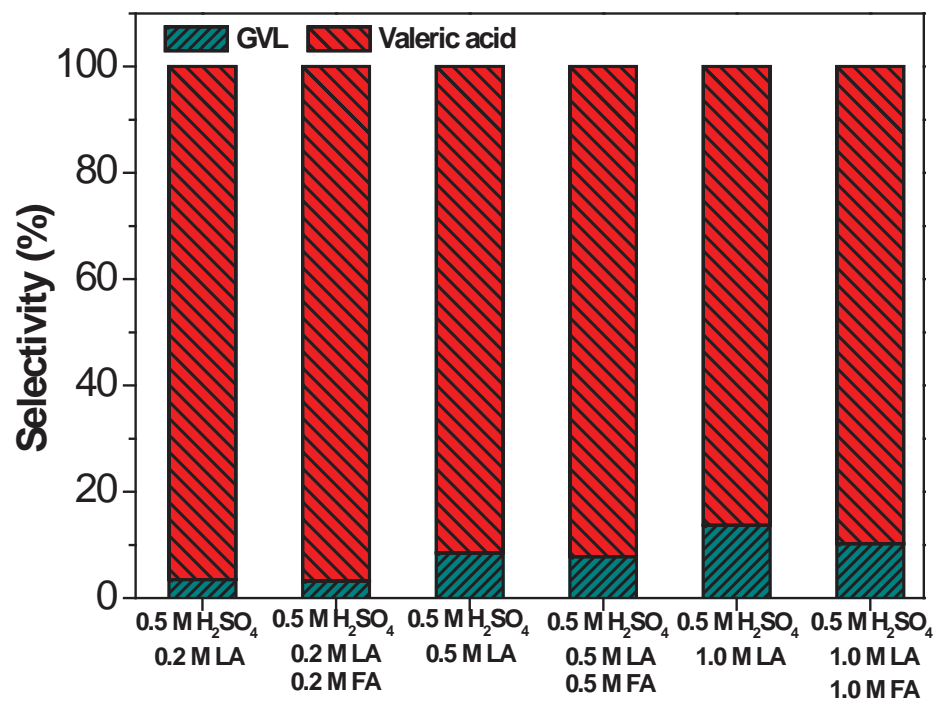

Fig. 7.22 Selectivity of ECH of levulinic acid at $-1.5 \mathrm{~V}$ vs. RHE on a Pb electrode in the PEM-based electrolysis cell reactor under ambient pressure and room temperature: LA = levulinic acid; $\mathrm{FA}$ = formic acid.

The Faradaic efficiency represents the competition between the ECH and the HER. In general, Faradaic efficiency drops gradually in the course of ECH of levulinic acid, 
regardless of the different compositions of levulinic acid solutions introduced into the system, as shown in Fig. 7.23. It indicates that a larger fraction of the current goes to generating hydrogen gas as more levulinic acid is converted. With the equal moles of formic acid added, no apparent change is observed regarding the Faradaic efficiency for $\mathrm{ECH}$ of $0.2 \mathrm{M}$ and $0.5 \mathrm{M}$ levulinic acid, while the average Faradaic efficiency increases by $4 \%$ when comparing $1.0 \mathrm{M}$ levulinic acid without and with $1.0 \mathrm{M}$ formic acid added. During the ECH of levulinic acid of higher concentration, higher current was observed, which accelerates the proton generation near the $\mathrm{Pb}$ electrode surface. Not only will it result in higher local $\mathrm{pH}$ and more GVL production, but also the overall reaction rate and efficiency are decreased. However, the replenishment of consumed protons in proximity to the surface due to the dilution by formic acid increases Faradaic efficiency.

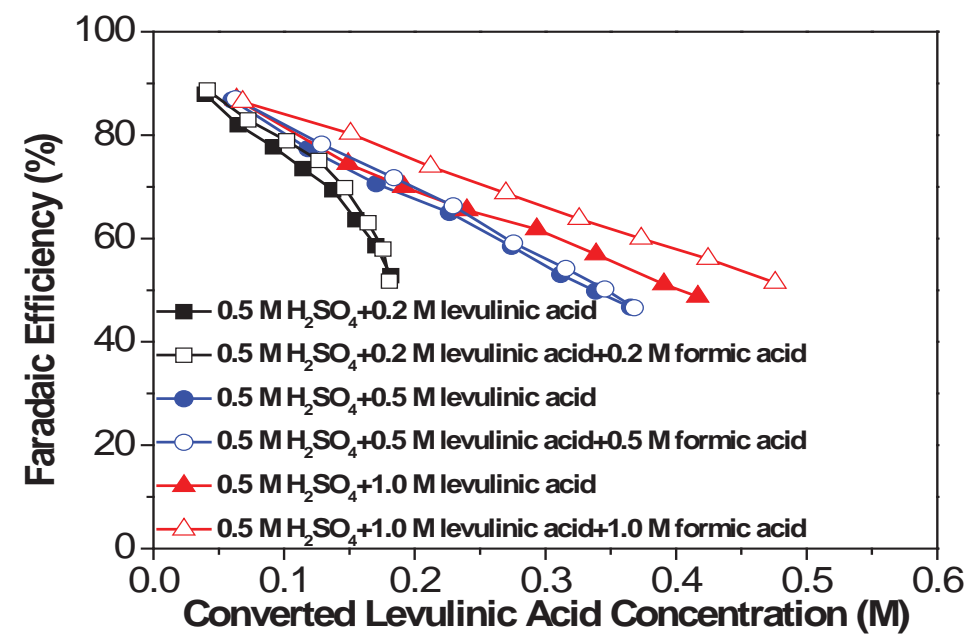

Fig. 7.23 Faradaic efficiency versus the converted levulinic acid concentration at $-1.5 \mathrm{~V}$ vs. RHE on a $\mathrm{Pb}$ electrode in the PEM-based electrolysis cell reactor under ambient pressure and room temperature.

Taken together, the presence of formic acid in the levulinic acid aqueous solution has been found to have no negative effect on the $\mathrm{ECH}$ of levulinic acid in terms of conversion, reaction rate, selectivity, as well as Faradaic efficiency. Although the detailed mechanisms of the role of formic acid in the ECH of levulinic acid are not very clear yet, the results show promise to upgrade the levulinic acid obtained directly from the downstream of cellulose hydrolysis with sulfuric acid to provide an upstream (valeric 
acid + levulinic acid + sulfuric acid) for subsequent electrocatalytic oxidation of formic acid to purify the biofuel intermediate valeric acid.

\subsubsection{Electrocatalytic oxidation of formic acid + valeric acid}

Employing a PEM-DFAFC offers a great opportunity to not only remove formic acid to purify valeric acid biofuel intermediate, but also simultaneously generate electrical energy to supplement the energy cost resulting from ECH of levulinic acid. Compared with liquid alcohol fuels, PEM-DFAFC has shown higher output electrical power density. It has been discovered that formic acid electro-oxidation on Pd-based catalysts proceeds primarily via the pathway without the formation of strongly poisoning $\mathrm{CO}$ intermediates and exhibits higher fuel cell performance than that on Pt. ${ }^{216-222}$ PEM-DFAFCs with Pdbased catalysts can yield very high power density under optimized test conditions, which has great potential for portable devices. Masel et al. have shown that a PEM-DFAFC with $\mathrm{Pd}$ black and $\mathrm{Pd} / \mathrm{C}$ anode catalysts can reach a maximum power density of $243 \mathrm{~mW} \mathrm{~cm} \mathrm{~cm}^{-2}$ and $171 \mathrm{~mW} \mathrm{~cm}{ }^{-2}$, respectively, with $3 \mathrm{M}$ formic acid at $30^{\circ} \mathrm{C}^{216,217}$ Therefore, in the present work, carbon supported Pd nanoparticles ( $\mathrm{Pd} / \mathrm{C} c a .40$ wt.\%) was used as an anode catalyst for a PEM-DFAFC to self-sustainably remove formic acid remaining in the downstream of ECH of levulinic acid + formic acid. The electrocatalytic oxidation (removal) of formic acid was performed by continuously cycling the effluent of a formic acid - valeric acid mixture in $\mathrm{H}_{2} \mathrm{SO}_{4}$ solution $(50 \mathrm{ml})$ into the anode chamber of PEMDFAFC at $1.0 \mathrm{ml} \mathrm{min}^{-1}$ for 6 hours. A constant fuel-cell voltage of $0.1 \mathrm{~V}$ was applied by controlling the outer-circuits resistance to cogenerate electrical energy. As shown in Fig. 7.24 (a), fed with 1.0 $\mathrm{M}$ formic acid + $0.3 \mathrm{M}$ valeric acid of $0.5 \mathrm{M} \mathrm{H}_{2} \mathrm{SO}_{4}$ solution, the current density drops to $17.8 \mathrm{~mA} \mathrm{~cm}^{-2}$ from its initial value $\left(218.6 \mathrm{~mA} \mathrm{~cm}^{-2}\right)$ after 6 hours operation; meanwhile $47 \%$ of the FA present in the reactant mixture has been electrocatalytically removed (Fig. 7.24 (b)). It is interesting to note that the independent experiment conducted by feeding $0.3 \mathrm{M}$ valeric acid $+0.5 \mathrm{M} \mathrm{H}_{2} \mathrm{SO}_{4}$ into the fuel cell produces a current density of $<0.1 \mathrm{~mA} \mathrm{~cm}^{-2}$ under identical operation conditions, indicating the inertness of valeric acid over the $\mathrm{Pd} / \mathrm{C}$ anode catalyst (Fig. 7.25). The measured concentration of valeric acid remains close to $90 \%$, shown in Fig. 7.24 (b), as 
compared with its normalized concentration at the beginning of the reaction. The small loss of valeric acid after 6 hours reaction may be due to its evaporation, and could be minimized by optimizing future fuel cell reactor design. In addition, it is worthwhile to mention that the difference of total electrons calculated by integrating the total generated charges from formic acid electro-oxidation using the coulometer in the fuel cell tester and by counting the converted formic acid assuming that two-electron transfer to $\mathrm{CO}_{2}$ is less than $2 \%$, which suggests a satisfactory experiment accuracy of the electrochemical and analytical methods. In order to investigate the effect of added valeric acid on formic acid electro-oxidation, $1.0 \mathrm{M}$ formic acid alone with $0.5 \mathrm{M} \mathrm{H}_{2} \mathrm{SO}_{4}$ was fed into the PEMDFAFC. Fig. 7.24 (a) shows that in the absence of valeric acid, the current density also gradually decreased and stabilized at $17.5 \mathrm{~mA} \mathrm{~cm}{ }^{-2}$ because the reaction rate would decrease with more FA converted. However, the conversion of formic acid can reach $69 \%$ after 6 hours reaction, which is higher than that when valeric acid was added in the solution (Fig. 7.24 (b)). The presence of valeric acid in the solution appears to inhibit the formic acid electro-oxidation rate over $\mathrm{Pd} / \mathrm{C}$, resulting in low current density at fuel cell operation at $0.1 \mathrm{~V}$. 

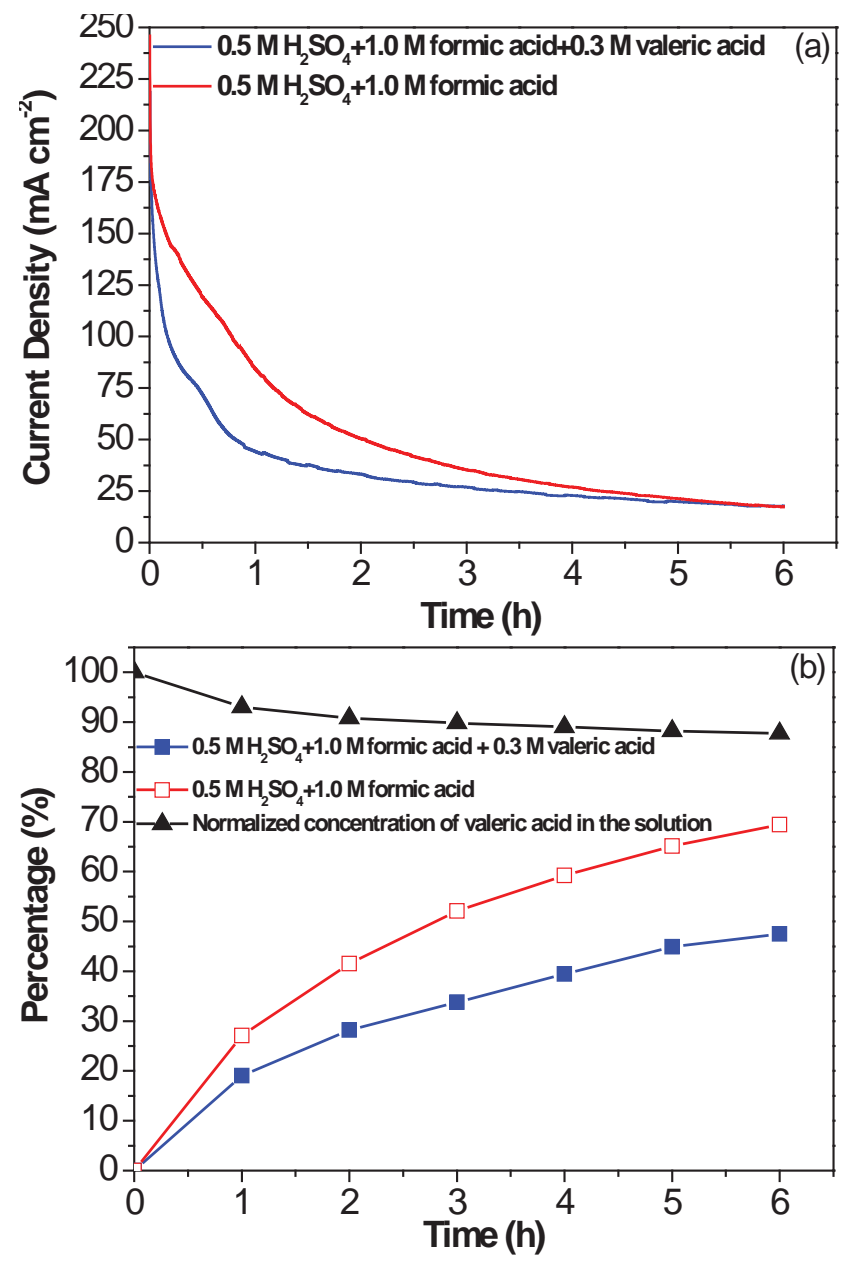

Fig. 7.24 (a) Current density and (b) formic acid conversion and normalized concentration of valeric acid as a function of time for electro-oxidation of formic acid in the PEM-DFAFC at constant fuel cell voltage of $0.1 \mathrm{~V}, 30 \mathrm{C}$. 


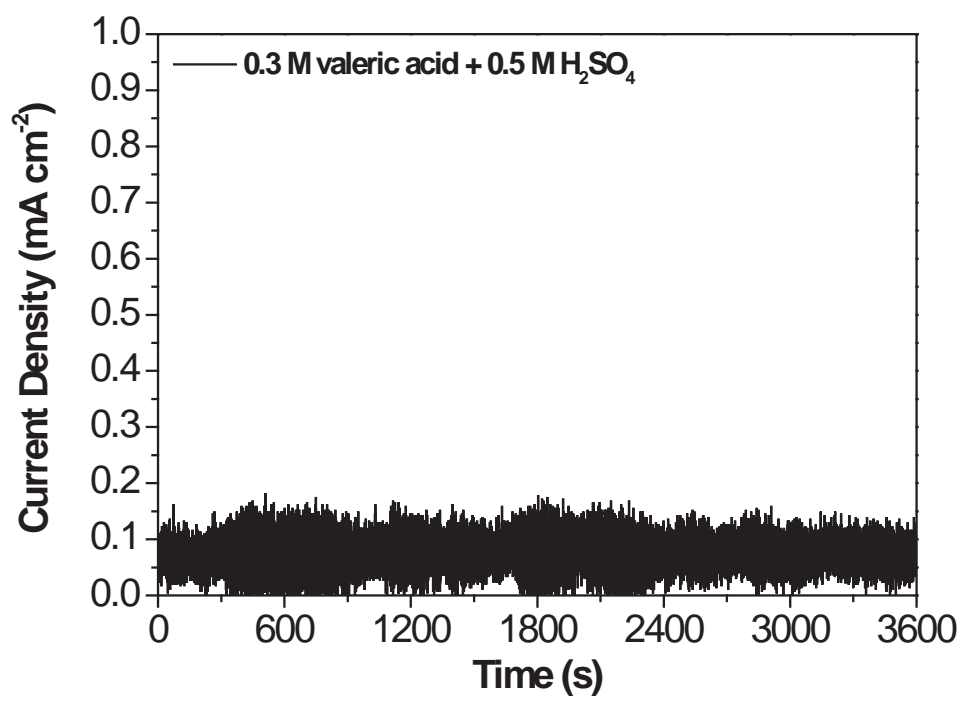

Fig. 7.25 Current density as a function of time for electro-oxidation of valeric acid in the PEM-DFAFC at constant fuel cell voltage of $0.1 \mathrm{~V}, 30^{\circ} \mathrm{C}$.

The polarization and power density curves of PEM-DFAFC with two different fuels are shown in Fig. 7.26. When fed with $1.0 \mathrm{M}$ formic acid $+0.5 \mathrm{M} \mathrm{H}_{2} \mathrm{SO}_{4}$ at a flow rate of 1.0 $\mathrm{ml} \mathrm{min}{ }^{-1}$, the PEM-DFAFC with a loading of $3.0 \mathrm{mg}_{\mathrm{Pd}} \mathrm{cm}^{-2}$ yielded an OCV of $0.92 \mathrm{~V}$ and a peak power density of $61.3 \mathrm{~mW} \mathrm{~cm}^{-2}$ (at $135.9 \mathrm{~mA} \mathrm{~cm}^{-2}$ ) at $30{ }^{\circ} \mathrm{C}$. However, with the addition of $0.3 \mathrm{M}$ valeric acid, this PEM-DFAFC only produced an OCV of $0.87 \mathrm{~V}$ and its peak power density drops to $44.9 \mathrm{~mW} \mathrm{~cm}^{-2}$ (at $95.9 \mathrm{~mA} \mathrm{~cm}^{-2}$ ). The observed inhibition of $\mathrm{Pd} / \mathrm{C}$ electro-catalysts by a valeric acid-formic acid mixture fuel can be further evidenced by the decrease of the limiting current density from $208.1 \mathrm{~mA} \mathrm{~cm}^{-2}$ to $127.9 \mathrm{~mA} \mathrm{~cm}^{-2}$, which implies poor fuel diffusion due to the presence of valeric acid in the electrolyte. However, after the 6 hours reaction, the MEA was cleaned by washing with copious deionized water until no valeric acid was detected in the filtrate. The polarization and power density curves of the PEM-DFAFC with the recovered MEA were collected again by feeding 1.0 $\mathrm{M}$ formic acid $+0.5 \mathrm{M} \mathrm{H}_{2} \mathrm{SO}_{4}$. As shown in Fig. 7.26, nearly repeated $\mathrm{I}-\mathrm{V}$ curves indicate no fuel cell performance drop between the fresh MEA and its recovery with DI water washing, indicating that the negative effect of valeric acid on formic acid electro-oxidation is a reversible process, the $\mathrm{Pd} / \mathrm{C}$ anode catalyst is highly stable and the PEM-DFAFC performance can be recovered with DI water washing. 


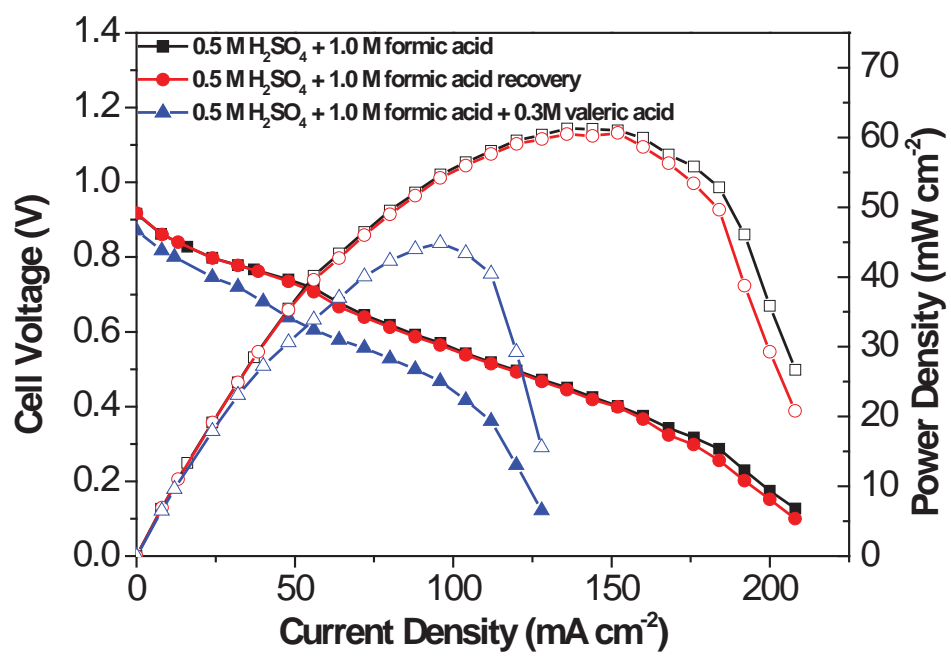

Fig. 7.26 Polarization and power density curves of a PEM-DFAFC employing $\mathrm{Pd} / \mathrm{C}$ anode catalyst without and with valeric acid addition and after DI water washing recovery, ambient pressure, $30 \mathrm{C}$.

To study the valeric acid effects on the electrocatalytic oxidation of formic acid over $\mathrm{Pd} / \mathrm{C}$, various concentrations of valeric acid ranging from $0.1 \mathrm{M}$ to $0.3 \mathrm{M}$ was added to 1.0 $\mathrm{M}$ formic acid $+0.5 \mathrm{M} \mathrm{H}_{2} \mathrm{SO}_{4}$ and the cyclic voltammetry experiment was performed on $\mathrm{Pd} / \mathrm{C}$ in half cells. Fig. 7.27 shows that the peak currents for formic acid electrooxidation in the presence of $0.1 \mathrm{M}$ and $0.2 \mathrm{M}$ valeric acid are $12.7 \mathrm{~mA}$ and $0.22 \mathrm{~mA}$, respectively, which are $46 \%$ and $99 \%$ lower than the original current of $23.6 \mathrm{~mA}$. As the valeric acid concentration is increased to $0.3 \mathrm{M}$, hardly any anodic current can be observed. To confirm that the decreased current is not attributed to the competitive electro-oxidation of valeric acid, blank $\mathrm{CV}$ experiments with different valeric acid concentrations of $0.1 \mathrm{M}, 0.2 \mathrm{M}$, and $0.3 \mathrm{M}$ were conducted under identical test conditions in $0.5 \mathrm{M} \mathrm{H}_{2} \mathrm{SO}_{4}$ aqueous solution. Compared with the $\mathrm{CV}$ of a blank $0.5 \mathrm{M} \mathrm{H}_{2} \mathrm{SO}_{4}$, there is nearly no anodic current generated from valeric acid oxidation on $\mathrm{Pd} / \mathrm{C}$ in the course of the cyclic voltammetry scan $(0.1 \mathrm{~V}$ to $1.2 \mathrm{~V})$ (Fig. 7.28), which agrees well with the negligible current density observed when $0.3 \mathrm{M}$ valeric acid $+0.5 \mathrm{M} \mathrm{H}_{2} \mathrm{SO}_{4}$ fed into the PEM-DFAFC (Fig. 7.25). Therefore, the product valeric acid from ECH of levulinic acid clearly suppresses the electro-oxidation of formic acid over $\mathrm{Pd} / \mathrm{C}$ in the PEM-DFAFC reactor, which is integrated for the electrocatalytically oxidize (remove) formic acid to refine the valeric acid biofuel intermediate. It is also noted in Fig. 7.28 that the degree of 
inhibition is directly correlated to the concentration of valeric acid presented in the formic acid sulfuric solution. In contrast to the $\mathrm{CV}$ curve recorded in blank $0.5 \mathrm{M} \mathrm{H}_{2} \mathrm{SO}_{4}$, both the hydrogen desorption and PdO reduction peaks are decreased with the increase of valeric acid concentration. The ECSA is calculated by quantification of the electric charges associated with the reduction of the surface $\mathrm{PdO}$ layer. The upper potential bound of $1.2 \mathrm{~V}$ vs. RHE corresponds to a charge density of around $300 \mu \mathrm{C} \mathrm{cm}^{-2},{ }^{223}$ leading to ECSA of $45.8 \mathrm{~m}^{2} \mathrm{~g}^{-1}$ in $0.5 \mathrm{M} \mathrm{H}_{2} \mathrm{SO}_{4}$. When the valeric acid concentration was increased from $0.1 \mathrm{M}$ to $0.3 \mathrm{M}$, the ECSA of $\mathrm{Pd} / \mathrm{C}$ dropped to 25.5 and $8.6 \mathrm{~m}^{2} \mathrm{~g}^{-1}$, respectively, as depicted in Fig. 7.28. The loss of ECSA indicates that the catalytic active sites have been blocked by valeric acid via its carboxylic group adsorption.
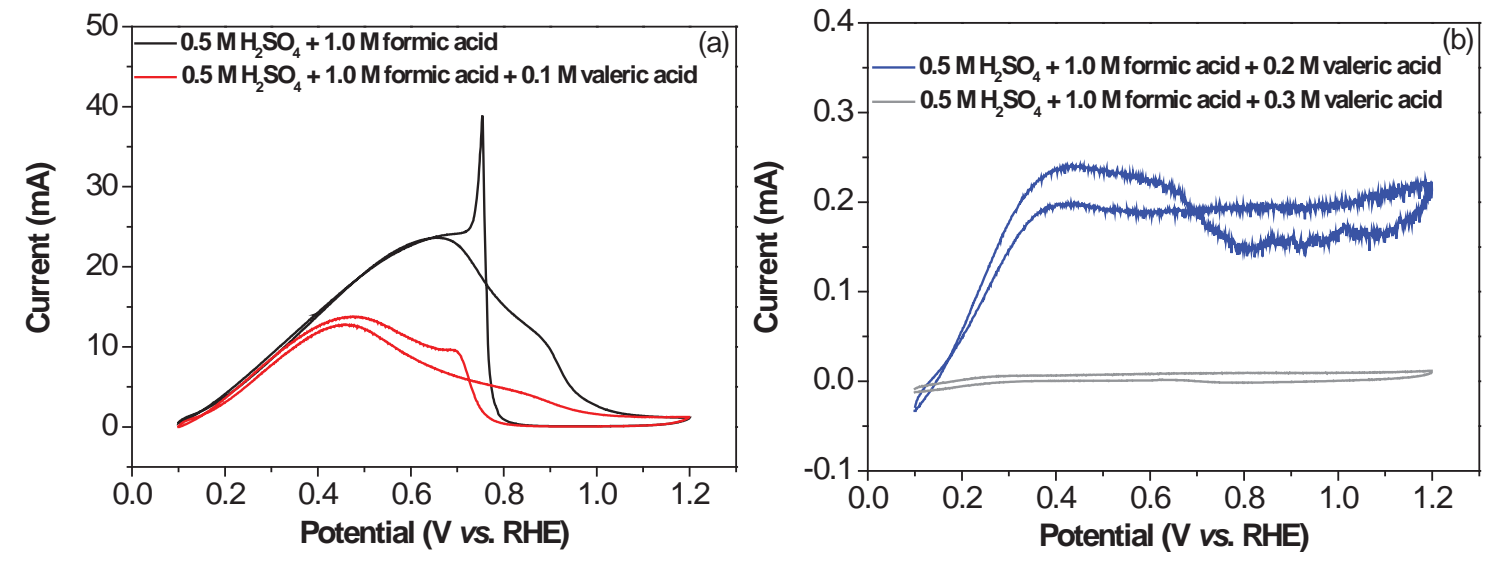

Fig. 7.27 CVs of $\mathrm{Pd} / \mathrm{C}$ electro-catalyst in (a) $0 \mathrm{M}$ and $0.1 \mathrm{M}$, (b) $0.2 \mathrm{M}$ and $0.3 \mathrm{M}$ valeric acid $+1.0 \mathrm{M}$ formic acid $+0.5 \mathrm{M} \mathrm{H}_{2} \mathrm{SO}_{4}$ solution, at $50 \mathrm{mV} \mathrm{s}^{-1}$, room temperature. 

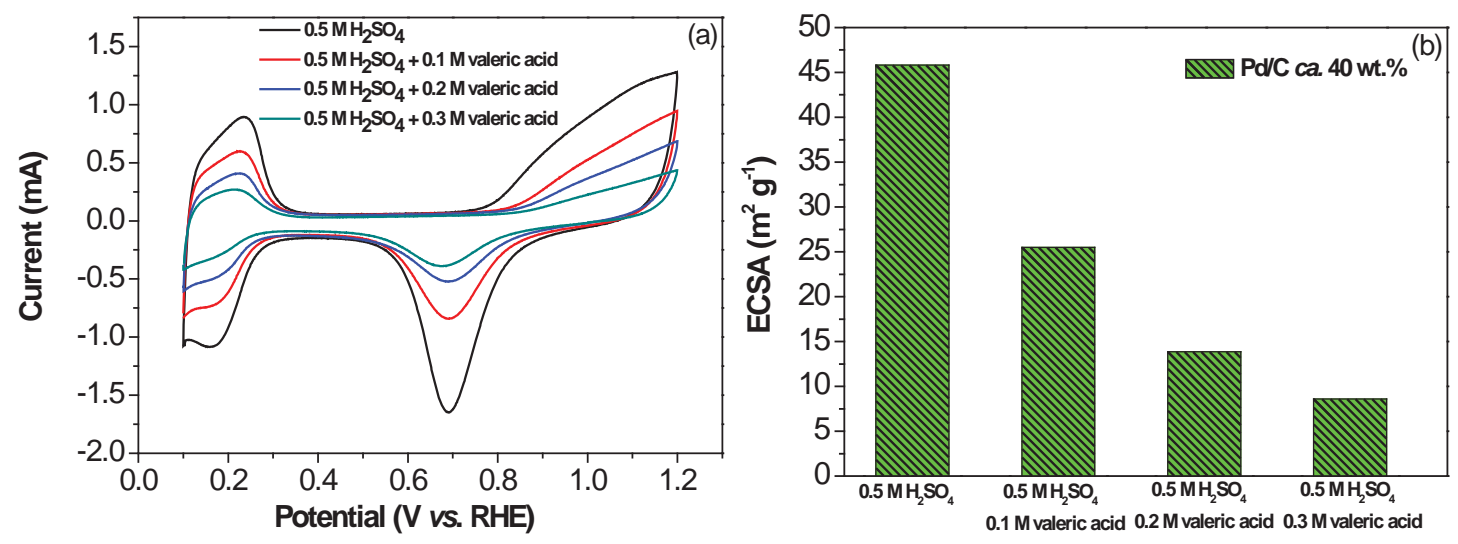

Fig. 7.28 (a) CVs and (b) ECSAs of Pd/C electro-catalyst in $0 \mathrm{M}, 0.1 \mathrm{M}, 0.2 \mathrm{M}$ or $0.3 \mathrm{M}$ valeric acid $+0.5 \mathrm{M} \mathrm{H}_{2} \mathrm{SO}_{4}$ solution, at $50 \mathrm{mV} \mathrm{s}^{-1}$, room temperature.

To further investigate how valeric acid inhibited the electro-oxidation of formic acid, various carboxylic acids ( $0.2 \mathrm{M}$ acetic acid, propionic acid, butyric acid and VA) with different alkyl group sizes (from $\mathrm{C}_{2}$ to $\mathrm{C}_{5}$ ) were added to the $1.0 \mathrm{M}$ formic acid $+0.5 \mathrm{M}$ $\mathrm{H}_{2} \mathrm{SO}_{4}$ solution. Compared with the $\mathrm{CV}$ curve of blank $0.5 \mathrm{M} \mathrm{H}_{2} \mathrm{SO}_{4}$, it is noted in Fig. 7.29 that the $\mathrm{C}_{2}-\mathrm{C}_{5}$ carboxylic acids present in the electrolyte, despite showing no activity on $\mathrm{Pd} / \mathrm{C}$, significantly reduce the ECSA of the Pd catalyst. Moreover, upon the increase of the carbon chain length from $\mathrm{C}_{2}$ to $\mathrm{C}_{5}$, the ECSA loss of $\mathrm{Pd} / \mathrm{C}$ becomes more severe. For example, when $0.2 \mathrm{M}$ acetic acid ( $\mathrm{C}_{2}$ carboxylic acid) is added, ECSA drops to $35.8 \mathrm{~m}^{2} \mathrm{~g}^{-1}$ (22\% decrease from the original ECSA), and it decreases to $30.9,24.1$, and $13.9 \mathrm{~m}^{2} \mathrm{~g}^{-1}$ with the addition of $0.2 \mathrm{M}$ propionic acid $\left(\mathrm{C}_{3}\right)$, butyric acid $\left(\mathrm{C}_{4}\right)$ and valeric acid $\left(\mathrm{C}_{5}\right)$, respectively. These results indicate that the anion adsorption of $-\mathrm{COOH}$ in valeric acid is responsible for the inhibition of formic acid electro-oxidation on $\mathrm{Pd} / \mathrm{C}$, and it will prevent formic acid from continuously oxidation on $\mathrm{Pd} / \mathrm{C}$ in the PEM-DFAFC. 

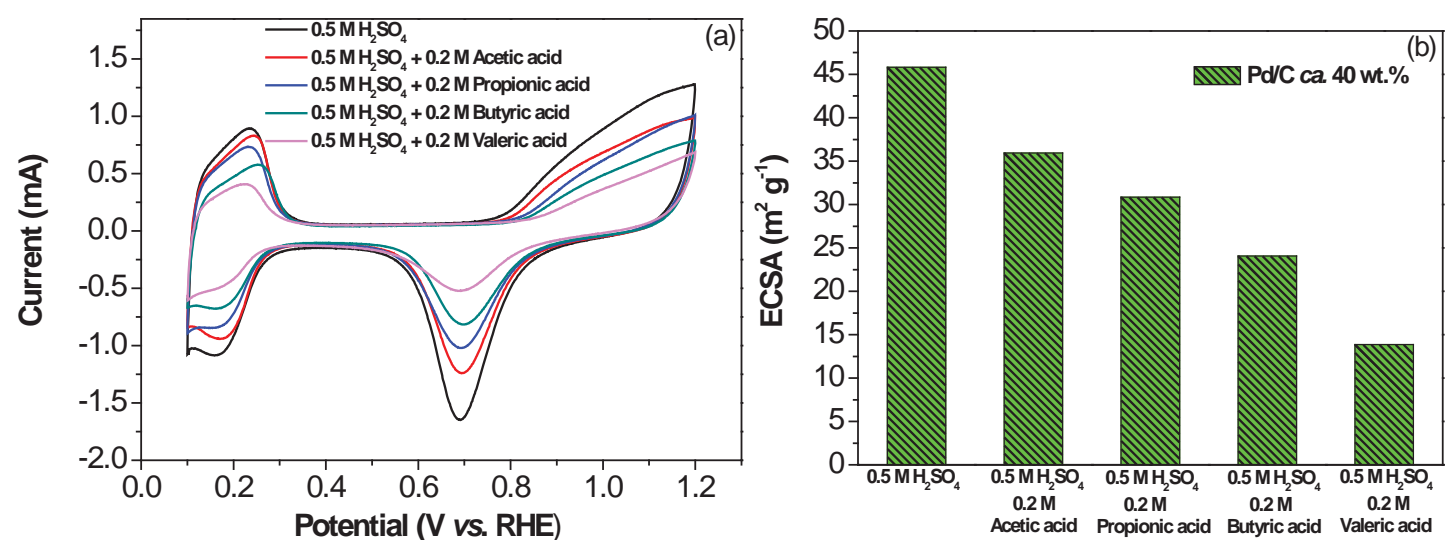

Fig. 7.29 (a) CVs and (b) ECSA of $\mathrm{Pd} / \mathrm{C}$ catalyst in $0.2 \mathrm{M}$ acetic acid, propionic acid, butyric acid or valeric acid $+0.5 \mathrm{M} \mathrm{H}_{2} \mathrm{SO}_{4}$ solution, at $50 \mathrm{mV} \mathrm{s}^{-1}$, room temperature.

A previous study on the influence of acetate ions on ethanol electro-oxidation on a polycrystalline platinum electrode demonstrated that the accumulation of the product acetic acid in the electrolyte will lead to acetate anions adsorbed on the platinum electrode, which will compete with ethanol adsorption, thus significantly impeding ethanol oxidation in direct ethanol fuel cells. ${ }^{224}$ It appears similar to the aforementioned findings of the blocking effect of alkyl carboxylic acids. In addition, an alkyl group linked to $-\mathrm{COOH}$ tends to donate electrons to carboxylic ions, and based on DFT calculation, the electronegativity of alky groups, being electron releasing, was found to decrease with the increase of the length of the alkyl chain. ${ }^{225}$ Therefore, the electrodonating effect of the alky group will increase the electron density of carboxylic ions, making it destabilized, and readily coordinate with the metallic electrocatalysts, such as $\mathrm{Pd} / \mathrm{C}$. Also, the long carbon chains will also entangle each other to prevent the formic acid diffusion to the catalyst surface for the electro-oxidation reaction.

In summary, it is promising that formic acid conversion of $47 \%$ can be achieved in 6 hours of electro-oxidation of formic acid-valeric acid $\mathrm{H}_{2} \mathrm{SO}_{4}$ solution in PEM-DFAFC, and the valeric acid present is inert to the $\mathrm{Pd} / \mathrm{C}$ anode catalyst. However, the results also suggest that Pt-group metal catalysts used for electrocatalytic conversion of formic acid cannot tolerate the impurities of carboxylic acid with long alkyl chains. 


\subsection{Conclusions}

This chapter reports an efficient approach to renewable electricity storage in biofuel by selective electrocatalytic reduction of biomass-derived levulinic acid to high-energydensity valeric acid or GVL on a Pb electrode in the continuous flow-type solid -polymer electrolyte membrane based electrolysis cell reactor. Compared to batch-type half-cell reactor, it has been demonstrated a very high yield of valeric acid ( $>90 \%)$, a high Faradaic efficiency $(>86 \%)$, a promising electricity storage efficiency $(70.8 \%)$, and a low electricity consumption $\left(1.5 \mathrm{kWh} \mathrm{L}_{\text {valeric acid }}{ }^{-1}\right)$. In addition, the applied potential and electrolyte $\mathrm{pH}$ were found to be able to accurately control the selectivity of reduction products: lower overpotentials favor the production of GVL, whereas higher overpotentials facilitate the formation of valeric acid. A selectivity of $95 \%$ to valeric acid in acidic electrolyte $(\mathrm{pH} \cong 0)$ and $100 \%$ selectivity to GVL in neutral electrolyte $(\mathrm{pH} \cong$ 7.5) are obtained. The effects of the molecular structure on the electrocatalytic reduction of ketone and aldehyde groups of biomass compounds were also investigated. Levulinic acid can be fully electro-reduced to VA though a four-electron transfer, whereas the $\mathrm{C}=\mathrm{O}$ groups are only electro-reduced to -OH by a two-electron- transfer process when glyoxylic acid and pyruvic acid served as feedstock.

Next, the electro-biorefinery of the downstream of acid-catalyzed cellulose hydrolysis process was studied in an integrated electrocatalytic process that couples the ECH of levulinic acid + formic acid in the continuous flow-type PEM-based electrolysis cell reactor and electrocatalytic oxidation (removal) of formic acid in the PEM-DFAFC reactor. The investigations on ECH of levulinic acid + formic acid in $\mathrm{H}_{2} \mathrm{SO}_{4}$ aqueous solution to valeric acid and GVL on a Pb electrode in the electrolysis cell reactor show that high selectivity to valeric acid (>90\%) and high Faradaic efficiency $(>47 \%)$ can be maintained during 8 hours of reaction. It was also clearly demonstrated that the presence of formic acid in the levulinic acid aqueous solution is stable and has been found to have no negative effect in terms of levulinic acid conversion, ECH reaction rate and Faradaic efficiency. When 1.0 M formic acid + 0.3 M valeric acid was directly fed into the PEMDFAFC, $47 \%$ formic acid conversion was achieved in 6 hours and valeric acid is inert to 
the $\mathrm{Pd} / \mathrm{C}$ anode catalyst during the formic acid electro-oxidation reaction. However, $\mathrm{Pd} / \mathrm{C}$ was found to be reversibly deactivated by valeric acid in the reactant mixtures. The halfcell tests demonstrated that higher valeric acid concentration leads to more serious competition with formic acid for electrochemical active sites of $\mathrm{Pd} / \mathrm{C}$. In addition, carboxylic acids with different lengths of alkyl chains $\left(\mathrm{C}_{2}\right.$ to $\left.\mathrm{C}_{5}\right)$ were explored under the formic acid electro-oxidation conditions and these compounds with longer carbon chains apparently adsorbed stronger onto $\mathrm{Pd} / \mathrm{C}$, resulting in a lower ECSA.

The results suggest that the proposed integrated electro-biorefinery process, though very promising, currently remains challenging. Advanced electrocatalytic materials that can tolerate impurities existing in the streams of a crude biomass process need to be developed. Coupling important electrocatalytic transformations of biomass-compounds can be further optimized to minimize the overall material and energy costs. 


\section{Chapter 8 Supported Non-Platinum Group Metal Ag Catalyst for Oxygen Reduction Reaction (ORR) in Alkaline Electrolyte*}

\subsection{Background}

ORR coupled at the cathode of fuel cells involves multiple electron transferred steps and proceeds sluggishly. Therefore a large overpotential is required for the delivery of a satisfactory Faradaic current. Oftentimes in PEMFCs, PGMs have to be employed as cathode catalysts in order to improve the kinetics of ORR and maintain long catalyst life time. ${ }^{176}$ In high $\mathrm{pH}$ media, the ORR kinetics can be greatly improved due to enhanced ion transport and facile charge transfer. ${ }^{36}$ Recently, low-temperature AEMFCs have resurged due to the introduction of novel solid anion exchange membranes that have demonstrated high anion conductivity and chemical/electrochemical stability. ${ }^{37,226-229}$ An attractive merit of AEMFCs is inexpensive non-PGMs can be used as electrocatalysts. ${ }^{230}$

In Chapter 3-5, it has been studied that the cogeneration of chemicals and electrical energy in AEM-DAFCs using glycerol and EG as fuels, where the research focus was placed on the anodic reactions. To advance the electrochemical valorization of alcohols in the fuel cell reactors, efficient non-PGMs catalysts need to be explored. Among them, $\mathrm{Ag}$ has exhibited very high ORR intrinsic activity and durability in high $\mathrm{pH}$ electrolyte. ${ }^{35,36}$ In addition, the price of Ag is about $20 \mathrm{US} \$ \mathrm{oz}^{-1}$, which is about 75 times

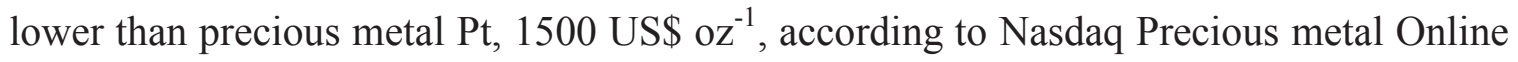
Price. Carbon supported Ag electrocatalysts have aroused extensive interests as an

\footnotetext{
*The material contained in this chapter was previously published in Frontiers in Chemistry 2013;1: "Carbon Supported Ag Nanoparticles as High Performance Cathode Catalyst for Anion Exchange Membrane Fuel Cell” by Xin L, Zhang Z, Wang Z, Qi J, Li W. Copyright (C) 2013 Xin, Zhang, Wang, Qi and Li.
} 
alternative to Pt for ORR in alkaline media. ${ }^{35,36,227,230-233}$ Blizanac and coworkers have demonstrated that on $\operatorname{Ag}(111)$ single crystal, the ORR proceeds via four-electron pathway in high alkaline media (i.e. $\mathrm{pH}>15$ ), with very little production of undesirable $\mathrm{H}_{2} \mathrm{O}_{2}$ byproduct. It was also suggested that although $\mathrm{Ag}(111)-\mathrm{O}_{\mathrm{ad}}$ interaction is weaker when compared with $\mathrm{Pt}$, it is still strong enough to facilitate dissociation of the $\mathrm{O}-\mathrm{O}$ bond. ${ }^{234} \mathrm{In}$ addition, the research efforts were also given to the effect of carbon support on the pathway of ORR in the alkaline electrolyte ${ }^{235}$, and the preparation of $\mathrm{Ag} / \mathrm{C}$ allows its application in AEMFCs. Ag-based nanowire catalysts were also successfully synthesized and it was concluded that four-electron ORR was predominant on the $\mathrm{Ag}$ nanostructures. $^{236}$

In this chapter, the nanocapsule method was modified to prepare carbon supported $\mathrm{Ag}$ nanoparticles with an average size of $5.4 \mathrm{~nm}$ at near room temperature. The ORR mechanisms and activity on $\mathrm{Ag} / \mathrm{C}$ was studied in comparison with commercial $\mathrm{Pt} / \mathrm{C}$ and non-precious Acta 4020 series cathode catalyst (with approx. 3.5 wt.\% Fe-Cu based transition metals on carbon support).

\subsection{General experimental}

\subsubsection{Preparation of $\mathrm{Ag} / \mathrm{C}(40$ wt. \%)}

The organic solution phase-based nanocapsule method was applied to prepare the carbon black supported Ag nanoparticles. The detail synthesis procedures have been described in Section 2.4.5.

\subsubsection{Physical characterizations}

The morphology, nanostructure and metal loading of the catalysts were analyzed by TEM, XRD and ICP-OES, as described in Section 2.5.1, 2.5.3 and 2.5.4.

\subsubsection{Electrochemical tests in half cells}

A conventional three-electrode-cell setup (Fig. 2.1 (b)) consisting of a glassy carbon disk $\left(0.1963 \mathrm{~cm}^{2}\right) / \mathrm{Pt} \operatorname{ring}\left(0.1099 \mathrm{~cm}^{2}\right)$ working electrode, a $\mathrm{Hg} / \mathrm{HgO} / 1.0 \mathrm{M} \mathrm{KOH}$ 
reference electrode and a coiled Pt counter electrode, was used for RRDE tests of ORR activity on cathode catalysts $(\mathrm{Ag} / \mathrm{C}, \mathrm{Pt} / \mathrm{C}$ (40 wt.\%, Fuel Cell Store) and Acta 4020).(Section 2.2.1) Before testing, $1.0 \mathrm{mg}$ catalyst was dispersed in $1.0 \mathrm{ml}$ isopropanol by ultrasonication to form a uniform ink. The working electrode was prepared by depositing $20 \mu \mathrm{l}$ of the ink on the glassy carbon electrode and left to dry at room temperature. Next, Next, $10 \mu \mathrm{l}$ of 0.05 wt.\% AS-4 anion exchange ionomer solution was drop-casted on the catalyst layer in order to attach the electrocatalyst particles on the glass carbon substrate. (Section 2.3.1) The RRDE test was conducted in $\mathrm{O}_{2}$-saturated $0.1 \mathrm{M} \mathrm{KOH}$ electrolyte .LSV at a sweep rate of $10 \mathrm{mV} \mathrm{s}^{-1}$ was performed from -0.9 to 0.1 or $0.2 \mathrm{~V}$ vs. $\mathrm{Hg} / \mathrm{HgO} / 1.0 \mathrm{M} \mathrm{KOH}$ at room temperature, on $\mathrm{Ag} / \mathrm{C}, \mathrm{Pt} / \mathrm{C}$ and Acta 4020 catalysts. The working electrode rotation rate is $2500 \mathrm{rpm}$.

\subsection{Results and discussion}

A typical TEM image of $\mathrm{Ag} / \mathrm{C}$ catalyst is shown in Fig. 8.1 (a). Uniformly dispersed $\mathrm{Ag}$ nanoparticles were observed on carbon black support. The corresponding particle size histogram in Fig. 8.1 (b) evaluated from 100 random particles in an arbitrarily chosen area presents a narrow distribution of $2-9 \mathrm{~nm}$, centered at $5.4 \mathrm{~nm}$ for $\mathrm{Ag}$ nanoparticles, which indicates the modified nanocapsule method has a strong ability to control over nanoparticle size and morphology. The XRD patterns in Fig. 8.1 (c) show a typical Ag fcc structure, with the peaks at $38.2,44.3,64.4,77.5$, and $81.5^{\circ}$ assigned to $\mathrm{Ag}$ (111), (200), (220), (311), and (222) facets, respectively. The average particle size calculated from the Ag (220) diffraction peak by Debye-Sherrer equation (Equation 2-8) is $4.2 \mathrm{~nm}$, which confirms the small size of Ag particles prepared by this nanocapsule method. The metal loading of $\mathrm{Ag} / \mathrm{C}$ catalyst has been determined by ICP-OES to be $31 \mathrm{wt} . \%$. The lower metal loading ( $31 \mathrm{wt} . \%$ vs. setting value of $40 \mathrm{wt} . \%$ ) may be due to the small amount of surfactant residue still left on the carbon supported Ag catalyst after the filtration process. 

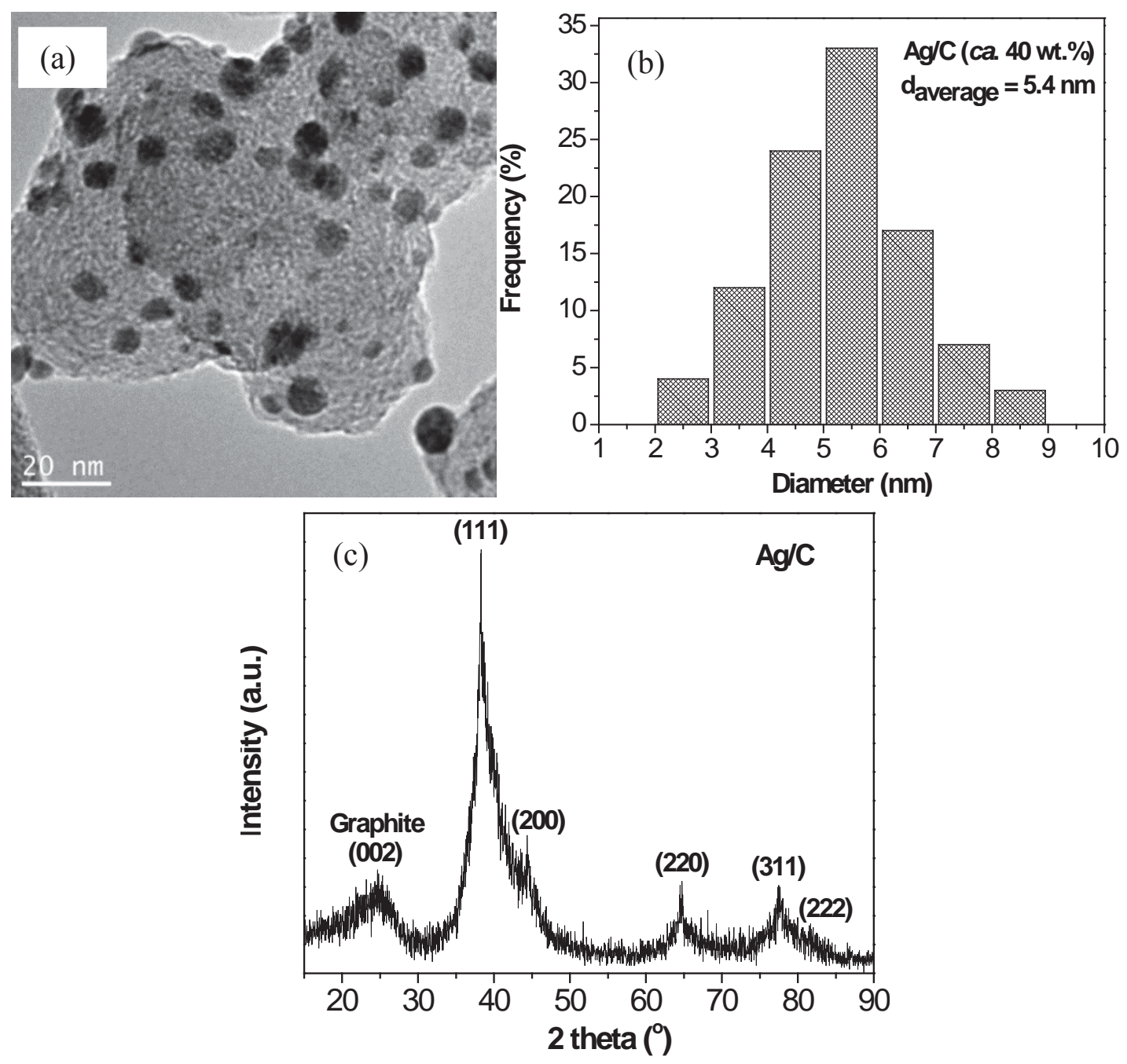

Fig. 8.1 (a) TEM image, (b) particle size histogram and (c) XRD patterns of Ag/C catalyst.

Steady state polarization curves for the ORR on $\mathrm{Ag} / \mathrm{C}$ and its ring current corresponding to $\mathrm{HO}_{2}^{-1}$ oxidation on Pt ring electrode are shown in Fig. 8.2 (a) and (b), and compared with those of the commercial $\mathrm{Pt} / \mathrm{C}$ and Acta 4020 catalysts. The onset potential on $\mathrm{Ag} / \mathrm{C}$ is $0.034 \mathrm{~V}$ vs. $\mathrm{Hg} / \mathrm{HgO} / 1.0 \mathrm{M} \mathrm{KOH}$, which is more negative than those on $\mathrm{Pt} / \mathrm{C}(0.104 \mathrm{~V}$ vs. $\mathrm{Hg} / \mathrm{HgO} / 1.0 \mathrm{M} \mathrm{KOH})$ and Acta 4020 (0.075 V vs. Hg/HgO/1.0 M KOH). However, it is interesting to observe that the ring current on $\mathrm{Ag} / \mathrm{C}$ is smaller than those on $\mathrm{Pt} / \mathrm{C}$ and Acta 4020 catalyst, indicating a lower $\mathrm{HO}_{2}^{-1}$ generation on $\mathrm{Ag} / \mathrm{C}$. The $\mathrm{HO}_{2}{ }^{-1}$ is the main ORR by-product that will not only reduce the energy efficiency by $50 \%$, but also can deteriorate the ionomer and membrane, thus affect the durability of AEMFCs. The lower 
$\mathrm{HO}_{2}{ }^{-1}$ generation rate suggests $\mathrm{Ag} / \mathrm{C}$ is a more efficient and safe catalyst when employed in AEMFCs. The number of transferred electron $(n)$ during ORR on all three cathode catalysts was caculated according to Equation 8-1:237

$$
n=\frac{4 \times i_{d}}{i_{d}+\left(\frac{i_{r}}{N}\right)}
$$

where $i_{d}$ is the disk current, $i_{r}$ is the ring current and $N=0.23$ is the RRDE collection efficiency, the determination of which is discussed in Section 2.2.1 and Fig. 2.2. The calculated $n$ for $\mathrm{Ag} / \mathrm{C}, \mathrm{Pt} / \mathrm{C}$ and Acta 4020 are 3.94, 3.92 and 3.56, respectively. This indicates that they all catalyze ORR mainly through the four-electron pathway in alkaline electrolyte. It has been reported that on Ag (111) single crystal, the oxygen reduction proceeds four-electron pathway in base, whereas two-electron pathway in acid, suggesting that although $\mathrm{Ag}-\mathrm{O}_{\text {ads }}$ interaction is weaker than Pt- $\mathrm{O}_{\text {ads }}$, but it is still strong enough to break the $\mathrm{O}-\mathrm{O}$ bond in high $\mathrm{pH}$ electrolyte. While in acid electrolyte, anion coverage on Ag is relatively high, thereby disabling the surface to provide the required number of virgin sites for adsorption of $\mathrm{O}_{2}$ and subsequent $\mathrm{O}-\mathrm{O}$ bond cleavage processes. $^{234}$

Fig. 8.3 shows the Tafel plots on $\mathrm{Ag} / \mathrm{C}, \mathrm{Pt} / \mathrm{C}$ and Acta 4020 for the comparison of their intrinsic activities. The kinetic current density $\left(j_{k}\right)$ is estimated by correcting the mass transport limiting current though Equation 8-2, which is derived from Levich-Koutecky equation by assuming that ORR obeys first-order kinetics. ${ }^{238}$

$$
j_{k}=\frac{j \times j_{l}}{j_{l}-j}
$$

where $j_{l}$ is the diffusion limiting current density and $j$ is the collected current density. In Fig. 8.3, the Tafel slopes on $\mathrm{Ag} / \mathrm{C}, \mathrm{Pt} / \mathrm{C}$ and Acta 4020 can be divided into two regions. The values of $50.4,46.0,53.8 \mathrm{mV}$ decade $^{-1}$ are for $\mathrm{Ag} / \mathrm{C}, \mathrm{Pt} / \mathrm{C}$ and Acta 4020 in the low overpotential region, which could be attributed to the transfer of the first electron as a rate determine step and Temkin condition of intermediate adsorption ${ }^{239}$. The close values of Tafel slopes of these three catalysts also suggest the ORR pathway and rate determine 
step occurs similarly. However, in the high overpotential region, the Tafel slopes of 125.4 and $128.5 \mathrm{mV} \mathrm{dec}^{-1}$ are obtained for $\mathrm{Ag} / \mathrm{C}$ and $\mathrm{Pt} / \mathrm{C}$ and $275.6 \mathrm{mV}$ decade $^{-1}$ for Acta 4020 . The higher Tafel slope observed on Acta 4020 is probably due to the worse mass transport issue associated with the thicker catalyst layer as Acta 4020 being coated on the glassy carbon electrode.
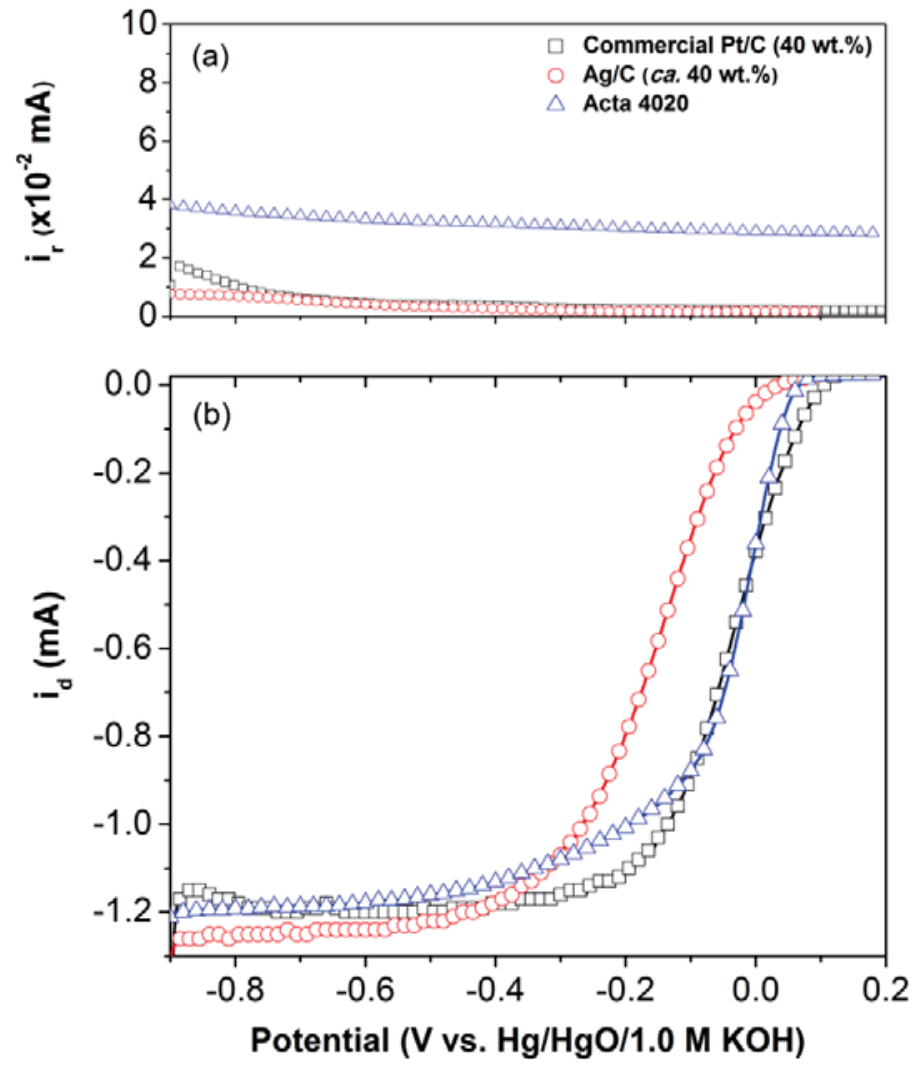

Fig. 8.2 Linear sweep voltammograms of $\mathrm{Pt} / \mathrm{C}, \mathrm{Ag} / \mathrm{C}$ and $\mathrm{Act} 4020$ catalysts for ORR in $\mathrm{O}_{2}$-saturated 0.1 M KOH. (a) Ring current; (b) Steady state polarization curve. 


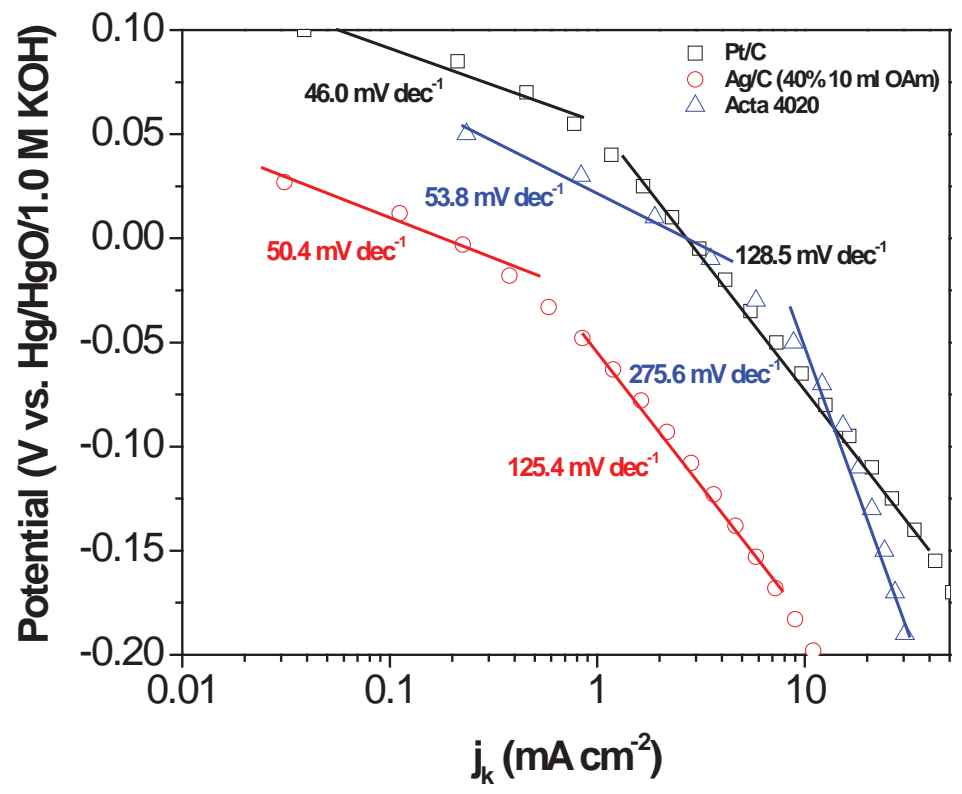

Fig. 8.3 Tafel plots of ORR on $\mathrm{Pt} / \mathrm{C}, \mathrm{Ag} / \mathrm{C}$ and Act 4020 catalysts in $\mathrm{O}_{2}$-saturated $0.1 \mathrm{M}$ $\mathrm{KOH}$.

\subsection{Conclusion}

In this chapter, a solution phase-based nanocapsule method was developed to prepare $\mathrm{Ag} / \mathrm{C}$ (ca. 40 wt.\%) catalyst. The characterizations reveal that Ag nanoparticles had small size of $5.4 \mathrm{~nm}$ and narrow size distribution of 2-9 $\mathrm{nm}$. High activity and four-electron reaction pathway of ORR in alkaline media on $\mathrm{Ag} / \mathrm{C}$ were confirmed by using RRDE tests and compared with commercial Pt/C (40 wt.\%) and Acta $4020\left(\mathrm{Fe}-\mathrm{Cu}-\mathrm{N}_{4} / \mathrm{C}\right)$. 


\section{Chapter 9 Concluding Remarks and Recommendations}

My Ph.D. research has been focused on the electrocatalytic selective conversion of biomass-derived compounds (ethylene glycol, 1,2-propanediol, glycerol and levulinic acid) to production of value-added chemicals, biofuels and electricity on the model electrocatalysts $(\mathrm{Pt} / \mathrm{C}, \mathrm{Pd} / \mathrm{C}, \mathrm{Au} / \mathrm{C}, \mathrm{Pb}$ and $\mathrm{Cu}$ bulk electrodes). In addition, ORR that often couples with the electro-biorefinery process in AEMFCs reactor was also investigated on non-PGM catalyst $\left(\mathrm{Ag} / \mathrm{C}\right.$ and commercial $\left.\mathrm{Fe}-\mathrm{Cu}-\mathrm{N}_{4} / \mathrm{C}\right)$. These studies have led to cogeneration of electrical energy and fine chemicals in AEM-DAFCs and electrochemical upgrading biomass feedstock to biofuels while storing renewable electricity in the continuous flow electrolysis cell reactors. Further understanding of these potential-regulated electrocatalytic reactions and charge transfer process at the electrified electrode-electrolyte interface was also achieved by introducing an on-line sample collection system and combining experimental and DFT studies.

Recommendations for the future work include:

(1) Rational design and engineering of multi-metallic catalysts with optimized nano-scale structures guided by experimental and theoretical researches shown in Chapters 3-6 is needed, in order to enhance their electrocatalytic functions to convert chemical energy in biorenewable fuels to electricity and simultaneously generate high selectivity of valuable products with high reaction rate.

(2) In Chapter 7, although it has demonstrated the promise of harvesting excess renewable electrical energy from PV cell or wind power through electrochemical upgrading biomass-based feedstock into biofuels of higher energy density, it was found that a higher reaction rate achieved has to be at a sacrifice of the input energy, because higher overpotentials $(>1.0 \mathrm{~V})$ are needed to produce sufficient atomic hydrogen adsorbed on the bulk $\mathrm{Pb}$ electrode to trigger the $\mathrm{ECH}$ reaction, as well as overcome the activation energy barrier of the electro-hydrogenation reaction. One method to improving the overall reaction efficiency is to replace the bulk electrode by incorporating the nanostructured metallic catalysts into the membrane electrode assembly (MEA) to 
improve the ECH activity while suppressing HER. On the other hand, the calculations of electricity consumption (EC) and energy storage efficiency (ESE) were only accounted for the cathode reaction in continuous flow electrolysis cells. Preparation of affordable electrocatalysts that has high activity and durability towards oxygen evolution reaction (OER) is also needed in the future research. Further translating the performances of OER obtained in the half cells to the continuous electrocatalytic membrane cells is necessary for large scale applications. Our preliminary results on $\mathrm{NiFe} / \mathrm{C}$ for OER have already demonstrated superior activity and stability in alkaline electrolyte compared with stateof-art precious metal Ir/C (Qiu $Y^{*}$, Xin L ${ }^{*}$, Li WZ. ("equal contribution) An Effective Supported Ni-Fe Electrocatalyst for Water Oxidation, Langmuir 2014 (submitted)).

(3) Another challenge discussed in Chapter 7 is the observed serious catalyst deactivation issue associated with electrocatalytic oxidation of formic acid + valeric acid mixture downstream in PEM-DFAFC during integrated electrocatalytic refinery of levulinic acid and formic acid process. The possible explanation was provided based on a series of experiments that it is mainly due to the presence of valeric acid - a primary alkyl-carboxylic acid, which can act as an electron donor occupying the noble metal catalytic active sites for formic acid oxidation. Therefore, theoretical and experimental work is needed in the future to screen the proper catalysts and rationally design more efficient catalysts so as to weaken the interaction between the alkyl-carboxylic group and metal via electronic structure manipulation. This may provide important knowledge for directly applying electrocatalysis for upgrading crude biomass/biorefinery streams to biofuels/chemicals.

(4) In Chapter 4, 6 and 7, the proposed reaction pathways were derived based on the products quantified in the bulk liquid electrolyte with variation of electrode potentials. However, understanding of the surface electrochemistry is desired in a way that the stateof-art electrochemical microscopic and spectroscopic techniques need to be developed in conjunction with electrochemical tests. The acquired knowledge incorporated with the quantum mechanical modeling (DFT) will then help elucidate the atomic and electronic interaction between each component of electrocatalyst and the supporting materials at the 
most fundamental level as well as their functions in the electrocatalytic reactions, thus leading to the exploitation of novel advanced electrocatalytic materials to fulfill the goals of effective conversion of biomass into chemicals, biofuels with industrial significance and electricity. 


\section{References:}

1. Lee R. The Outlook for Population Growth. Science 2011;333(6042):569-573.

2. Chu S, Majumdar A. Opportunities and challenges for a sustainable energy future. Nature 2012;488(7411):294-303.

3. Dudley B. BP Enrgy Outlook 2030. London, January 2011.

4. Annual Enrgy Outlook-Early Release Overview. U.S. Energy Information Administration (EIA), Department of Energy, Washington, D.C. 2014. Avalaible from Figure 8 on Page 11 and Figure 13 on Page 14 of: http://www.eia.gov/forecasts/aeo/er/pdf/0383er(2014).pdf

5. World Energy Outlook 2013 Launch-a presentation by Maria van der Hoeven in London (C) OECD/IEA 2013. Available from slide [4] of: http://www.worldenergyoutlook.org/media/weowebsite/2013/LondonNovember1 2.pdf

6. Ragauskas AJ, Williams CK, Davison BH, Britovsek G, Cairney J, Eckert CA, Frederick WJ, Hallett JP, Leak DJ, Liotta CL and others. The Path Forward for Biofuels and Biomaterials. Science 2006;311(5760):484-489.

7. Multi-Year Program Plan. Bioenergy Technologies Office, Energy Efficiency \& Renewable Energy, U.S. Department of Energy May 2013. Avalabile from: https://www1.eere.energy.gov/bioenergy/pdfs/mypp_may_2013.pdf

8. Röper H. Renewable Raw Materials in Europe - Industrial Utilisation of Starch and Sugar. Starch - Stärke 2002;54(3-4):89-99.

9. Corma A, Iborra S, Velty A. Chemical routes for the transformation of biomass into chemicals. Chemical Reviews 2007;107(6):2411-2502.

10. Huber GW, Iborra S, Corma A. Synthesis of transportation fuels from biomass: Chemistry, catalysts, and engineering. Chemical Reviews 2006;106(9):4044-4098.

11. Short-term Energy and Summer Fuels Outlook. U.S. Energy Information Administration (EIA), Department of Energy, Washington, D.C. March 11, 2014.

12. Biofuels for Tranport: An International Perspective. International Energy Agency (IEA), OECD April 2004. Available from: 
http://www.cti2000.it/Bionett/All-2004-004\%20IEA\%20biofuels\%20report.pdf

13. Werpy T, Petersen G (Editors). Top Value Added Chemicals From biomass, Volume 1-Results of Screening for Potential Candidates from Sugars and Sythesis Gas. Energy Efficiency \& Renewable Energy, U.S. Department of Energy August 2004. Available from: https://www1.eere.energy.gov/bioenergy/pdfs/35523.pdf

14. Bozell JJ, Petersen GR. Technology development for the production of biobased products from biorefinery carbohydrates-the US Department of Energy's "Top 10" revisited. Green Chemistry 2010;12(4):539-554.

15. Gallezot P. Conversion of biomass to selected chemical products. Chemical Society Reviews 2012;41(4):1538-1558.

16. Monthly Biodiesel Production Report. U.S. Energy Information Administration (EIA), Department of Energy, Washington, D.C. February 2014.

17. Van Gerpen J. Biodiesel processing and production. Fuel Processing Technology 2005;86(10):1097-1107.

18. Data adapted from Aternative Fuels Data Center, Energy Efficiency \& Renewable Energy, U.S. Department of Energy. Available from:

http://www.afdc.energy.gov/fuels/biodiesel_production.html.

19. Katryniok B, Kimura H, Skrzynska E, Girardon J-S, Fongarland P, Capron M, Ducoulombier R, Mimura N, Paul S, Dumeignil F. Selective catalytic oxidation of glycerol: perspectives for high value chemicals. Green Chemistry 2011;13(8):1960-1979.

20. Monthly Energy Review. U.S. Energy Information Administration (EIA), Department of Energy, Washington, D.C. February 2014.

21. Lange J-P, Price R, Ayoub PM, Louis J, Petrus L, Clarke L, Gosselink H. Valeric Biofuels: A Platform of Cellulosic Transportation Fuels. Angewandte ChemieInternational Edition 2010;49(26):4479-4483.

22. Zhou C-H, Xia X, Lin C-X, Tong D-S, Beltramini J. Catalytic conversion of lignocellulosic biomass to fine chemicals and fuels. Chemical Society Reviews 2011;40(11):5588-5617. 
23. Guerbuez EI, Alonso DM, Bond JQ, Dumesic JA. Reactive Extraction of Levulinate Esters and Conversion to gamma-Valerolactone for Production of Liquid Fuels. ChemSusChem 2011;4(3):357-361.

24. Braden DJ, Henao CA, Heltzel J, Maravelias CT, Dumesic JA. Production of liquid hydrocarbon fuels by catalytic conversion of biomass-derived levulinic acid. Green Chemistry 2011;13(7):1755-1765.

25. Girisuta B, Janssen LPBM, Heeres HJ. Kinetic Study on the Acid-Catalyzed Hydrolysis of Cellulose to Levulinic Acid. Industrial \& Engineering Chemistry Research 2007;46(6):1696-1708.

26. Bozell JJ, Moens L, Elliott DC, Wang Y, Neuenscwander GG, Fitzpatrick SW, Bilski RJ, Jarnefeld JL. Production of levulinic acid and use as a platform chemical for derived products. Resources Conservation and Recycling 2000;28(34):227-239.

27. Fitzpatrick SW (Biofine Incorporated). US 4897497, 1990.

28. Fitzpatrick SW (Biofine Incorporated). US 5608105, 1997.

29. BioMetics Inc. Final Technical Report Commercialization of the Biofine Technology for Levulinic Acid Production from Paper Sludge; Report No. DOE/CE/41178. U.S. Department of Energy, Washington D.C. 2002

30. Hayes DJ, Ross J, Hayes MHB, Fitzpatrick S. The Biofine Process - Production of Levulinic Acid, Furfural, and Formic Acid from Lignocellulosic Feedstocks. Biorefineries-Industrial Processes and Products: Wiley-VCH Verlag GmbH; 2008. p 139-164.

31. Borup R, Meyers J, Pivovar B, Kim YS, Mukundan R, Garland N, Myers D, Wilson M, Garzon F, Wood D and others. Scientific aspects of polymer electrolyte fuel cell durability and degradation. Chemical Reviews 2007;107(10):3904-3951.

32. Vielstich W, Gasteiger HA, Yokokawa H (Editors). Handbook of Fuel Cells: Advances in Electrocatalysis, Materials, Diagnostics and Durability, Volumes 5 \& 6. Wiley-VCH April 2009. 
33. Barbaro P, Bianchini C (Editors). Catalysis for Sustainable Energy Production. Wiley-VCH Verlag GmbH \& Co. KGaA 2009.

34. Steele BCH, Heinzel A. Materials for fuel-cell technologies. Nature 2001;414(6861):345-352.

35. Antolini E, Gonzalez ER. Alkaline direct alcohol fuel cells. Journal of Power Sources 2010;195(11):3431-3450.

36. Spendelow JS, Wieckowski A. Electrocatalysis of oxygen reduction and small alcohol oxidation in alkaline media. Physical Chemistry Chemical Physics 2007;9(21):2654-2675.

37. Varcoe JR, Slade RCT. Prospects for alkaline anion-exchange membranes in low temperature fuel cells. Fuel Cells 2005;5(2):187-200.

38. Prakash GKS, Krause FC, Viva FA, Narayanan SR, Olah GA. Study of operating conditions and cell design on the performance of alkaline anion exchange membrane based direct methanol fuel cells. Journal of Power Sources 2011;196(19):7967-7972.

39. Matsuoka K, Iriyama Y, Abe T, Matsuoka M, Ogumi Z. Alkaline direct alcohol fuel cells using an anion exchange membrane. Journal of Power Sources 2005;150:27-31.

40. Bambagioni V, Bianchini C, Marchionni A, Filippi J, Vizza F, Teddy J, Serp P, Zhiani M. Pd and Pt-Ru anode electrocatalysts supported on multi-walled carbon nanotubes and their use in passive and active direct alcohol fuel cells with an anion-exchange membrane (alcohol $=$ methanol, ethanol, glycerol). Journal of Power Sources 2009;190(2):241-251.

41. Shen S, Zhao TS, Xu J, Li Y. High performance of a carbon supported ternary PdIrNi catalyst for ethanol electro-oxidation in anion-exchange membrane direct ethanol fuel cells. Energy \& Environmental Science 2011;4(4):1428-1433.

42. Fujiwara N, Siroma Z, Yamazaki S-i, Ioroi T, Senoh H, Yasuda K. Direct ethanol fuel cells using an anion exchange membrane. Journal of Power Sources 2008;185(2):621-626. 
43. Li YS, Zhao TS, Liang ZX. Performance of alkaline electrolyte-membrane-based direct ethanol fuel cells. Journal of Power Sources 2009;187(2):387-392.

44. Bambagioni V, Bianchini C, Chen Y, Filippi J, Fornasiero P, Innocenti M, Lavacchi A, Marchionni A, Oberhauser W, Vizza F. Energy Efficiency Enhancement of Ethanol Electrooxidation on $\mathrm{Pd}-\mathrm{CeO} 2 / \mathrm{C}$ in Passive and Active Polymer Electrolyte-Membrane Fuel Cells. ChemSusChem 2012;5(7):1266-1273.

45. Bambagioni V, Bevilacqua M, Filippi J, Marchionni A, Moneti S, Vizza F, Bianchini C. Direct alcohol fuel cells as chemical reactors for the sustainable production of energy and chemicals Energy and chemicals from renewables by electrocatalysis. Chimica Oggi-Chemistry Today 2010;28(3):VII-X.

46. Dimos MM, Blanchard GJ. Electro-catalytic oxidation of 1,2-propanediol at nanoporous and planar solid Pt electrodes. Journal of Electroanalytical Chemistry 2011;654(1-2):13-19.

47. Dimos MM, Blanchard GJ. Examining the Electrocatalytic Oxidation of Selected Diols at Nanoporous and Planar Pt Electrodes. Journal of Physical Chemistry C 2011;115(22):11247-11256.

48. Bianchini C, Shen PK. Palladium-Based Electrocatalysts for Alcohol Oxidation in Half Cells and in Direct Alcohol Fuel Cells. Chemical Reviews 2009;109(9):4183-4206.

49. Ilie A, Simoes M, Baranton S, Coutanceau C, Martemianov S. Influence of operational parameters and of catalytic materials on electrical performance of Direct Glycerol Solid Alkaline Membrane Fuel Cells. Journal of Power Sources 2011;196(11):4965-4971.

50. Lamy C, Belgsir EM, Leger JM. Electrocatalytic oxidation of aliphatic alcohols: Application to the direct alcohol fuel cell (DAFC). Journal of Applied Electrochemistry 2001;31(7):799-809.

51. Abad A, Concepcion P, Corma A, Garcia H. A collaborative effect between gold and a support induces the selective oxidation of alcohols. Angewandte ChemieInternational Edition 2005;44(26):4066-4069. 
52. Mallat T, Baiker A. Oxidation of alcohols with molecular oxygen on solid catalysts. Chemical Reviews 2004;104(6):3037-3058.

53. Braunchweig B, Hibbitts D, Neurock M, Wieckowski A. Electrocatalysis: A direct alcohol fuel cell and surface science perspective. Catalysis Today 2013;202(0):197-209.

54. Zope BN, Hibbitts DD, Neurock M, Davis RJ. Reactivity of the Gold/Water Interface During Selective Oxidation Catalysis. Science 2010;330(6000):74-78.

55. Alcaide F, Cabot P-L, Brillas E. Fuel cells for chemicals and energy cogeneration. Journal of Power Sources 2006;153(1):47-60.

56. Bard AJ, Faulkner LR. Electrochemical Methods: Fundamentals and Application, Second Edition. John Wiley \& Sons Inc.: New York; p. Chapter 32001.

57. Dresselhaus MS, Thomas IL. Alternative energy technologies. Nature 2001;414(6861):332-337.

58. Elvers B (Editor). Handbook of Fuels. Wiley-VCH November 2007.

59. Michel H. Editorial: The Nonsense of Biofuels. Angewandte Chemie International Edition 2012;51(11):2516-2518.

60. Lefevre M, Proietti E, Jaouen F, Dodelet J-P. Iron-Based Catalysts with Improved Oxygen Reduction Activity in Polymer Electrolyte Fuel Cells. Science 2009;324(5923):71-74.

61. Gang W, More KL, Johnston CM, Zelenay P. High-performance electrocatalysts for oxygen reduction derived from polyaniline, iron, and cobalt. Science 2011;332(6028).

62. Feng J, Liang Y, Wang H, Li Y, Zhang B, Zhou J, Wang J, Regier T, Dai H. Engineering manganese oxide/nanocarbon hybrid materials for oxygen reduction electrocatalysis. Nano Research 2012;5(10):718-725.

63. Gorlin Y, Chung C-J, Nordlund D, Clemens BM, Jaramillo TF. Mn3O4 Supported on Glassy Carbon: An Active Non-Precious Metal Catalyst for the Oxygen Reduction Reaction. ACS Catalysis 2012;2(12):2687-2694.

64. Liang Y, Wang H, Diao P, Chang W, Hong G, Li Y, Gong M, Xie L, Zhou J, Wang J and others. Oxygen Reduction Electrocatalyst Based on Strongly Coupled 
Cobalt Oxide Nanocrystals and Carbon Nanotubes. Journal of the American Chemical Society 2012;134(38):15849-15857.

65. Liang Y, Wang H, Zhou J, Li Y, Wang J, Regier T, Dai H. Covalent Hybrid of Spinel Manganese-Cobalt Oxide and Graphene as Advanced Oxygen Reduction Electrocatalysts. Journal of the American Chemical Society 2012;134(7):35173523.

66. Cheng F, Zhang T, Zhang Y, Du J, Han X, Chen J. Enhancing Electrocatalytic Oxygen Reduction on $\mathrm{MnO} 2$ with Vacancies. Angewandte Chemie International Edition 2013;52(9):2474-2477.

67. Wei W, Liang H, Parvez K, Zhuang X, Feng X, Müllen K. Nitrogen-Doped Carbon Nanosheets with Size-Defined Mesopores as Highly Efficient Metal-Free Catalyst for the Oxygen Reduction Reaction. Angewandte Chemie International Edition 2014;53(6):1570-1574.

68. Gorlin Y, Jaramillo TF. A Bifunctional Nonprecious Metal Catalyst for Oxygen Reduction and Water Oxidation. Journal of the American Chemical Society 2010;132(39):13612-13614.

69. Suntivich J, May KJ, Gasteiger HA, Goodenough JB, Shao-Horn Y. A Perovskite Oxide Optimized for Oxygen Evolution Catalysis from Molecular Orbital Principles. Science 2011;334(6061):1383-1385.

70. Marini S, Salvi P, Nelli P, Pesenti R, Villa M, Berrettoni M, Zangari G, Kiros Y. Advanced alkaline water electrolysis. Electrochimica Acta 2012;82:384-391.

71. McCrory CCL, Jung S, Peters JC, Jaramillo TF. Benchmarking Heterogeneous Electrocatalysts for the Oxygen Evolution Reaction. Journal of the American Chemical Society 2013.

72. Man IC, Su H-Y, Calle-Vallejo F, Hansen HA, Martínez JI, Inoglu NG, Kitchin J, Jaramillo TF, Nørskov JK, Rossmeisl J. Universality in Oxygen Evolution Electrocatalysis on Oxide Surfaces. ChemCatChem 2011;3(7):1159-1165.

73. Sun S, Zeng H, Robinson DB, Raoux S, Rice PM, Wang SX, Li G. Monodisperse MFe2O4 (M = Fe, Co, Mn) Nanoparticles. Journal of the American Chemical Society 2003;126(1):273-279. 
74. Cullity BD, Stock SR. Elements of X-ray Diffraction. Prentice Hall 2001.

75. Yu EH, Krewer U, Scott K. Principles and Materials Aspects of Direct Alkaline Alcohol Fuel Cells. Energies 2010;3(8):1499-1528.

76. Zhang Z, Xin L, Li W. Electrocatalytic oxidation of glycerol on $\mathrm{Pt} / \mathrm{C}$ in anionexchange membrane fuel cell: Cogeneration of electricity and valuable chemicals. Applied Catalysis B-Environmental 2012;119:40-48.

77. Marchionni A, Bevilacqua M, Bianchini C, Chen Y-X, Filippi J, Fornasiero P, Lavacchi A, Miller H, Wang L, Vizza F. Electrooxidation of Ethylene Glycol and Glycerol on Pd-(Ni-Zn)/C Anodes in Direct Alcohol Fuel Cells. ChemSusChem 2013;6(3):518-528.

78. Johnson DT, Taconi KA. The glycerin glut: Options for the value-added conversion of crude glycerol resulting from biodiesel production. Environmental Progress 2007;26(4):338-348.

79. Thompson JC, He BB. Characterization of crude glycerol from biodiesel production from multiple feedstocks. Applied Engineering in Agriculture 2006;22(2):261-265.

80. Sheng W, Gasteiger HA, Shao-Horn Y. Hydrogen Oxidation and Evolution Reaction Kinetics on Platinum: Acid vs. Alkaline Electrolytes. Journal of the Electrochemical Society 2010;157(11):B1529-B1536.

81. Jiang L, Hsu A, Chu D, Chen R. Size-Dependent Activity of Palladium Nanoparticles for Oxygen Electroreduction in Alkaline Solutions. Journal of the Electrochemical Society 2009;156(5):B643-B649.

82. Burke LD, Moran J, Nugent P. Cyclic voltammetry responses of metastable gold electrodes in aqueous media. Journal of Solid State Electrochemistry 2003;7(9):529-538.

83. Paulus UA, Wokaun A, Scherer GG, Schmidt TJ, Stamenkovic V, Radmilovic V, Markovic NM, Ross PN. Oxygen Reduction on Carbon-Supported Pt-Ni and Pt-Co Alloy Catalysts. The Journal of Physical Chemistry B 2002;106(16):41814191. 
84. Markovic NM, Schmidt TJ, Grgur BN, Gasteiger HA, Behm RJ, Ross PN. Effect of temperature on surface processes at the $\mathrm{Pt}(111)$-liquid interface: Hydrogen adsorption, oxide formation, and CO oxidation. Journal of Physical Chemistry B 1999;103(40):8568-8577.

85. Ma L, Chu D, Chen R. Comparison of ethanol electro-oxidation on $\mathrm{Pt} / \mathrm{C}$ and $\mathrm{Pd} / \mathrm{C}$ catalysts in alkaline media. International Journal of Hydrogen Energy 2012;37(15):11185-11194.

86. Tripkovic AV, Popovic KD, Grgur BN, Blizanac B, Ross PN, Markovic NM. Methanol electrooxidation on supported Pt and PtRu catalysts in acid and alkaline solutions. Electrochimica Acta 2002;47(22-23):3707-3714.

87. Tripkovic AV, Strbac S, Popovic KD. Effect of temperature on the methanol oxidation at supported Pt and PtRu catalysts in alkaline solution. Electrochemistry Communications 2003;5(6):484-490.

88. Simoes M, Baranton S, Coutanceau C. Electro-oxidation of glycerol at Pd based nano-catalysts for an application in alkaline fuel cells for chemicals and energy cogeneration. Applied Catalysis B-Environmental 2010;93(3-4):354-362.

89. Tremiliosi-Filho G, Dall'Antonia LH, Jerkiewicz G. Limit to extent of formation of the quasi-two-dimensional oxide state on $\mathrm{Au}$ electrodes. Journal of Electroanalytical Chemistry 1997;422(1-2):149-159.

90. Zhang Z, Xin L, Li W. Supported gold nanoparticles as anode catalyst for anionexchange membrane-direct glycerol fuel cell (AEM-DGFC). International Journal of Hydrogen Energy 2012;37(11):9393-9401.

91. Kwon Y, Lai SCS, Rodriguez P, Koper MTM. Electrocatalytic Oxidation of Alcohols on Gold in Alkaline Media: Base or Gold Catalysis? Journal of the American Chemical Society 2011;133(18):6914-6917.

92. Zhang Z, Xin L, Qi J, Wang Z, Li W. Selective electro-conversion of glycerol to glycolate on carbon nanotube supported gold catalyst. Green Chemistry 2012;14(8):2150-2152.

93. Kwon Y, Koper MTM. Combining Voltammetry with HPLC: Application to Electro-Oxidation of Glycerol. Analytical Chemistry 2010;82(13):5420-5424. 
94. Kwon Y, Schouten KJP, Koper MTM. Mechanism of the Catalytic Oxidation of Glycerol on Polycrystalline Gold and Platinum Electrodes. ChemCatChem 2011;3(7):1176-1185.

95. Xin L, Zhang Z, Wang Z, Li W. Simultaneous Generation of Mesoxalic Acid and Electricity from Glycerol on a Gold Anode Catalyst in Anion-Exchange Membrane Fuel Cells. ChemCatChem 2012;4(8):1105-1114.

96. Bianchini C, Bambagioni V, Filippi J, Marchionni A, Vizza F, Bert P, Tampucci A. Selective oxidation of ethanol to acetic acid in highly efficient polymer electrolyte membrane-direct ethanol fuel cells. Electrochemistry Communications 2009;11(5):1077-1080.

97. Arechederra RL, Minteer SD. Complete Oxidation of Glycerol in an Enzymatic Biofuel Cell. Fuel Cells 2009;9(1):63-69.

98. Arechederra RL, Treu BL, Minteer SD. Development of glycerol/ $\mathrm{O}_{2}$ biofuel cell. Journal of Power Sources 2007;173(1):156-161.

99. Zhang Z, Xin L, Sun K, Li W. Pd-Ni electrocatalysts for efficient ethanol oxidation reaction in alkaline electrolyte. International Journal of Hydrogen Energy 2011;36(20):12686-12697.

100. Verma A, Basu S. Experimental evaluation and mathematical modeling of a direct alkaline fuel cell. Journal of Power Sources 2007;168(1):200-210.

101. An L, Zhao TS, Shen SY, Wu QX, Chen R. Alkaline direct oxidation fuel cell with non-platinum catalysts capable of converting glucose to electricity at high power output. Journal of Power Sources 2011;196(1):186-190.

102. Zhou C-H, Beltramini JN, Fan Y-X, Lu GQ. Chemoselective catalytic conversion of glycerol as a biorenewable source to valuable commodity chemicals. Chemical Society Reviews 2008;37(3):527-549.

103. Davis WR, Tomsho J, Nikam S, Cook EM, Somand D, Peliska JA. Inhibition of HIV-1 reverse transcriptase-catalyzed DNA strand transfer reactions by 4chlorophenylhydrazone of mesoxalic acid. Biochemistry 2000;39(46):1427914291. 
104. Kosaka K, Akanuma Y. Historical changes in diabetes therapy in Japan. Diabetes Research and Clinical Practice 1994;24:S221-S227.

105. Gandolfi CA, Cotini L, Mantovanini M, Caselli G, Clavenna G, Omini C (Dompe Farmaceutici S.P.A). WO 1994010127 A1, 1994.

106. Powers T (Multisorb Technologies Inc., Thomas Powers). WO 2005040304, 2005.

107. Powers T (Multisorb Technologies Inc., Thomas Powers). WO 2006016916, 2006.

108. Solovyov SE (Multisorb Technologies Inc., Thomas Powers). WO 2007013978, 2007.

109. Bizot PM, Bailey BR, Hicks PD (Nalco Chemical Co.). WO 9816475, 1998.

110. Carrettin S, McMorn P, Johnston P, Griffin K, Hutchings GJ. Selective oxidation of glycerol to glyceric acid using a gold catalyst in aqueous sodium hydroxide. Chemical Communications 2002(7):696-697.

111. Carrettin S, McMorn P, Johnston P, Griffin K, Kiely CJ, Hutchings GJ. Oxidation of glycerol using supported Pt, Pd and Au catalysts. Physical Chemistry Chemical Physics 2003;5(6):1329-1336.

112. Porta F, Prati L. Selective oxidation of glycerol to sodium glycerate with gold-oncarbon catalyst: an insight into reaction selectivity. Journal of Catalysis 2004;224(2):397-403.

113. Carrettin S, McMorn P, Johnston P, Griffin K, Kiely CJ, Attard GA, Hutchings GJ. Oxidation of glycerol using supported gold catalysts. Topics in Catalysis 2004;27(1-4):131-136.

114. Bianchi CL, Canton P, Dimitratos N, Porta F, Prati L. Selective oxidation of glycerol with oxygen using mono and bimetallic catalysts based on $\mathrm{Au}, \mathrm{Pd}$ and $\mathrm{Pt}$ metals. Catalysis Today 2005;102:203-212.

115. Dimitratos N, Messi C, Porta F, Prati L, Villa A. Investigation on the behaviour of $\mathrm{Pt}(0) /$ carbon and $\operatorname{Pt}(0), \mathrm{Au}(0) /$ carbon catalysts employed in the oxidation of glycerol with molecular oxygen in water. Journal of Molecular Catalysis A: Chemical 2006;256(1-2):21-28. 
116. Ketchie WC, Fang Y-L, Wong MS, Murayama M, Davis RJ. Influence of gold particle size on the aqueous-phase oxidation of carbon monoxide and glycerol. Journal of Catalysis 2007;250(1):94-101.

117. Ketchie WC, Murayama M, Davis RJ. Promotional effect of hydroxyl on the aqueous phase oxidation of carbon monoxide and glycerol over supported $\mathrm{Au}$ catalysts. Topics in Catalysis 2007;44(1-2):307-317.

118. Villa A, Veith GM, Prati L. Selective Oxidation of Glycerol under Acidic Conditions Using Gold Catalysts. Angewandte Chemie International Edition 2010;49(26):4499-4502.

119. Ketchie WC, Murayama M, Davis RJ. Selective oxidation of glycerol over carbon-supported AuPd catalysts. Journal of Catalysis 2007;250(2):264-273.

120. Dimitratos N, Lopez-Sanchez JA, Anthonykutty JM, Brett G, Carley AF, Tiruvalam RC, Herzing AA, Kiely CJ, Knight DW, Hutchings GJ. Oxidation of glycerol using gold-palladium alloy-supported nanocrystals. Physical Chemistry Chemical Physics 2009;11(25):4952-4961.

121. Dimitratos N, Villa A, Prati L. Liquid Phase Oxidation of Glycerol Using a Single Phase (Au-Pd) Alloy Supported on Activated Carbon: Effect of Reaction Conditions. Catalysis Letters 2009;133(3-4):334-340.

122. Zope BN, Davis SE, Davis RJ. Influence of Reaction Conditions on Diacid Formation During Au-Catalyzed Oxidation of Glycerol and Hydroxymethylfurfural. Topics in Catalysis 2012;55(1-2):24-32.

123. Villa A, Chan-Thaw CE, Prati L. Au NPs on anionic-exchange resin as catalyst for polyols oxidation in batch and fixed bed reactor. Applied Catalysis BEnvironmental 2010;96(3-4):541-547.

124. Zope BN, Davis RJ. Influence of Reactor Configuration on the Selective Oxidation of Glycerol over Au/TiO2. Topics in Catalysis 2009;52(3):269-277.

125. Kimura H (Kao Corp.). JP 1994315623, 1996.

126. Kimura H, Imanaka T, Yokota Y (Kao Corp.). JP 199395253, 1994. 
127. Villa A, Wang D, Veith GM, Prati L. Bismuth as a modifier of Au-Pd catalyst: Enhancing selectivity in alcohol oxidation by suppressing parallel reaction. Journal of Catalysis 2012;292:73-80.

128. Fordham P, Besson M, Gallezot P. Catalytic oxidation with air of tartronic acid to mesoxalic acid on bismuth-promoted platinum. Catalysis Letters 1997;46(34):195-199.

129. Gallezot P. Selective oxidation with air on metal catalysts. Catalysis Today 1997;37(4):405-418.

130. Roquet L, Belgsir EM, Léger JM, Lamy C. Kinetics and mechanisms of the electrocatalytic oxidation of glycerol as investigated by chromatographic analysis of the reaction products: Potential and $\mathrm{pH}$ effects. Electrochimica Acta 1994;39(16):2387-2394.

131. Jeffery DZ, Camara GA. The formation of carbon dioxide during glycerol electrooxidation in alkaline media: First spectroscopic evidences. Electrochemistry Communications 2010;12(8):1129-1132.

132. Gomes JF, Tremiliosi-Filho G. Spectroscopic Studies of the Glycerol ElectroOxidation on Polycrystalline Au and Pt Surfaces in Acidic and Alkaline Media. Electrocatalysis 2011;2(2):96-105.

133. Simoes M, Baranton S, Coutanceau C. Enhancement of catalytic properties for glycerol electrooxidation on $\mathrm{Pt}$ and $\mathrm{Pd}$ nanoparticles induced by $\mathrm{Bi}$ surface modification. Applied Catalysis B-Environmental 2011;110:40-49.

134. Simões M, Baranton S, Coutanceau C. Electrochemical Valorisation of Glycerol. ChemSusChem 2012;5(11):2106-2124.

135. Mougenot M, Caillard A, Simoes M, Baranton S, Coutanceau C, Brault P. $\mathrm{PdAu} / \mathrm{C}$ catalysts prepared by plasma sputtering for the electro-oxidation of glycerol. Applied Catalysis B-Environmental 2011;107(3-4):372-379.

136. Vasiliu M, Guynn K, Dixon DA. Prediction of the Thermodynamic Properties of Key Products and Intermediates from Biomass. Journal of Physical Chemistry C 2011;115(31):15686-15702. 
137. Zhang Z, Xin L, Qi J, Chadderdon DJ, Sun K, Warsko KM, Li W. Selective electro-oxidation of glycerol to tartronate or mesoxalate on $\mathrm{Au}$ nanoparticle catalyst via electrode potential tuning in anion-exchange membrane electrocatalytic flow reactor. Applied Catalysis B: Environmental 2014;147(0):871-878.

138. Perrin DD, Dempsey B, Serjeant EP. pKa Prediction for Organic Acids and Bases, Chapman and Hall, London, 1981.

139. Demirel S, Kern P, Lucas M, Claus P. Oxidation of mono- and polyalcohols with gold: Comparison of carbon and ceria supported catalysts. Catalysis Today 2007;122(3-4):292-300.

140. Demirel S, Lucas M, Waerna J, Murzin D, Claus P. Reaction kinetics and modelling of the gold catalysed glycerol oxidation. Topics in Catalysis 2007;44(1-2):299-305.

141. Zope BN, Davis RJ. Inhibition of gold and platinum catalysts by reactive intermediates produced in the selective oxidation of alcohols in liquid water. Green Chemistry 2011;13(12):3484-3491.

142. Beden B, Çetin I, Kahyaoglu A, Takky D, Lamy C. Electrocatalytic oxidation of saturated oxygenated compounds on gold electrodes. Journal of Catalysis 1987;104(1):37-46.

143. Lai SCS, Kleijn SEF, Öztürk FTZ, van Rees Vellinga VC, Koning J, Rodriguez P, Koper MTM. Effects of electrolyte $\mathrm{pH}$ and composition on the ethanol electrooxidation reaction. Catalysis Today 2010;154(1-2):92-104.

144. Worz N, Brandner A, Claus P. Platinum-Bismuth-Catalyzed Oxidation of Glycerol: Kinetics and the Origin of Selective Deactivation. The Journal of Physical Chemistry C 2009;114(2):1164-1172.

145. Fordham P, Besson M, Gallezot P. Selective catalytic oxidation of glyceric acid to tartronic and hydroxypyruvic acids. Applied Catalysis A-General 1995;133(2):L179-L184.

146. Serov A, Kwak C. Recent achievements in direct ethylene glycol fuel cells (DEGFC). Applied Catalysis B-Environmental 2010;97(1-2):1-12. 
147. Ji N, Zhang T, Zheng M, Wang A, Wang H, Wang X, Chen JG. Direct Catalytic Conversion of Cellulose into Ethylene Glycol Using Nickel-Promoted Tungsten Carbide Catalysts. Angewandte Chemie-International Edition 2008;47(44):85108513.

148. Zheng M-Y, Wang A-Q, Ji N, Pang J-F, Wang X-D, Zhang T. Transition MetalTungsten Bimetallic Catalysts for the Conversion of Cellulose into Ethylene Glycol. ChemSusChem 2010;3(1):63-66.

149. Parsons R, Vandernoot T. The Oxidation of Small Organic-Molecules - a Survey of Recent Fuel-Cell Related Research. Journal of Electroanalytical Chemistry 1988;257(1-2):9-45.

150. Wasmus S, Kuver A. Methanol oxidation and direct methanol fuel cells: a selective review. Journal of Electroanalytical Chemistry 1999;461(1-2):14-31.

151. BeltowskaBrzezinska M, Luczak T, Holze R. Electrocatalytic oxidation of monoand polyhydric alcohols on gold and platinum. Journal of Applied Electrochemistry 1997;27(9):999-1011.

152. Kadirgan F, Bouhiercharbonnier E, Lamy C, Leger JM, Beden B. Mechanistic Study of the Electrooxidation of Ethylene-Glycol on Gold and Adatom-Modified Gold Electrodes in Alkaline-Medium. Journal of Electroanalytical Chemistry 1990;286(1-2):41-61.

153. Christensen PA, Hamnett A. The Oxidation of Ethylene-Glycol at a PlatinumElectrode in Acid and Base - an insitu FTIR Study. Journal of Electroanalytical Chemistry 1989;260(2):347-359.

154. Hauffe W, Heitbaum J. Electrooxidation of Ethylene-Glycol at Platinum in Potassium Hydroxide. Electrochimica Acta 1978;23(4):299-304.

155. Hauffe W, Heitbaum J. Electrooxidation of Ethylene Glycol at Gold in Potassium Hydroxide. Berichte Der Bunsen-Gesellschaft-Physical Chemistry Chemical Physics 1978;82(5):487-491.

156. Matsuoka K, Iriyama Y, Abe T, Matsuoka M, Ogumi Z. Electro-oxidation of methanol and ethylene glycol on platinum in alkaline solution: Poisoning effects and product analysis. Electrochimica Acta 2005;51(6):1085-1090. 
157. Matsuoka K, Inaba M, Iriyama $\mathrm{Y}$, Abe T, Ogumi Z, Matsuoka M. Anodic Oxidation of Polyhydric Alcohols on a Pt Electrode in Alkaline Solution. Fuel Cells 2002;2(1):35-39.

158. Chang SC, Ho YH, Weaver MJ. Applications of Real-time FTIR Spectroscopy to the Elucidation of Complex Electroorganic Pathways - Electrooxidation of Ethylene-Glycol on Gold, Platinum, and Nickel in Alkaline-Solution. Journal of the American Chemical Society 1991;113(25):9506-9513.

159. Demarconnay L, Brimaud S, Coutanceau C, Leger JM. Ethylene glycol electrooxidation in alkaline medium at multi-metallic Pt based catalysts. Journal of Electroanalytical Chemistry 2007;601(1-2):169-180.

160. Wang H, Jusys Z, Behm RJ. Electrochemical oxidation kinetics and mechanism of ethylene glycol on a carbon supported Pt catalyst: A quantitative DEMS study. Journal of Electroanalytical Chemistry 2006;595(1):23-36.

161. Chen A, Lipkowski J. Electrochemical and Spectroscopic Studies of Hydroxide Adsorption at the $\mathrm{Au}(111)$ Electrode. The Journal of Physical Chemistry B 1999;103(4):682-691.

162. Bambagioni V, Bevilacqua M, Bianchini C, Filippi J, Marchionni A, Vizza F, Wang LQ, Shen PK. Ethylene Glycol Electrooxidation on Smooth and Nanostructured Pd Electrodes in Alkaline Media. Fuel Cells 2010;10(4):582-590.

163. Bayer D, Berenger S, Joos M, Cremers C, Tubke J. Electrochemical oxidation of C-2 alcohols at platinum electrodes in acidic and alkaline environment. International Journal of Hydrogen Energy 2010;35(22):12660-12667.

164. Miyazaki K, Matsumiya T, Abe T, Kurata H, Fukutsuka T, Kojima K, Ogumi Z. Electrochemical oxidation of ethylene glycol on Pt-based catalysts in alkaline solutions and quantitative analysis of intermediate products. Electrochimica Acta 2011;56(22):7610-7614.

165. Kadirgan F, Beden B, Lamy C. Electrocatalytic Oxidation of Ethylene-Glycol .2. Behavior of Platinum-Ad-Atom Electrodes in Alkaline-Medium. Journal of Electroanalytical Chemistry 1983;143(1-2):135-152. 
166. Miyazawa T, Kusunoki Y, Kunimori K, Tomishige K. Glycerol conversion in the aqueous solution under hydrogen over $\mathrm{Ru} / \mathrm{C}+$ an ion-exchange resin and its reaction mechanism. Journal of Catalysis 2006;240(2):213-221.

167. D'Agostino C, Ryabenkova Y, Miedziak PJ, Taylor SH, Hutchings GJ, Gladden LF, Mantle MD. Deactivation studies of a carbon supported AuPt nanoparticulate catalyst in the liquid-phase aerobic oxidation of 1,2-propanediol. Catalysis Science \& Technology 2014;4(5):1313-1322.

168. Prati L, Rossi M. Gold on carbon as a new catalyst for selective liquid phase oxidation of diols. Journal of Catalysis 1998;176(2):552-560.

169. Kresse G, Furthmüller J. Efficient iterative schemes for ab initio total-energy calculations using a plane-wave basis set. Physical Review B 1996;54(16):1116911186.

170. Perdew JP, Burke K, Ernzerhof M. Generalized Gradient Approximation Made Simple. Physical Review Letters 1996;77(18):3865-3868.

171. Challenges of Electricity Storage Technologies: A Report from the APS Panel on Public Affairs Committee on Energy and Environment. APS physics May 2007. Available from:

http://www.aps.org/policy/reports/popa-reports/upload/Energy-2007-Report ElectricityStorageReport.pdf

172. Girishkumar G, McCloskey B, Luntz AC, Swanson S, Wilcke W. Lithium - Air Battery: Promise and Challenges. Journal of Physical Chemistry Letters 2010;1(14):2193-2203.

173. Harrison KW, Martin, GD, Ramsden, TG, Kramer, WE, Novachek, FG. The Wind-to-Hydrogen Project: Operational Experience, Performance Testing, and Systems Integration. U.S. Department of Energy-NREL Technical Report, Washington 2009.

174. Troncoso E, Newborough M. Electrolysers for mitigating wind curtailment and producing 'green' merchant hydrogen. International Journal of Hydrogen Energy 2011;36(1):120-134. 
175. Gasteiger HA, Markovic NM. Just a Dream-or Future Reality? Science 2009;324(5923):48-49.

176. Gasteiger HA, Kocha SS, Sompalli B, Wagner FT. Activity benchmarks and requirements for Pt, Pt-alloy, and non-Pt oxygen reduction catalysts for PEMFCs. Applied Catalysis B-Environmental 2005;56(1-2):9-35.

177. Yeager E. Electrocatalysts for $\mathrm{O}_{2}$ Reduction. Electrochimica Acta 1984;29(11):1527-1537.

178. Stamenkovic VR, Fowler B, Mun BS, Wang G, Ross PN, Lucas CA, Markovic NM. Improved oxygen reduction activity on $\mathrm{Pt}_{3} \mathrm{Ni}(111)$ via increased surface site availability. Science 2007;315(5811):493-497.

179. Carrette L, Friedrich KA, Stimming U. Fuel Cells - Fundamentals and Applications. Fuel Cells 2001;1(1):5-39.

180. Lee SW, Carlton C, Risch M, Surendranath Y, Chen S, Furutsuki S, Yamada A, Nocera DG, Shao-Horn Y. The Nature of Lithium Battery Materials under Oxygen Evolution Reaction Conditions. Journal of the American Chemical Society 2012.

181. Huber GW. Breaking the chemical and engineering barriers to lignocellulosic biofuels: next generation hydrocarbon biorefineries. NSF, ACS and U.S.Department of Energy Workshop Report, Washington D.C. 2007.

182. Sen SM, Alonso DM, Wettstein SG, Gurbuz EI, Henao CA, Dumesic JA, Maravelias CT. A sulfuric acid management strategy for the production of liquid hydrocarbon fuels via catalytic conversion of biomass-derived levulinic acid. Energy \& Environmental Science 2012;5(12):9690-9697.

183. Sen SM, Gurbuz EI, Wettstein SG, Alonso DM, Dumesic JA, Maravelias CT. Production of butene oligomers as transportation fuels using butene for esterification of levulinic acid from lignocellulosic biomass: process synthesis and technoeconomic evaluation. Green Chemistry 2012;14(12):3289-3294.

184. Manzer LE. Biomas Derivatives: A Sustainalbe Source of Chemicals. ACS Symposium Series 2006; Vol. 921, Chapter 4:40-51. 
185. Kulesa G. Manufacture of Industrial Chemical From Levulinic Acid: A New Feedstock For The Chemicals Industry. Chemical Project Fact Sheet. U.S. Department of Energy, Washington D.C. 1999.

186. Deng L, Zhao Y, Li J, Fu Y, Liao B, Guo Q-X. Conversion of Levulinic Acid and Formic Acid into gamma-Valerolactone over Heterogeneous Catalysts. ChemSusChem 2010;3(10):1172-1175.

187. Wright WRH, Palkovits R. Development of Heterogeneous Catalysts for the Conversion of Levulinic Acid to $\gamma$-Valerolactone. ChemSusChem 2012(5):16571667.

188. Wettstein SG, Bond JQ, Alonso DM, Pham HN, Datye AK, Dumesic JA. RuSn bimetallic catalysts for selective hydrogenation of levulinic acid to gammavalerolactone. Applied Catalysis B-Environmental 2012;117:321-329.

189. Serrano-Ruiz JC, Wang D, Dumesic JA. Catalytic upgrading of levulinic acid to 5-nonanone. Green Chemistry 2010;12(4):574.

190. Bond JQ, Alonso DM, Wang D, West RM, Dumesic JA. Integrated Catalytic Conversion of gamma-Valerolactone to Liquid Alkenes for Transportation Fuels. Science 2010;327(5969):1110-1114.

191. Serrano-Ruiz JC, Braden DJ, West RM, Dumesic JA. Conversion of cellulose to hydrocarbon fuels by progressive removal of oxygen. Applied Catalysis BEnvironmental 2010;100(1-2):184-189.

192. Alonso DM, Wettstein SG, Mellmer MA, Gurbuz EI, Dumesic JA. Integrated conversion of hemicellulose and cellulose from lignocellulosic biomass. Energy \& Environmental Science 2013;6(1):76-80.

193. Ayoub PM (Shell International Research Maatschappij B. V., The Netherlands). WO 070867 A1, 2005.

194. Du XL, Bi QY, Liu YM, Cao Y, Fan KN. Conversion of Biomass-Derived Levulinate and Formate Esters into $\gamma$-Valerolactone over Supported Gold Catalysts. ChemSusChem 2011;4(12):1838-1843. 
195. Saravanamurugan S, Nguyen Van Buu O, Riisager A. Conversion of Mono- and Disaccharides to Ethyl Levulinate and Ethyl Pyranoside with Sulfonic AcidFunctionalized Ionic Liquids. ChemSusChem 2011;4(6):723-726.

196. Dalavoy TS, Jackson JE, Swain GM, Miller DJ, Li J, Lipkowski J. Mild electrocatalytic hydrogenation of lactic acid to lactaldehyde and propylene glycol. Journal of Catalysis 2007;246(1):15-28.

197. Green SK, Tompsett GA, Kim HJ, Kim WB, Huber GW. Electrocatalytic Reduction of Acetone in a Proton-Exchange-Membrane Reactor: A Model Reaction for the Electrocatalytic Reduction of Biomass. ChemSusChem 2012: 5(12):2410-2420.

198. Parpot P, Bettencourt AP, Chamoulaud G, Kokoh KB, Beigsir EM. Electrochemical investigations of the oxidation-reduction of furfural in aqueous medium - Application to electrosynthesis. Electrochimica Acta 2004;49(3):397403.

199. Li ZL, Kelkar S, Lam CH, Luczek K, Jackson JE, Miller DJ, Saffron CM. Aqueous electrocatalytic hydrogenation of furfural using a sacrificial anode. Electrochimica Acta 2012;64:87-93.

200. Green SK, Lee J, Kim HJ, Tompsett GA, Kim WB, Huber G. The Electrocatalytic Hydrogenation of Furanic Compounds in a Continuous Electrocatalytic Membrane Reactor. Green Chemistry 2013;15(7):1869-1879.

201. Nilges P, Schroder U. Electrochemistry for biofuel generation: production of furans by electrocatalytic hydrogenation of furfurals. Energy \& Environmental Science 2013;6(10):2925-2931.

202. Kwon Y, Jong ED, Raoufmoghaddam S, Koper MTM. Electrocatalytic Hydrogenation of 5-Hydroxymethylfurfural in the Absence and Presence of Glucose. ChemSusChem 2013:6(9):1659-1667.

203. Kwon Y, Koper MTM. Electrocatalytic Hydrogenation and Deoxygenation of Glucose on Solid Metal Electrodes. ChemSusChem 2013: 6(3):455-462.

204. Li ZL, Garedew M, Lam CH, Jackson JE, Miller DJ, Saffron CM. Mild electrocatalytic hydrogenation and hydrodeoxygenation of bio-oil derived 
phenolic compounds using ruthenium supported on activated carbon cloth. Green Chemistry 2012;14(9):2540-2549.

205. Li W, Liang C, Zhou W, Qiu J, Zhou, Sun G, Xin Q. Preparation and Characterization of Multiwalled Carbon Nanotube-Supported Platinum for Cathode Catalysts of Direct Methanol Fuel Cells. The Journal of Physical Chemistry B 2003;107(26):6292-6299.

206. Gattrell M, Gupta N, Co A. A review of the aqueous electrochemical reduction of $\mathrm{CO} 2$ to hydrocarbons at copper. Journal of Electroanalytical Chemistry 2006;594(1):1-19.

207. Hori Y, Takahashi I, Koga O, Hoshi N. Selective formation of C2 compounds from electrochemical reduction of $\mathrm{CO}_{2}$ at a series of copper single crystal electrodes. Journal of Physical Chemistry B 2002;106(1):15-17.

208. Agarwal AS, Zhai Y, Hill D, Sridhar N. The Electrochemical Reduction of Carbon Dioxide to Formate/Formic Acid: Engineering and Economic Feasibility. ChemSusChem 2011;4(9):1301-1310.

209. Williams R, Bloom A. US 4160816, 1979.

210. Electricity Prices for Industry. U.S. Energy Information Administration (EIA), Department of Energy, Washington, D.C. 2011. Available from: http://www.eia.gov/electricity/data.cfm

211. Weingarten R, Cho J, Xing R, Conner WC, Jr., Huber GW. Kinetics and Reaction Engineering of Levulinic Acid Production from Aqueous Glucose Solutions. ChemSusChem 2012;5(7):1280-1290.

212. Carlos Serrano-Ruiz J, Luque R, Sepulveda-Escribano A. Transformations of biomass-derived platform molecules: from high added-value chemicals to fuels via aqueous-phase processing. Chemical Society Reviews 2011;40(11):5266-5281.

213. Solomons TWG, Fryhle C. Organic Chemistry, $10^{\text {th }}$ ed. Wiley-VCH, Weinheim 2009.

214. Xin L, Zhang Z, Qi J, Chadderdon DJ, Qiu Y, Warsko KM, Li W. Electricity Storage in Biofuels: Selective Electrocatalytic Reduction of Levulinic Acid to Valeric Acid or $\gamma$-Valerolactone. ChemSusChem 2013;6(4):674-686. 
215. Saveant J-M. Molecular catalysis of electrochemical reactions. Mechanistic aspects. Chemical Reviews 2008;108(7):2348-2378.

216. Ha S, Larsen R, Zhu Y, Masel RI. Direct Formic Acid Fuel Cells with $600 \mathrm{~mA} \mathrm{~cm}-2$ at $0.4 \mathrm{~V}$ and $22^{\circ} \mathrm{C}$. Fuel Cells 2004;4(4):337-343.

217. Ha S, Larsen R, Masel RI. Performance characterization of $\mathrm{Pd} / \mathrm{C}$ nanocatalyst for direct formic acid fuel cells. Journal of Power Sources 2005;144(1):28-34.

218. Liu ZL, Hong L, Tham MP, Lim TH, Jiang HX. Nanostructured Pt/C and Pd/C catalysts for direct formic acid fuel cells. Journal of Power Sources 2006;161(2):831-835.

219. Wang X, Tang Y, Gao Y, Lu T. Carbon-supported Pd-Ir catalyst as anodic catalyst in direct formic acid fuel cell. Journal of Power Sources 2008;175(2):784788.

220. Jung C, Sánchez-Sánchez CM, Lin C-L, Rodríguez-López Jn, Bard AJ. Electrocatalytic activity of $\mathrm{Pd}-\mathrm{Co}$ bimetallic mixtures for formic acid oxidation studied by scanning electrochemical microscopy. Analytical Chemistry 2009;81(16):7003-7008.

221. Liu Z, Zhang X. Carbon-supported PdSn nanoparticles as catalysts for formic acid oxidation. Electrochemistry Communications 2009;11(8):1667-1670.

222. Haan JL, Stafford KM, Morgan RD, Masel RI. Performance of the direct formic acid fuel cell with electrochemically modified palladium-antimony anode catalyst. Electrochimica Acta 2010;55(7):2477-2481.

223. Chierchie T, Mayer C, Lorenz WJ. Structural-changes of surface oxide layers on palladium. Journal of Electroanalytical Chemistry 1982;135(2):211-220.

224. Gilman S. Study of Acetate Adsorption at the Platinum Electrode/Acid Electrolyte Interface Using "Blocking Effects": Influences of Acetate Adsorption on Ethanol Fuel Cell Electrodes. Electrochimica Acta 2012;65:141-148.

225. De Proft F, Langenaeker W, Geerlings P. Acidity of alkyl substituted alcohols: Are alkyl groups electron-donating or electron-withdrawing? Tetrahedron 1995;51(14):4021-4032. 
226. Varcoe JR, Slade RCT, Lam How Yee E. An alkaline polymer electrochemical interface: a breakthrough in application of alkaline anion-exchange membranes in fuel cells. Chemical Communications 2006(13):1428-1429.

227. Lu S, Pan J, Huang A, Zhuang L, Lu J. Alkaline polymer electrolyte fuel cells completely free from noble metal catalysts. Proceedings of the National Academy of Sciences of the United States of America 2008;105(52):20611-20614.

228. Gu S, Sheng W, Cai R, Alia SM, Song S, Jensen KO, Yan Y. An efficient Agionomer interface for hydroxide exchange membrane fuel cells. Chemical Communications 2013;49(2):131-133.

229. Li X, Popov BN, Kawahara T, Yanagi H. Non-precious metal catalysts synthesized from precursors of carbon, nitrogen, and transition metal for oxygen reduction in alkaline fuel cells. Journal of Power Sources 2011;196(4):1717-1722.

230. Varcoe JR, Slade RCT, Wright GL, Chen Y. Steady-State dc and Impedance Investigations of $\mathrm{H}_{2} / \mathrm{O}_{2}$ Alkaline Membrane Fuel Cells with Commercial $\mathrm{Pt} / \mathrm{C}$, $\mathrm{Ag} / \mathrm{C}$, and $\mathrm{Au} / \mathrm{C}$ Cathodes. The Journal of Physical Chemistry B 2006;110(42):21041-21049.

231. Furuya N, Aikawa H. Comparative study of oxygen cathodes loaded with Ag and Pt catalysts in chlor-alkali membrane cells. Electrochimica Acta 2000;45(2526):4251-4256.

232. Chatenet M, Micoud F, Roche I, Chainet E. Kinetics of sodium borohydride direct oxidation and oxygen reduction in sodium hydroxide electrolyte - Part I. $\mathrm{BH}_{4-}$ electro-oxidation on Au and Ag catalysts. Electrochimica Acta 2006;51(25):54595467.

233. Chatenet M, Micoud F, Roche I, Chainet E, Vondrak J. Kinetics of sodium borohydride direct oxidation and oxygen reduction in sodium hydroxide electrolyte - Part II. O-2 reduction. Electrochimica Acta 2006;51(25):5452-5458.

234. Blizanac BB, Ross PN, Markovic NM. Oxygen electroreduction on $\operatorname{Ag}(1 \& \# x a 0 ; 1 \& \# x a 0 ; 1):$ The pH effect. Electrochimica Acta 2007;52(6):22642271. 
235. Lima FHB, de Castro JFR, Ticianelli EA. Silver-cobalt bimetallic particles for oxygen reduction in alkaline media. Journal of Power Sources 2006;161(2):806812.

236. Kostowskyj MA, Kirk DW, Thorpe SJ. Ag and Ag-Mn nanowire catalysts for alkaline fuel cells. International Journal of Hydrogen Energy 2010;35(11):56665672.

237. Paulus UA, Schmidt TJ, Gasteiger HA, Behm RJ. Oxygen reduction on a highsurface area Pt/Vulcan carbon catalyst: a thin-film rotating ring-disk electrode study. Journal of Electroanalytical Chemistry 2001;495(2):134-145.

238. Gojkovic SL, Gupta S, Savinell RF. Heat-treated iron(III) tetramethoxyphenyl porphyrin chloride supported on high-area carbon as an electrocatalyst for oxygen reduction - Part II. Kinetics of oxygen reduction. Journal of Electroanalytical Chemistry 1999;462(1):63-72.

239. Sepa DB, Vojnovic MV, Damjanovic A. Reaction intermediates as a controlling factor in the kinetics and mechanism of oxygen reduction at platinum-electrodes. Electrochimica Acta 1981;26(6):781-793. 


\section{Appendix A Copyright permission of Fig. 1.1 (a) and Fig. 1.4}

Fig. 1.1 (a) and Fig. 1.4 in Chapter 1 of this dissertation were initially published on: http://www.eia.gov/forecasts/aeo/er/pdf/0383er(2014).pdf. The reproduction of these graphs is in compliance with the "Reuse and Copyright" info provided by the U.S. Energy Information Administration (EIA), as attached below:

\begin{tabular}{|c|}
\hline eja U.S. Finergy Info \\
\hline ABOUT EIA \\
\hline About ElA \\
\hline , Our Work \\
\hline , Our Organization \\
\hline 1 Budget, Plans \& Performance \\
\hline Our History \\
\hline EIA Conferences \\
\hline - Policies \& Procedures \\
\hline $\begin{array}{l}\text { - Inbromation Cuality } \\
\text { Guidefines }\end{array}$ \\
\hline - EIA Stendardas Manuat \\
\hline $\begin{array}{l}\text { - Statement of Commratment to } \\
\text { Scientific integrity by } \\
\text { Ptincipal Statistical / Agencies }\end{array}$ \\
\hline - Accossbitity \\
\hline - Copyrights \& Reuse \\
\hline - Freedom of Information Act \\
\hline $\begin{array}{l}\text { - Privacy Stitement s. } \\
\text { Securtay Policy }\end{array}$ \\
\hline $\begin{array}{l}\text { - Publisting Pricatites \& } \\
\text { Schedile }\end{array}$ \\
\hline - CIPSEAReparting \\
\hline - About Our Website \\
\hline
\end{tabular}

Copyrights and Reuse

Public domain and use of EIA content

U.S. Government publications are in the public domain and are not subject to copyright protection. You may use and/or distribute any of our data, files, databases, reports, graphs, charts, and other information products that are on our website or that you receive through our email distribution service. However, if you use or reproduce any of our information products, you should use an acknowledgment, which includes the publication date, such as: "Source: U.S. Energy Information Administration (Oct 2008)."

Quoting EIA content and translations

When quoting ElA text, the acknowledgment should clearly indicate which text is EIA content and which is not. When translating EIA content into another language, please indicate the organization responsible for the translation and provide a link back to the original EIA web page in the acknowledgment.

Protected materials

You may see on our website documents, illustrations, photographs, or other information resources contributed or licensed by private individuals, companies, or organizations that may be protected by U.S. and foreign copyright laws. Transmission or reproduction of protected items beyond that allowed by fair user as defined in the copyright laws requires the written permission of the copyright owners.

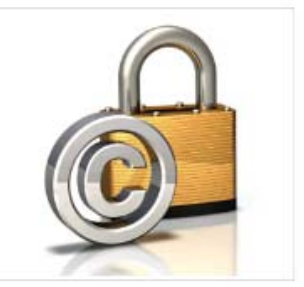




\section{Appendix B Copyright permission of Fig. 1.1 (b)}

Fig. 1.1 (b) in Chapter 1 of this dissertation was initially published on: www.worldenergyoutlook.org/media/weowebsite/2013/LondonNovember12.pdf. The reproduction of this graph is in compliance with the "Terms and Conditions, Use and Copyright" info provided by the International Energy Agency, as attached below:

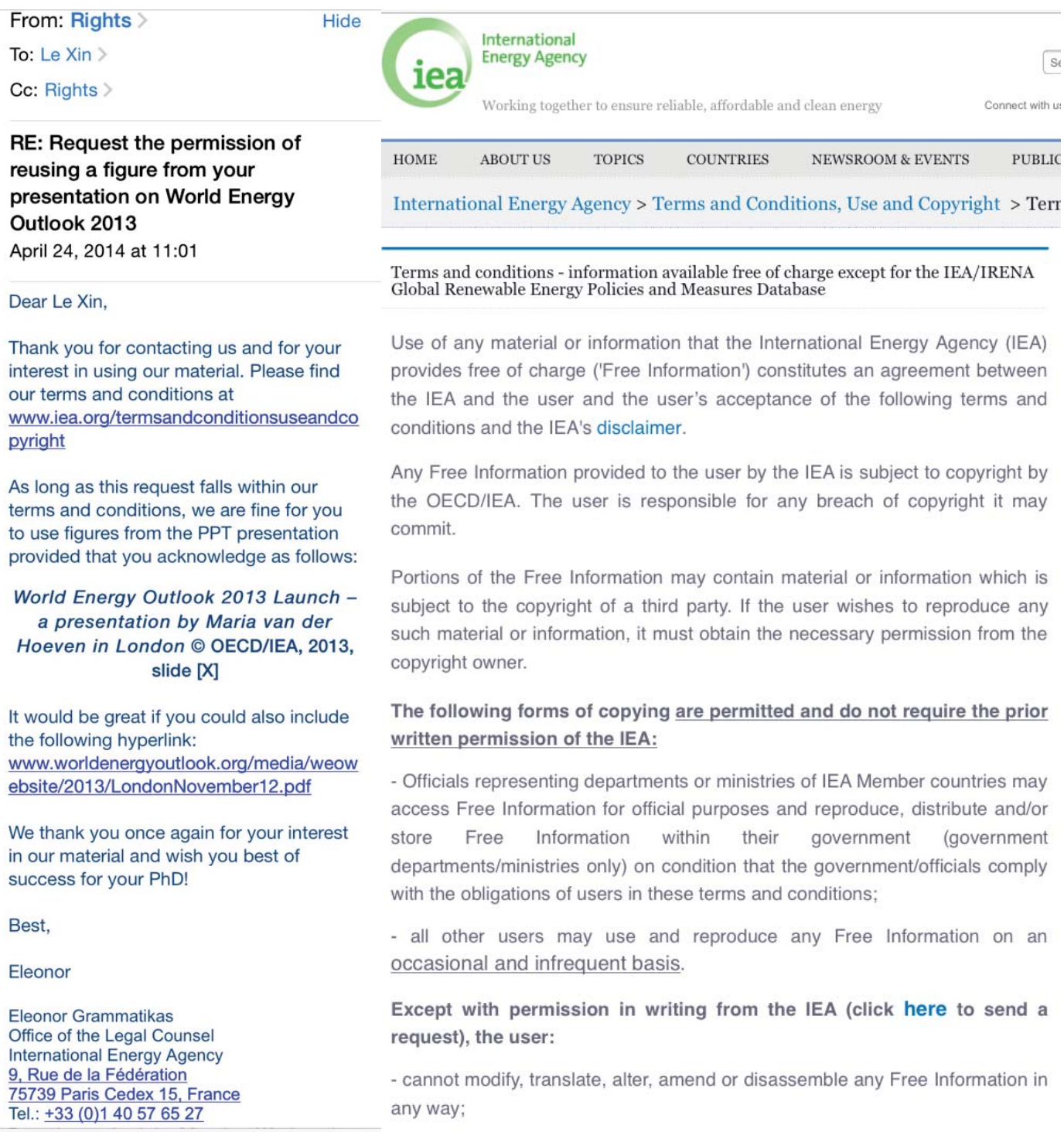




\section{Appendix C Copyright permission of Chapter 3}

Chapter 3 in this dissertation was initially published in Applied Catalysis B: Environmental, Elsevier, titled "Supported Pt, Pd and Au nanoparticle anode catalysts for anion-exchange membrane fuel cells with glycerol and crude glycerol fuels", Volumes 136-137, 5 June 2013, Pages 29-39. Permission to reproduce the aforementioned copyrighted materials in both print and electronic formats was kingly granted by Elsevier, and the copy of License Agreement is attached below:

This is a License Agreement between Le Xin ("You") and Elsevier ("Elsevier") provided by Copyright Clearance Center ("CCC"). The license consists of your order details, the terms and conditions provided by Elsevier, and the payment terms and conditions.

\begin{tabular}{|l|l|}
\hline Supplier & $\begin{array}{l}\text { Elsevier Limited } \\
\text { The Boulevard,Langford Lane } \\
\text { Kidlington,Oxford,OX5 1GB,UK }\end{array}$ \\
\hline $\begin{array}{l}\text { Registered Company } \\
\text { Number }\end{array}$ & 1982084 \\
\hline Customer name & Le Xin \\
\hline Customer address & 1400 Townsend Drive, \\
\hline & Houghton, MI 49931 \\
\hline License number & 3371490035471 \\
\hline License date & Apr 17, 2014 \\
\hline Licensed content publisher & Elsevier \\
\hline $\begin{array}{l}\text { Licensed content } \\
\text { publication }\end{array}$ & Applied Catalysis B: Environmental \\
\hline Licensed content title & $\begin{array}{l}\text { Supported Pt, Pd and Au nanoparticle anode catalysts for } \\
\text { anion-exchange membrane fuel cells with glycerol and } \\
\text { crude glycerol fuels }\end{array}$ \\
\hline Licensed content author & $\begin{array}{l}\text { Zhiyong Zhang,Le Xin,Ji Qi,David J. } \\
\text { Chadderdon,Wenzhen Li }\end{array}$ \\
\hline Licensed content date & 5 June 2013 \\
\hline $\begin{array}{l}\text { Licensed content volume } \\
\text { number }\end{array}$ & $136-137$ \\
\hline $\begin{array}{l}\text { Licensed content issue } \\
\text { number }\end{array}$ & \\
\hline Number of pages & 11 \\
\hline Start Page & 29 \\
\hline
\end{tabular}




\begin{tabular}{|l|l|}
\hline End Page & 39 \\
\hline Type of Use & reuse in a thesis/dissertation \\
\hline $\begin{array}{l}\text { Intended publisher of new } \\
\text { work }\end{array}$ & other \\
\hline Portion & full article \\
\hline Format & both print and electronic \\
\hline $\begin{array}{l}\text { Are you the author of this } \\
\text { Elsevier article? }\end{array}$ & Yes \\
\hline Will you be translating? & No \\
\hline $\begin{array}{l}\text { Title of your } \\
\text { thesis/dissertation }\end{array}$ & $\begin{array}{l}\text { Electrocatalytic Processing of Renewable Biomass- } \\
\text { derived Compounds for Production of Chemicals, Fuels } \\
\text { and Electricity }\end{array}$ \\
\hline Expected completion date & May 2014 \\
\hline $\begin{array}{l}\text { Estimated size (number of } \\
\text { pages) }\end{array}$ & 200 \\
\hline Elsevier VAT number & GB 494 6272 12 \\
\hline Permissions price & 0.00 USD \\
\hline VAT/Local Sales Tax & 0.00 USD / 0.00 GBP \\
\hline Total & 0.00 USD \\
\hline
\end{tabular}




\section{Appendix D Copyright permission of Chapter 4}

Chapter 4 in this dissertation was initially published in Applied Catalysis B: Environmental, Elsevier and ChemCatChem, John Wiley and Sons, titled "Selective electro-oxidation of glycerol to tartronate or mesoxaltate on Au nanoparticle catalyst via electrode potential tuning in anion-exchange membrane electro-catalytic flow reactor", Volume 147, 5 April 2014, Pages 871-878, Applied Catalysis B: Environmental; "Electrocatalytic selective oxidation of glycerol to tartronate on $\mathrm{Au} / \mathrm{C}$ anode catalysts in anion exchange membrane fuel cells with electricity cogeneration", Volumes 154-155, July-August 2014, Pages 360-368, Applied Catalysis B: Environmental; "Simultaneous generation of mesoxalic acid and electricity from glycerol on a gold anode catalyst in anion-exchange membrane fuel cells", Volume 4, Issue 8, Pages 1105-1114, August 2012, ChemCatChem. Permissions to reproduce the aforementioned copyrighted materials in both print and electronic formats were kingly granted by Elsevier and John Wiley and Sons, and the copies of License Agreement are attached below: 
Selective electro-oxidation of glycerol to tartronate or mesoxaltate on Au nanoparticle catalyst via electrode potential tuning in anion-exchange membrane electro-catalytic flow reactor, Volume 147, 5 April 2014, Pages 871-878, Applied Catalysis B: Environmental

This is a License Agreement between Le Xin ("You") and Elsevier ("Elsevier") provided by Copyright Clearance Center ("CCC"). The license consists of your order details, the terms and conditions provided by Elsevier, and the payment terms and conditions.

\begin{tabular}{|l|l|}
\hline Supplier & $\begin{array}{l}\text { Elsevier Limited } \\
\text { The Boulevard,Langford Lane } \\
\text { Kidlington,Oxford,OX5 1GB,UK }\end{array}$ \\
\hline $\begin{array}{l}\text { Registered Company } \\
\text { Number }\end{array}$ & 1982084 \\
\hline Customer name & Le Xin \\
\hline Customer address & 1400 Townsend Drive, \\
\hline License number & Houghton, MI 49931 \\
\hline License date & 3371500034321 \\
\hline $\begin{array}{l}\text { Licensed content } \\
\text { publisher }\end{array}$ & Apr 17, 2014 \\
\hline $\begin{array}{l}\text { Licensed content } \\
\text { publication }\end{array}$ & Elsevier \\
\hline Licensed content title & $\begin{array}{l}\text { Selective electro-oxidation of glycerol to tartronate or } \\
\text { mesoxalate on Au nanoparticle catalyst via electrode } \\
\text { potential tuning in anion-exchange membrane electro- } \\
\text { catalytic flow reactor }\end{array}$ \\
\hline Licensed content author & $\begin{array}{l}\text { Zhiyong Zhang,Le Xin,Ji Qi,David J. Chadderdon,Kai } \\
\text { Sun,Kayla M. Warsko,Wenzhen Li }\end{array}$ \\
\hline Licensed content date & 5 April 2014 \\
\hline $\begin{array}{l}\text { Licensed content volume } \\
\text { number }\end{array}$ & 147 \\
\hline $\begin{array}{l}\text { Licensed content issue } \\
\text { number }\end{array}$ & \\
\hline Number of pages & 8 \\
\hline Start Page & 871 \\
\hline End Page & 878 \\
\hline Type of Use & reuse in a thesis/dissertation \\
\hline $\begin{array}{l}\text { Intended publisher of new } \\
\text { work }\end{array}$ & other \\
\hline Portion & full article \\
\hline
\end{tabular}




\begin{tabular}{|l|l|}
\hline Format & both print and electronic \\
\hline $\begin{array}{l}\text { Are you the author of this } \\
\text { Elsevier article? }\end{array}$ & Yes \\
\hline Will you be translating? & No \\
\hline $\begin{array}{l}\text { Title of your } \\
\text { thesis/dissertation }\end{array}$ & $\begin{array}{l}\text { Electrocatalytic Processing of Renewable Biomass- } \\
\text { derived Compounds for Production of Chemicals, Fuels } \\
\text { and Electricity }\end{array}$ \\
\hline Expected completion date & May 2014 \\
\hline $\begin{array}{l}\text { Estimated size (number of } \\
\text { pages) }\end{array}$ & 200 \\
\hline Elsevier VAT number & GB 494 6272 12 \\
\hline Permissions price & 0.00 USD \\
\hline VAT/Local Sales Tax & 0.00 USD / 0.00 GBP \\
\hline Total & 0.00 USD \\
\hline
\end{tabular}


Electrocatalytic selective oxidation of glycerol to tartronate on $\mathrm{Au} / \mathrm{C}$ anode catalysts in anion exchange membrane fuel cells with electricity cogeneration, Volumes 154-155, July-August 2014, Pages 360-368, Applied Catalysis B: Environmental

This is a License Agreement between Le Xin ("You") and Elsevier ("Elsevier") provided by Copyright Clearance Center ("CCC"). The license consists of your order details, the terms and conditions provided by Elsevier, and the payment terms and conditions.

\begin{tabular}{|l|l|}
\hline Supplier & $\begin{array}{l}\text { Elsevier Limited } \\
\text { The Boulevard,Langford Lane } \\
\text { Kidlington,Oxford,OX5 1GB,UK }\end{array}$ \\
\hline $\begin{array}{l}\text { Registered Company } \\
\text { Number }\end{array}$ & 1982084 \\
\hline Customer name & Le Xin \\
\hline Customer address & 1400 Townsend Drive, \\
\hline & Houghton, MI 49931 \\
\hline License number & 3371501212122 \\
\hline License date & Apr 17,2014 \\
\hline Licensed content publisher & Elsevier \\
\hline $\begin{array}{l}\text { Licensed content } \\
\text { publication }\end{array}$ & Applied Catalysis B: Environmental \\
\hline Licensed content title & $\begin{array}{l}\text { Electrocatalytic selective oxidation of glycerol to } \\
\text { tartronate on Au/C anode catalysts in anion exchange } \\
\text { membrane fuel cells with electricity cogeneration }\end{array}$ \\
\hline Licensed content author & $\begin{array}{l}\text { Ji Qi,Le Xin,David J. Chadderdon,Yang Qiu,Yibo } \\
\text { Jiang,Neeva Benipal,Changhai Liang,Wenzhen Li }\end{array}$ \\
\hline Licensed content date & July-August 2014 \\
\hline $\begin{array}{l}\text { Licensed content volume } \\
\text { number }\end{array}$ & $154-155$ \\
\hline $\begin{array}{l}\text { Licensed content issue } \\
\text { number }\end{array}$ & \\
\hline Number of pages & 9 \\
\hline Start Page & 360 \\
\hline End Page & 368 \\
\hline Type of Use & reuse in a thesis/dissertation \\
\hline $\begin{array}{l}\text { Intended publisher of new } \\
\text { work }\end{array}$ & other \\
\hline Portion & full article \\
\hline Format & Yoth print and electronic \\
\hline Are you the author of this & Yes \\
\hline
\end{tabular}




\begin{tabular}{|l|l|}
\hline Elsevier article? & \\
\hline Will you be translating? & No \\
\hline $\begin{array}{l}\text { Title of your } \\
\text { thesis/dissertation }\end{array}$ & $\begin{array}{l}\text { Electrocatalytic Processing of Renewable Biomass- } \\
\text { derived Compounds for Production of Chemicals, Fuels } \\
\text { and Electricity }\end{array}$ \\
\hline Expected completion date & May 2014 \\
\hline $\begin{array}{l}\text { Estimated size (number of } \\
\text { pages) }\end{array}$ & 200 \\
\hline Elsevier VAT number & GB 494627212 \\
\hline Permissions price & 0.00 USD \\
\hline VAT/Local Sales Tax & 0.00 USD / 0.00 GBP \\
\hline Total & 0.00 USD \\
\hline
\end{tabular}


Simultaneous generation of mesoxalic acid and electricity from glycerol on a gold anode catalyst in anion-exchange membrane fuel cells, Volume 4, Issue 8, Pages 11051114, August 2012, ChemCatChem

This is a License Agreement between Le Xin ("You") and John Wiley and Sons ("John Wiley and Sons") provided by Copyright Clearance Center ("CCC"). The license consists of your order details, the terms and conditions provided by John Wiley and Sons, and the payment terms and conditions.

\begin{tabular}{|l|l|}
\hline License Number & 3371510108045 \\
\hline License date & Apr 17,2014 \\
\hline $\begin{array}{l}\text { Licensed content } \\
\text { publisher }\end{array}$ & John Wiley and Sons \\
\hline $\begin{array}{l}\text { Licensed content } \\
\text { publication }\end{array}$ & ChemCatChem \\
\hline Licensed content title & $\begin{array}{l}\text { Simultaneous Generation of Mesoxalic Acid and Electricity } \\
\text { from Glycerol on a Gold Anode Catalyst in Anion- } \\
\text { Exchange Membrane Fuel Cells }\end{array}$ \\
\hline Licensed copyright line & $\begin{array}{l}\text { Copyright C 2012 WILEY-VCH Verlag GmbH \& Co. } \\
\text { KGaA, Weinheim }\end{array}$ \\
\hline Licensed content author & Le Xin,Zhiyong Zhang,Zhichao Wang,Wenzhen Li \\
\hline Licensed content date & May 22, 2012 \\
\hline Start page & 1105 \\
\hline End page & 1114 \\
\hline Type of use & Dissertation/Thesis \\
\hline Requestor type & Author of this Wiley article \\
\hline Format & Print and electronic \\
\hline Portion & Full article \\
\hline Will you be translating? & No \\
\hline $\begin{array}{l}\text { Title of your thesis / } \\
\text { dissertation }\end{array}$ & $\begin{array}{l}\text { Electrocatalytic Processing of Renewable Biomass-derived } \\
\text { Compounds for Production of Chemicals, Fuels and } \\
\text { Electricity }\end{array}$ \\
\hline $\begin{array}{l}\text { Expected completion } \\
\text { date }\end{array}$ & May 2014 \\
\hline $\begin{array}{l}\text { Expected size (number } \\
\text { of pages) }\end{array}$ & 200 \\
\hline Total & 0.00 USD \\
\hline
\end{tabular}




\section{Appendix E Copyright permission of Chapter 5}

Chapter 5 in this dissertation was initially published in Applied Catalysis B: Environmental, Elsevier, titled "Electrocatalytic oxidation of ethylene glycol (EG) on supported Pt and Au catalysts in alkaline media: Reaction pathway investigation in threeelectrode cell and fuel cell reactor", Volume 125, 21 August 2012, Pages 85-94. Permission to reproduce the aforementioned copyrighted materials in both print and electronic formats was kingly granted by Elsevier, and the copy of License Agreement is attached below:

This is a License Agreement between Le Xin ("You") and Elsevier ("Elsevier") provided by Copyright Clearance Center ("CCC"). The license consists of your order details, the terms and conditions provided by Elsevier, and the payment terms and conditions.

\begin{tabular}{|l|l|}
\hline Supplier & $\begin{array}{l}\text { Elsevier Limited } \\
\text { The Boulevard,Langford Lane } \\
\text { Kidlington,Oxford,OX5 1GB,UK }\end{array}$ \\
\hline Registered Company Number & 1982084 \\
\hline Customer name & Le Xin \\
\hline Customer address & 1400 Townsend Drive, \\
\hline & Houghton, MI 49931 \\
\hline License number & 3371461281946 \\
\hline License date & Apr 17, 2014 \\
\hline Licensed content publisher & Elsevier \\
\hline Licensed content publication & Applied Catalysis B: Environmental \\
\hline Licensed content title & $\begin{array}{l}\text { Electrocatalytic oxidation of ethylene glycol (EG) } \\
\text { on supported Pt and Au catalysts in alkaline media: } \\
\text { Reaction pathway investigation in three-electrode } \\
\text { cell and fuel cell reactors }\end{array}$ \\
\hline Licensed content author & $\begin{array}{l}\text { Le Xin,Zhiyong Zhang,Ji Qi,David } \\
\text { Chadderdon,Wenzhen Li }\end{array}$ \\
\hline Licensed content date & 21 August 2012 \\
\hline $\begin{array}{l}\text { Licensed content volume } \\
\text { number }\end{array}$ & 125 \\
\hline Licensed content issue number & \\
\hline Number of pages & 10 \\
\hline Start Page & 85 \\
\hline
\end{tabular}




\begin{tabular}{|l|l|}
\hline End Page & 94 \\
\hline Type of Use & reuse in a thesis/dissertation \\
\hline Portion & full article \\
\hline Format & both print and electronic \\
\hline $\begin{array}{l}\text { Are you the author of this } \\
\text { Elsevier article? }\end{array}$ & Yes \\
\hline Will you be translating? & No \\
\hline Title of your thesis/dissertation & $\begin{array}{l}\text { Electrocatalytic Processing of Renewable Biomass- } \\
\text { derived Compounds for Production of Chemicals, } \\
\text { Fuels and Electricity }\end{array}$ \\
\hline Expected completion date & May 2014 \\
\hline $\begin{array}{l}\text { Estimated size (number of } \\
\text { pages) }\end{array}$ & 200 \\
\hline Elsevier VAT number & GB 494 6272 12 \\
\hline Permissions price & 0.00 USD \\
\hline VAT/Local Sales Tax & 0.00 USD / 0.00 GBP \\
\hline Total & 0.00 USD \\
\hline
\end{tabular}




\section{Appendix F Copyright permission of Chapter 7}

Chapter 7 in this dissertation was initially published in ChemSusChem, John Wiley and Sons and Green Chemistry, The Royal Society of Chemistry, titled "Electricity storage in biofuels: selective electrocatalytic reduction of levulinic acid to valeric acid or $\gamma$-valerolactone", Volume 6, Issue 4, Pages 674-686, April 2013, ChemSusChem, and "Integrated electrocatalytic processing of levulinic acid and formic acid to produce biofuel intermediate valeric acid", Volume 16, Issue 3, Pages 1305-1315, 2014, Green Chemistry. Permissions to reproduce the aforementioned copyrighted materials in both print and electronic formats were kingly granted by John Wiley and Sons and The Royal Society of Chemistry, and the copies of License Agreement are attached below: 
Electricity storage in biofuels: selective electrocatalytic reduction of levulinic acid to valeric acid or $\gamma$-valerolactone, Volume 6, Issue 4, Pages 674-686, April 2013, ChemSusChem

This is a License Agreement between Le Xin ("You") and John Wiley and Sons ("John Wiley and Sons") provided by Copyright Clearance Center ("CCC"). The license consists of your order details, the terms and conditions provided by John Wiley and Sons, and the payment terms and conditions.

\begin{tabular}{|c|c|}
\hline License Number & 3371510968016 \\
\hline License date & Apr 17, 2014 \\
\hline $\begin{array}{l}\text { Licensed content } \\
\text { publisher }\end{array}$ & John Wiley and Sons \\
\hline $\begin{array}{l}\text { Licensed content } \\
\text { publication }\end{array}$ & ChemSusChem \\
\hline Licensed content title & $\begin{array}{l}\text { Electricity Storage in Biofuels: Selective Electrocatalytic } \\
\text { Reduction of Levulinic Acid to Valeric Acid or } \gamma- \\
\text { Valerolactone }\end{array}$ \\
\hline Licensed copyright line & $\begin{array}{l}\text { Copyright (C) } 2013 \text { WILEY-VCH Verlag GmbH \& Co. } \\
\text { KGaA, Weinheim }\end{array}$ \\
\hline Licensed content author & $\begin{array}{l}\text { Le Xin,Zhiyong Zhang,Ji Qi,David J. Chadderdon,Yang } \\
\text { Qiu,Kayla M. Warsko,Wenzhen Li }\end{array}$ \\
\hline Licensed content date & Mar 1,2013 \\
\hline Start page & 674 \\
\hline End page & 686 \\
\hline Type of use & Dissertation/Thesis \\
\hline Requestor type & Author of this Wiley article \\
\hline Format & Print and electronic \\
\hline Portion & Full article \\
\hline Will you be translating? & No \\
\hline $\begin{array}{l}\text { Title of your thesis / } \\
\text { dissertation }\end{array}$ & $\begin{array}{l}\text { Electrocatalytic Processing of Renewable Biomass-derived } \\
\text { Compounds for Production of Chemicals, Fuels and } \\
\text { Electricity }\end{array}$ \\
\hline $\begin{array}{l}\text { Expected completion } \\
\text { date }\end{array}$ & May 2014 \\
\hline $\begin{array}{l}\text { Expected size (number } \\
\text { of pages) }\end{array}$ & 200 \\
\hline Total & 0.00 USD \\
\hline
\end{tabular}




\section{Integrated electrocatalytic processing of levulinic acid and formic acid to produce}

biofuel intermediate valeric acid, Volume 16, Issue 3, Pages 1305-1315, 2014, The Royal

\section{Society of Chemistry}

RSCl |civancing the

\section{Permission Requests}

Material in RSC and other publishers' publications is subject to all applicable copyright, database protection, and other rights. Therefore for any article, whether printed or electronic, permission must be obtained to use material for which the author(s) does not already own the copyright. This material may be, for example, a figure, diagram, table, photo or some other image. Note that permission is not needed to re-use your own figures, diagrams, etc, which were originally published in an RSC publication. However, permission should be requested for use of the whole article or chapter.

Use of RSC Material in RSC Publications

Authors contributing to RSC publications (joumal articles, book or book chapters) do not need to formally request permission to reproduce material contained in another RSC publication. Permission should, however, be requested for use of a whole article or chapter. For all cases of reproduction the correct acknowledgement should be given in the caption of the reproduced material. The acknowledgement depends on the RSC publication in which the material was published and the RSC publication in which it is being reproduced. The form of the acknowledgement to be included in the caption can be found on the page entitled Acknowledgements for reproduction of RSC material in RSC publications.

\section{Downloadable Files}

Acknowledgements for reproduction of RSC material in RSC

\section{publications}

Details of what acknowledgements should be used by authors

reproducing material from RSC publications in another RSC publication

๑PDF (189k)

PDF files require $\unlhd$ Adobe Acrobat Reader

Author Use of Own Material in Third Party Publications

Authors of RSC publications (journal articles, book or book chapters) do not need to formally request permission to reproduce material contained in their own article or chapter which was originally

published in an RSC publication. Permission should, however, be requested for use of the whole article or chapter, except for the exception specified below. For all cases of reproduction the correct

acknowledgement should be given in the caption of the reproduced material. The acknowledgement depends on the RSC publication in which the material was published. The form of the acknowledgement to be included in the caption can be found on the page entitled Acknowedgements to be used by RSC authors.

Author Use of Own Material in Theses and Dissertations

Authors of articles in RSC journals or chapters in RSC books do not need to formally request permission to reproduce their article or book chapter in their thesis or dissertation. For all cases of reproduction the correct acknowledgement should be given in the caption of the reproduced material. The acknowledgement depends on the RSC publication in which the material was published. The form of the acknowledgement to be included in the caption can be found on the page entitled Acknowledgements to be used by RSC authors.

Please ensure that your co-authors are aware that you are including the paper in your thesis. 


\section{Appendix G Copyright permission of Chapter 8}

Chapter $\mathbf{8}$ in this dissertation was initially published in frontiers in Chemistry: Green and Environmental Chemistry, Frontiers Media S.A., titled "Carbon supported Ag nanoparticles as high performance cathode catalyst for $\mathrm{H}_{2} / \mathrm{O}_{2}$ anion exchange membrane fuel cell”, Volume 1, Article 16, September 2013, frontiers in Chemistry. Permissions to reproduce the aforementioned materials in both print and electronic formats were kingly granted by Frontiers Media S.A. and in compliance with the Copyright clause attached below regarding to the reproduction:

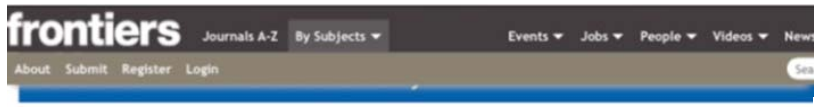

$<$ Archive

ORIGINAL RESEARCH ARTICLE

Carbon supported Ag nanoparticles as high performance cathode catalyst for $\mathrm{H}_{2} / \mathrm{O}_{2}$ anion exchange membrane fuel cell

Le Xin, Zhiyong Zhang, Zhichao Wang, Ji Qi and Wenzhen Li*

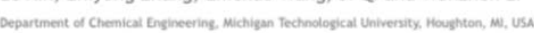

A solution phase-based nanocapsule method was successfully developed to synthesize non-platinum metal catalyst-carbon supported $\mathrm{Ag}$ nanoparticles $(\mathrm{Ag} / \mathrm{C})$. XRD patterns and TEM image show $\mathrm{Ag}$ nanoparticles with a small average size $(5.4 \mathrm{~nm})$ and narrow size distribution $(2-9 \mathrm{~nm})$ are uniformly dispersed on the carbon black Vulcan XC-72 support. The intrinsic activity and pathway of oxygen reduction reaction (ORR) on the $\mathrm{Ag} / \mathrm{C}$ and commercial $\mathrm{Pt} / \mathrm{C}$ were investigated using rotating ring disk electrode (RRDE) tests at room temperature. The results confirmed that the 4 -electron pathway of ORR proceeds on small Ag nanoparticles, and showed comparable ORR activities on the self-prepared $\mathrm{Ag} / \mathrm{C}$ and a commercial $\mathrm{P} / \mathrm{C}$. A single $\mathrm{H}_{2}-\mathrm{O}_{2}$ anion exchange membrane fuel cell (AEMFC) with the $\mathrm{Ag} / \mathrm{C}$ cathode catalyst exhibited an open circuit potential of $0.98 \mathrm{~V}$ and a peak power density of $190 \mathrm{~mW} / \mathrm{cm}^{2}$ at $80^{\circ} \mathrm{C}$.

\section{lead Fuil Toxt}

Keymord: non-platinum catalyt, electrocatalynt, nanoparticies, anion exchange membrane, fuel cell, arypen reduction

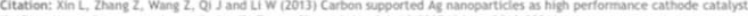
$\mathrm{H}_{2} / \mathrm{O}_{2}$ anion exchange membrane fuel cell. Front. Chem. 1:16. dot: 10.335s/tchem.2013.00016 Received: 24 Suly 2013: Paper pending publithed: of hugust 2013:

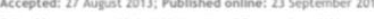
Edited by: Wu Let, University of Connecticut, usi Reviewed by: John Z. Guo, Lamar University, Usi

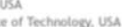

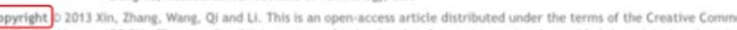
Witribution License iCC Bn. The use, distribution or reproduction in other forums is permilted, prowided the originat authoris) of

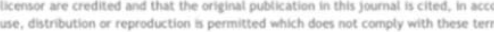

"Correspondence: Wenchen Li, Depard

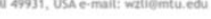

ILEs.Lexn

Whese a coment

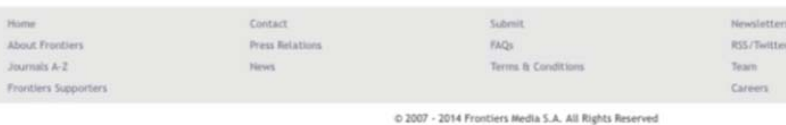

Received: 24 July 2013; paper pending published: 07 August 2013; accepted: 27 August 2013; published online: 23 September 2013.

Citation: Xin L, Zhang Z, Wang Z, Qi J and $\mathrm{Li} W$ (2013) Carbon supported $\mathrm{Ag}$ nanoparticles as high performance cathode catalyst for $\mathrm{H}_{2} / \mathrm{O}_{2}$ anion exchange membrane fuel cell. Front. Chem. 1:16. doi: 10.3389/fchem.2013.00016

This article was submitted to Green and Environmental Chemistry, a section of the journal Frontiers in Chemistry. Copyright (c) 2013 Xin, Zhang, Wang, Qi and Li. This is an open-access article distributed under the terms of the Creative Commons Attribution License (CC BY). The use, distribution or reproduction in other forums is permitted, provided the original author(s) or licensor are credited and that the original publication in this journal is cited, in accordance with accepted academic practice. No use, distribution or reproduction is permitted which does not comply with these terms. 